\title{
Accessibility and utilisation of health services in Ghana
}

Citation for published version (APA):

Buor, D. (2004). Accessibility and utilisation of health services in Ghana. [Doctoral Thesis, Maastricht University]. Universiteit Maastricht. https://doi.org/10.26481/dis.20040623db

Document status and date:

Published: 01/01/2004

DOI:

$10.26481 /$ dis.20040623db

Document Version:

Publisher's PDF, also known as Version of record

\section{Please check the document version of this publication:}

- A submitted manuscript is the version of the article upon submission and before peer-review. There can be important differences between the submitted version and the official published version of record.

People interested in the research are advised to contact the author for the final version of the publication, or visit the DOI to the publisher's website.

- The final author version and the galley proof are versions of the publication after peer review.

- The final published version features the final layout of the paper including the volume, issue and page numbers.

Link to publication

\footnotetext{
General rights rights.

- You may freely distribute the URL identifying the publication in the public portal. please follow below link for the End User Agreement:

www.umlib.nl/taverne-license

Take down policy

If you believe that this document breaches copyright please contact us at:

repository@maastrichtuniversity.nl

providing details and we will investigate your claim.
}

Copyright and moral rights for the publications made accessible in the public portal are retained by the authors and/or other copyright owners and it is a condition of accessing publications that users recognise and abide by the legal requirements associated with these

- Users may download and print one copy of any publication from the public portal for the purpose of private study or research.

- You may not further distribute the material or use it for any profit-making activity or commercial gain

If the publication is distributed under the terms of Article $25 \mathrm{fa}$ of the Dutch Copyright Act, indicated by the "Taverne" license above, 


\section{Accessibility and utilisation of health services in Ghana}

Daniel Buor 
ISBN 90-6905-674-7

http://www.nivel.nl

nivel@nivel.nl

Telephone +31302729700

Fax +31302729729

C2004 Daniel Buor

Cover design: $\quad$ I.K. Appiah

Word processing / layout: Christel van Aalst

Printing: Twin Design

All rights reserved. No part of this publication may be reproduced, stored in a retrieval system or transmitted, in any form or by any means, electronic, mechanical, photocopying, recording or otherwise, without the prior written permission of Daniel Buor. Exceptions are allowed in respect of any fair dealing for the purpose of research, private study or review. 


\section{Accessibility and utilisation of health services in Ghana}

\section{PROEFSCHRIFT}

ter verkrijging van de graad van doctor aan

de Universiteit Maastricht, op gezag van de Rector Magnificus Prof. Mr. G.P.M.F. Mols, volgens het besluit van het College van Decanen, in het openbaar te verdedigen

op woensdag 23 juni 2004 om 12.00 uur

door

Daniel Buor 


\section{Promotores:}

Prof. dr. J. van der Zee

Prof. dr. P.P. Groenewegen (Universiteit Utrecht)

\section{Beoordelingscommissie:}

Prof. dr. R. Vos (voorzitter)

Mw. prof. dr. Y. Verhasselt (em. Vrije Universiteit Brussel)

Prof. dr. W.J.A. van den Heuvel

Prof. dr. J.A.M. Maarse

Dr. W. Devillé (NIVEL)

The study presented in this book was funded by the Netherlands Foundation for the Advancement of Tropical Research (WOTRO) and supported by NIVEL Netherlands Institute for Health Services Research. 


\section{Contents}

1 Accessibility and utilisation of health services in Ghana: an overview

2 The economy, health spending, and health status in Sub-Saharan Africa

3 Comparative analysis of utilisation of health services in rural and urban areas in developing countries

4 Distance as a predominant factor in the utilisation of health services in the Kumasi Metropolis, Ghana

5 Analysing the primacy of distance in the utilisation of health services in the Ahafo-Ano South District, Ghana

6 Gender and the utilisation of health services the Ashanti Region, Ghana

7 Mother's education and childhood mortality in Ghana

8 Income and the utilisation of health services in the Ahafo-Ano South District of Ghana

9 The potential of a national health insurance scheme for improving the utilisation of health services in Ghana

Literature

Summary

Samenvatting

Acknowledgement

Curriculum vitae 


\section{Accessibility and utilisation of health services I in Ghana: an overview}




\section{Introduction}

The thesis aims at assessing the impact of accessibility and socioeconomic factors that influence the utilisation of health services in developing countries, with special emphasis on Ghana. It attempts to test conceptual models on utilisation and also to structure new models based upon empirical findings. Finally, it aims at drawing policy implications that will help redress the imbalances between demand and supply of health facilities in developing countries. The poor living conditions in developing countries lead to disease patterns that are not met by access to health facilities. Besides, the thesis wants to deviate from the normal bivariate approach that has been largely used in analysing utilisation problems in developing countries in favour of a multivariate approach that ensures a comparison and weighting of the effects of various independent variables.

The study consists of a number of chapters that have been published, accepted for publication in or submitted to international scholarly journals. They consist of two types, theoretical and empirical. The theoretical chapters examine the utilisation of health services in Ghana, and in developed and developing economies. The empirical chapters examine access and utilisation in two districts in Ghana that are respectively representative of urban and rural districts, Kumasi Metropolis and Ahafo-Ano South District (figure 1.1), both in the Ashanti Region, one of the country's most populous and most cosmopolitan administrative regions.

The thesis is in two parts. Part I gives an overview of the whole study and deals with a discussion of the economy of Ghana, emphasising the health and other social and economic indicators. This precedes the analysis of the problem, literature survey, theoretical frameworks and research questions. The methodological framework and analysis of the results used in the chapters then follow. Part II contains the separate chapters. It starts with a chapter on the economic development of Ghana and its relationship to health and health care. The chapter on the economy and health and health care is based on World Bank and World Health Report data. The body of the thesis (chapters 3-9) attempts an empirical analysis of utilisation of health services in rural and urban settings in Ghana. Chapters 4 and 5 discuss the effects of distance on utilisation in rural and urban settings. Chapter 6 takes a look at gender issues in health care utilisation. The impact of education of mothers on the use of health services (chapter 7) is assessed in terms of the relationship between 
maternal education and childhood mortality. This chapter draws a relation between the two variables and reaches conclusions about the efficacy of mothers' education and effective use of child health services that results in positive health outcomes. Chapter 8 isolates the impact of income in the utilisation of health services in the rural district that suffers more from poverty than urban areas. The main text closes with the impact of health insurance on utilisation of health services and a discussion of the potentials of health insurance in a low-income country. This final chapter tries to offer a way out of the poverty-underutilisation connection.

Figure 1.1 The study area

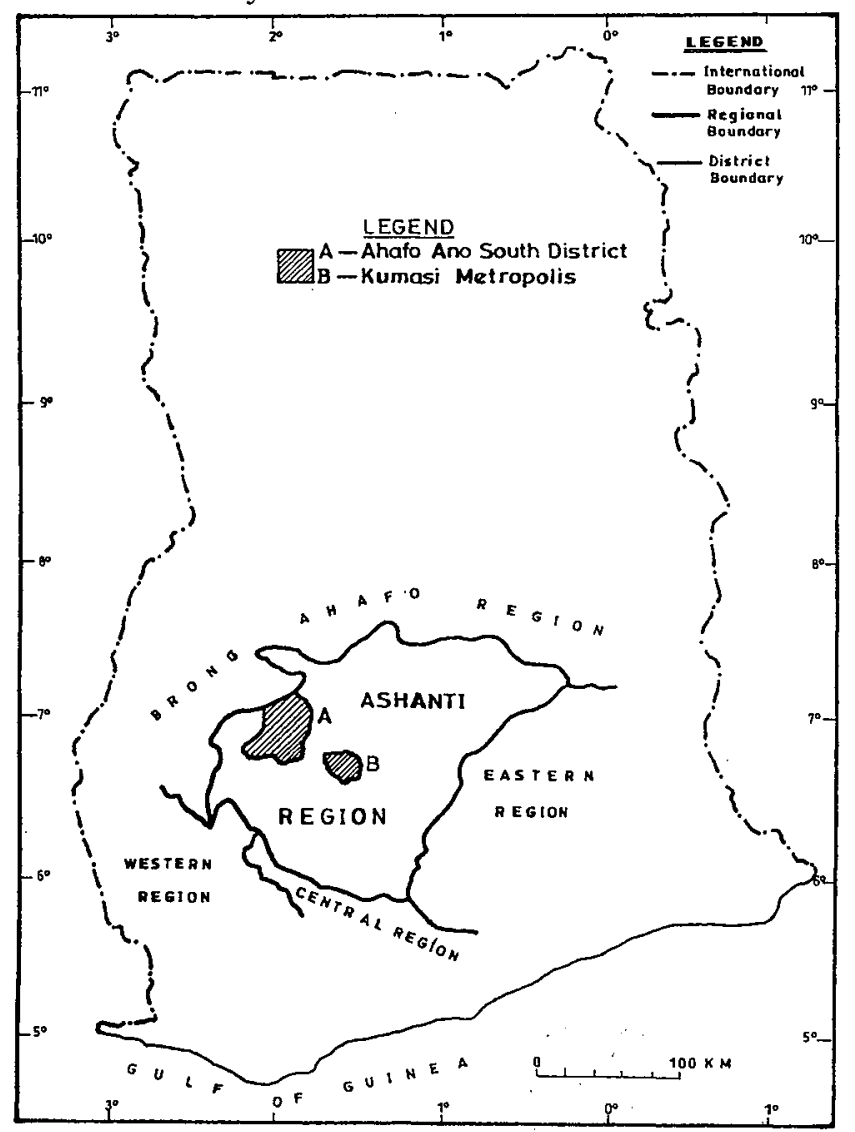

Source: Town and Country Planning Department and Ministry of Health, 1996 


\section{The Ghanaian economy, health and health service The economy and social services}

Ghana lies within the West African sub-region, bordered to the west by the Republic of Togo, north by Burkina Faso, east by Cote d'Ivoire and south by the Gulf of Guinea. A former colony of Great Britain, she attained independence on $6^{\text {th }}$ March, 1957, being the first country south of the Sahara to attain independence. Ghana became a republic on July 1 , 1960. It is a unitary state divided into ten administrative regions, with Accra as the national capital. The Northern region is the largest administrative region in terms of physical size. The Ashanti Region is the most populous. Plains and plateaus traverse the country, with a few peaks in the southeast. It has a wealth of water resources including Lake Volta supposed to be the largest man-made lake in the world, and the rivers Oti, Ofin, Pra, Ankobra and lake Bosumtwi. The abundant water resources, which occasionally result in flooding with the setting in of the monsoon rains, have implications for environmental health through several insect vectors, including mosquitoes and the black fly (simulium).

Ghana, which used to be dominated by forests in greater parts of the south, is now faced with deforestation, with concomitant environmental and health hazards. Rain forest is yielding to secondary forest, and savannah, which has serious implications for the agricultural sector, and the logging industry. The deprivation of soil fertility, due to overuse of the land, affects the cultivation of leguminous crops that can enhance nutritional status.

The varied ecological zones of Ghana give her the advantage of cultivating various tropical crops including cocoa, shea nuts, cashew nuts, palm fruits, maize, guinea corn, millet, and forest food crops like plantain, cocoyam and cassava. The country is also blessed with mineral resources including gold, manganese, bauxite, and diamonds. The gold mine at Obuasi in Ghana is supposed to be the richest gold mine in the world. Gold happens to be the leading export commodity of Ghana, previously known as the Gold Coast. Notwithstanding the gains due the mining industry, the environmental degradation caused by the mines has serious health implications, and also for the agricultural and housing industry. Other export commodities include cocoa, timber, manganese, bauxite, hydro-electric power, and, of late, non-traditional exports like fruits, shea nuts, cashew nuts and vegetables. Tourism is currently growing as a major foreign exchange earner. 
Ghanaians are mostly Negroes, the main ethnic groups being the Akans, Dagombas, Mole-Dagbanis, Ga-Adangbes and Ewes. The Ashantis are the largest group among the Akans. The total population is approximately 19 million; and, with a total land surface of $238,533 \mathrm{~km}^{2}$, the density is as low as 79.3 per square kilometre (GSS, 2002, p.17). The labour force is 8 million (World Bank, WDI, 1999, p.50), representing $42.3 \%$ of the total population. The main economic activities are farming, employing the largest labour force, mining, lumbering, fishing and food processing.

A discussion of health services supply and use will not be complete without a picture of the status of the economy in which the system operates. The socio-economic system reflects on the health care services, and health status.

The economic and social indicators have been compared with Ghana's immediate neighbours as well as low and high-income countries. The comparison is to bring to illustrate the development status of the country in the context of developing countries making the analyses of health service utilisation in Ghana more meaningful. The economic and social indicators are indicated in table 1.1.

Table 1.1 Economic and social indicators of Ghana, her neighbours and other economies

\begin{tabular}{|c|c|c|c|c|c|c|}
\hline Indicator & Ghana & $\begin{array}{r}\text { Cote } \\
\text { d'Ivoire }\end{array}$ & Togo & $\begin{array}{l}\text { Burkina- } \\
\text { fasso }\end{array}$ & $\begin{array}{r}\text { Low } \\
\text { Income } \\
\text { Countries }\end{array}$ & $\begin{array}{r}\text { High } \\
\text { Income } \\
\text { Countries }\end{array}$ \\
\hline GNP per capita \$ & 340 & 600 & 290 & 210 & 410 & 27680 \\
\hline $\begin{array}{l}\% \text { (Annual) Growth of GDP } \\
\text { per capita }\end{array}$ & 3.7 & -2.3 & -0.7 & 2.2 & 4.2 & 3.5 \\
\hline $\begin{array}{l}\text { School enrolment ratio as } \\
\text { of age group: }\end{array}$ & & & & & & \\
\hline - primary & 79 & 78 & 124 & 42 & 83 & 102 \\
\hline - secondary & 41 & 23 & 33 & 10 & 29 & 87 \\
\hline - tertiary & 2 & 7 & 4 & $<0.5$ & 6 & 36 \\
\hline $\begin{array}{l}\text { Adult illiteracy rate (\%) of } \\
\text { people } 15 \text { and above }\end{array}$ & $\begin{aligned} F & =37 \\
M & =20\end{aligned}$ & $\begin{aligned} F & =61 \\
M & =46\end{aligned}$ & $\begin{aligned} F & =58 \\
M & =28\end{aligned}$ & $\begin{aligned} \mathrm{F} & =86 \\
\mathrm{M} & =66\end{aligned}$ & $\begin{aligned} F & =47 \\
M & =28\end{aligned}$ & $\begin{array}{l}\text { No data } \\
\text { No data }\end{array}$ \\
\hline $\begin{array}{l}\text { Pop. below the national } \\
\text { poverty line }\end{array}$ & 31.4 & 32.3 & 32.3 & No data & No data & No data \\
\hline
\end{tabular}

Source: World Bank, 2002, p.18-92 
The Ghanaian economy could be described as fragile. The country falls within the low-income group, and, even in that group, it is not among those with relatively better indicators. Its socio-economic indicators fall below the average for low-income countries, but Ghana performs better than her neighbours. The Gross National Product (GNP) per capita of $\$ 340$ puts the nation barely on the poverty line. Educational participation is low for higher education, a fact that could have implications for health care utilisation. The weak economy also means that resources to provide health care facilities are very scarce.

Poverty is a predominant feature. The population below the national poverty line is $31.4 \%$. There are no statistics for low-income and highincome economies. Minimum daily wage is just above one dollar ( $\$ 1.00)$. These indicators have far-reaching negative effects on the ability of the masses of the people to use health services in a country where a national health insurance scheme is yet to be fully implemented.

Demographic and health indicators of a country are indices for determining quality of life and access to health services. These indicators also give an indication of the capacity and strength of an economy, which is a tool for determining progress in other sectors of national life. The demographic and health indicators of Ghana vis-à-vis low-and-high-income economies, and also her immediate neighbours, are indicated in table 1.2.

The population of Ghana has a high capacity to grow. The average annual population growth of $2.9 \%$ is high, even within low-income economies, which have an average of $2.1 \%$ per annum. The Total Fertility Rate (TFR), though decreasing, is quite high as compared with the average for lowincome countries, but relatively low when compared with her immediate neighbours. For 1980, it was 6.5, which improved to 5.1 in 1995 (World Bank, 1997, WDI, p.7). The Ghana Statistical Service, in its 1998 Ghana Demographic and Health Survey, gives the TFR as 4.5 (GSS, 1999, p.27). It is currently 4.2 , as indicated in table 1.2 .

The high crude birth rate of 30 per 1,000, and a relatively low crude death rate of 11 per 1,000 indicate a high rate of natural increase. Contraceptive use between 1990 and 1998 was $20 \%$ of women in the reproductive age group of 15-49 (World Bank, WDI, 1999, p.220). These statistics indicate a high momentum for the population to grow, which will further put pressure on the already inadequate facilities. 
Table 1.2 Demographic and health indicators of Ghana, her neighbours and other economies

\begin{tabular}{|c|c|c|c|c|c|c|}
\hline Indicator & Ghana & $\begin{array}{r}\text { Cote } \\
\text { d'Ivoire }\end{array}$ & Togo & $\begin{array}{r}\text { Burki- } \\
\text { nafasso }\end{array}$ & $\begin{array}{r}\text { Low } \\
\text { income } \\
\text { countries }\end{array}$ & $\begin{array}{r}\text { High } \\
\text { income } \\
\text { countries }\end{array}$ \\
\hline \multicolumn{7}{|l|}{ Average annual population } \\
\hline growth rate & 2.9 & 3.3 & 2.9 & 2.4 & 2.1 & 0.7 \\
\hline Total fertility rate & 4.2 & 4.8 & 5.0 & 6.0 & 3.6 & 1.7 \\
\hline Crude birth rate per 1,000 pop. & 30 & 37 & 37 & 44 & 29 & 12 \\
\hline Crude death rate per 1,000 pop. & 11 & 17 & 15 & 19 & 11 & \\
\hline \multicolumn{7}{|l|}{ Infant mortality rate per 1,000} \\
\hline live births & 58 & 111 & 75 & 104 & 76 & \\
\hline \multicolumn{7}{|l|}{ Maternal mortality ratio per } \\
\hline 100,000 live births & 210 & 600 & 980 & No data & No data & No data \\
\hline Life expectancy at Birth & 57 & 46 & 49 & 44 & 59 & 78 \\
\hline \multicolumn{7}{|l|}{ Population (\%) with access to: } \\
\hline - safe water & 64 & 77 & 54 & 53 & 76 & No data \\
\hline - sanitation & 63 & 49 & 34 & 29 & 45 & No data \\
\hline Adult HIV prevalence; \% of & & & & & & \\
\hline pop. aged 15-49 & 3.60 & 10.76 & 5.98 & 6.44 & 2.01 & 0.33 \\
\hline Physician per 1,000 pop. & 0.1 & 0.1 & 0.1 & $<0.05$ & 0.5 & 2.9 \\
\hline Hospital beds per 1,000 pop. & 1.5 & 0.8 & 1.5 & 1.4 & 1.3 & 7.2 \\
\hline Health expenditure per capita (\$) & 19 & 28 & 9 & 9 & 21 & 2733 \\
\hline
\end{tabular}

Source: World Bank, 2002, p.48-50, p.110-124

The health indicators picture a bad health situation of the population, including those in working age, which is unfavourable for achieving economic growth. The health indicators are life expectancy, which is now defined in terms of Disability Adjusted Life Expectancy (DALE), mortality and morbidity. The country's life expectancy at birth of 57 is close to the average for low-income countries, and exceeds those of her immediate neighbours. Infant mortality rate of 58 per 1000 live births is relatively better than her immediate neighbours and low-income countries. The same cannot be said for maternal mortality ratio which is as high as 210 per 100,000 live births. Though this figure is encouraging, compared with those of neighbouring countries, there is much room for improvement. This high figure corresponds with the low number of skilled health staff attending to births.

Health facilities, with regard to physicians and beds, are poor. The number of physicians per 1000 population is as low as 0.1 , as against an average of 0.5 for low-income countries, and 2.9 for high-income countries. The figure is at par with those of all her immediate neighbours, 
but Burkina Fasso. The number of 1.5 hospital beds per 1000 population is however relatively better, compared with 1.3 for low-income countries; and above the average for her immediate neighbours.

The expenditure on health is a reflection of the state of the economy, as indicated by World Bank's linear regression analysis of the relationship between GDP and the health budget. According to the analysis, Ghana, with a GDP per capita of $\$ 400$ for 1991, and 3.5\% of her GDP for the same period used on health, fell below the linear regression line (World Bank, 1993, WDR, p.110, 210, 238). Currently, health expenditure per capita is $\$ 19$, as against $\$ 21$ for low-income countries. It is exceeded only by Cote d'Ivoire among her immediate neighbours. The low health expenditure per capita affects the provision of health facilities, hence, access and utilisation.

The current health pandemic, Acquired Human Immunodeficiency Syndrome (AIDS) as compared to Ghana's immediate neighbours, is not alarming. Whereas the adult prevalence rate (population aged 15-49) for Human Immunodeficiency Virus (HIV) is about $3.6 \%$, it is as high as $10.8 \%$ for Cote d'Ivoire, $6.0 \%$ for Togo, and $6.4 \%$ for Burkina Faso. It is however high compared with the average for low-income countries, and excessively high compared with high-income countries. The predominance of HIV-infected people within the sub-region however has implications for the spread of the virus.

Access to facilities to ensure health is also not encouraging. Poor access to potable water and sanitation facilities has far reaching implications for health. Viral and bacterial infections, as well as vectored diseases, are prevalent in areas that lack such facilities, leading to diseases like malaria, typhoid fever, respiratory tract infections, and skin and eye infections. Rural areas are the most affected.

\section{Health care system}

\section{Health sectors}

The health system in Ghana is complex. Three sectors can be distinguished, viz. the popular sector, the folk sector, and the professional sector. This has roots in colonial times when the British concentrated Western professional health facilities in the few towns where they lived, leaving the rural areas with traditional folk practices. After colonialism, traditional medicine has operated, without restrictions, alongside allopathy. 
In the popular sector, all therapeutic options are used, without consulting either folk healers or medical practitioners. People could easily move to chemists and pharmaceutical shops without medical prescription, and purchase drugs of their choice. Even though the Pharmacy Council has its ethics, they are not rigidly enforced. Within this sector operate "quack doctors" and "charlatans" whose operations are detrimental to health. These operate widely in rural areas, and some make a significant appeal among the rural and illiterate population. In the same manner, patients can use herbal medicine without restraint. They could make their own prescriptions, based upon trial and error, without consulting the herbal 'doctor'. Such 'laissez faire' practice however has serious health implications. Most of the serious cases reported at hospitals, according to an informal interview with health personnel during reconnaissance survey, are due to the abuse of medication. In the folk sector, individuals specialise in forms of healing that are either sacred or secular, or a mixture of the two. The healers are not part of the official medical system, and occupy an intermediate position between the popular and professional sectors (Herman, 1984).

The professional sector comprises the organised, legally sanctioned healing professions such as modern Western scientific medicine, or allopathy. It includes not only physicians of various types and specialities, but also the recognised para-medical professions such as nurses, midwives, and physiotherapists. Private midwives operate widely. In Ghana, efforts are being made to integrate traditional medicine into scientific medicine. Practitioners are now voluntarily required to register for some recognition, and to get their drugs tested scientifically. There are however no legal restrictions on those who do not register before operating. Some herbal practitioners are becoming 'professionalised'. A few physicians have entered the area of herbal medicine, and are gaining popularity through efficacy of service.

The main difficulty when trying to integrate the professional and folk sectors is the lack of trust and respect each category of practitioners has for the other. Whereas scientific medical practitioners look upon folk practitioners with contempt for their lack of knowledge of health and its complex relationships and practices, folk practitioners have the feeling that scientific medicine has sacrificed the efficacy of curative methods. They consider themselves as the natural healers, and have the feeling that integration will weaken the potency of their operations. The government has established an institution for research into plant medicine at 
Mampong-Akwapim in a typical forest area. Their products are widely used, and their effectiveness is recognised. This is part of the arrangement to integrate plant medicine and scientific medicine.

\section{Administrative structures}

The public health system is organised hierarchically from the national level to the local level. At the peak of the system, the government appoints the Minister of health and his Deputy, with parliamentary approval. They take political decisions on health. The professional sector has the Director-General of Ghana Health Service as head of the service. At his secretariat are directors for various divisions like finance and administration, training and manpower, etc. The Ghana Health Service (GHS) has been established with autonomous powers to administer health services in the country. It controls the professional aspects of health services in the country.

At the Regional level, the Regional Co-ordinating Council (RCC) has the political responsibility for health in a region, whilst at the district level the District Assembly has the political responsibility. At the Regional level health administration is in the hands of a Regional Health Management Team (RHMT) with the Regional Director of health services as chairman. The RHMT is politically responsible to the RCC. Among the team are technical staff for various aspects of health care. The highest health institution at the regional level is the regional hospital that is supposed to be the final referral point within a region. In the Greater Accra and Ashanti Regions where there are Teaching Hospitals, these hospitals serve as the final referral points. There are plans to convert some polytechnics into regional hospitals in these regions.

At the District level, a District Health Management Team (DHMT) that is responsible to the District Assembly under the new decentralisation policy manages health administration. In practice, however, there is a lot of 'bureaucratic red tape' in the system, with the dominance of the topbottom approach in health decisions. Each district is divided into zones with a health centre catering for a zone. The district health administration is under the supervision of the District Director for health services.

There are two Teaching Hospitals, which are autonomous in their respective regions. They are located in the two most urban centres in Ghana, Accra, the national capital, and Kumasi. Teaching hospitals send their reports directly to the headquarters in Accra. They are not under the 
administrative control of the Regional Directors in the areas they are located. In practice, they are regarded as regions in health administration. They have budgets (provided by the Ministry of Health) separate from those of the regions in which they are located. They are the final referral points. The Komfo Anokye Teaching Hospital (KATH) in Kumasi serves the northern sector of the country, whilst Korle-Bu Teaching Hospital in Accra serves the southern sector. Facilities at the Korle Bu Teaching Hospital in Accra are, however, more advanced than those at the KATH in Kumasi. Consequently, certain health problems are referred from $\mathrm{KATH}$ to Korle-Bu in Accra.

Private health dominates the health system in Ghana, owning a greater quantum of the health institutions. They operate on profit basis and are supposed to send periodic reports about their operations to the District Directors who will forward them to the Regional Directors, then to headquarters in Accra. Mission hospitals, which are supposed to operate not-for-profit, receive some assistance in paying the salaries of health staff from government. They are also used as service points for primary health activities, like immunisation and child and maternal health services. There are also quasi-government hospitals, like university hospitals, police and armed forces' hospitals, etc. that receive some subvention from government for their operations. Universities, the police and the army have a form of health insurance for their staff and number of their dependents.

\section{Associations}

The various health sectors are organised into associations. We have the Ghana Medical Association (GMA) that represents the interest of doctors and to ensure quality health delivery standards. It is an umbrella association for all medical staff, whether in private or public practice. Even though membership is voluntary in principle, it is compulsory in practice, since monthly dues to support it are deducted from members' salaries at source. Since the association is the official mouthpiece of doctors, and responsible for bargaining with government on their service conditions, it becomes morally imprudent and poorly thought-out, for a member to opt out. Membership thus becomes obligatory. Private medical practitioners also have their own association. There is also the Ghana Registered Nurses' Association (GRNA) that seeks the welfare of registered nurses in Ghana. Membership is open to registered nurses in both public and private practice. 
There are institutions that are managed by government that are responsible for the health sector. These are the Ghana Medical and Dental Council, and the Ghana Nurse's and Midwifery Council. These institutions are basically for the improvement of health care and professional management of the various sectors of the health system. There is also the Ghana Pharmaceutical Association responsible for the welfare of pharmaceutical practitioners. There is the governmentcontrolled Pharmacy Board responsible for the efficient management of the drug sector.

Herbal and traditional healers have also formed an association, Ghana Herbal and Traditional Healers' Association, at the regional and national levels. They ensure quality products by requiring that they be tested at the pharmaceutical laboratories. They discipline members who do not conform to their established standards. There are also the spiritual healers, a wing of the traditional healers who resort to magic and occultism in healing. Of late, some 'spiritual' churches resort to healing methods that do not deviate much from those of traditional healers.

\section{Practice patterns}

In Ghana, General Practitioners are in health institutions, including hospitals and polyclinics. Health centres in the urban centres have been converted to polyclinics. Medical assistants manage health centres in the rural areas. Referral is from a lower health institution to a higher health institution. When a patient has been referred to a higher level of service, the doctor does not seem to be obliged to follow it up. In fact, a patient can refuse the doctor's referral instructions and go to another health institution for care. Because of the low level of insurance coverage, patients have to pay as they are served (fee-for-service). Regular service goes on at the health institutions except for the weekends when skeleton staff is left for emergency cases. Out-station services are also rendered for communities, especially rural communities, for selected days in areas like immunisation and maternal care. Follow-ups by physicians are not a regular feature of the health system.

\section{Health insurance}

The country has structured a national health insurance scheme as a means of ameliorating the cost burden for health care on the population, and for ensuring the financial capacity of the health system. The National Health insurance Bill (Parliament of the Republic of Ghana, 2003) has been passed by Parliament and, on $18^{\text {th }}$ March 2004, the scheme was 
formally inaugurated by the President. Mutual Health (Support) Organisations have been initiated in some selected districts on experimental basis, as precursor for the full implementation of the scheme. There is, however, a health-user exemption policy in which certain categories of patients and the very poor who genuinely cannot pay for the services are exempted. This policy is more a theory than a practice.

Contributors to the Social Security and National Insurance Trust (SSNIT), which include all workers both in public and private sector, have $1 \%$ of their contributions allocated for health care when they go on pension, but this proportion is not used by contributors. They prefer to use it for other purpose when they go on pension. They deliberately do not access it. There is a free medical care policy for civil and public servants, which is part of their conditions of service. The health care package has some limitations. Payment for drugs for instance is only limited to certain prescribed ones. Cost of blood tonics meant to alleviate anaemia for instance is not reimbursed, and there are no compensations for disabilities due to accidents. The system is bedevilled with a lot of bottlenecks including lack of funds for prompt payment of care costs. This system cannot be said to be health insurance in the strict sense of the word, since it is supposed to be part of the workers' incentives. No premiums are paid to receive the services. Staff and workers in semiautonomous state institutions like the universities and armed forces, as well as health workers, enjoy a wider range of health benefits than those in the civil and other public services. The benefits cover their wives/husbands, children and a stipulated number of dependants. At the universities for instance, a number of dependants, apart from children, also enjoys a proportion of the health benefits.

There are community and institution-based social support systems. In some communities, contributions are made to assist community members in areas like health, education and family care in the event of bereavement of the husband or parents. Some of these operate like the cooperative system. In some communities and institutions, welfare clubs have been formed to assist members in the event of need. A few health and life insurance organisations are operating, in which policyholders pay premium on monthly basis. The package varies from company to company, and the quantum of the premium determines the coverage of benefits. 
Government has made great efforts to get the National Health Insurance Scheme established. In 1996/97, the Ministry of health commissioned a team to carry out a pilot survey in the Eastern Region of Ghana on the potentials for introducing a national health insurance. The team was to find out the minimum premium to be paid by each insured each month to be able to run the insurance system, as well as the willingness of the people to pay.

The team came out with a recommendation of a monthly insurance premium of six thousand cedis $(46,000.00)(\$ 1.33)$, which was found to be too high by the ministry, in view of mass unemployment and poverty. The ministry rather suggested community-based insurance schemes in which beneficiaries in communities would make regular contributions towards their health care costs (The Daily Graphic, May 1, 2000). Membership is voluntary. This recommendation was made prior to the establishment of a national health insurance scheme. Currently a private health insurance scheme has been initiated by the Ghana Health Insurance Company, with the support of the Ministry of Health and the SSNIT. The ministry proposed the $1 \%$ of contributors' contribution meant for health becomes the retiree's contribution to the Ghana Health Care Company Scheme. The structure of health insurance in Ghana, pending the full implementation of the NHIS, is depicted in table 1.3.

The NHIS has been inaugurated, awaiting full implementation. A number of districts in Ghana have been selected to run the Mutual Health (Support) Organisations (MHOs) as a precursor for the full operation of a National Health Insurance Scheme (NHIS). Results indicate that the MHOs are operating successfully. The major problem with the introduction of a NHIS is the mass poverty and mass unemployment, which will make payment of monthly premiums a problem. 


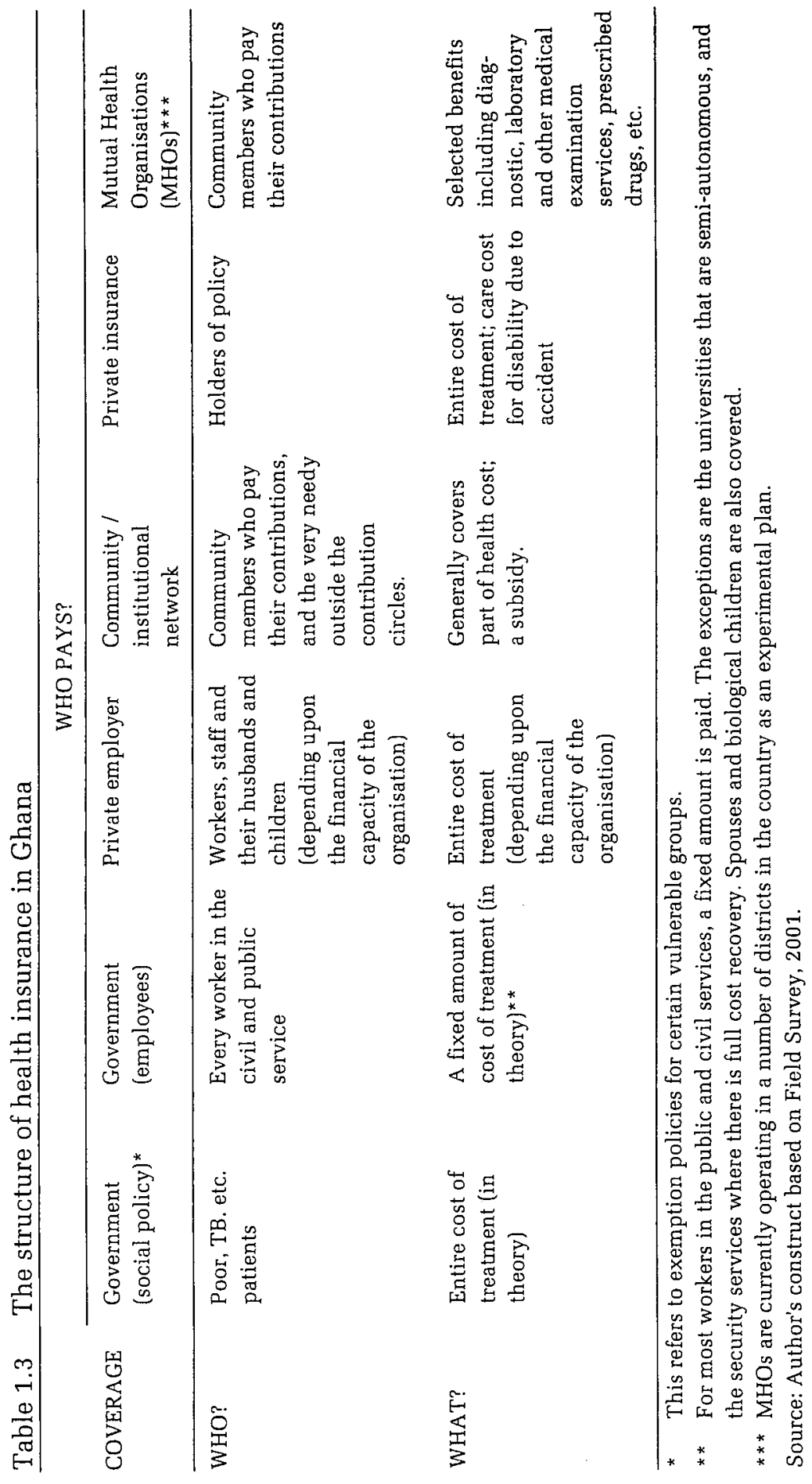




\section{The problem, literature and theoretical framework}

\section{The problem: access and utilisation of health services in Ghana}

The socio-economic status of Ghana reflects on the health situation. Generally, the better the economic indicators, the better the health conditions. In Ghana and some other developing countries, the low expenditure on health has affected the provision of physical and consumable health facilities. Low wages make quality care inaccessible to a greater proportion of the population. Moreover, there is lack of facilities like potable water that promote health. This is also the picture in the two selected districts, Kumasi Metropolis and Ahafo-Ano South District (figure 1.1), where the study was situated.

As table 1.2 showed, in developing countries, the basic needs for life such as clean drinking water or an adequate food supply are far from universally met (Gatrell et al., 2000). Since rural areas have even worse access to such health promoting facilities, they experience a poorer health status, hence, the greater need for health services.

The main features of accessibility and utilisation in Ghana are, long distances to health centres, an urban-bias in the distribution of health services, inadequate budgetary allocation to the health sector, high transport cost, poor roads from homes to some facilities, especially in rural areas, long hours spent in travelling to health centres and long hours of waiting, and the considerable time mothers spend in caring for the health needs of their children. There is also over-utilisation of drugs in medical care, wide use of untested traditional medicine, and no health insurance for a greater part of the population. Moreover, mass illiteracy affects perception of health care needs and knowledge of health services. Especially the education of women is important as it affects the use of primary care services and the health outcomes by their children.

In Ghana as a whole, and the Ashanti Region, where the two districts have been selected, in particular, access to health facilities is not encouraging. In Ghana as a whole, $35 \%$ of rural households cover a distance of between 1 and 9 miles to travel to the nearest hospital (GSS, 1993). Of the rest, the majority covers more than 9 miles to reach a health facility. The Ashanti Region only boasts of six district hospitals outside the Kumasi Metropolis.

There is a dichotomy in the spatial distribution of health services in Ghana as a whole, the bulk of the services being concentrated in the 
South of the country. The two Teaching hospitals that are the final referral points are located in Accra and Kumasi both in the south. This has geopolitical implications. The distribution of health services is highly skewed towards the urban centres of the country. In the Ashanti Region, the Kumasi Metropolis has, apart from a Teaching hospital, three polyclinics, with facilities over and above the six district hospitals that are sited in the rural districts. Indeed, Kumasi Metropolis alone has over $34 \%$ of all the health institutions (private, public and mission) in the Ashanti Region (Ghana Ministry of Health (MOH), Ashanti Region, 2000, p. 48) even though it constitutes about $32.4 \%$ of the regional population (GSS, 2002, p.47) and about $1 \%$ of the land area in the region. For the region as a whole, having 77 hospitals of all kind, the hospital-population ratio is $1: 42,497$ (Ghana $\mathrm{MOH}$, Ashanti, 2000, p.4). With a total of 224 doctors in the Region, including those of Komfo Anokye Teaching Hospital (KATH), the doctor-population ratio is $1: 14,608$. If doctors at KATH are discounted, it shall come to $1: 53,194$, which better reflects the regional situation because KATH serves the entire northern sector of the country. This ratio is worse than the 1:10,000 recommended as the maximum by the WHO over 30 years ago for developing countries (Veitch, 1972).

The Ahafo-Ano South District, a typical rural district covering an area of over 1,420 square kilometres, and an estimated population of 133,632 (GSS, 2002, p.47) has only 1 public hospital situated at the district capital, Mankranso, 6 health centres, and 3 clinics/maternity homes. With 2 doctors, the doctor-population ratio is 1:66,816 (Ghana MOH, AhafoAno South, 2000, p.1).

The Kumasi Metropolis, with a population of 1,170,270 and 39 hospitals of all categories, has a hospital-population ratio of 1:30,006; and with 202 doctors has a doctor-population ratio of 1:5,793. The ratios for Kumasi Metropolis, though not very encouraging, are better than those of AhafoAno South. The distribution of health institutions in Kumasi Metropolis and Ahafo-Ano South District is respectively indicated in figures 1.2 and 1.3 . 
Figure 1.2 Distribution of sampled settlements and sampled health institutions in the Kumasi Metropolis

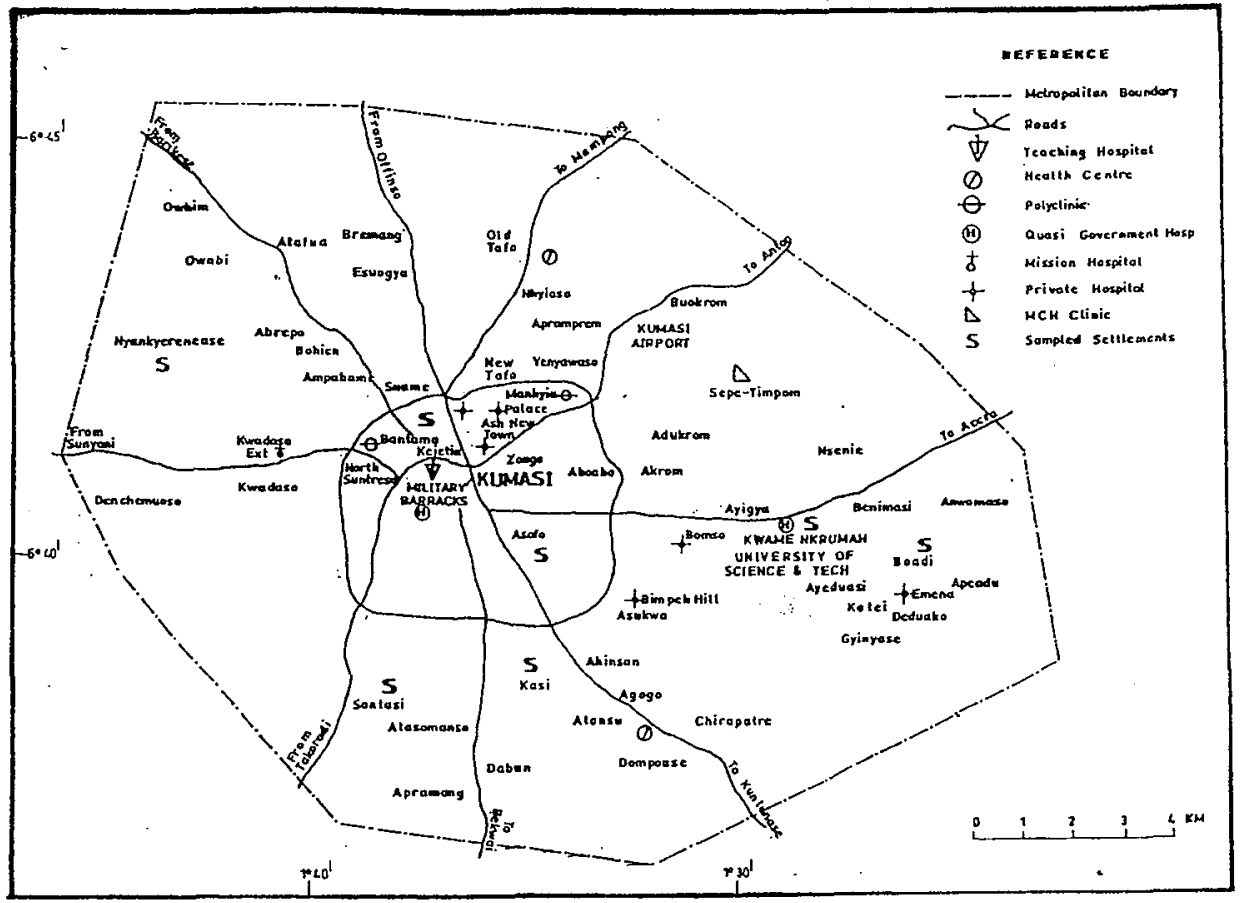

Source: Town and Country Planning Department and Ministry of Health, 1996

Figure 1.3 Idem for the Ahafo-Ano South District

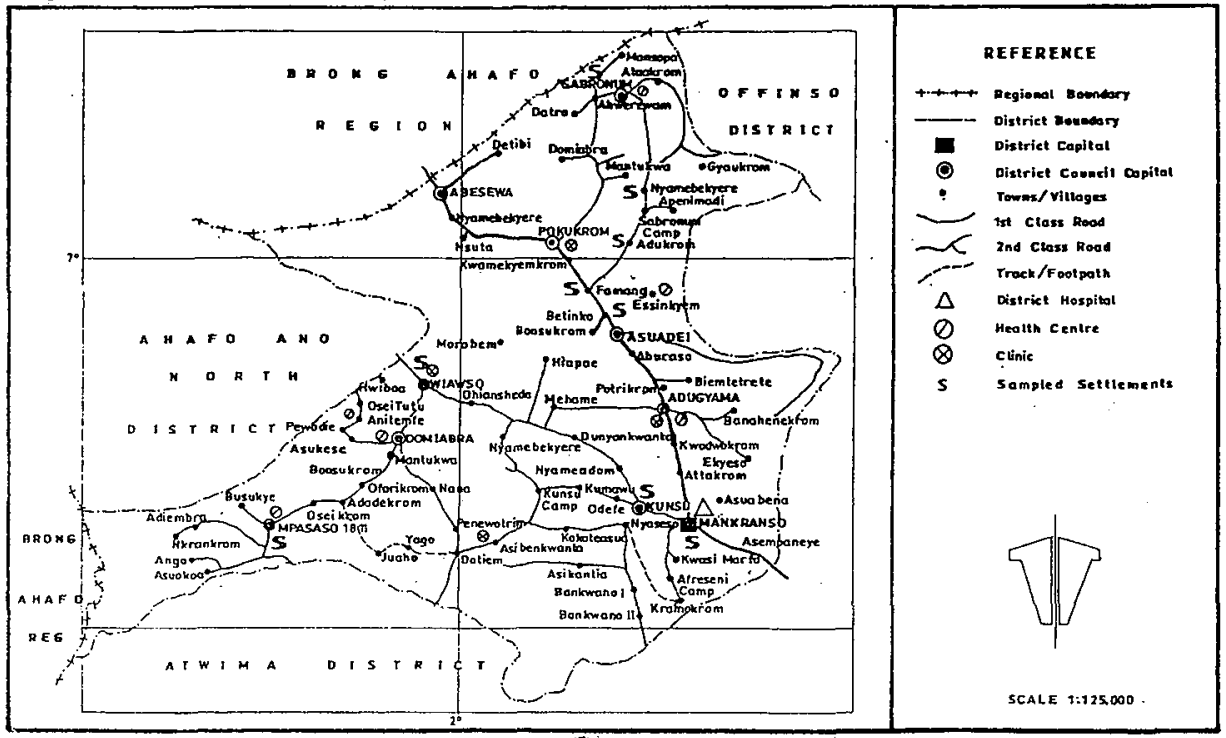

Source: District Assembly and Ministery of Health, 1996 
The poor budgetary allocation to the health sector may partly explain the inadequate health facilities in the region. The budget for the health sector in the study Region, with an estimated population of 3.6 million, was over $\$ 20.4$ billion $(\$ 5,104,800)$, giving a per capita health expenditure of $\$ 1.7$ (Republic of Ghana, 1996). The per capita health expenditure for Ghana, is lower than for the average for low-income countries (table 1.2).

Dimensions of distance to services, such as travel time, waiting time, appointment time with a doctor, nature of the means of transport, and cost, have effects on revealed accessibility, i.e. utilisation. Distance, generally has an inverse relationship with utilisation: the greater the distance, the lower the utilisation (Jolly and King, 1966; Meise et al. 1996). In Ghana, the poor economy and resultant poor health funding, mass poverty, unemployment and low wages, deprive a lot of the population from health services. An important predictor of utilisation is whether or not a physician is located within the wider set of places that people visit regularly (Nemet and Bailey, 2000). Going by such an observation, utilisation rate would be lower for rural areas where people have limited activity spaces. Factors other than distance however have been found to explain utilisation as there are no uniform rates of distance decay (Giggs, 1983).

The poor nature of roads, especially in the rural areas of the region, could also discourage health service use. Most of the rural roads are not in good condition during the rainy season. This leads either to very high transport costs; or non-use of vehicles.

Poverty and illiteracy potentially affect use of health services. These are the most important influences other than physical accessibility that could hinder the utilisation of health services. Most of the people lack enabling resources; and, because of high rate of illiteracy, they might not perceive the need for health service use, especially rural people, resulting in the use of unscientifically tested traditional medicine, some of which has negative health implications.

Finally, government policy influences utilisation in the region. The introduction of the Hospital Fee Regulation of 1985, under the Structural Adjustment Programme (SAP), has led to a decline in hospital use in the country as a whole (Kwabia, 1996). As a result of low wages and a high rate of unemployment, with a high rate of increase in consumer price and food price indexes, health service use has become less affordable. 
It is evident from the foregoing that access and utilisation of health services are an important problem in the Ashanti region in part and Ghana as whole. This study aims to identify the multiple causes of underutilisation. This study could be used as a model for studies in areas of developing countries that have similar socio-cultural, economic and political circumstances. Before further elaborating the research questions of the study, a survey of the literature was done, both for the developing and developed countries.

\section{Literature survey}

The literature review covers research findings on bivariate and multivariate studies on accessibility and utilisation. The review is to identify relationships of accessibility and other variables to utilisation and research methods in this field in order to develop a framework for the study. The literature review focuses on conditions in developing and developed countries. This comparison informs us about the applicability of research results in different contexts. It also might point to hypotheses about changes in determinants of access and utilisation of health services, when the economic situation develops. The first part concentrates on the review of literature on each of the groups of countries, developed and developing, whilst the second part concentrate on comparing the two situations. Finally, some conclusions are drawn.

\section{Conditions in developing countries \\ Distribution of health care facilities}

The distribution of all categories of health care facilities, tends to favour disproportionately the urban centres in developing countries. The differences in provision between rural and urban areas are often so great as to make national averages of population facilities almost meaningless. In his annual report of 1978, the WHO Regional Director for Africa drew attention to the concentration of physicians in urban centres and the development of health services predominantly in towns, depriving many rural communities of modern medical care (WHO, 1979). The situation does not however seem to have changed, as later literature indicates.

The Metro-Manila region in the Philippines, for instance, though contains $25 \%$ of the country's population, has $43 \%$ of total hospital beds (Phillips 1986). This inequality is mild when compared with other situations. In Kenya, it is estimated that only $10 \%$ of the country's doctors serve rural areas, and that some $70 \%$ of all doctors are in urban private practice. Doctor-to-population ratios range from $1: 990$ in the cities to $1: 70,000$ in 
rural areas (Good, 1987). Large disparity also exists within urban areas (Harpham, 1988; Bailey and Phillips, 1990). Variations have also been found to exist in the spatial provision of health facilities between rural local government areas (Okafor, 1984). In a prelude to the study of the spatial dimensions of accessibility to general hospitals in rural Nigeria, Okafor (1990) is of the opinion that the problem of inadequate health services in rural Nigeria is worsened by poor location decisions which have resulted in various degrees of inaccessibility to the existing health facilities.

\section{Accessibility and utilisation of health services}

a Distance decay: In developing countries, distance is only one variable that may interact more or less strongly with others to influence utilisation. Most people will not travel further than 5 kilometres to basic preventive and curative care (Muller et al., 1998). In a study of the effect of distance from home on attendance at a small rural health centre in Papua New Guinea he found that attendance decreased markedly with distance. There was a $50 \%$ decrease of the number of patients at a 3.5 kilometre distance.

In evaluating health service equity at a primary care clinic in Chilimarca, Bolivia, Kinman (1999) also discovered that, within the targeted service area, visitors of the clinic were concentrated in a few blocks of the community, with diminishing numbers with increasing distance from the clinic. In Nigeria, Stock (1987) found that at a distance of 5 kilometres from a dispensary, per capita utilisation fell to less than onethird of the $0-\mathrm{km}$ rate. An Indian study showed that the proportion of a community attending a dispensary decreased by $50 \%$ for every additional half-mile between the community and the facility (Frederiksen, 1964).

Wilson et al. (1997) also gathered from their study of the maternity home waiting concept at Nsawam in Ghana that distance from the hospital was, among others, one of the reasons for poor utilisation. In this study, focus groups were used. In the Jasikan district in Ghana, distance decay played a major role in health service utilisation (Institute of Development Studies, 1978). About 3/4 of all registered patients come from within 4 miles and that most people (over 90\%) living within 4 miles do, in fact, register at a health unit. However, registration drops off quite sharply for those living further away, and only about $1 / 10$ of the population living more than 6 miles from a health facility appear to be registered at all in Jasikan.

Some factors interfere with distance-decay. These include socioeconomic status (Bailey and Phillips, 1990), quality of care provided, 
and the nature of the illness. In rural Nigeria for instance, people are willing to travel farther for more specialised services, or better quality care (Stock, 1983).

The quality of care provided and the type of services offered, like specialist services can alter distance-decay (Smith, 1977). Distance decay may also be altered by the urgency of the service. In a study on male bias in health care utilisation for under-fives in a rural community in Western India, Ganatra and Hirve, (1994) found that parents were willing to travel greater distance to seek medical treatment for their sons, but would not for their daughters. This has a cultural cause.

b Time accessibility: The influence of time on utilisation can be examined in three perspectives, namely travel time, waiting time at the hospital, and waiting time with respect to appointments. In developing countries, travel time and waiting time at the facility are more important in examining utilisation. Waiting time for appointments is not a regular feature of the health system in developing countries.

One basic fact that the researchers fail to unearth is that, in developing countries, time, as a barrier to utilisation, would be influenced by the season of the year, and the nature of patient's business activities.

During the farming season, it would be expected that the rural farmers would not like to waste much time travelling long distances for health care, whilst a very busy entrepreneur may not sacrifice too much time for health care during peak seasons like Christmas. He may prefer using intervening alternatives.

c Financial accessibility: In a study of user satisfaction with health services in government health facilities in the Eastern Region of Ghana, code-named "What does the public want from us?", Delanyo, et al. (1990) identified high cost of services, among others, as a major cause of user dissatisfaction. In the Republic of Congo, the introduction of user charges led to a steep drop in the utilisation of health services (Turshen, 1999). In Ghana, the introduction of the Hospital Fee Regulation of 1985, under the Structural Adjustment Programme (SAP), has led to a decline in hospital use in the country as a whole (Kwabia, 1996).

d Social accessibility: Social accessibility refers to situations in which patients in a community consulted the doctor or General Practitioner with whom they feel comfortable. In a survey on spatial patterns of attendance at general practitioner services in New Zealand Hays et al. (1990) found that the Maori were less spatially bounded than other members of the sample and patients attended doctors who had been recommended by family and relations. 


\section{Other factors influencing utilisation of health services}

Apart from accessibility variables, socio-economic and demographic, and political factors influence the use of health services. These factors are income, education, health insurance, demography, government policy, ethnicity, place of residence, quality management and affective behaviour.

a Income: Habib and Vaughan (1986) in a household survey in rural Iraq, found that the use of higher level government health services and private clinics did increase substantially with increasing income. In Indonesia, Chernichovsky and Meesook (1986) in a household survey found low income to be a strong barrier to the utilisation of modern primary medical facilities, even when publicly provided. Pickett and Hanlon (1990); and Ensor and Pham-Bich-San (1996) conclude in separate studies on access to health services that, in the developing countries, the poor have less realised access to health services.

Employment is also an important determinant, since it is a determinant of income, hence an enabling factor. The status one has acquired in his workplace is also a factor of income status. There is very little literature on the relationship between employment status, type of employment, and professional status, and utilisation in developing countries. Such areas need research.

b Education: One important predictor of utilisation of health services is education. Education and demand for health care are in general positively related (Grossman 1972; 1975). The educated are more cautious and conscious of their health, and tend to use health services more. Illiterate persons with high income are likely to use health facilities less than the educated in the same income category. Of greater impact in determining the use of health facilities is the education of mothers (Caldwell, 1983; Caldwell, 1986; Caldwell, 1989; Swenson, et al.1993; Mensch, et al. 1985; Raghupathy, 1996; Wong, et al. 1987). Educated women tend to use health facilities more than the uneducated, and the level of education of a woman and the number of living children also determine her use of pre-natal and antenatal services.

The educational levels of mothers are generally strongly related to levels of infant mortality, effective feeding, and good use of health services. In studies in the Philippines, Wong, et al., (1987) discovered that improved education of women is associated with increased use of modern prenatal care. An ILO study carried out in Bolivia, Egypt and Kenya showed that access of women to maternal and child health services were strongly influenced by their level of education and rural-urban status (ILO, 2000). The education of mothers in Ghana is a determinant of child immunisation. Whereas 42.2 per cent of mothers without formal 
education immunised their children against BCG, DPT, polio, and measles between 1989 and 1993, 86.7 per cent of mothers with secondary education and above did (GSS, 1994:101). In Ghana, there is also a direct relationship between the level of mother's education and tetanus toxoid vaccinations (GSS, 1999, p.95), a factor that influences maternal and child health. The education of mothers and its influence on their use of health services have positive effects on their children's health outcomes through better nutrition and effective use of health services (Hobcraft, 1993). In a study of the differential effect of mother's education on mortality of boys and girls in India, Bourne and Walker (1991) found that improved mother's education reduced mortality at all ages below five years for both sexes.

c Health insurance: Health insurance, which is very important in utilisation, is least developed in most developing countries. Utilisation is higher for insured patients in developing countries where health insurance exists. In a study of the Bwamanda hospital insurance scheme in Zaire (Democratic Republic of the Congo), Criel, et. al (1999) found that utilisation increased among insured patients. Supakankunti (2000), in a study of the future prospects of voluntary health insurance in Thailand, concluded that greater use of health services was the result of the introduction of the Health Card program. There was an improvement in accessibility to health care and a high level of satisfaction among Cardholders. Chen, et al., (2001) also conclude in a study of the impact of national health insurance on the utilisation of health care services by pregnant women in Taiwan that the utilisation of prenatal and intrapartum care services, especially for the more expensive services, substantially increased in Taiwan since the implementation of the national health insurance plan.

d Demographic factors: The demographic factors of age and sex show some correlation with the use of health services. In rural India, rural Nigeria, and rural Ethiopia, Kroeger (1983) discovered that children are important clients of Traditional Medical Practitioners (TMPs), whilst Good (1987) found that in India, women consulted TMPs most. They accounted for 55 to 60 per cent of consultations. The two situations could stem from poverty, ignorance, and cultural practices. Ethnomedicine is intrinsically embedded in the rural economies of developing countries where poor access to and less knowledge of scientific medicine exist.

Taylor et al. (1983) found in an empirical study that, in rural India, there were no significant differences within the 15-49 year married women age group in the use of women's health services. The study does not show how socio-economic variables and place of residence would affect 
utilisation. In a developed economy, social security services make it easier for the aged to have easier financial access to health services. This is unlike developing countries such as the study area where there is a weak social security system, making most of the aged rely on the humanitarian goodwill of family members, and sometimes friends.

In an empirical research on accessibility and utilisation of health services in a rural district in Ghana, Abugri (1995:97) found that the youth made use of health services more than the aged. The ages below 20 had more visits to the clinic than those above that age. The elderly above 50 used the clinic very seldomly. The explanation is that the elderly are generally dependent on the middle age group for support; hence, their decisions to visit clinics were constrained by either lack of financial or physical support.

Generally women use health facilities more than men, which relates to higher morbidity and a lower threshold to consult a physician (Kohn and White 1976; Verbrugge 1979). Gender disparities also impact negatively on the use of health services. Ojanuga and Gilbert (1992) in a work on women's access to health care in developing countries established the premise that myriad socio-cultural factors negatively impinge upon the physical well-being and accessibility of appropriate health care facilities of women. In developing nations, women's roles affect their use of health services, since men who monopolise family decisions are strong determinants of health care utilisation (Santow, 1995).

e Political factors: Political, economic and social structures internationally and nationally determine who is going to get what, where and how (Smith, 1979). This finds expression in the impact of the Structural Adjustment Programme (SAP), which is having serious repercussions on the socio-economic life of a section of the population of countries adopting them. Some of the features of the SAP are the devaluation of the local currencies, removal of subsidies from social services, trade liberalisation, and labour retrenchment. The cost of health services is therefore unbearable for the masses.

The SAP has not been able to eliminate poverty, which seriously affects utilisation. Moderated levels of poverty are not consistent with SAP basic prescriptions. The growing poverty has led to a remarkable decline in hospital use. In two empirical studies, Kambarin (1996) and Abugri (1995:34) confirm the negative impact the SAP has had on health services utilisation in mainly rural Ghana.

According to Kambarin the introduction of the SAP has seriously affected the utilisation of health facilities of the rural people. It has also led to the reduction of medical staff, with its negative effects on the 
quality of services. Abugri also discovered that, in the Volta Region of Ghana, there were significant cuts in outpatient attendance, with the introduction of hospital fees (user charges), which was a by-product of the SAP.

f Ethnicity: The issue of ethnicity in accessibility and utilisation is very important. Certain ethnic groups show a bias to the utilisation of certain types of healers or medical providers. In the developing nations, Ramesh and Hyma (1981) have found that preferences for health facilities may be based on a common language or religion that leads to the utilisation of certain types of healers or medical providers. In developing countries, the traditional sector has health beliefs in which disorders are seen not to require the intervention of scientific medicine (Joseph and Phillips, 1984). The modern sector thus tends to patronise health services the more.

g Quality of care: Finally, the application of Total Quality Management (TQM) has been found to enhance accessibility (Dhungel and Dias, 1988). The supplier-inducement model has been used to explain utilisation. The objective of patients is to get better, so they seek quality service that can help them achieve this goal. This is, however, limited by enabling and predisposing factors of education, finance, attitudes and physical access.

\section{Conditions in developed countries}

\section{Distribution of health facilities}

The distribution of health facilities is generally biased towards the urban centres. Rural areas, though served with hospital facilities, are deprived of specialist services. Consequently, people in rural areas will have to go on referral to urban hospitals. There are, however, usually adequate primary care services. In Western countries, Phillips (1990, p.206) has discovered that residence in less desirable urban locations and socio-economic deprivation can lead to poor access to health care. Major health facilities are located at the privileged urban core.

\section{Accessibility and utilisation of health services}

a Distance decay: Meise et al. (1996) in a study of the quality of location as a principle in psychiatric health care planning in the Austrian state of Tyrol found an inverse relationship between the utilisation of available facilities by patients and the distance from their homes. They conclude that longer distance results in lower utilisation. In a study of distance on hospital use in South Dakota, United States, Folland (1977) found that a one-mile increase in the distance to a hospital decreases the hospital's 
market share from that county by $1.7 \%$. Distance decay has a negative impact on utilisation of health services both in rural and urban areas in developed countries. This is very much evident in rural Newfoundland (Girt, 1973) and metropolitan Liverpool (Hopkins et al. 1968). This trend is still predominant. The nature of illness will however modify distancedecay in most cases. Girt (1973), in a study of distance to general medical practice and its effect on revealed ill-health in rural Newfoundland confirms that gradients of distances patients travel to seek health care are relative to the nature of illness.

b Time accessibility: Meise et al. (1996) saw time distance as a major obstacle to hospital attendance in developed countries. Their investigation showed that, the temporal dimension---the distance between home and hospital measured in terms of the time it takes to get to the hospital---is the most significant determinant of the quality of location. In their studies, time is linked up with distance in utilisation of health services. Acton (1975) also concludes in a study of the effects of waiting time on utilisation that the length of time the patient spends in waiting at a physician's office is an important time price that determines utilisation levels. Bentham and Hayes (1985) in a study of health, personal mobility and the use of health services in rural Norfolk gathered that increased distance between residents and health care providers tends to decrease utilisation. Aday and Andersen (1974) also note that this negative effect on utilisation is greater for rural farm residents because they have been found to have the highest traits to see a physician. This may be based on their low socio-economic status.

c Financial accessibility: Even in developed countries, service cost could scare utilisation. In the United States, lower-class persons under-utilise health services because of the financial cost of services and because of a sub-culture of poverty that has failed to emphasise the importance of good health (Cockerham 1978). McKinley (1972) also points out that there are a number of examples of economic barriers to the receipt of care in fee-for-service systems. High costs of medical care and low incomes appear to force some groups to change their venues of health care. In a study of Oklahoma City, for example, the elderly were identified as attending hospital emergency rooms and outpatient departments for primary care due to the cost of private physicians (Bohland and French, 1982).

Other more recent studies have established similar trends. In a study of the effects of fee bundling, an aspect of the payment system, on dental utilisation in Ontario, Canada, Porter et al. (1999) discovered that the volume and intensity of services received by adult patients increased 
when fee constraints were imposed on dentists. In a study of the effect of patient charges on the utilisation of prescription medicines in Britain, O'Brien (1989) found that increases in the real value of the prescription charge are associated with a reduction in the consumption of chargeable drugs. Sintonen and Maljanen (1995), using the supplier-inducement model to explain the utilisation of dental care in Finland saw that the effects of money price was a significant factor which influenced utilisation.

Grytten (1991) in a study of supplier-inducement on dental care in Norway concluded that dentists in areas of excess supply were able to maintain their workload, with an increase in the demand for utilisation of health services. This study underscores the fact that, in developed countries, the cost factor would not affect demand for certain critical services.

d Social accessibility: Gesler and Meade (1988), in a study of locational and population factors in health care-seeking behaviour in Savannah, Georgia observed that people who had lived in an area for a short time might have preferred to visit a doctor or clinic closer to their previous residence.

\section{Other factors affecting utilisation of health services}

a Income: Income exhibits a direct relationship with health service use, the institution of insurance scheme notwithstanding. In a study of income characteristics of rural older women and implications for health status in the USA, Barnes and Bern-Klug (1999) concluded that, gender, rural residence, and poverty are identified as risk factors for reduced access to health care services, lower rates of health care service utilisation, and poorer health outcomes. In a study of determinants of rural travel distance for obstetrics care in rural Alabama, Bronstein and Morrisey (1990), concluded that as incomes rise, rural citizens substitute out of the local rural hospital and seek care elsewhere. A $1 \%$ increase in the per capita income in the county leads to a $4 \%$ increase in the distance travelled for obstetrics services.

b Education: Writing on strategies for regional welfare planning based upon the Norwegian experience, Aase (1996) assumes that other public sectors (than health care) can contribute individually, or through intersectoral action towards better health. He emphasises for instance, a link between education and health-related behaviour. Education however does not seem to be an equally strong variable influencing utilisation in the developed countries as in the developing countries. Grossman (1975) emphasises the influence of education in the utilisation 
of health services even in the developed nations. This factor is more evident in the developing countries where education is a more variable factor than in the developed countries.

c Health insurance: Health insurance influences utilisation significantly in the developed countries. In a research on response to health insurance by previously uninsured rural children in a school-based health insurance programme in the Mississippi delta, Tilford, et al. (1999) found that the use of services increased.

In a research on the influence of insurance status on non-urgent pediatric visits to the emergency department at the Children's Hospital, Harvard Medical School, Boston, Fong (1999), found that, paediatric patients with private insurance were more likely to present for emergency care for non-urgent reasons when compared with HMO patients.

Research by Lillard et al. (1999) on insurance coverage for prescription drugs: and its effects on use and expenditures in a Medicare population in the United States showed that insurance coverage for prescription drugs significantly increases the probability of use, but not total expenditures, among those who use prescription drugs.

In a study of health insurance and utilisation of medical care for children with special health care needs, Aday et al. (1993) also discovered that in general, poor, minority children who lived with their mother or someone other than their parents, or those without insurance or an identifiable regular medical provider, were most likely to experience financial barriers to access, or were less apt to seek care than other children with comparable needs.

Finally, Sox et al. (1998) in a study of the role of insurance in hospital admissions through the emergency departments in Boston and Cambridge, Massachusetts's academic hospitals, concluded that uninsured patients with one of three common chief complaints appear to be less frequently admitted to the hospital than are insured patients.

d Demographic factors: In some developed countries, the elderly retain statutory health insurance, but are no longer covered by any other social security programme. Since they are retired, they no longer need unemployment, work-accident or disability insurance (Glaser, 1991). In Britain and America, primary care utilisation rates on the average do increase with age (Joseph and Phillips, 1984). Bowling et al. (1991) writing on the use of health services in old age in London and Essex note that, utilisation of health and social services was found to be higher in urban areas, and increased with age. 
In the developed world, women tend to receive more health services, more extensive diagnostic services, and more follow-up consultations (Verbrugge and Steiner, 1981). In a study of sex differences in the use of health care services in Manitoba, Canada, Mustard, et al. (1998) found that women used health services more than men. The crude annual per capita use of health care resources was greater for women than for men. Approximately 22 per cent of health care expenditures for women was associated with conditions specific to sex, including pregnancy and childbirth, as compared with 3 per cent of expenditures for men.

In another study on differential use of medical care by sex in Ohio, Sindelar (1982) concludes that women use health services more than men. The results of her studies indicated that $10 \%$ per cent of men and 17 per cent of women entered the hospital per year; and, whereas women spent $\$ 128$ per year on average on doctor's care, men spent $\$ 78$.

The average numbers of consultations with a General Practitioner (GP) per person per year in England and Wales show that, in all age groups from age 15, women consult GPs more than men. In 1977, whereas average number of women consultations for age group 15-44 was 2.4 for men, it was 4.5 for women; the women consultations almost twice the men (Joseph and Phillips, 1984).

e Political factors: Governments of developed countries have adopted policies that make health insurance obligatory, with the utmost goal of ensuring access to health services. Western European countries have either a social insurance system or a national health service. Countries of Eastern Europe increasingly develop social insurance systems (Marree, Groenewegen, 1997). The United States of America has tried several times to create universal heath insurance, but always failed (Navarro, 1992).

f Ethnicity: In the United States of America (USA), preventive medical care is more a white middle-class preserve, which is less utilised by ethnic minority groups (Rathwell and Phillips, 1986; Joseph and Phillips, 1984). Ethnic minority groups tend to rely on curative services and traditional sources.

The residence in certain locations, especially in urban areas, can affect accessibility, hence utilisation. Membership of certain ethnic or even cultural-religious groups can be associated with access to superior or inferior health care. In Western countries, residence of certain ethnic groups in less desirable urban locations and socio-economic deprivation, and linguistic or cultural impediments, can lead to poorer physical and 
social access to health care (De Vise, 1973; Shannon and Dever, 1974; Thomas, 1976; Phillips, 1990).

g Quality of care: In developed economies, (Donabedian, 1980; Donabedian, 1996) saw access as a function of Total Quality Management (TQM) of health services. TQM has been found to enhance quality and improve access. In the study of rural travel distance for obstetrics care by Brownstein and Morrisey (1990) in the state of Alabama, as incomes rose, patients moved from the local rural hospital to others where they perceived the services to be more effective. Sintonen and Maljanen (1995) use the supplier-inducement model to explain utilisation of dental care in Finland.

\section{Comparison of developing and developed countries}

The review of the literature on the two groups of countries show that certain aspects of accessibility and utilisation are common to both, with relative strengths, whilst some are specific to one of the two situations. The comparison is as summarised in table 1.4. Whereas distribution of health facilities, distance, service cost, income and political factors have moderate effect in developed countries, they have strong effect in developing countries; and whereas education is a weak variable influencing utilisation in the developed countries, it has a strong influence in developing countries. Quality of care has a moderate effect in developing countries due to mass poverty, but has a strong effect in developed countries. Moreover, whereas ethnicity has a moderate influence in developing countries, it has a strong influence in developed countries.

Social accessibility has probably little influence on utilisation in the developed countries, apparently due to low illiteracy rate, high enlightenment, demise of traditional society, and high perception of quality service; as against a moderate effect in developing countries where there is segmentation of society based upon cultural and traditional links, illiteracy, low perception of high quality service and poverty. 
Table 1.4 Comparative analysis of access and utilisation framework in developed and developing countries

\begin{tabular}{|c|c|c|}
\hline \multirow{2}{*}{ Variables } & \multicolumn{2}{|c|}{ Economy } \\
\hline & Developed & Developing \\
\hline Distribution pattern & Moderately urban-biased & Strongly urban-biased \\
\hline Distance & $\begin{array}{l}\text { Moderate effect (due to good } \\
\text { access roads and high incomes) }\end{array}$ & $\begin{array}{l}\text { Strong effect (due to poor } \\
\text { access roads, high transport } \\
\text { cost, and low incomes) }\end{array}$ \\
\hline Time & Strong (inadequate literature) & Strong \\
\hline Service cost & $\begin{array}{l}\text { Moderate (due to insurance } \\
\text { coverage) }\end{array}$ & Strong \\
\hline Social accessibility & No effect (lack of data) & Moderate effect \\
\hline Income & $\begin{array}{l}\text { Moderate (average incomes are } \\
\text { adequate) }\end{array}$ & $\begin{array}{l}\text { Strong (especially in rural and } \\
\text { urban margins) }\end{array}$ \\
\hline Education & $\begin{array}{l}\text { Weak variable (in view of high } \\
\text { literacy rate) }\end{array}$ & $\begin{array}{l}\text { Strong (especially for women } \\
\text { education) }\end{array}$ \\
\hline Demographic & $\begin{array}{l}\text { Elderly more than youth/female } \\
\text { more than male }\end{array}$ & $\begin{array}{l}\text { Youth more than } \\
\text { elderly/Women more than men } \\
\text { for lower services/Men more } \\
\text { than women for higher services }\end{array}$ \\
\hline Political & Moderate (no adequate data) & Strong \\
\hline Insurance & Strong & Strong (but a very low coverage) \\
\hline Ethnicity & Strong & Moderate (inadequate data) \\
\hline Quality of care & $\begin{array}{l}\text { Strong (based upon ability to } \\
\text { pay) }\end{array}$ & $\begin{array}{l}\text { Moderate (due to poverty and } \\
\text { low perceived need }\end{array}$ \\
\hline
\end{tabular}

\section{Research questions and their elaboration}

The following research questions emerge from the description of the problem situation and the literature survey:

1 a To what extent does the accessibility of health services, in terms of distance, waiting and travel time, and service and transport costs have a negative effect on utilisation?

$b$ What impact do socio-economic variables of education and income have on utilisation beside accessibility? 
c To what extent does government policy, or non-policy, on insurance impact on utilisation?

2 Do the variables mentioned in research questions $1 a-1 \mathrm{C}$ have a different influence on access and utilisation of health services according to place of residence?

3 a What are the utilisation patterns of women who are a vulnerable group by virtue of their fragile health status and discrimination against them due to cultural perceptions?

$b$ To what extent does maternal education influence the health outcomes of their children due to effective utilisation of health services?

The first questions relate to aspects of accessibility. In analysing the relationships between distance and time variables and health service utilisation other relevant variables such as age, sex, and some other social variables will be taken into account. Specifically, for the purpose of empirical research, the distance variable and the relative impact of distance, nature of the transport system, time variables and cost, will be the focus.

Question $1 \mathrm{~b}$ relates to population characteristics. Education influences the decision to initiate care, creates the condition for earning income to be able to use health services, and influences attitudes to health care. It is also a potential for ensuring effective use of health care. The education of women will be critically examined for the purpose of this research.

Government policy has been given an important position in the explanation of health service utilisation. It is a determinant of cost of service, insurance, and location of health facilities. In this research, the impact of health insurance on utilisation will be examined. Even though health insurance is not common in the study area, especially in the rural area, it is worth studying its role in health service utilisation. There is generally a dichotomy between rural and urban areas, and within urban milieus in the distribution of health facilities, and such situation can have an impact on utilisation. The impact of place of residence will also draw in socio-economic and cultural factors.

There is also the need to examine the utilisation behaviour of women, who are a vulnerable group. This study is very important when we 
examine the key role of women in childcare. Their poor access to health care will have serious repercussions on the future security and stability of the population. Finally, the role of education of women and how it influences their use of child health and concomitant health outcomes of their children need to be examined.

\section{Objectives of the study}

The goal of the study is to identify the quantitative relationships between accessibility and related socio-economic factors, and health service utilisation in order to formulate policy implications to redress the pandemic of non-use of health services.

The specific objectives of the study are to:

a attempt a critical analysis of the relationship between the economy and health in Sub-Saharan Africa, isolating Ghana as a case study.

b attempt a comparative analysis of the utilisation patterns of rural and urban areas in Ghana and assess the impact of accessibility on utilisation in both rural and urban settings in Ghana;

c assess the impact of income and education on utilisation;

d examine the utilisation patterns of women; and, to

e examine the potential of health insurance for health care use in Ghana.

\section{Conceptual framework}

There have been quantitative models and frameworks on access and utilisation. Some of the quantitative models are gravity models by Shannon et al. (1969), Morrill and Earickson (1968), Kon-Kyun (1972), and Pyle (1974). These mathematical models cannot be applied to the developing countries where data are not available and where they are available, they are not reliable. There is also the problem of determining the values of certain parameters that work in the model.

The explanatory model of health services utilisation that has been the basis of most works on access and utilisation is Andersen and Newman's (1973) predisposing-enabling-need (PEN) model. Andersen and Newman had three main groups of variables to define their utilisation model, namely predisposing, enabling and need. This model was initially structured to assess the degree of equity in a health care system, and takes into account social and individual determinants. The original idea was that in developed countries need would be predominant and that the influence of predisposing and enabling variables would be signs of lack of equity. In developing countries, in view of socio-economic problems, predisposing 
and enabling factors will serve as barriers to utilisation. However, the model emphasises the characteristics of the population at risk, neglecting those of the health provider. The model also fails to recognise the role of perception of the efficacy of the health system and of what constitutes illness, as impeding factors of need. Health beliefs are also not factored into the analysis of need in predominantly traditional societies.

Aday and Andersen (1974) use an input and output approach in their framework for the study of access to health services. They identify the characteristics of the population and of the delivery system as input factors, and consumer satisfaction and utilisation of health services as the output factors, both of which are impacted upon by health policy (figure 1.4).

Figure 1.4 A framework for the study of access to health services

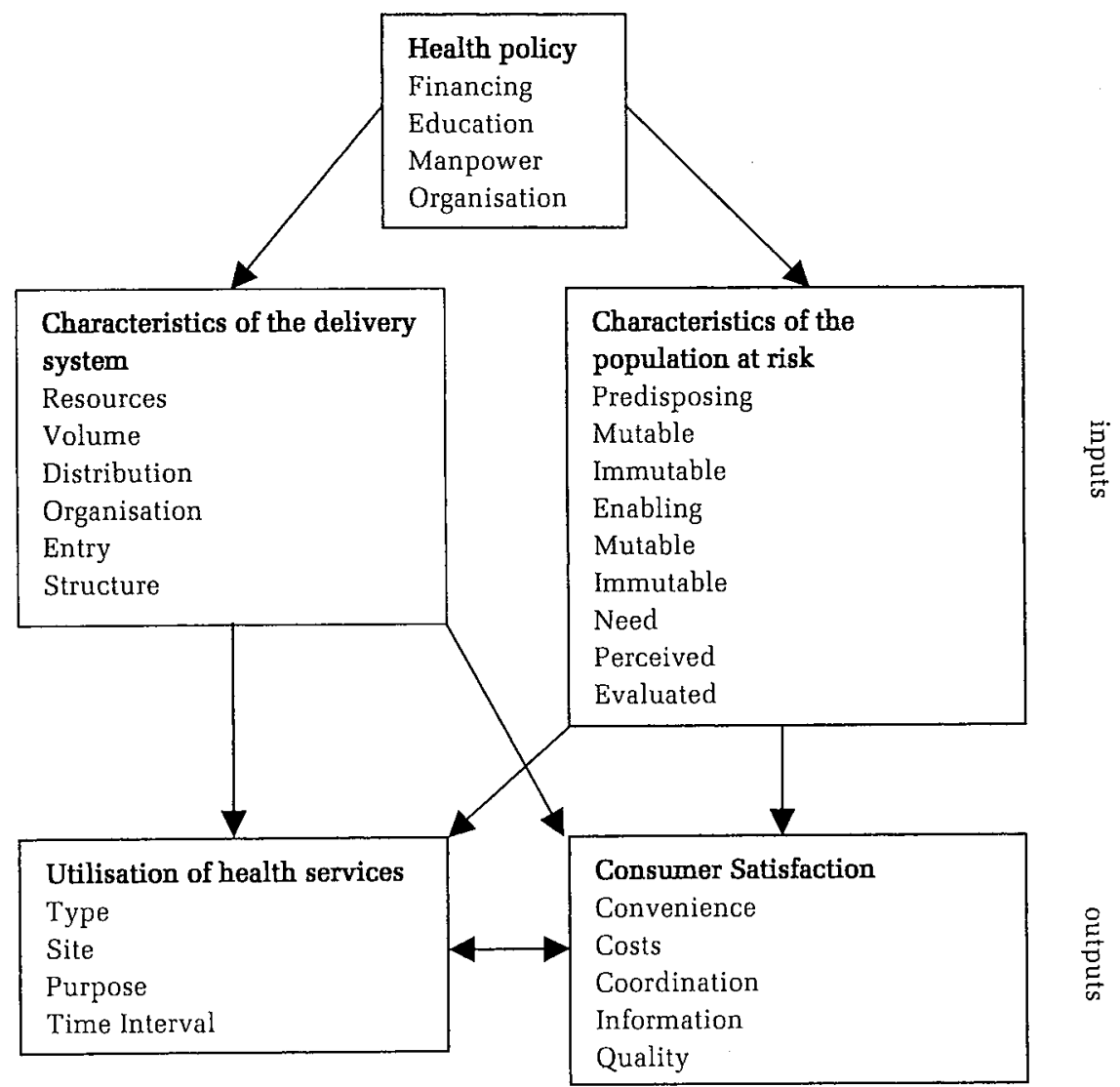

Source: After Aday and Andersen, 1974 
This model however fails to highlight the spatial component of utilisation as a factor of health policy. Moreover, the influence of distance and distance decay on utilisation is not illustrated. Finally, the utilisation of health services and consumer satisfaction can also have direct effects on the characteristics of the delivery system, but this is not reflected in the model.

Dutton's (1986) utilisation model is an improvement upon Andersen and Aday's, with the introduction of physician characteristics, and expanding the role of the provider. Demographic factors have also been clearly isolated. The problem with Dutton's model, especially when applied to developing countries, is that the spatial aspect has not been identified. In developing countries distance decay is very important in determining health care use. Another weakness in applying it to developing countries is the emphasis on follow-up visits as a physician-controlled factor in utilisation. Such models were structured in the developed countries where practice patterns are different, and where income levels do not frustrate utilisation. Nevertheless, most aspects of the models have universal appeal.

The more recent model, which has been structured in the study of access and use of health care, is by Andersen (1995), in his behavioural model of health service use. His model has four components, namely environment, population characteristics, health behaviour, and outcomes. The interrelationships between personal practices, use of health services, and health outcomes are clearly drawn. So is the relationship between population characteristics and health outcomes, which are used to evaluate the efficacy and quality of service.

The role of health personnel (physicians) is however not clearly defined, nor is the role of health policy. There is no indication in the model that such factors are embodied in the environment. Moreover, population characteristics could influence the environment, but this is not illustrated. Finally, the impact of distance, and place of residence (spatial relationships) are not clearly illustrated. Nevertheless the emerging model takes care of a lot of variables that reflect the situation of developing countries.

Taking the conditions in the study area into consideration, and the entire developing nations into context; and bearing that other variables need to be tested to discover any possible emerging trends in developing countries, a hypothetical model for the study (figure 1.5) has been structured. 
Figure 1.5 A hypothetical model for the study of access and utilisation of health services

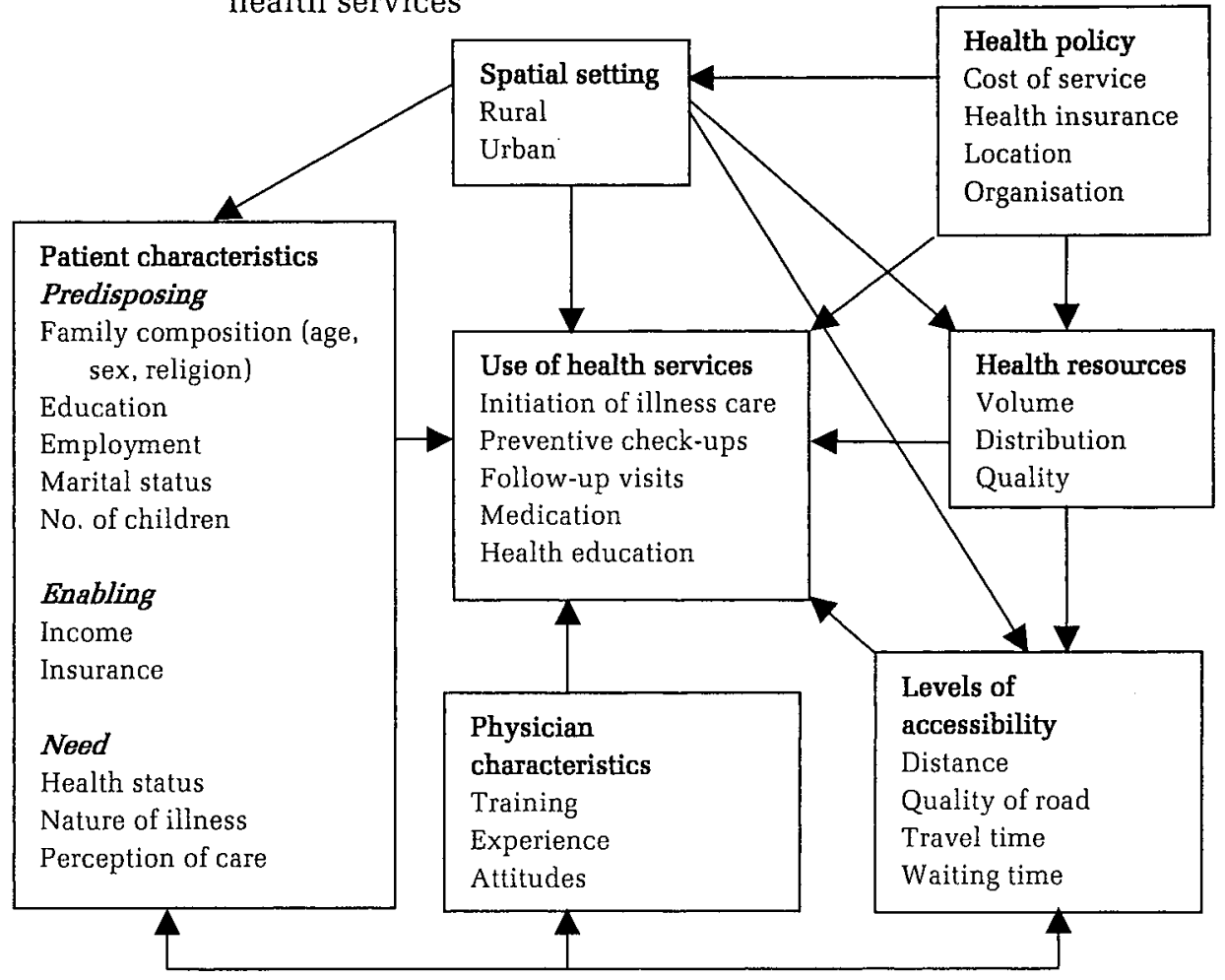

Source: Author's construct, 2001.

The model has use of health services at the centre, being the dependent (outcome) variable. It is the aim of policy makers that health facilities are used when necessary, to ensure sound health which is a 'sine qua non' of development. Service here also implies health education by medical staff, which can help realise a basic objective of primary health care.

Influencing health care use, and showing a relationship with it are the spatial setting, health policy, health resources, levels of physical accessibility, physician characteristics, patient characteristics, and health outcomes. Indeed, health outcomes could have the potential of influencing utilisation. One is more encouraged to use health services if their efficacy in ensuring good health is guaranteed.

Health policy is very important in the use of health services in developing countries, since it is the policy makers who determine cost, where to 
locate health facilities, and also who initiate insurance policies. These are critical factors of utilisation. Levels of physical accessibility play a crucial role in utilisation in developing countries that are plagued by poor roads and poor transport network.

Physician characteristics of training and experience will determine the quality of service, whilst physician attitudes to patients will influence utilisation. All patient characteristics: predisposing, enabling and need are crucial to utilisation in developing countries, even though enabling factors rank very high. There tends to be a low perception of the need for modern health care among some primitive and rural communities that are taboo inclined. Social enlightenment plays a role in evaluating the need for health care. Financial constraints are, however, about the most important hindrance.

In developing countries, there is a dichotomy in the distribution of health facilities, with the urban areas having the lion's share. Even within the urban setting, there is a dichotomy between the periphery and core. The periphery, mostly marked by slums, tends to be deprived of important social services. The specialised health services are concentrated at the core. The model seeks to explain the dynamics of health use, and charts the path for solving the critical health and social problems of developing countries. It attempts to fill gaps created by earlier and contemporary model builders, whose works have formed a basis for structuring such a framework. Based on this framework, in the separate chapters specific hypotheses have been formulated and empirically tested.

\section{Methods}

\section{The study design}

The objective of the study is to measure the impact of certain independent variables on utilisation of health services, as means of structuring a utilisation framework for policy initiatives. The study is a cross-sectional retrospective survey among representative rural and urban districts. The sample is composed of persons of varied socio-economic backgrounds to give the survey a representative character.

The survey is mainly correlational. It does not seek to analyse cause-effect relationships. In correlational studies, measures that represent the characteristics of entire populations are used to describe a specific health problem in relation to some factor of interest (Hennekens and Buring, 1987). Cross sectional surveys take instantaneous look at the relationship 
between the independent (predictor) variables, and the dependent (outcome) variables.

The study is also to experiment the use of multivariate techniques in analysing the relationships and impacts. Studies in developing countries have, in general, concentrated on bivariate relationships. The design for the study is indicated in table 1.5 .

\section{Concepts and measurements}

The dependent variable used for the utilisation survey is utilisation, defined as the number of times a respondent attended hospital the last three times he experienced illness spells. The independent variables are firstly the accessibility factors of 'distance', 'travel time', 'waiting time', 'service cost', 'status of road' and 'transport cost'; secondly, demographic and socio-economic variables of 'age', 'sex', 'marital status', 'number of children', 'income', 'education', 'education of spouse', 'health insurance'; and, thirdly, health status as an indicator of need. The other independent variables, which are related to the health providers, are perceived quality of health care and affective behaviour of medical staff.

Data for Utilisation were ranked from 0 to 3 . No attendance was given rank 0 and defined as rarely; one attendance ranked 1 and defined as irregularly; 2 attendances ranked 2 and defined moderately, and 3 attendances ranked 3 and defined regularly. Health status is defined as the number of times a respondent fell sick within a week (ranked 1), two weeks (ranked 2), a month (ranked 3), three months (ranked 4); or if he/she rarely falls sick (ranked 5). Education is defined as completed educational status. It was ranked 1 to 4 , being 1 for no formal education, 2 for basic education, 3 for secondary education and 4 for tertiary education. Quality of care is as perceived by the respondent. They were given indicators like the time for diagnosis of disease; whether there were laboratory tests; waiting time and availability of drugs. Quality of care was ranked 1 to 4 , being 1 for poor, 2 for satisfactory, 3 for good and 4 for very good. The affective behaviour of medical staff was also ranked, from 1 to 4 . Rank 1 was poor, 2 satisfactory, 3 good and 4 very good. 


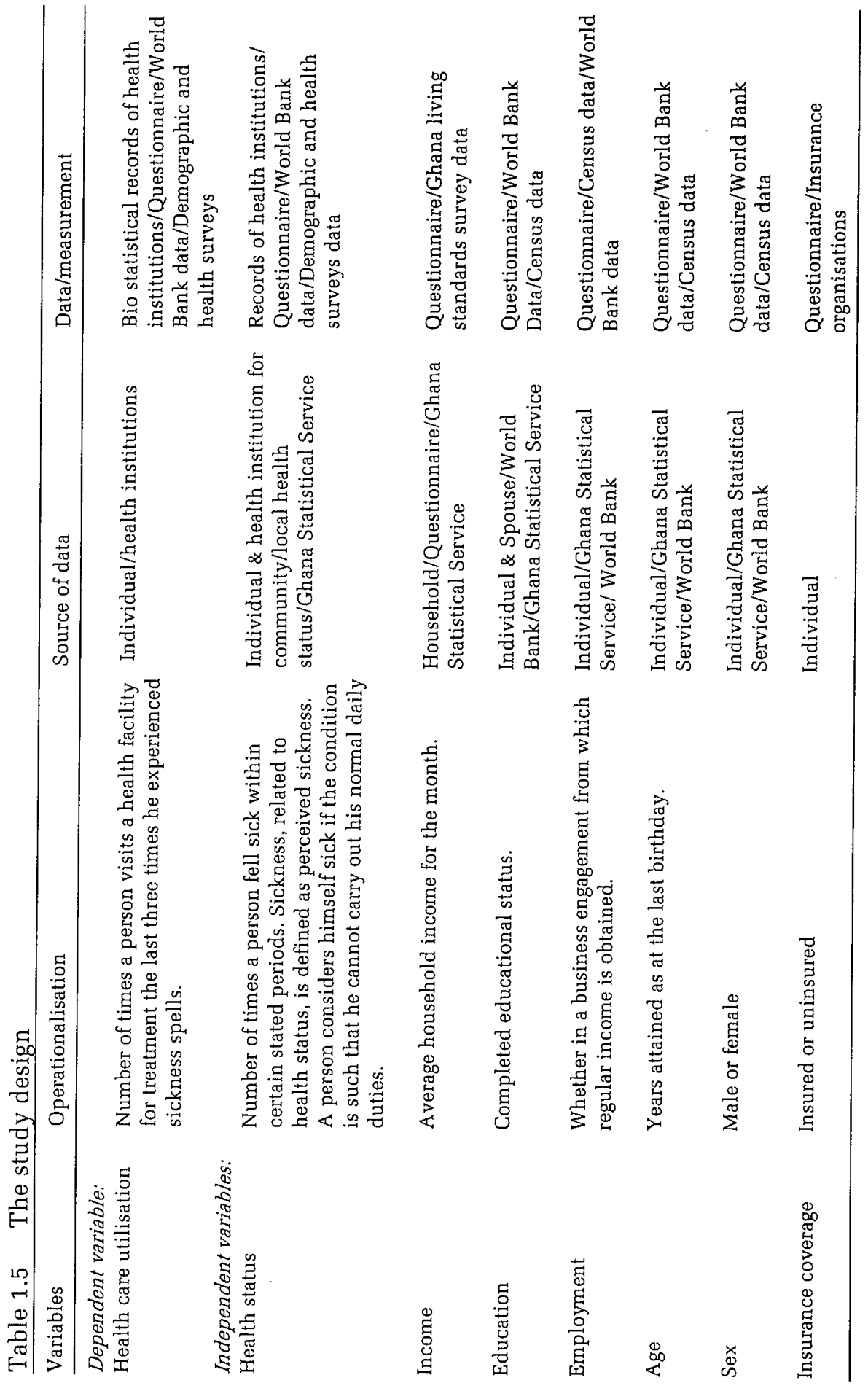




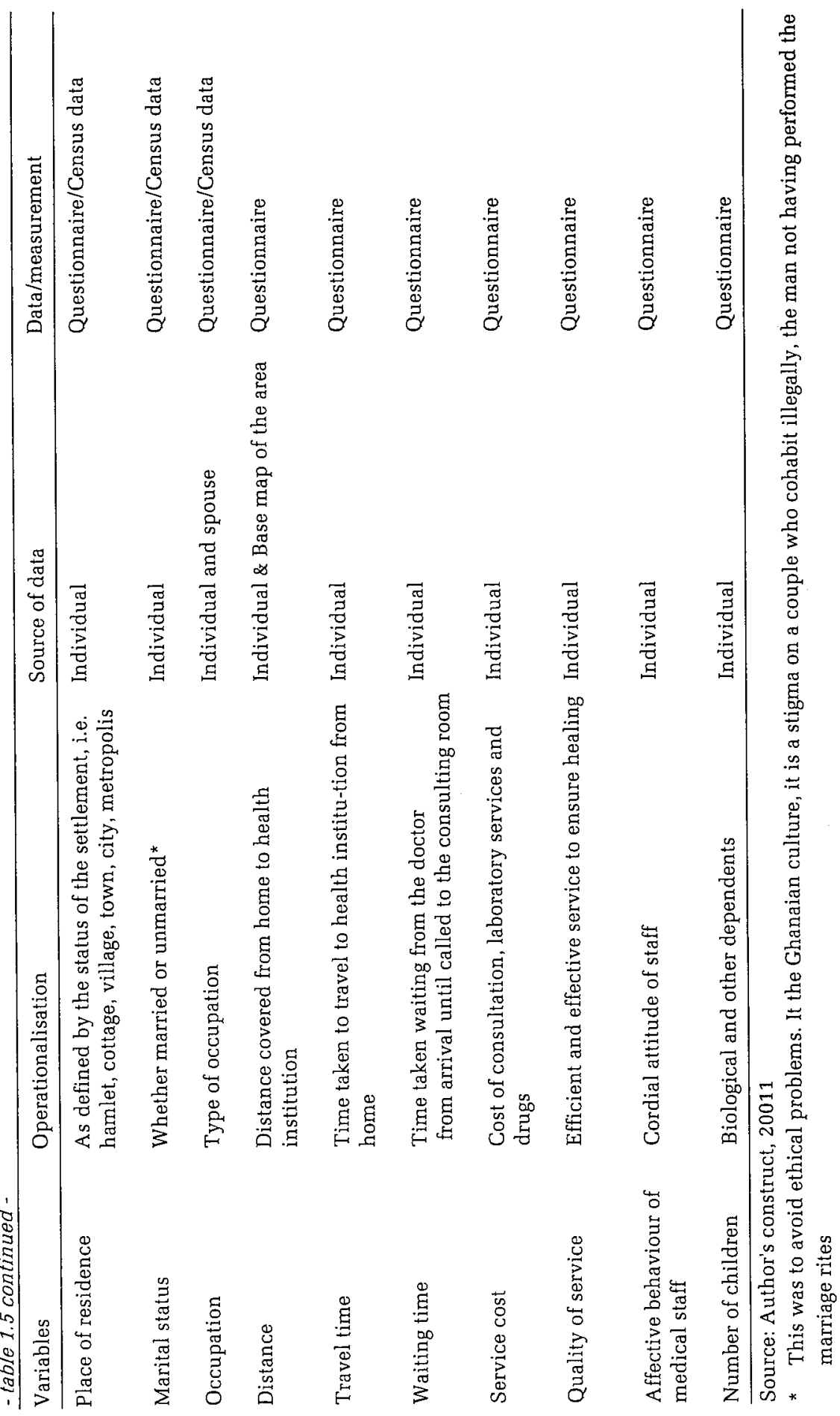


Age is defined as age at the last birthday. Travel distance is the distance from home to the hospital, whilst waiting time is the time a patient spends from arrival at the hospital until he/she is called to see the doctor. Travel time is the time taken to cover the distance from home to the hospital, whilst transport cost is the cost of travelling to a hospital and back. Income is defined as mean monthly family income. The collection of data on income was guided by the methods used in the Ghana Living Standards Surveys. The components were, wage income from employment, household agricultural income, non-farm self-employment income, rental income and net remittance and other minor sources (GSS, 2000, p. 103). Insurance was categorised into two, insured (including partly insured) and uninsured. Service cost includes the cost of consultation, laboratory services and drugs. Marital status was categorised into two, married and unmarried. Cohabitation was considered as marriage. Number of children includes both biological and non-biological children who are dependent on respondents. Age, income, distance, travel time, waiting time, service cost and transport cost were entered as continuous variables whilst sex, marital status, employment status and insurance status were entered as dichotomous variables. Male, unmarried, unemployed and uninsured were each given code 0 , whilst female, married, employed and insured were each given code 1. Thus nominal, ranked and continuous data were used.

\section{Sampling}

\section{Selection of the study area}

The study covers a developing country. The main objective is to find the utilisation situation in the developing countries, and structure policies to redress any teething obstacles and imbalances. The Ghana situation is used as typical for the situation in developing countries, given that the socio-economic status of developing countries is roughly similar. Two districts, rural and urban (Ahafo-Ano South District and Kumasi Metropolis) (figure 1.1), are selected from the Ashanti region, one of the most cosmopolitan, and the most populous region in Ghana that could be representative of the socio-economic landscape of Ghana, as case study. The region is centrally located in the country, and contains people of different socio-economic and demographic characteristics. Moreover, it contains all classes of traffic arteries, including railways, and a complex system of health facilities, viz. public, private, mission, quasigovernment, and traditional healing centres as well as a final referral point, a Teaching Hospital. There are sharp cleavages of income and educational levels. 
The Kumasi Metropolis is the main urban district in the region and second largest in the country. People of all walks and status of life occupy it: rich and poor, educated and illiterate, professional and worker, farmer and petty trader, and all categories of health institutions. It is a national commercial, industrial, social and cultural centre; and with an environment that is deteriorating very fast, with poor drains and accumulated hills of refuse that can induce all forms of viral and bacterial infections. The Ahafo-Ano South District is very representative of the rural districts, having very few sub-urban centres, and predominantly engaged in primary economic activities. Moreover, it has very poor road networks and poor health facilities that are physically inaccessible to greater proportion of the population.

\section{Selection of settlements}

In the selection of the settlements, their spatial relationships with health institutions were taken into consideration: i.e. those nearer, farther and within. Their level of physical accessibility, as determined by the nature of the road network, was also taken into consideration, i.e., access to health institutions by major, secondary and minor roads. The distribution of the selected settlements is indicated in table 1.6 (figures 1.2 and 1.3).

The settlements covered 3,108 housing units, 1,732 for the rural AhafoAno South District, and 1,376 for the Kumasi Metropolis.

Table 1.6 Sampled settlements

\begin{tabular}{lll}
\hline District & With health facility & Without health facility \\
\hline Kumasi & Asafo, Bantama, KNUST & $\begin{array}{l}\text { Kaase, Boadi, Santase, } \\
\text { Nyankyerenease }\end{array}$ \\
Ahafo-Ano South & $\begin{array}{l}\text { Mankranso, Sabronum, Wioso, } \\
\text { Mpasaaso }\end{array}$ & $\begin{array}{l}\text { Adukrom, Faamang, Betinko } \\
\text { Aburaso, Nyamebekyere, Kunsu }\end{array}$ \\
\hline
\end{tabular}

Source: Author's construct, 2000.

\section{Data collection}

Data were collected between October 2000 and March 2001. Both primary and secondary sources of data were used. The instruments used for the primary data collection were personal observation, informal interviews, questionnaire and interview schedules, constituting the main instruments and micro data. The same questions were used for both questionnaire and formal interviews to ensure standardisation and comparability. Questionnaire schedule was applied on the educated whilst formal 
interview schedule was applied on the illiterate and the educated who opted for it to save time in completing the questionnaire and to avoid callbacks.

Secondary sources of data include population census reports on socioeconomic and demographic characteristics of the population of Ghana, the Ashanti Region, and the sampled districts; books, journals, periodicals, and survey reports on accessibility and health service utilisation in the developing countries, and specific ones on Ghana; Ghana Demographic and Health Surveys, 1988 and 1993; World Bank Development Reports; the Ghana Living Standards Survey (GLSS) of 1991/92; and Annual Health Reports of Ashanti Region, Kumasi Metropolis and Ahafo-Ano South District.

\section{Sample size, allocation and methods}

A sample size of 650 from the target population, selected using the systematic procedure, was used for the study. The sample represents approximately $.02 \%$ of the total population of Ashanti Region, which is $3,612,950$ (GSS, 2002, p.17). It however represents $.06 \%$ of the total population of the sampled districts of Kumasi Metropolis and Ahafo-Ano South District. The sample size is enough to perform multivariate analysis of health service utilisation. In the main research a sample of 650 was used for the survey, with Kumasi Metropolis allocated 250 and Ahafo-Ano South allocated 400 . The disproportionate allocation deviates from the population criterion and uses the accessibility index. The access problem of Ahafo-Ano South District is rather alarming, as compared to Kumasi Metropolis, so was allocated a greater proportion of the sample. In all 26 persons, ten in the metropolis and sixteen in the rural district failed to respond to the interviews. Most of these were illiterate or semiliterate, who saw the interview as a waste of time, since such surveys had not resulted in the improvement of their quality of life. There was a suitable replacement for such sample, so their refusal did not affect the survey results. The allocation of the respondents by age, sex and education was pre-determined. These are variables for which information could be obtained with relative ease. The lower threshold of the age variable is 18 and the old age, 60 and above. The average age for senior secondary school graduates is 18 , at which age they are eligible to vote in national elections and may start being independent of parental control. The old age commences at 60 , which is the retiring age in the public service. After age 60, an employee could apply for engagement on contract basis. 
Based upon these proportions, and adjustments in the field, the allocation to the two districts is as indicated in table 1.7. (Adjustments became necessary due to the difficulty in attaining the targets, going by the systematic procedure. With regard to tertiary education there were virtually lack of such in the rural district, whilst for secondary education graduates were fewer than expected.)

Table $1.7 \quad$ Sample allocations to the sampled districts

\begin{tabular}{llrr}
\hline Variable & Sub-variables & \multicolumn{2}{c}{ District / Sample } \\
\cline { 3 - 4 } & & Kumasi & Ahafo-Ano South \\
\hline Age & $18-59$ & 200 & 320 \\
& $60+$ & 50 & 80 \\
Sex & Male & 100 & 240 \\
& Female & 150 & 160 \\
Education & & & 170 \\
& Never-been to school & 74 & 130 \\
& Primary education & 70 & 96 \\
& Secondary education & 72 & 4 \\
\hline
\end{tabular}

Source: Author's construct, 2000

With regard to the variables of employment and income, it was ensured during data collection that all the various categories were represented. In the collection of household data, the systematic random and purposive random techniques were used. In the application of the systematic method, the first house in every street was selected. The sample interval depended upon the number of houses and size of the sample. The interval was greater for the Kumasi Metropolis and the sub-urban settlements than the purely rural settlements that had fewer houses.

Most Ghanaian houses contain several households. Upon entering a house, respondents were selected at random. The number of respondents with tertiary education was very small in the rural district. To include enough people with tertiary education in the sample to be able to perform statistical analysis, their numbers were increased for the Kumasi Metropolis.

The allocation to the settlements was done taking into consideration availability of a health facility, population and physical accessibility to a health institution. The rationale is that those living within the location of 
the hospitals will tend to use them more than those farther away. For Kumasi Metropolis, settlements where there are hospitals, and with a population of 10,000 and above had an allocation of 50 , whilst settlements without hospitals but with a population of 1,000 and above had an allocation of 30 each. Those with less than 1,000 had an allocation of 25 each. The Kwame Nkrumah University of Science and Technology (KNUST) was given a special allocation of 40 , since it assured data on health insurance. Since there are no workers staying on campus who do not have primary education, and most of the staff have tertiary education, the allocation to primary education was added to the tertiary, to make the tertiary have a proportion of $40 \%$.

For Ahafo-Ano South District, each of the five semi-urban settlements: Mankranso, Sabronum, Wioso, Mpasaaso and Kunsu, had an allocation of 50. Each of these settlements have a population of above 3,000. Of the five, it is at Mankranso that a hospital is located. Each of the rural settlements: Betinko, Faamang, Aburaso, Nyamebekyere and Adukrom (each with a population of less than 1,500), was given an allocation of 30 . Of the semi-urban settlements selected, it is Mankranso that is linked to the regional capital, Kumasi, by a major road. All the others are served with minor roads. Of the rural settlements only Aburaso lies on the main highway to Kumasi the capital. All the others are served with a minor road that is difficult to be used by vehicles during the rainy season. Physical accessibility is a major problem in the district. It is about the most deprived in the region in terms of physical accessibility.

The quality of data will apparently be undermined by certain deficiencies, despite the level of carefulness and perspicacity exercised in the process of data collection. Certain biases could therefore not be ruled out. First, for macro data like that derived by national surveys like the Demographic and Health Surveys (DHS), there is bound to be the problem of age misreporting (Awusabo Asare, 1980). The same could also go for the determination of income for those who are not on fixed salaries and wages, who indeed constitute greater proportion of the population. The problem of age misreporting, especially for the illiterate may be ameliorated by using events that coincided with his or her birth, or age of first child as related to age of marriage.

There were problems of respondents' determination of certain quantitative information, like frequency of attendance at hospitals, distance to the nearest health institution, time taken to cover distance, 
and waiting time. This will particularly involve illiterate respondents who constitute greater proportion of the sample. Such respondents were not able to determine distances to health institutions. There were also problems of determining qualitative data like quality of health services. Maps of the area were carried along to determine distances covered by respondents. Respondents were given indicators to evaluate quality of service. These included time for consultation, diagnoses equipment, laboratory services, drug supply, waiting time before consultation, affective behaviour of hospital staff, reporting for review, et cetera.

There was also a problem with deriving personal information like marital status that was an ethical problem. There were a few respondents who, though cohabiting, responded that they were married, because of the stigma which co-habitation carries. In the Ghanaian culture, if the man has not paid the bride price, the relationship between her and her "wife" is not recognised by the woman's family, and indeed by society, and the children born are deemed not to be his. Cohabitation was categorised as married since the man is obliged to perform most of the functions performed in legal marriage. This categorisation therefore did not affect the explanation of results.

A few respondents, mostly illiterate, found difficulty in recalling the number of times they attended hospital the last three times they experienced sickness spells. Other family members assisted such. Among the illiterate, especially in the rural areas, there was the suspicion that questions involving personal incomes and costs were meant for taxation, and to increase costs of certain services. In such situations where cooperation was difficult, the assistant of the Unit Committee was sought to ensure respondents' cooperation. (Under the decentralisation policy, the Unit Committee is the organ responsible for ensuring compliance and implementation of government policy at the Community level. It is also responsible for initiating and implementing development programmes at the community level). Therefore, for the problems efforts were made to reduce their effects on precision.

\section{Data analysis}

After careful auditing and coding of data, the data were organised into frequency tables. Both bivariate and multivariate techniques were used for the analysis of data. Bivariate analysis has the advantage of showing in greater detail the relationship between, the outcome (dependent variable), and a predictor (independent) variable. Poland et al. (1990) 
used bivariate and logit techniques to analyse the ecology of health services utilisation in Grenada, West Indies. Both parametric and nonparametric methods were used for the analysis; chi-square tests were used to determine the significance of differences between variables in the data for the urban and rural area. The qualitative method was also used in the analysis, since some information could not be reduced to quantitative measurement. This was especially in the chapter on health insurance.

To measure the relative impact of the selected independent variables on health service utilisation, the multiple regression technique was used. Multiple regression is used when additional independent variables are introduced into a regression model (Yeomans, 1979) and also when the dependent variable is continuously distributed (Hennekens and Buring, 1987). Although the dependent variable in our analyses was ordinal, linear regression was used for ease of interpretation. Correlation coefficients of the independent-dependent variables were used to assess the strength of relationships, whilst multiple regression values were used to measure changes that occur in the dependent variable with changes in the independent (predictor) variables. The bivariate correlations also helped in determining multicollinearity that is likely to affect the results. Both bivariate and multiple regression results were derived form the SPSS software. The stepwise method was used to identify the key variables and eliminate the weaker variables.

\section{Results}

The first element of the study is to determine the position of Ghana relative to comparable Sub-Saharan countries. This was done by constructing a predictive model for the explanation of two major health indicators: infant mortality on the one hand and Healthy Life Expectancy (HALE) on the other hand. Independent variables in the model were: the strength of the economy, health expenditures, immunisation and sanitation, illiteracy, political stability and HIV-infection rates. The question was to what extent the economic position influences the health indicators. Ghana's infant mortality rate could be predicted by Ghana's economic strength (or weakness) and is influenced by classic public health measures like immunisation rates. Healthy life expectancy in Ghana, however, is better than predicted by the economic position and the relatively low rate of HIV-infections. These latter factors do influence healthy life expectancy in Sub-Saharan countries, so, in Ghana, too; but Ghanaians are still healthier than our model could predict. 
The main part of our study deals with accessibility and utilisation of health services in Ghana; the results are derived from a survey in respectively a metropolitan area (the Ashanti capital Kumasi) and a typical rural district (Ahafo-Ano South). About a quarter of the entire sample use health services regularly. Over $60 \%$ of the total sample either rarely use health services or use them irregularly. For the entire study area, variables that show a significant relationship with utilisation are distance, education, income, and service cost and health status, following an order of importance. Variables that show relatively stronger bivariate association with utilisation are distance, education, income, service cost, insurance and place of residence.

Comparing the two districts, Kumasi Metropolis and Ahafo-Ano South (rural district), respondents in Kumasi use health services more regularly. Utilisation is rather low for the Ahafo-Ano South rural district. Not only health service utilisation differs, but, apart from health status and age, all the other variables differ significantly for both districts. The variables that have a significant relationship with utilisation in Kumasi Metropolis are education, distance, service cost, quality of service and health status, following an order of importance. For Ahafo-Ano South District, they are distance, income, service cost, and education. The Ahafo-Ano south results however show a higher coefficient of determination than Kumasi metropolitan results based on the adjusted $\mathrm{R}^{2}$, which are .358 and .531 respectively. The hypotheses that income and cost of service are the most outstanding factors determining the use of health services in both rural and urban areas, has not been justified by the study. The hypotheses that distance and cost of service have been found to show inverse relationships with utilisation of health services in both rural and urban areas have however been justified by the study. Secondly, that education shows a greater significant impact on the use of health services in the Kumasi Metropolis and that distance has a greater negative impact on utilisation in the rural areas have also been justified.

Separate chapters were written about the effect of distance on utilisation for the two districts. For the Kumasi Metropolis the bivariate correlation between distance and utilisation was -0.271 , significant at a probability of .000. The related variable of travel time shows a very weak negative association with utilisation. Transport cost does not have a negative association with utilisation. Education shows a stronger association with utilisation than distance in the Kumasi Metropolis. It is as high as 0.428 at 0.01 probability. Regression results, however, show that education and 
distance are equally strong in influencing the utilisation of health services. The beta co-efficient for education is 0.327 , that of distance being -.291. The other significant variables are service cost, service quality and health status, following an order of importance. Respondents with better health utilise health services more. The effect is, however, not profound. The adjusted coefficient of determination $\left(R^{2}\right)$ is barely average, 0.352 . Cross-tabulation shows that men, the healthy, the economically active population, the middle-income earners and the literate are more negatively affected by distance. Certain hypotheses were not supported by the research results. First, transport cost, a factor related to distance, does not negatively influence utilisation in the metropolis. Second, the vulnerable groups of women, the aged, the sickly, the illiterate and the poor are not influenced negatively by the distance factor. An empirical model of distance and utilisation has emerged from this study.

The picture at the Ahafo-Ano South District is slightly different. The association between distance and utilisation (-.553) is far stronger for the rural district than the urban. Travel time also shows a stronger association with utilisation than in the metropolis, whilst the association with transport cost, though negative, is weak. The $\mathrm{R}^{2}$ is far stronger for the rural district, indicating a better fit for the model for the rural district. In the Ahafo-Ano South District, distance is the predominant factor influencing utilisation. The beta co-efficient for distance is -.536, explaining a great proportion of utilisation. The other significant factor with a coefficient of .335 is income. This is followed by service cost that is related to income and education. Analysis of cross-tabulations show different patterns for some groups. The negative associations between distance and utilisation are higher for the literate, middle-income earners, the aged, the female and the sickly. The hypotheses that distance decay has negative effects on the poor and illiterate in utilisation and that service cost and income supersede distance in influencing utilisation have not been justified.

Gender and utilisation issues are very important because of the problem of inequity that defies fairness in the delivery of health services. This was also due to the fact that women bear a greater burden in child health. The magnitude thus ought to be investigated and measures of redress for possible inequity identified. Results show that, although women have a greater need for health services than men, they do not use health services as much. Secondly, whereas education, income and quality of service have milder positive effects on men than women in the utilisation of health services, distance has a greater negative effect on women than 
men, whilst service cost has a greater negative impact on men than on women.

In a study of the health outcomes of children in relation to mothers' education using secondary data, it was evident that educated mothers use health services, especially primary health services more, and that explains the better health status of their children. In Ghana, educated mothers use antenatal care facilities more than illiterate and lowly educated mothers. Whereas over $67 \%$ of mothers with secondary education and above received two doses or more tetanus toxoid injections, only $46 \%$ of mothers with no education did. Vaccination also shows a significant difference by mothers' education. Whereas $30 \%$ of mothers with secondary education and above fully vaccinated their children between 1993 and 1998, only 18\% of mothers with no education did. Disease prevalence among children also differed by mothers' education during the period. Whereas $21.3 \%$ of children of mothers with no formal education suffered from diarrhoea infections that are blamed mostly on lack of vaccinations and improper feeding, only $8.2 \%$ of children with mothers who had attained secondary education and above did. These results reflect the status of childhood mortality as well. Whereas $69.3 \%$ of mothers of no education experienced child mortality between 1993 and 1998, mothers with secondary education and above experienced just $23.9 \%$ of child mortality within the same period. There is thus a strong inverse relationship between mothers' education and childhood mortality.

Income has a significant effect on utilisation of health services. The bivariate correlation between the two is as high as .515 for the entire study area, being significant at .001 probability. Over $95 \%$ of high-income earners use health services either moderately or regularly. Service cost, which is related to income, shows a relatively high correlation with utilisation. High-income earners are better able to afford high service costs. Greater proportion of low-income earners responded that high service cost would have a negative effect on their utilisation of health services. The $\mathrm{R}^{2}$ for the results on income and utilisation is as high as .529 , indicating a high confidence in the results. Income however is exceeded by distance in impact on utilisation of health services. Service cost, compared with income is low in impact, whilst the effect of education is positively significant. Transport cost, which is also related to income, does not have a negative impact on utilisation. An empirical model of utilisation based on income has emerged from this survey. 
Utilisation is influenced by health insurance. The difference in utilisation for the insured and uninsured is significant at 001 probability. The bivariate correlation between insurance and utilisation is .338. This is exceeded only by education (.415) and income (.382) among the nonaccess factors in influencing utilisation. Cross-tabulations show that the economically active population, the very rich, the literate, men and the healthy are more positively influenced by insurance in the utilisation of health services than the other related groups. Respondents recognise the need for the introduction of a national health insurance scheme as a means to improve utilisation. The deduction of a fixed percentage of a person's monthly income is generally accepted.

\section{Discussion and conclusions}

The study has been carried out in a multivariate framework bringing in broad-based provider-user characteristics, using multiple regression as a tool for analysis. The broader characteristics include predisposingenabling-need (PEN) factors that are contained in most life-cycle determinant models. These models derive from the Andersen-Newman framework (1973) that makes an argument about the intrusion of factors other than need in determining utilisation. The PEN factors constitute the characteristics of the user. The predisposing factors include education, age, sex, marital status, employment status and number of children, whilst the need factor is health status. The enabling factors are income, insurance. It has also introduced restrictive factors that are extraneous factors to the user and beyond his control. These are service cost, transport cost, travel time, waiting time and distance. These factors come under the umbrella of provider location. Other factors that come under the provider are quality of service and affective behaviour of medical staff.

The survey has established the fact that utilisation rate of health services is low. On average, less than $27 \%$ of respondents use health services regularly. This is partly due to the weak economy that results in inadequate allocation of resources to the health sector. Yet, the country performs better, compared with her immediate neighbours regarding the allocation of resources to the health sector vis-à-vis health outcomes. What this implies is that if the economy improves and adequate resources are allocated the health sector, access and use could improve significantly to improve health. Where in an ideal situation need would be the most important determinant of health service utilisation, in our study, health status, as an indicator of need, is of low importance. 
The metropolitan utilisation rate is far higher than the rural rate. Whereas the principal factors affecting utilisation in the metropolis are, in order of magnitude, education, distance and service cost, those affecting the rural district are, in order of magnitude, distance, income and service cost and education. It could therefore be concluded that the limiting factors to the utilisation of health services in the country are illiteracy and ignorance, poverty and physical access, bearing that the service cost factor is at tandem with distance. Education could economically empower a person and would also predispose him to using health services; whilst physical access (distance) has a strong influence on health service use. A person is more likely to use health services nearer him. In the rural areas an illiterate with good income is likely to avoid going to hospital when it is too far away from his residence.

Although women have been found to have a worse health status than men, their rate of utilisation is relatively low compared with men. Given the vulnerability of women to health risks due to their reproductive functions, the disparity strikes a note of inequity in health care. The health risks of women are further compounded by their domestic roles that are defined by culture. They are supposed to be responsible primarily for domestic services and reproduction. Since health outcomes of children of women with a good standard of education are higher, it implies that education of women has a significant effect on the health of a population. The health outcome is found to be dependent on the effective use of health services, especially primary health services. Utilisation by educated women is higher than by illiterate women. For women utilisation shows an inverse relationship with the level of education. Women with higher education are particular about accessing health care for their children, especially regarding immunisation against the major killer diseases.

There was a strong potential for the introduction of a national health insurance to improve utilisation of health services in the country. The President of the Republic of Ghana, on $18^{\text {th }_{1}}$ March 2004, inaugurated the NHIS. The utilisation rate of the insured is far higher than the uninsured and qualitative survey indicates that the ground is prepared for the people to embrace the introduction of a national health insurance scheme, despite the constraints of unemployment, low wages and a large informal sector. An insurance system based on a percentage of a person's income is preferred. The consensus is that the population be categorised by income: low, middle and high, and a fixed percentage for each group charged as premium. 
The weak economy of the country thus has a negative effect on health services, with concomitant effect on utilisation. The weak economic status make it difficult for government to allocate adequate resources for building hospitals and clinics and providing maternal and child health services. Such a situation affects utilisation that is strongly dictated by access. The other factor influencing access and utilisation are cost of service and income that are also related to the poor economy. Mass poverty and high service cost makes out-of-pocket payment of health service difficult for a majority of the population. Health insurance is still poorly developed. The state is thus a contributory factor to the low utilisation rate. Institutional measures and frameworks to ensure improvement in the economy would significantly improve access and utilisation.

Background characteristics of respondents relate to levels of utilisation, implying that, apart from the provider's characteristics, user characteristics are determinants of health care use. The survey has established that the need factor is not as significant as the predisposing, enabling factors, as envisaged by Andersen-Newman. This study has also introduced restrictive factors to beef up the theoretical base of Andersen-Newman's model. People will go to hospital only when they have the means to do so and when the cost is affordable and the facility, easily accessible.

There is the need to empower the population through income generation and education, which are at tandem. Increased education would solve the income problem and increase predisposition to the use of health services. Government policy of Free Compulsory Universal Basic Education (FCUBE) must be effectively implemented. Facilities must be provided to realise its goals and the education of the girl-child must be a priority. Informal education programmes must be run for illiterate adults. It will also ensure effective use of health services that is needed to ensure health.

Since service cost comes in the income problem, that is a serious barrier, the need for the introduction of a national health insurance scheme (NHIS) was urgent. The government has introduced a Mutual Health (Support) Organisations in selected districts. Although reports indicate that these are functioning effectively, the coverage is woefully inadequate. The process of the full implementation of a NHIS must speed up to ensure adequate access of a greater quantum of the population to health services. The Mutual Health (Support) Organisations must quickly 
give way to a fully-fledged scheme to improve access to health care. Although there would be the problem of full implementation of a NHIS where a good part of the population is unemployed and not integrated in a monetary economy, systematic measures to improve the economy would eventually result in unemployment decline to empower a significant proportion of the population to pay premium. Payment in kind by farmers and fishermen whose jobs are seasonal could be experimented with.

Access is a serious problem, especially in the rural district. Since the ailing economy cannot, in the short run, support the putting up of more hospitals at easily accessible areas, roads to the few hospitals, especially in the rural areas, must be improved. Second, intermediate health facilities, Primary Health Centres, must be located within convenient distances between hospitals/health centres. There must be facilities for immunisation and treatment of minor ailments. At the same time the health centres must be upgraded to hospitals to improve their performance.

Finally, with teething financial constraints, efforts must also be made to improve upon traditional medicine which is rooted in the culture of the people and which is more acceptable to the older generation, especially in the rural areas and among the illiterate. This could reduce the cost of health care and contain the health problem pending the putting up of adequate infrastructure to ensure the full take-off of modern health care.

Access to health services in Ghana as a whole and the study areas in particular is poor, and this has affected utilisation. Factors other than access have also impacted on utilisation. Such a situation does not augur well for a developing economy that requires an efficient human resource for its development. To ensure a full coverage of the problem, a wider scope of variable have been related to utilisation, and a multiple regression was used as an instrument for analysis. This deviates from other studies that use a bivariate approach and also put in fewer variables.

This study has identified poverty, ignorance and poor access to health services as barriers to the utilisation of health services. The need factor of health status has not been found to be the only significant factor affecting utilisation, indicating a serious lack of equity in access to health services. The recommendation that FCUBE be improved to increase economic 
capacity, the introduction of a NHIS, improvement in traditional medicine, and introduction of intervening primary health facilities, if implemented would help improve utilisation and ensure improved health that is a sine qua non of development. 


\section{The economy, health spending, and health status in Sub-Saharan Africa}

This chapter has been submitted as:

Buor D, Kroneman M, Zee J van der, Groenewegen P. The economy, health spending, and health status in Sub-Saharan Africa. 


\section{Introduction}

The starting point for this paper forms the well known general and positive relationship between a country's economic strength and the health of its population. The famous World Bank graph in the World Development Report of 1993 showed that this relationship was valid for the whole $20^{\text {th }}$ century (World Bank, WDR, 1993, p.34). Especially for low-income countries, with an average income below US\$ 500, the relationship between health (i.e. life expectancy) and wealth (GNP per capita) is very strong. For richer countries, especially above US $\$ 10,000$, the relationship levels out. A similar (positive) relationship has been found between a country's economic strength and its health care expenditures. Countries with stronger economies tend to spend more on health, in terms of per capita health care expenditures. From these two observations, one might draw the conclusion that the relationship between a country's health and wealth mainly goes through its health care expenditures, e.g. via investments in immunisation programmes or the health care facilities, which is also the idea of the WHO's Commission on Macroeconomics and Health.

Increasing the health status of the population results in a healthier workforce, which leads to more wealth (WHO, 2001; Morrow, 2002; Waitzkin, 2003).

Besides contributing through health care expenditures, the wealth of a country also contributes indirectly to the health of its population, via, e.g., the improvement of schooling and the eradication of illiteracy, especially of women (World Bank, WDR, 1991; Buor, 2003; Berhane et al., 2002; Mellington and Cameron, 1999) or via the improvement of hygiene, an activity usually funded outside the health care budget.

However, wealth is not the only contributor to a country's health status. For instance, a publication by Evans et al. (2001) stated that major external factors, like the political stability of a country or devastating epidemics, like the HIV/AIDS epidemic, influence health outcomes independently of a country's economic position.

A last remark that is relevant for explaining the relation between health and wealth is the observation that, examining the scattergram and regression line between 'health' and 'wealth', countries can be divided into a group just on or close to this line (that is countries whose health can be predicted fully from their economic position (the 'rule') and 
countries distinctly below or above this line (the 'exceptions'). At global level, famous exceptions form the USA (in a negative sense having lower life expectancies than predicted by its economic strength) and Japan (in a positive sense) (Evans and Stoddard, 1990). Apparently countries health statistics are not totally determined by the state of the economy. There are always some degrees of freedom for policy making.

\section{Aim}

The first aim of this paper is to specify the association between a country's health outcomes and the strength of its economy, as expressed by its Gross National Income per capita for a group of low income countries (in this case the Sub-Saharan countries). A graphic representation of the supposed relationships can be found in figure 2.1.

Figure 2.1 Explanatory model of the relationship between health and wealth

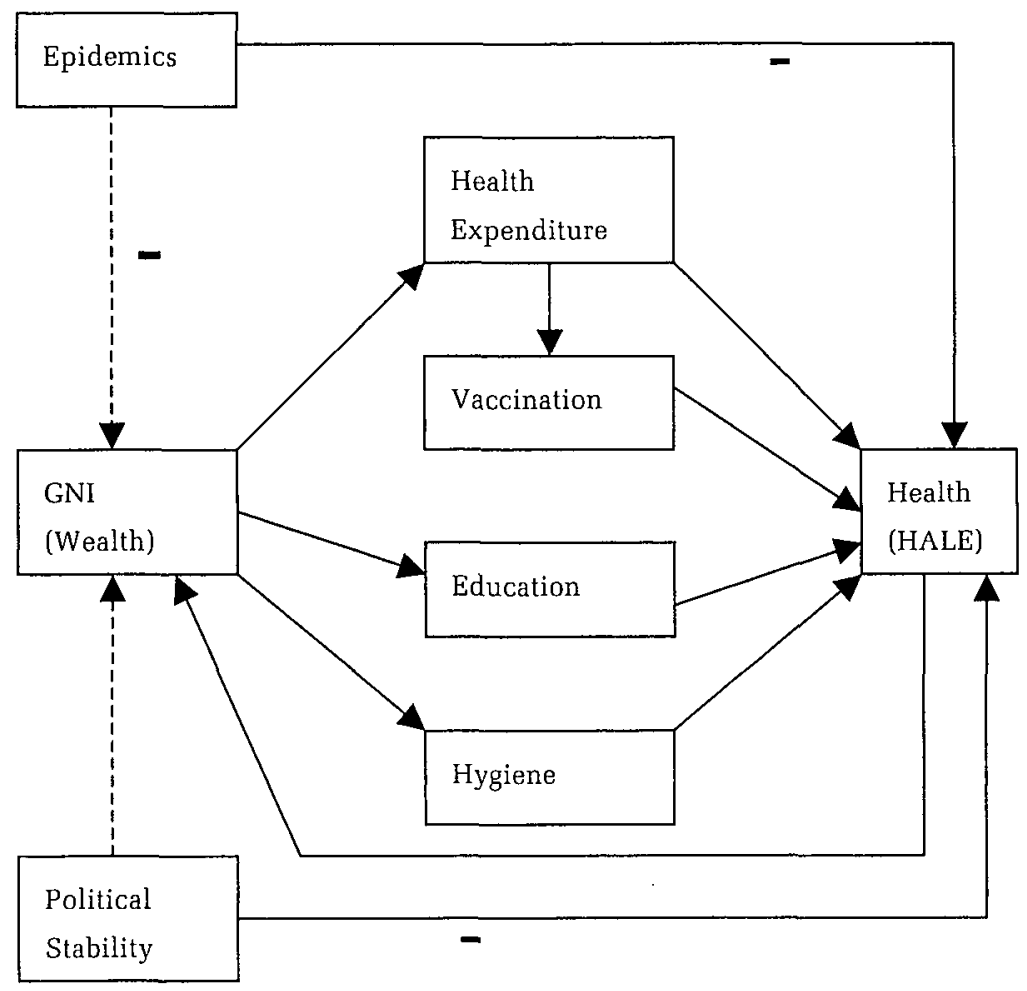


The second aim is more specific and concerns the room for health policy in a specific group of countries. What can low-income countries like the Sub-Saharan countries learn from their position on the graph that expresses the relationship between 'health' and 'wealth' and what are the consequences or the possibilities for health policy, given its position? Since the first author's country of origin is Ghana, we will focus on this country. By including (public) health policy measures like child immunization and hygiene, policy recommendations for Ghana become possible.

Summarizing the above, the following research questions are derived:

1 What is the direct and indirect influence of wealth on the health status of Sub-Saharan countries?

2 What is the effect of health policy measures and external causes on the health status of Sub-Saharan countries?

3 How can a specific country (in this case Ghana) improve its health outcomes based on the answers on the questions above?

\section{Methods}

\section{Study population}

Mainly inspired by the opportunities for policy analysis relevant for Ghana, the 38 countries of Sub-Saharan Africa were taken as subjects for analysis. Four countries were excluded because they did not belong to the low-income group; these were the Republic of South Africa, Namibia, Botswana and Gabon. A few other countries (Liberia, Somalia, Madagascar) have been excluded because of too many missing data. This left us with 31 countries.

\section{Data}

The data were collected at country level. We used two sources: The World Bank Development Indicators (World Bank, WDI, 2002) and the WHO Health Report 2002 (WHO, 2002). The variables in figure 2.1 are operationalized as follows (see also Appendix 2.1):

1 Health: The most sophisticated indicator of health is the Healthy Life Expectancy (HALE), used worldwide by WHO in the World Health Report 2002 (WHO, 2002). HALE is most easily understood as the expectation of life lived in equivalent full health. It has some 
advantage over other summary measures, because it measures 'health' and not illness or death and it is easy to calculate using the Sullivan method based on age-specific information on the prevalence of nonfatal health outcomes. Beside this health indicator we also use a classic indicator of (bad) health: namely 'infant mortality' (neonatal and perinatal deaths per 1,000 life births) (Larson, 1991).

2 Economy: For the purpose of this paper, Gross National Income (GNI) per capita in PPP\$ is used as a standard measure of the status of an economy (World Bank, WDI, 2002).

3 Health care expenditures: For this paper 'Per capita health expenditure in PPP\$' was calculated from the per capita health expenditure in $\$$ presented in the World Development Indicators. It was calculated as follows: health care expenditure per capita in PPP\$ $=$ health expenditure per capita in $\$$ (GNI per capita in PPP $\$ / G N I$ per capita in \$).

4. Education: Education was operationalized as the average illiteracy rate of males and females. Adult illiteracy rate is the percentage of people aged 15 and above who cannot, with understanding, read and write a short, simple statement on their everyday life (World Bank, WDI, 2002). Some studies have pointed out that years of education is more important to health than literacy as such (Mellington and Cameron, 1999; Glewwe, 1999). However, since these data are not available at country level, we choose to use illiteracy rate as proxy for education.

5 Sanitation and safe water: two indicators taken from the World Development Indicator list: percentage of households with access to improved water sources and improved sanitation (World Bank, WDI, 2002).

6 Immunisation: percentage of children immunized against major infectious diseases (diphtheria, pertussis (whooping cough), and tetanus (DPT)) (World Bank, WDI, 2002).

7 Political instability: This variable is put together by evaluating the internal conflicts of a country. The score ranged from 3 for countries with a stable government without internal conflicts to zero in the case of internal conflicts of a devastating magnitude (civil war etc.). Source: authors' own construct.

8 Epidemics: The HIV prevalence rate as percentage of the adult population was used to indicate epidemics in the country (World Bank, WDI, 2002). 


\section{Analysis}

A stepwise multiple regression analysis (OLS) was used to establish the relative effect of the independent variables. We used stepwise regression because of the low number of countries. Since we identified quite a lot of explaining variables in relation to the number of observations, stepwise regression has the advantage of including only those variables that contribute significantly to the explanation of the variation in healthy life expectancy. The few missing data were dealt with by the pair-wise deletion option. Ghana, the first author's country of residence, was used as an example to describe the deviation from the regression lines. Appendix 2.2 shows the correlation matrix of the variables. Due to the high correlation between GNI and health care expenditure (Pearson's $r=$ 0.76), we excluded health care expenditure from the multivariate analysis.

\section{Results}

First the relationships between GNP per capita, Health care expenditures (EXP) and HALE will be shown graphically, also showing the position of Ghana in relation to the regression line.

In figure 2.2 the familiar linear relationship between 'health' and 'wealth' seems to be present, although Angola, Lesotho and Zimbabwe seem to be outliers. A higher income correlates quite strongly with a longer healthy life expectancy when these countries are left out (Pearson's $r=0.70$, $\mathrm{p}<0.01$, outliers excluded). A higher income correlates with a lower infant mortality (Pearson's $r=-0.56, p<0.01$, Angola, Lesotho and Zimbabwe left out). There is quite a strong association between a higher income and the proportion of that income spent on health care (see figure 2.3 , Pearson's $r=0.63, p<0.01$, outliers excluded). The proportion of income spent on health care is not larger for relatively higher income countries. The average proportion of income spent on health care for these low-income countries lies between $4 \%$ and $5 \%$. We expected a positive relationship between HALEs and health care expenditures (see figure 2.4). This, however, is not the case. Between infant mortality and health care expenditure, there is a negative association, higher income is associated with lower infant mortality. 
Figure 2.2 GNI and HALE and infant mortality for Ghana and 31 SubSaharan African countries

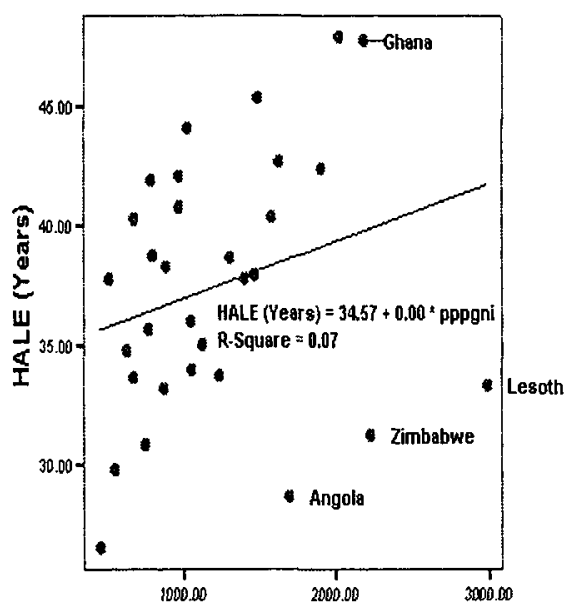

Gross National Income per capita in PPP\$

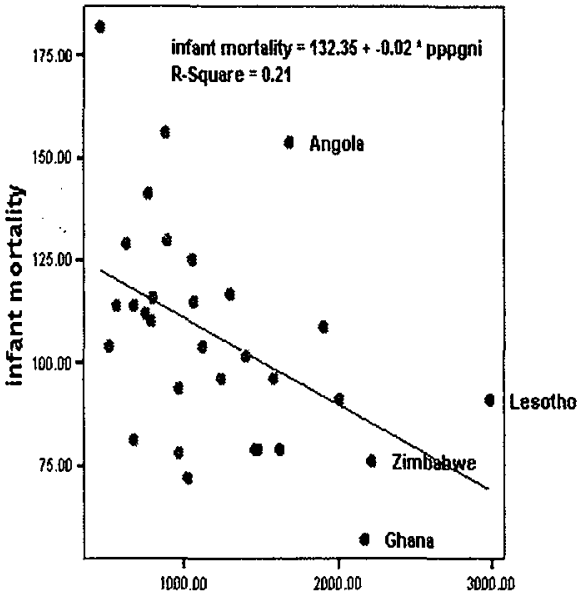

Gross National Income per capita in PPPS

Sources: World Bank, 2003; WHO, 2002

Figure 2.3 GNI and per capita health care expenditure in Ghana and 31 Sub-Saharan African countries

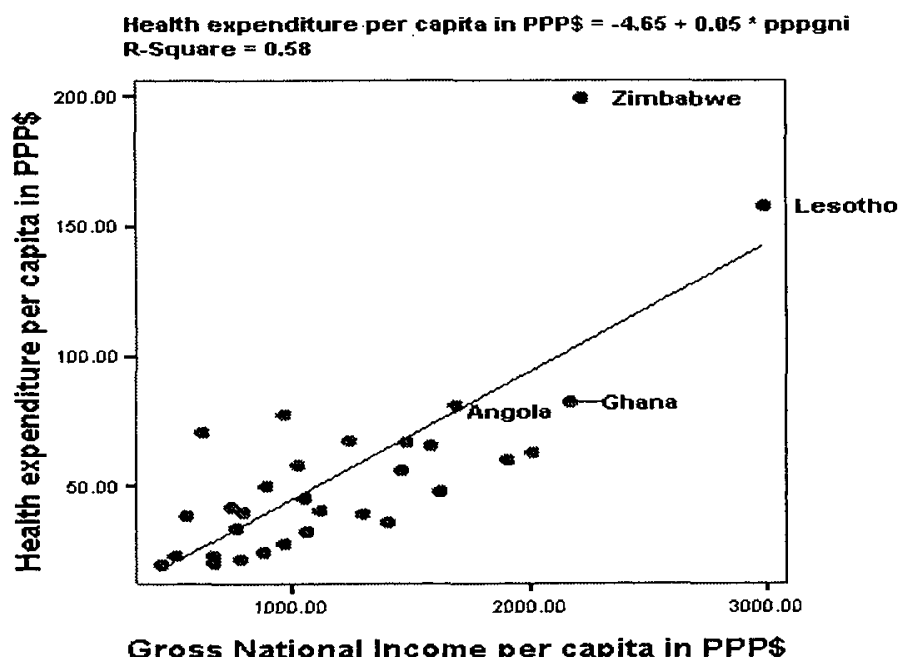

Source: World Bank, 2003 
Figure 2.4 HALE, infant mortality and health care expenditure for Ghana and 30 Sub-Saharan African countries

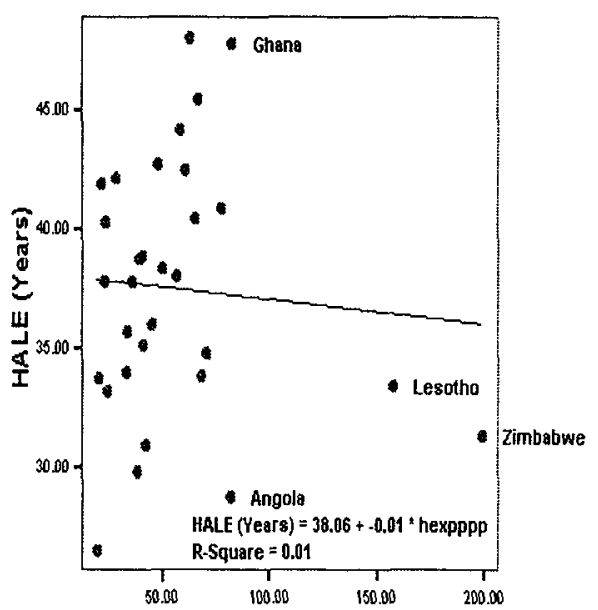

Health expenditure per capita in PPP\$

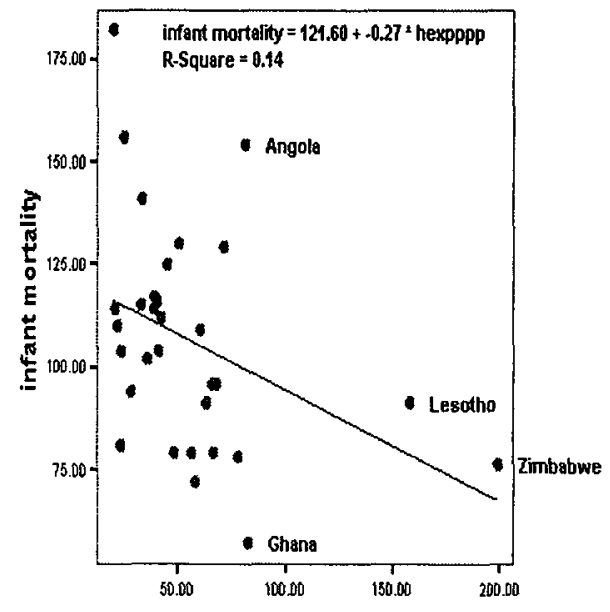

Health expenditure per capita in PPP\$

Sources: World Bank, 2003; WHO, 2002

\section{Position of Ghana}

Ghana's position is above the regression line regarding the relationship between healthy life expectancy and GNI per capita. The health of Ghana's inhabitants is better than would be predicted by the economic strength of their country. Figure 2.4, representing the relationship between HALE and health care expenditure shows that the health of Ghana's population realizes a high HALE with a somewhat above average health care expenditure share.

\section{Multivariate analysis}

In table 2.1 the results of the multivariate regression analyses (OLS) for HALE are presented. For healthy life expectancy, we see that the prevalence of HIV and 'wealth' explains approximately $42 \%$ of the variation. All other variables do not contribute significantly. For infant mortality rate we see that besides prevalence of HIV and GNI per capita, also adult illiteracy rate and child immunisation rates contribute to this rate (together explaining approximately $52 \%$ of the variation). So, the general relationship between a country's wealth and the health in the sense of healthy years lived remains intact in this multivariate approach. 
The observation of Evans et al. (2001) that devastating disasters like the HIV-epidemic and political instability are determinants of a country's health irrespective of its economic position also holds true in our model.

Table 2.1 Healthy life expectancy: stepwise regression analysis for the effects of wealth and health policy and some major threads for health (HIV and political instability)

\begin{tabular}{|c|c|c|}
\hline Predictor variables & Model 1 & Model 2 \\
\hline Constant & 40.21 & 35.83 \\
\hline Prevalence of HIV & $-0.32 * \star$ & $-0.43^{\star \star \star}$ \\
\hline GNI per capita & .. & $0.004 * * *$ \\
\hline Childhood immunisation & -- & -- \\
\hline Access to improved water source & - & -- \\
\hline Adult illiteracy rate & -- & -- \\
\hline Access to improved sanitation & -- & -- \\
\hline Political stability & -- & -- \\
\hline Per capita health care expenditure & -- & -- \\
\hline Adjusted $\mathrm{R}^{2}$ & 0.22 & 0.42 \\
\hline F-statistic & $6.99 * *$ & $8.68 * * *$ \\
\hline
\end{tabular}

* Significant at the 0.10 level

* * Significant at the 0.05 level

*** Significant at the 0.01 level

-- Excluded from the model

Source: Data based on World Development Indicators 2003; World Health Report 2002

\section{Position of Ghana}

To calculate the predicted HALE for Ghana, we recalculated the regression equation with only the significant variables included. When applying the regression equation (HALE $=0.004 \mathrm{GNI}-0.428 \mathrm{HIVpre-}$ valence + 35.83) to Ghana gives a predicted HALE of the Ghanaian population of 43.2 years. The figure for healthy life expectancy computed by the WHO is 47.8 years, a difference of almost 5 years. So even in a multivariate model (albeit with a limited number of variables) the healthy life expectancy of the Ghanaian population is higher than would be predicted from the National income per capita, the (limited) number of HIV infected persons.

For infant mortality a comparable picture can be drawn (table 2.2). If we fill out the regression equation with the significant variables included, the predicted infant mortality rate of Ghana is 58.9 per 1,000 live births. (infant mortality $=0.934^{*}$ adult illiteracy rate $-0.017^{*} \mathrm{PPP}$ GNI $+1.585^{*}$ HIV prevalence $-0.37 *$ child immunisation +95.45 .) The real infant mortality rate is 57 per 1,000 live births. Here Ghana's position can be predicted from the model. 
Table 2.2 Infant mortality: stepwise regression analysis for the effects of wealth and health policy and some major threads for health (HIV and political instability)

\begin{tabular}{|c|c|c|c|c|}
\hline Predictor variables & Model 1 & Model 2 & Model 3 & Model 4 \\
\hline Constant & 71.98 & 95.88 & 73.81 & 95.45 \\
\hline Adult illiteracy rate & $0.80^{* * *}$ & $0.67 * * *$ & $1.01 * \star \star$ & $0.93^{* * *}$ \\
\hline GNI per capita & -- & $-0.02^{*}$ & $-0.02 * *$ & $-0.017^{\star \star}$ \\
\hline Prevalence of HIV & -- & - & 1.41 * * & $1.59 * *$ \\
\hline Child immunisation & -- & -- & -- & $-0.37^{\star}$ \\
\hline Access to improved water source & -- & -- & -- & -- \\
\hline Access to improved sanitation & -- & -- & -- & -- \\
\hline Political stability & -- & -- & -- & -. \\
\hline Per capita health care expenditure & -- & -- & -. & .. \\
\hline Adjusted $R^{2}$ & 0.30 & 0.38 & 0.46 & 0.52 \\
\hline F-statistic & $11.9 * * *$ & $8.85 * * *$ & $8.28^{* * *}$ & $8.15^{\star \star \star}$ \\
\hline
\end{tabular}

* Significant at the 0.10 level

** Significant at the 0.05 level

*** Significant at the 0.01 level

-- Excluded from the model

Source: Data based on World Development Indicators 2003; World Health Report 2002

\section{Conclusions}

The first and second research question of this paper addressed the association between economic prosperity and health policy measures and healthy life expectancy of the populations of 31 countries in Sub-Saharan Africa. All 31 countries are qualified as low income countries by the World Bank. The direct relationship between the strength of a country's economy (expressed as GNI per capita in PPP\$) and the healthy life expectancy was apparent, although there were some distinct exceptions. Angola, Lesotho and Zimbabwe scored much lower than expected from their economic situation. For Lesotho and Zimbabwe this is due to the high HIVprevalence, which is the second important association with HALE. Deaton, in a review of the literature on income inequality and health, expressed the view that income determines mortality before the epidemiological transition, while after it income inequality determines mortality (Deaton, 2001). Since these low income countries are within the process of the epidemiological transition, and maybe set back by the HIV epidemic, the effect of income is not surprising.

None of the other factors that were expected to influence HALE were indeed associated with a longer HALE. This may have several reasons. Firstly, the effect of these factors (better sanitation etc.) may become important only at higher levels of economic prosperity. Secondly, the 
reliability of the data may be low. Entities like access to improved water sources and improved sanitation require sound administrative processes to get reliable estimates, for political stability applies that major political instability (e.g. war or recovering from war) also hampers data collection.

For infant mortality, the classical public health model was found: low mortality rates are associated with higher income, education and immunization. New in the model is the prevalence of HIV. Countries with high HIV prevalence (and this can be over $30 \%$ of the adult population in some countries) experience higher infant mortality rates. This may be due to HIV infection of the children themselves or of their mothers, due to which the care the children receive may be suboptimal.

The second research question concerned the position of Ghana. In Ghana the healthy life expectancy is higher than expected from their economic position and HIV prevalence: the difference is about 5 years. The measured infant mortality rate is not deviant from the one calculated from the public health model. This implies that Ghana is doing well on its education and immunization policy, and they should continue to do so. It is not clear why Ghana is doing better than its fellow Sub-Saharan countries on healthy life expectancy. May be life style factors like smoking, traffic behaviour (accidents) play a role. Further research is necessary to shed a light on this issue.

Another important finding is that different health indicators are influenced through different routes in our model. Healthy life expectancy is mainly influenced by HIV-prevalence and wealth (GNI per capita), whereas infant mortality is influenced by the same indicators plus education and immunization policies. The effect of education may directly influence infant mortality and healthy life expectancy with a lag of years. When immunization against HIV or anti-virals against the consequences of HIV become available for the population, this will also dramatically affect healthy life expectancy.

This study knows several limitations. Firstly, by this study still the causality of the associations cannot be established. The question whether health influences wealth or the other way round remains unanswered. Secondly, the unit of analysis is the country. This may lead to biases due to large within country variations. Thirdly, the data are not always reliable. Some are expert estimates, and also experts may err (Kroneman and Van der Zee, 1997). Others are biased because countries might not 
want to admit bad health status figures (e.g. they report lower HIV rates than reality). Important in this case is also the comparability of the data among the countries. Are the indicators composed and measured in a uniform way in all countries? Due to these limitations, the results have to be considered with caution. Fourthly, the number of countries in our study is quite low. However, by selecting only low income countries from one continental region, we hope that the comparability of the countries is larger than would be when including middle and/or high income countries or other continents.

Our study revealed that the association between health and wealth in these low income countries is still very strong. However, a second important factor is the prevalence of HIV infections. This may imply that these countries, that are within the epidemiological transition for infant mortality, are set back to the pre-transition situation, due to infectious diseases at adult age. This implies that health policy measures for these countries may concentrate on education and combating HIV. Ghana is doing better than can be predicted based on its economic position and HIV-prevalence. Since Ghana has a relatively good economic position, maybe other factors, like life style and traffic accidents, start playing a role. Further research, preferably at the level of the individual, is necessary to find explanations and clarify causality. 


\section{Appendix 2.1 GNP per capita, per capita health care expenditure and healthy life expectancy (HALE in years) for selected Sub-Saharan African countries (excluding Republic of South Africa)}

\begin{tabular}{|c|c|c|c|}
\hline Country & $\begin{array}{r}\text { GNI per capita } \\
2001^{\star}(\mathrm{ppp} \$)\end{array}$ & $\begin{array}{r}\text { Per capita health care } \\
\text { expenditure } 2000^{* *} \\
(\mathrm{ppp} \$)\end{array}$ & $\begin{array}{r}\text { Hale 2001*** } \\
\text { (years }\end{array}$ \\
\hline Angola & 1690 & 81.12 & 28.7 \\
\hline Benin & 970 & 28.08 & 42.1 \\
\hline Burkina Faso & 1120 & 40.73 & 35.1 \\
\hline Burundi & 680 & 20.40 & 33.7 \\
\hline Cameroon & 1580 & 65.38 & 40.4 \\
\hline Central African Republic & 1060 & 32.62 & 34.0 \\
\hline Chad & 1300 & 39.00 & 38.7 \\
\hline Congo & 680 & 23.38 & 40.3 \\
\hline Cote d'Ivoire & 1400 & 35.56 & 37.8 \\
\hline Dem. Rep. of Congo & 630 & 70.88 & 34.8 \\
\hline Eritrea & 1030 & 57.94 & 44.1 \\
\hline Ethiopia & 800 & 40.00 & 38.8 \\
\hline Gambia & 2010 & 62.81 & 48.0 \\
\hline Ghana & 2170 & 82.31 & 47.8 \\
\hline Guinea & 1900 & 60.24 & 42.4 \\
\hline Guinea-Bissau & 890 & 50.06 & 38.3 \\
\hline Kenya & 970 & 77.60 & 40.8 \\
\hline Lesotho & 2980 & 157.43 & 33.4 \\
\hline Malawi & 560 & 38.50 & 29.8 \\
\hline Mali & 770 & 33.48 & 35.7 \\
\hline Mozambique & 1050 & 45.00 & 36.0 \\
\hline Niger & 880 & 24.44 & 33.2 \\
\hline Nigeria & 790 & 21.79 & 41.9 \\
\hline Rwanda & 1240 & 67.64 & 33.8 \\
\hline Senegal & 1480 & 66.45 & 45.4 \\
\hline Sierra-leone & 460 & 19.71 & 26.5 \\
\hline Togo & 1620 & 48.00 & 42.7 \\
\hline Uganda & 1460 & 56.15 & 38.0 \\
\hline United Republic of Tanzania & 520 & 23.11 & 37.8 \\
\hline Zambia & 750 & 42.19 & 30.9 \\
\hline Zimbabwe & 2220 & 198.88 & 31.3 \\
\hline
\end{tabular}




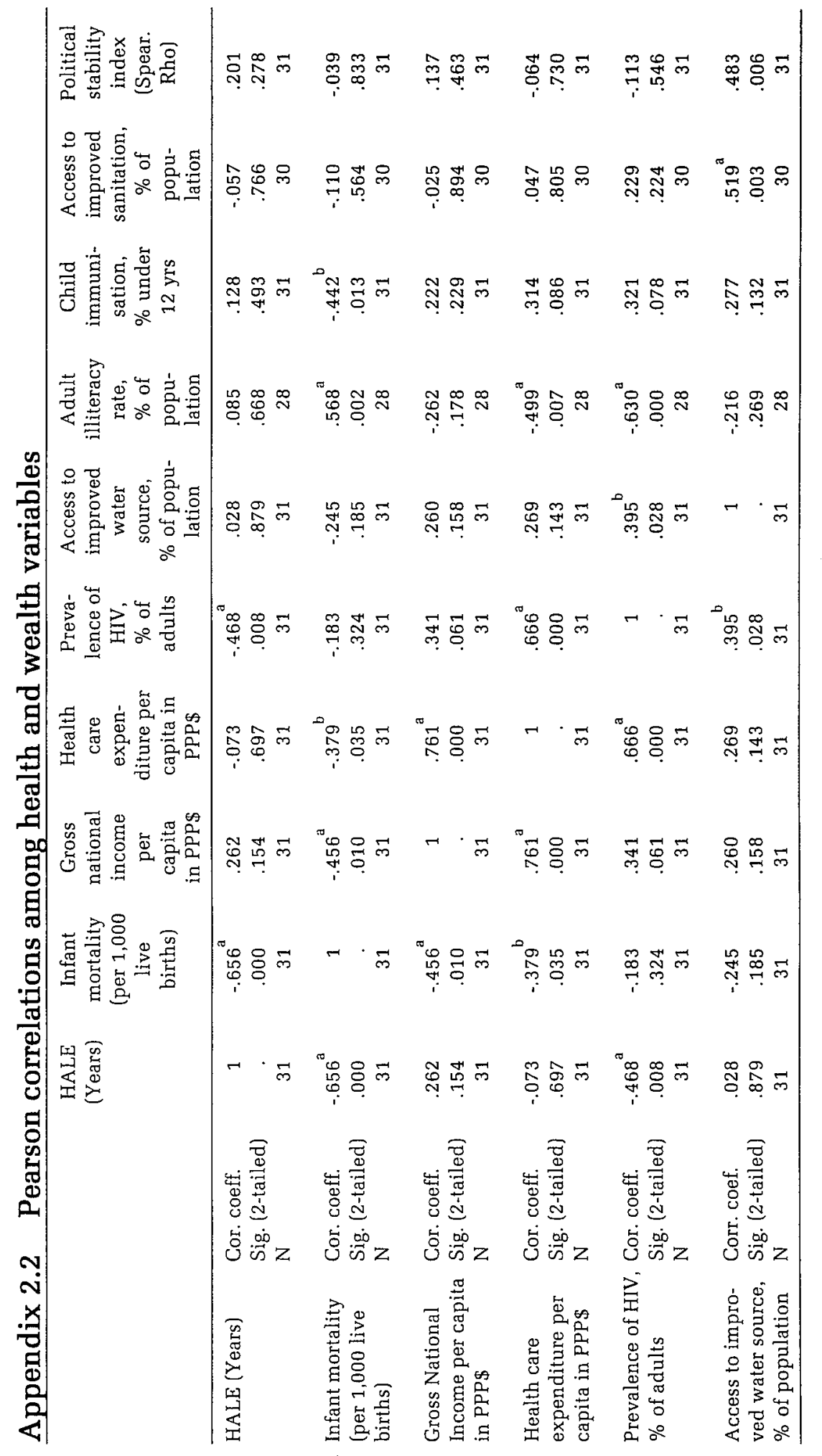




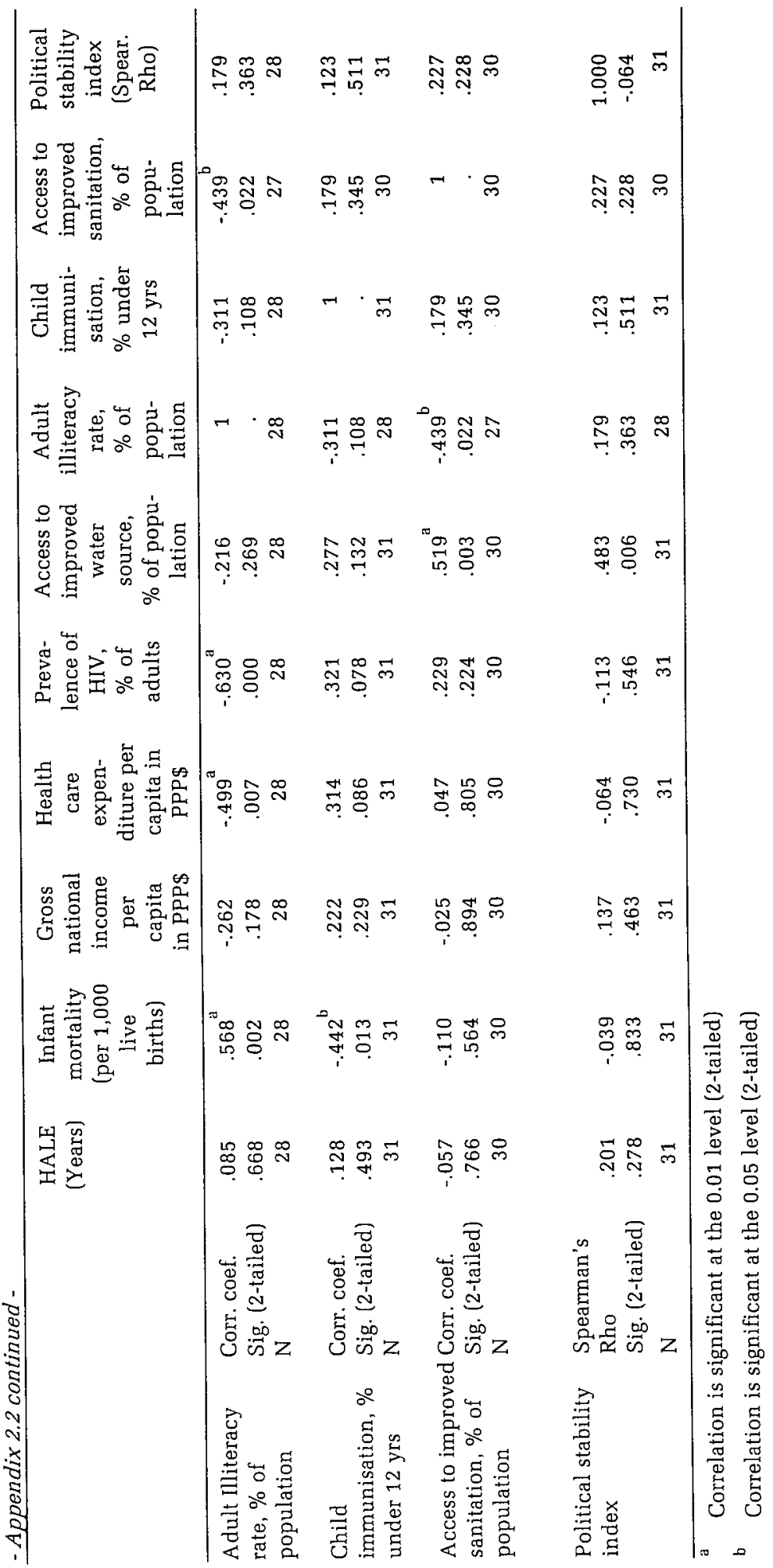




\section{Comparative analysis of utilisation of \\ ( health services in rural and urban areas in developing countries}

A case study of Ahafo-Ano South District and Kumasi Metropolis in Ghana

This chapter has been submitted as:

Buor D, Zee J van der, Groenewegen P. Comparative analysis of utilisation of health services in rural and urban areas in developing countries: a case study of Ahafo Ano South District and Kumasi Metropolis in Ghana. 


\section{Introduction}

This study attempts to assess the relevance of the Andersen/Newman model (1973) for evaluating the Ghanaian health care system. It compares the impact of access with the impact of other elements of the model on the utilisation of health services in a rural and metropolitan area in Ghana. With this approach the study returns to the 'roots' of the Andersen/Newman model. Originally it had been designed to evaluate the US health care system shortly before and after the introduction of Medicare/Medicaid.

Andersen and Newman used their analytical/empirical model and the division of the (independent) variables in the three well known categories "need-variables, predisposing and enabling variables" in order to be able to demonstrate whether and to what degree factors other than need or need related variables would influence health services utilisation. If that were the case, that would be considered as an indication that the health care system under study did not respond effectively to the health needs of the population and that, depending on the exact findings of the study, there would be room for improvement and policy measures.

Later, the Andersen/Newman model was transformed into a mere causal/analytical tool in the explanation of health services utilisation all over the world, but especially in developed countries. It lost its evaluative character, most probably because in developed countries financial barriers to health services utilisation ceased to exist in the last 3 to 4 decades of the $20^{\text {ll }}$ century. In this study we will apply the model in its original evaluative form in two areas in a developing country that basically differ in the degree of deprivation and accessibility of health services: a rural and a metropolitan health care setting.

Two key research questions emerge from the foregoing. Firstly, are there differences in health status (need) between people in rural and urban districts in Ghana and do these differences in need explain the differences in utilisation? Secondly, if differences in utilisation remain, what is the relative influence of enabling and predisposing variables in explaining differences in utilisation?

Research has vindicated Andersen and Newman's (1973) position regarding predisposing and enabling factors in influencing health services utilisation in developing countries. Habib et al. (1986); Chernichovsky and Mesook (1986); Pickett and Hanlon (1990); Ensor and Pham-Bich-San 
(1996); Delanyo et al. (1990) showed in various studies that poverty is a predominant factor in utilisation. Although these studies did not include rural-urban disparity in utilisation, the results imply, with poverty more endemic in deprived rural areas, that utilisation rates will more likely be lower in rural than urban areas. These studies confirm the observation of Mckinlay (1972) and Whitelegg (1982) regarding the influence of specific aspects of social class (lower income, worse health) to health services utilisation (Turshen, 1999).

An important predisposing factor indicated in the model is education. Education shows a direct positive relationship with the use of health care (Grossman, 1975). Especially in developing countries the education of women shows a positive relationship with the use of health services, in particular preventive services such as maternal care (Wong et al., 1987; Caldwell, 1983; Swenson et al., 1993; Mensch et al., 1985; Raghupathy, 1996). An ILO study conducted in Bolivia, Egypt and Kenya revealed that access of women to maternal and child health services were strongly influenced by their level of education and rural-urban status (ILO, 2000). In Ghana the adult illiteracy rate is quite high, with $30 \%$ of adults unable to read and write (World Bank, 2002). With a very low literacy rate in rural areas, one could conclude that utilisation would be lower there than in urban areas.

In the 1973 version of the Andersen Newman model little attention was paid to health care provider and policy characteristics. In a later version (Aday and Andersen, 1974) some characteristics of the delivery system and health care policy were added. The model also fails to recognise the role of perception of the efficacy of the health system and of what constitutes illness, as impeding factors of need. Health beliefs are also not factored into the analysis of need in predominantly traditional societies.

Urban and rural districts vary considerably in the level of health care provisions, especially in developing countries. The Metro-Manila region in the Philippines, for instance, though containing $25 \%$ of the country's population, has $43 \%$ of total hospital beds (Phillips, 1986). In Kenya, it is estimated that only $10 \%$ of the country's doctors serve rural areas, and that some $70 \%$ of all doctors are in urban private practice. African doctor-topopulation ratios range from 1:990 in the cities to 1:70000 in rural areas (Good, 1987). In South Africa, there is urban bias in the provision of health care (Gatrell, 2002) and X-ray service favour the urban areas (Walters et al., 1998). Urban bias in the provision of health facilities has been the trend in 
several developing countries (Gatrell et al., 1998). Variations have also been found to exist in the spatial provision of health facilities between rural local government areas (Okafor, 1984). Shannon and Dever (1974) have observed that the locational pattern of physicians, which favours urban areas, reflect their own needs rather than those of their client population.

An important policy that is lacking in developing countries including Ghana is health insurance, which has a positive impact on the utilisation of health services in developing countries (Criel et al., 1999). Health insurance is an urban practice in Ghana as well as other developing countries. Rural areas in developing countries are yet to have adequate access to health insurance, because insurance presupposes a flourishing monetary economy. Their lack of adequate access could be attributed to illiteracy and poverty.

The location and distribution policy of governments creates a distance problem for rural dwellers in accessing health facilities. In the developing nations, works by Muller et al. (1998); Kinman (1999); Stock (1987); Wilson (1997); Bailey and Phillips (1990); Stock (1983); and Ganatra and Hirve (1994), confirm this trend. Dutton (1986) added to the physician and user characteristics and structural barriers that come under the umbrella of the provider, thus, health policy. Such constraints, however, fail to emphasise the spatial differences. Need is strongly emphasised in the evaluation of equity in utilisation, yet need is a function of perception. Another deficiency regarding its application to developing countries is emphasis on follow-up visits. In the study area, follow-up visits by physicians are very rare. Need seems to be higher in rural than in urban areas in developing countries. In developing countries, access to health facilities like safe water and sanitation is poor, and poorer in the rural areas than in urban areas (World Bank, 2002). The result is that the rural areas tend to suffer from more preventable infections.

In Ghana, there is generally a dichotomy between the rural and urban areas in the distribution of health facilities. The two tertiary hospitals as well as all the eight regional hospitals are located in the key urban centres. In the Ashanti Region where the two districts for study were taken from Kumasi Metropolis has over $37 \%$ of all health facilities in the Region although it covers just about $1 \%$ of land space in the region (Ghana Ministry of Health, 2000) and constitutes less than $33 \%$ of the regional population. Moreover, one of the only two Teaching Hospitals, five polyclinics (with facilities better than those of district hospitals in 
semiurban centres), and the major private hospitals in the region are sited there (figure 3.1). Besides it has over $90 \%$ of all doctors in the Region.

Figure 3.1 Distribution of health facilities and settlements in Kumasi Metropolis

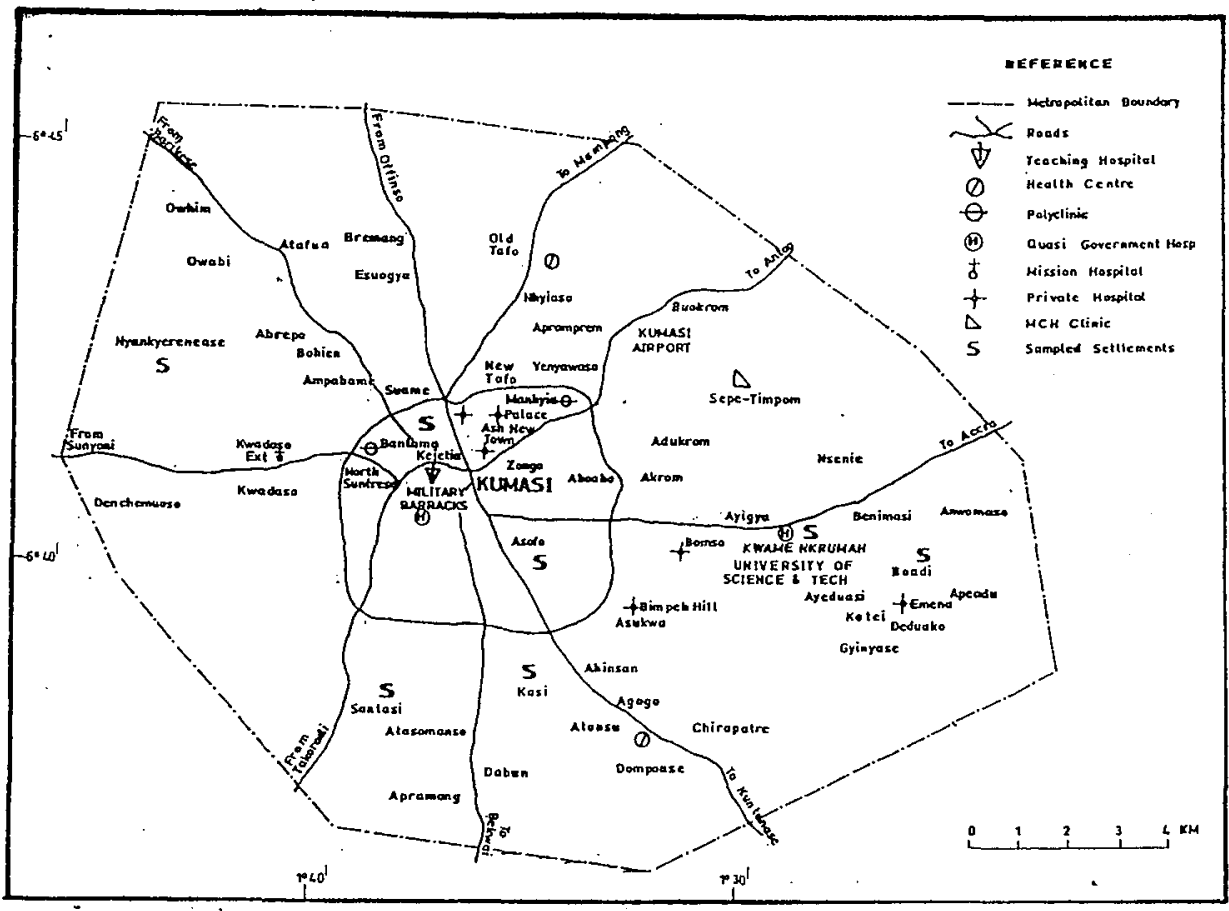

Source: Town and Country Planning Department and Ministery of Health, Kumasi, 1996

In contrast, Ahafo-Ano South District which has a land area of more than thrice that of Kumasi and has several scattered rural settlements with poor access roads, has just $2.7 \%$ of all health facilities, one resident doctor and two non-resident doctors. The three doctors constitute less than $2 \%$ of all doctors in the Region (Ghana Ministry of Health, 2000). The vast district has one district hospital with poor clinical facilities, and six health centres (figure 3.2) where basic laboratory facilities are lacking. At the district hospital only minor surgeries are conducted due to lack of sophisticated equipment for major surgeries. In the metropolis, however, radiological, pathological, and several major services are conducted. This situation calls for a thorough investigation of health care utilisation in rural and urban areas in Ghana to identify factors that influence it, in order to furnish policy makers with options for the improvement of health care utilisation. 
Figure 3.2 Distribution of health facilities and settlements in Ahafo-Ano South District

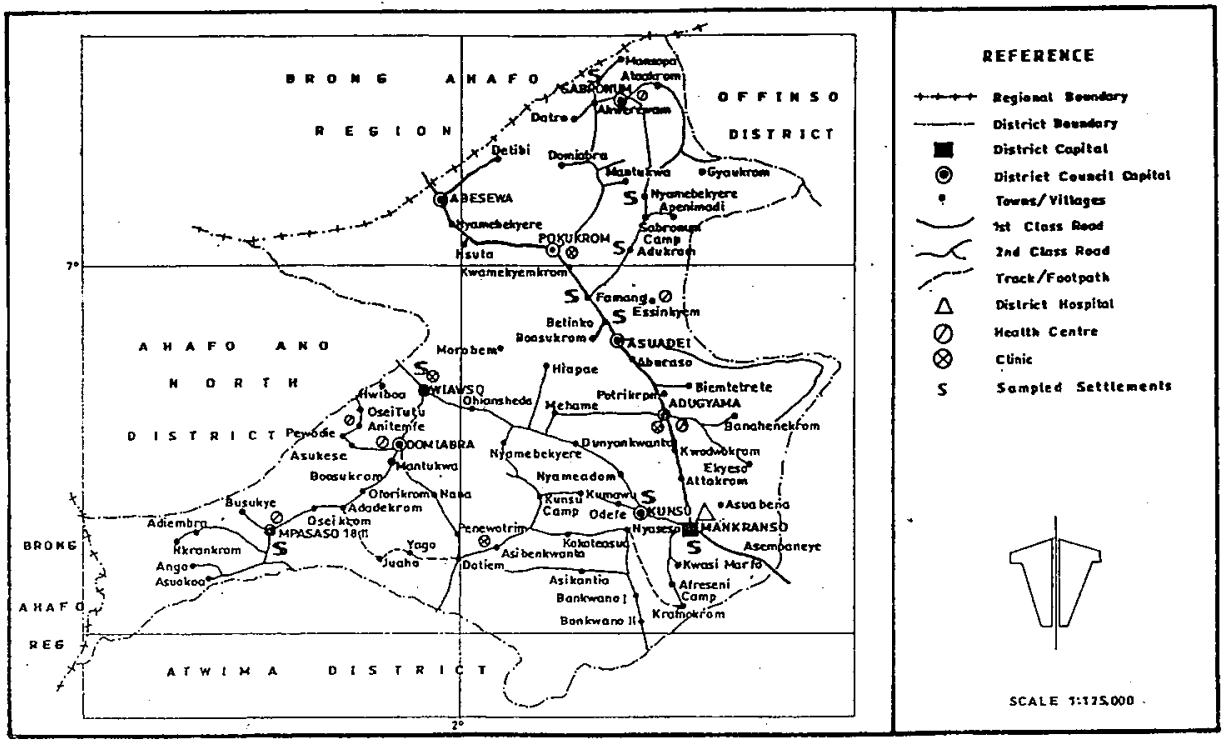

Source: District Assembly and Ministry of Health, Mankranso, 1996

So, based on the above-mentioned literature we arrive at the following expectations regarding a rural/urban health services utilisation comparison in Ghana:

- health care needs will be higher in the rural area, due to the higher deprivation indicators;

- utilisation will be higher in the urban area, especially due to the higher level of predisposing and enabling factors (income, insurance, proximity to service provision) in the urban area;

- differences between the rural and urban area can be fully explained by differences in the distribution of need, predisposing and enabling factors between the rural and urban area.

\section{Data and methods}

\section{The setting and variables}

The study is a retrospective, cross-sectional survey covering a rural and an urban district. It covers adults aged 18 years and above who are capable of deciding to use health services. The respondents' characteristics include age, sex, education, employment, place of residence (ruralurban), and income. The dependent variable is utilisation of health services whilst the independent variables are operationalisations of need, 
predisposing, and enabling and restrictive factors. Restrictive factors are part of the category of enabling factors. The variables derived are thus health status for need; age, sex, employment and education for predisposing factors; income and insurance for enabling; and distance, travel time, waiting time, quality of road, service cost, transport cost, quality of service and attitude of hospital staff as restrictive factors. The operationalisation of the variables and the codes used are indicated in table 3.1.

Table 3.1 Operationalisation of the study variables

\begin{tabular}{|c|c|c|}
\hline Variable & Operational definition & Codes \\
\hline Utilisation & $\begin{array}{l}\text { The number of times a respondent } \\
\text { attended a hospital/health centre the last } \\
\text { three times he/she experienced illness } \\
\text { spells }\end{array}$ & $\begin{array}{l}\text { No attendance (rarely) } \\
\text { Once (irregularly) } \\
\text { Two times (moderately) } \\
\text { Three times (regularly) } \\
\text { [ranked] }\end{array}$ \\
\hline Health status & $\begin{array}{l}\text { The number of times a respondent fell } \\
\text { sick during the stated }\end{array}$ & $\begin{array}{l}\text { Once a week } \\
\text { Once in two weeks } \\
\text { Once a month } \\
\text { Once in three nonths } \\
\text { Rarely } \\
\text { [anked] }\end{array}$ \\
\hline Age & $\begin{array}{l}\text { Number of full years attained at the last } \\
\text { birthday }\end{array}$ & Entered as continuous data \\
\hline Employment & $\begin{array}{l}\text { Engagement in an income-generating } \\
\text { activity, whether in the formal or } \\
\text { informal sector }\end{array}$ & $\begin{array}{l}\text { [Dummy/dichotomous] } \\
\text { Unemployed } \\
\text { Employed }\end{array}$ \\
\hline Education & $\begin{array}{l}\text { The completed level of schooling } \\
\text { attained }\end{array}$ & $\begin{array}{l}\text { Never-been-to-school } \\
\text { Basic education } \\
\text { Secondary education } \\
\text { Tertiary education } \\
\text { [ranked] }\end{array}$ \\
\hline Income & $\begin{array}{l}\text { Both monthly cash income and income } \\
\text { in kind of a household }\end{array}$ & Entered as continuous data \\
\hline Insurance & $\begin{array}{l}\text { Enjoyment of free medical care or part } \\
\text { thereof, upon payment of premium or } \\
\text { as part of service conditions }\end{array}$ & $\begin{array}{l}\text { [Dummy/dichotomous] } \\
\text { Uninsured } \\
\text { Insured }\end{array}$ \\
\hline Distance & $\begin{array}{l}\text { Total distance in kilometres covered } \\
\text { either on foot or by any means of } \\
\text { transport from home to a health facility }\end{array}$ & Entered as continuous data \\
\hline
\end{tabular}




\begin{tabular}{|c|c|c|}
\hline Distance & $\begin{array}{l}\text { Total distance in kilometres covered } \\
\text { either on foot or by any means of } \\
\text { transport from home to a health facility }\end{array}$ & Entered as continuous data \\
\hline Travel time & $\begin{array}{l}\text { Time taken to travel from home to a } \\
\text { health facility by any means of transport }\end{array}$ & Entered as continuous data \\
\hline Waiting time & $\begin{array}{l}\text { Time spent waiting for a doctor: from the } \\
\text { time of arrival at a health facility to the } \\
\text { time a patient is called to the doctor's } \\
\text { consultation room }\end{array}$ & Entered as continuous data \\
\hline Quality of road & $\begin{array}{l}\text { The status of the road covered to a health } \\
\text { facility: i.e. minor, secondary and major } \\
\text { roads }\end{array}$ & $\begin{array}{l}\text { Minor } \\
\text { Secondary } \\
\text { Major } \\
\text { [ranked] }\end{array}$ \\
\hline Transport cost & $\begin{array}{l}\text { The cost of transport paid for travelling } \\
\text { to the health facility and back }\end{array}$ & Entered as continuous data \\
\hline Service cost & $\begin{array}{l}\text { The cost of consultation, laboratory and } \\
\text { other tests, surgery and drugs }\end{array}$ & Entered as continuous data \\
\hline $\begin{array}{l}\text { Quality of } \\
\text { service }\end{array}$ & $\begin{array}{l}\text { The general performance of the hospital } \\
\text { as assessed by the patient relating to } \\
\text { diagnosing of disease by the doctor, } \\
\text { laboratory tests, availability of drugs etc. }\end{array}$ & $\begin{array}{l}\text { Poor } \\
\text { Satisfactory } \\
\text { Good } \\
\text { Very Good } \\
\text { [ranked] }\end{array}$ \\
\hline $\begin{array}{l}\text { Attitude of } \\
\text { medical staff }\end{array}$ & $\begin{array}{l}\text { Affective behaviour of medical staff } \\
\text { towards patients }\end{array}$ & $\begin{array}{l}\text { Poor } \\
\text { Satisfactory } \\
\text { Good } \\
\text { Very Good } \\
\text { [ranked] }\end{array}$ \\
\hline Sex & Whether male or female & $\begin{array}{l}\text { [Dummy/dichotomous] } \\
\text { Male } \\
\text { Female }\end{array}$ \\
\hline $\begin{array}{l}\text { Place of } \\
\text { residence }\end{array}$ & Whether rural or urban (metropolis) & $\begin{array}{l}\text { [Dummy/dichotomous] } \\
\text { Kumasi Metropolis } \\
\text { Ahafo-Ano South District }\end{array}$ \\
\hline
\end{tabular}

Health status is defined in terms of perceived sickness. In the study area a person regards himself as sick, if the alteration in his physical condition is such that he cannot perform his daily duties. Minor ailments that will not interfere with the performance of a person's daily chores are not generally deemed as sickness that should receive medical attention. Attendance is operationalised as presentation of oneself to a doctor for 
medical examination and prescription of treatment devices. Where a patient was asked by a physician to report for re-examination when a health problem persisted, this was deemed as another attendance. The collection of data on income was guided by the methods used in the Ghana Living Standards Surveys. The components were, wage income from employment, household agricultural income, non-farm self-employment income, rental income and net remittance and other minor sources (GSS, 2000). In the rural areas where agricultural income predominates, average monthly agricultural produce of farmers was determined using the operating market prices. In a few instances where there was a serious memory problem, average daily expenditure less financial credits were used as proxy to determine average monthly income of respondents.

\section{Sampling}

Two districts, Kumasi Metropolis, representing the urban areas, and Ahafo-Ano South District (figures 3.1 and 3.2), representing the rural areas, were selected from the 18 districts in the Ashanti Region for the survey. The rationale for the selection is the contrast between the two districts regarding the levels of health facilities and accessibility to them, socio-economic facilities and status that favour the metropolis. Besides, there is the predominance of tradition in the rural district, a factor that strongly influences utilisation. The selected urban and rural districts are broadly representative of the urban and rural milieus in Ghana.

A sample of 650 , representing $.06 \%$ of the total population of $1,303,902$ in the two districts (GSS, 2002), was used. Seventeen settlements, seven in the metropolis and ten in the rural district, were selected for the survey (figures 3.1 and 3.2). The settlements covered 3,108 housing units, 1,732 for the rural Ahafo-Ano South District, and 1,376 for the Kumasi Metropolis. The selection was based upon the spatial spread and differential access to health facilities, and residential status. In the Kumasi Metropolis, settlements from both high-class residential and lowclass residential areas were selected. The respondents were adults aged from 18 and above, and were selected from households through systematic random method. The sample interval of the residences was based upon the density of houses and households. The interval was 5 for the metropolis and semi-urban settlements in the rural district where there is greater density of houses than the rural settlements, and 3 for rural settlements. Sample sizes for age, sex and education were predetermined. Primary data were collected from households in the various communities in the rural and urban districts. Informal interview and 
questionnaire instruments were respectively applied on the illiterate and educated in the primary data collection. Some of the educated preferred to be interviewed to avoid the problem of callbacks. In all, 26 persons, ten in metropolis and sixteen in the rural district failed to respond to the interviews. Most of these were illiterate and semi-literate. They saw the interview as a waste of time, since such surveys had not resulted in the improvement of their quality of life. A replacement was sought for such persons.

\section{Analysis of data}

Multivariate relationships were tested using multiple regression. Multiple regression was used for the analysis, although the dependent variable is ranked. Multiple regression (stepwise) method (derived from the SPSS software) was used to determine significant factors that influence utilisation of health services. Variables with .05 or less $(\mathrm{p} \leq .05)$ probability were considered significant. Three sets of regression analyses were made. First all the variables and a new variable, 0 for Kumasi Metropolis and 1 for Ahafo-Ano South District were put in the regression model and run (using enter). This was to find out whether there was a significant difference between the two districts. Secondly, the new variable was eliminated from the data set and the stepwise method used to select the significant variables for each of the districts separately. Thirdly, all variables that were significant in either of the districts were put together in another regression model and run (using enter). The overall confidence in the multiple regression data for each of the districts was determined by the adjusted co-efficient of determination (Adjusted $\mathrm{R}^{2}$ ). Correlation matrixes were used to rule out multicollinearity (appendices 3.1 and 3.2).

\section{Results}

The distribution of the study variables for each district is indicated in table 3.2 .

The distribution brings out significant differences between the rural and urban area in all variables but health status and age. Even though the metropolis, in relative terms, uses health services more than the rural, the difference in health status (need) between the two districts is not significant. The coefficient between the two districts is insignificant. There is therefore a discrepancy between need and utilisation between the two districts. 
Table 3.2 Distribution of the study variables by district

\begin{tabular}{rrrr}
\hline Kumasiable Metropolis & Ahafo-Ano South & Difference (sig- \\
$\mathrm{N}=250 ;$ valid $\%$ & $\mathrm{n}=400 ;$ valid \% & nificance $\left.\left[\chi^{2}\right]\right)$
\end{tabular}

Need

Frequency of illness (health status):

once a week

once a fortnight

$\begin{array}{ll}1.2 & 1.8\end{array}$

once a month

$4.8 \quad 7.5$

once in 3 months

28.0

26.3

$30.4 \quad 28.5$

rarely

35.6

36.0

.661

\section{Utilisation}

Number of times attend hospital for

the last three sick spells

not at all (rarely)

once (irregularly)

14.4

28.5

twice (moderately)

33.6

41.5

14.8

11.0

thrice (regularly)

37.2

19.0

Predisposing

Age:

18-59

80.4

79.8

$60+$

19.6

20.3

42.1

41.8

Sex:

male

40.0

40.0

female

60.0

60.0

.000

Education:

never-been-to-school

29.6

42.5

basic education

28.0

32.5

secondary education

28.8

24.0

tertiary education

13.6

1.0

Employment:

employed

83.9

95.2

.000

unemployed

16.1

4.8

\section{Enabling}

Household income per month (in $\varphi$ ):

mean

[563947.4]

[226364.66]

.000

SD

[638185.2]

[157003.77]

.000

Health insurance:

insured

27.6

2.8

.000

uninsured

72.4

97.3 
- table 3.2 continued.

\begin{tabular}{|c|c|c|c|}
\hline Variable & $\begin{array}{l}\text { Kumasi Metropolis } \\
\mathrm{N}=250 ; \text { valid } \%\end{array}$ & $\begin{array}{l}\text { Ahafo-Ano South } \\
\mathrm{n}=400 ; \text { valid } \%\end{array}$ & $\begin{array}{l}\text { Difference (sig- } \\
\text { nificance }\left[\chi^{2}\right] \text { ) }\end{array}$ \\
\hline \multicolumn{4}{|c|}{ Restrictive factors } \\
\hline \multicolumn{4}{|c|}{$\begin{array}{l}\text { Distance to the nearest hospital } \\
\text { (inkm.): }\end{array}$} \\
\hline mean & {$[3.4]$} & {$[18.9]$} & \\
\hline $\mathrm{SD}$ & {$[2,0]$} & {$[12.4]$} & .000 \\
\hline \multicolumn{4}{|c|}{$\begin{array}{l}\text { Distance to hospital/health centre } \\
\text { utilised regularly (in } \mathrm{km} \text { ): }\end{array}$} \\
\hline mean & {$[4.1]$} & [19.7] & \\
\hline $\mathrm{SD}$ & {$[4.5]$} & [19.4] & .000 \\
\hline \multicolumn{4}{|c|}{ Travel time (in min.): } \\
\hline mean & 15.9 & 32.2 & \\
\hline$S D$ & 15.6 & 29.4 & .000 \\
\hline \multicolumn{4}{|c|}{ Service cost (in $\varnothing$ ): } \\
\hline \multicolumn{4}{|c|}{ Less than 30000} \\
\hline mean & 39622 & 36634 & \\
\hline $\mathrm{SD}$ & 29337 & 26022 & .000 \\
\hline \multicolumn{4}{|c|}{ Waiting time (in min.): } \\
\hline mean & 124.1 & 76.0 & \\
\hline SD & 86.1 & 61.5 & .000 \\
\hline \multicolumn{4}{|c|}{ Transport cost (in $\not)$ : } \\
\hline SD & [3315.34] & [4321] & .000 \\
\hline \multicolumn{4}{|c|}{ Quality of service: } \\
\hline poor & 2.4 & 1.3 & \\
\hline satisfactory & 35.2 & 37.7 & .033 \\
\hline good & 53.0 & 45.0 & \\
\hline very good & 9.3 & 16.1 & \\
\hline missing & 1.2 & 0.5 & \\
\hline \multicolumn{4}{|l|}{ Attitude of staff: } \\
\hline poor & 10.4 & 0.8 & \\
\hline satisfactory & 30.1 & 18.8 & \\
\hline good & 48.2 & 59.1 & \\
\hline very good & 11.2 & 21.3 & .000 \\
\hline missing & 0.4 & 0.3 & \\
\hline \multicolumn{4}{|l|}{ Quality of road: } \\
\hline minor road & 21.4 & 45.0 & \\
\hline secondary road & 6.7 & 18.9 & .000 \\
\hline major road & 71.8 & 32.4 & \\
\hline
\end{tabular}

US $\$ 1=7,000.00$ Ghana Cedi $(\varphi)$ at the time of data collection

Source: Based on Field Data, 2001 
With respect to predisposing factors, Kumasi Metropolis has higher level of education than Ahafo-Ano South, whereas enabling factors favour Kumasi Metropolis where incomes are higher. Another enabling variable, insurance, also favours the metropolis where there are private insurance facilities, with the absence of a national health insurance scheme. Most of the restrictive factors that are influenced by the providers' practice patterns and government policy disfavour the rural district. Distance, which has been a barrier factor in developing countries, is a major inhibiting factor in the rural district. People in the rural district live farther away from hospitals than in the metropolis where there is a high concentration of health facilities. Mean service cost does not show a significant difference between the two.

Do these differences in the level of the independent variables explain the differences in utilisation? The regression analysis gives a clue to the reality of the differences. Travel time was eliminated from the regression analysis for both districts due to muilticollinearity problems. The correlation between travel time and distance was as high as .744 for Kumasi Metropolis, and .856 for Ahafo-Ano South District that experiences greater problem with travelling by road. Travel time was eliminated in favour of distance from the regression analyses for each of the districts because they made a weaker association with utilisation than with distance. Distance was maintained because of its significance to the model. In developing countries the impact of distance is about the main physical obstacle to utilisation of health services. The regression results (adding the new variable of place of residence) indicate that the impact of place of residence on utilisation is significant (table 3.3). The influence of the urban/rural factor remains after introducing the other independent variables, that also differed between the urban and rural area. To select the variables for the final analysis, separate stepwise regressions for each area were run (not in table). The variables that were significant in one or both of the areas, were then used in the final analysis (table 3.4). 
Table 3.3 Multiple regression factors for independent variables (including place of residence)

\begin{tabular}{lcc}
\hline Variable & Coefficient & $p$-value \\
\hline Residence (rural-urban) & .146 & .002 \\
Sex & .043 & .200 \\
Age & .034 & .343 \\
Employment & .004 & .901 \\
Income & .154 & .000 \\
Insurance & .107 & .011 \\
Distance &. .483 & .000 \\
Quality of road & .033 & .350 \\
Service cost & -.130 & .001 \\
Attitude of medical staff & -.106 & .018 \\
Quality of service & .131 & .002 \\
Health status & -.089 & .009 \\
Transport cost & .086 & .025 \\
Education & .264 & .000 \\
Waiting time & .059 & .113 \\
\hline Dependent vasiable
\end{tabular}

Dependent variable: Utilisation

Source: Based on Field Data, 2001

Table 3.4 Multiple regression factors for Kumasi Metropolis and AhafoAno South District

\begin{tabular}{lrrrrrr}
\hline \multirow{2}{*}{ Variables } & \multicolumn{2}{c}{ Kumasi Metropolis } & & \multicolumn{2}{c}{ Ahafo-Ano South District } \\
\cline { 2 - 3 } \cline { 6 - 7 } & Beta coeffi. & Sig. ( $p$-values) & & Beta coeffi. & Sig. ( $p$-values) \\
\hline Distance & -.236 & .000 & & -.438 & .000 \\
Service cost & -.255 & .000 & & -.143 & .000 \\
Quality of service & .171 & .001 & & .059 & .096 \\
Health status & -.136 & .012 & & -.082 & .023 \\
Education & .308 & .000 & & .143 & .000 \\
Income & .097 & .104 & & .363 & .000 \\
Adjusted $\mathrm{R}^{2}$ & & .362 & & & .520 & \\
\hline
\end{tabular}

Dependent variable: Utilisation

Source: Based on Field Data, 2001

For the two settings, the variables that were simultaneously significant were distance (negative), service cost (negative), education (positive) and health status, which makes a rather weak negative impact on utilisation. Distance, the strongest factor influencing utilisation in the rural district, also makes a great impact on Kumasi Metropolis, whilst service cost and education have a greater effect in the Kumasi Metropolis than Ahafo-Ano 
South District. Income makes a positive impact in Ahafo-Ano South District whilst health status (need) and quality of service relatively influence Kumasi Metropolis, but not Ahafo-Ano South District. The difference in health status between the two districts is however insignificant. Whereas the adjusted $\mathrm{R}^{2}$ is .362 for Kumasi Metropolis, it is .520 for Ahafo-Ano South District, implying a higher level of prediction for the utilisation behaviour in the Ahafo-Ano South District than in Kumasi Metropolis.

\section{Discussion}

Intrinsic differences exist between urban Kumasi Metropolis and rural Ahafo-Ano South District in the utilisation of health services, which defy spatial equity in health care. The survey has further shown that there is no significant difference in health status between the two districts, as measured in our survey. The insignificant difference in the samples reflects in their relative impacts on utilisation. Nevertheless, there is need-utilisation discrepancy. Although the Kumasi Metropolis uses health services more than the rural Ahafo-Ano South District, the impact of health status on utilisation is nearly the same for both districts. Differences however remain in utilisation that can be explained by the other variables, i.e., predisposing, enabling and restrictive. The residence variable that was introduced into the model shows that there is a significant difference between the rural and urban district in utilisation. The predisposing factor of education has a considerable impact on health services utilisation in both Kumasi Metropolis and Ahafo-Ano South District, Kumasi Metropolis showing a bigger effect. Health status, the need factor in utilisation, influences health services utilisation in Kumasi Metropolis, but has a weaker effect on Ahafo Ano-South district in the uptake of health services. In the separate stepwise regression for AhafoAno South (data not shown) health status was not entered in the equation. With the Kumasi Metropolis utilising health services more than the Ahafo-Ano South District $37.2 \%$ of respondents utilising them regularly in Kumasi Metropolis whilst $19.0 \%$ utilise them regularly in Ahafo-Ano South District), it may be the case that the richer and/or urban respondents have a lower threshold in what they consider serious ailment that should attract medical attention.

The enabling factor of income exhibits a higher positive coefficient with utilisation in Ahafo-Ano South District. Income has the highest coefficient among all the socio-economic variables. With low-income opportunities in the rural areas, it is the higher income earners who would have 
a little more to spend on areas other than the basic necessities of food, clothing and shelter. The Kumasi situation, regarding income and utilisation, invites a hypothetical explanation that could form a basis for further research. Even though the bivariate correlation shows a positive effect of income on utilisation, the multiple regression results show a rather weak impact of income on utilisation. This might be due to the strong effect of the service cost factor that entered into the equation. There is also a strong relationship between insurance (more prevalent in Kumasi) and service costs: for those who have insurance, service costs are considerably lower.

The restrictive factor of distance has a far greater effect on the Ahafo-Ano South District than the Kumasi Metropolis. The survey has clearly revealed that the distance factor is the greatest barrier to utilisation in the rural areas whilst low education is the greatest impediment to utilisation in the urban district. The Ahafo-Ano South District is a typical rural district in Ghana. Apart from the fact that distances between health facilities are relatively longer, the quality of the roads is rather poor. Policy issues would therefore have to rigorously address the distance factor in the rural district and the education factor in the urban district.

Service cost, which has political connotations, has a greater effect in the Kumasi Metropolis than in the Ahafo-Ano South District. The higher proportion explained variance in the Ahafo Ano South District implies that non-need factors are more important in the rural district than in the urban district and that more policy efforts should be applied in order to improve the accessibility in the rural district. That is visible in the influence of distance. Income influences the rural district more than the urban, implying that it is the wealthy in the rural areas who would access health care. Incidentally, they would also have the capacity to access insurance. The relative unimportance of health status both in Kumasi and Ahafo-Ano south is an indicator of the validity of the original purpose of the Andersen and Newman model. Finally, quality of service shows no significant relationship with utilisation in the Ahafo-Ano South District, but has a positive impact in the Kumasi Metropolis. Quality of service is a function of income. The educated are more likely to seek quality health care, so are high-income earners, and a greater number of such people are in the urban district. The urban environment exhibits quality standard of living, which influences the lifestyle of both the rich and the poor. There is thus an emerging social ecology of quality lifestyle. 
Certain policy issues emanate from the research. First, there is a general low utilisation rate of health services in both the rural and urban districts, with less utilisation in the rural district. This creates the problem of inequity in health care. There must be a programme tailored towards stimulating interest in the utilisation of modern medicine in the rural areas. There must be an education programme involving health personnel, schools, opinion leaders and chiefs who, by virtue of their traditional roles, are very much respected in predominantly traditional societies.

Second, formal education must be emphasised in the urban district at the same time, not neglecting its propagation in the rural district where standards are very low. The government policy of Free Compulsory Universal Basic Education (FCUBE) must be emphasised to get children of school-going age to be in the classrooms. In addition to these, the adult illiterates must also be targeted. Illiterate adults must be taken through the Non-Formal Education programme introduced by the government to make them literate.

Third, in the Ahafo-Ano South District, the distance problem must be rigorously tackled. Health facilities must be within easy reach of the rural settlements. Primary Health Care (PHC) must be emphasised and encouraged, using the right strategies. Whereas it is very difficult, Igiven the ailing Ghanaian economy, with a per capita Gross National Income of three hundred and fifty dollars (\$350) and with a population of $38.8 \%$ living below one dollar ( $\$ 1$ ) a day (World Bank, 2002), to put up more hospitals, primary health care centres could be established within easy reach of the rural settlements. The survey shows that rural respondents are prepared to cover mean distance of 5.2 kilometres and above to receive health care. It is recommended that PHC centres manned by medical assistants or professional clinical and public health nurses, are established within 5-kilometre radii. The management of such facilities must involve the local people, chiefs, assemblymen and unit committee, which are local administrative structures.

Finally, service cost affects both the rural and urban districts. Service cost as a factor in the utilisation of health services has been a bane in the developing countries. The economy of the country is such that it cannot provide free health services for the populace. The most acceptable alternative is to introduce a national health insurance scheme, which has not been implemented yet at the national level. Government is operating 
Mutual Health (Support) Organisations, microinsurance schemes, in some selected districts as pilot projects. There are a few of such pilot projects operating at some rural and urban areas. To financially power the health sector to ensure improvement in basic health care, and to fully implement the national health insurance scheme are recommendations that must be given a serious consideration.

The research has some shortcomings. Need was measured by the frequency of ailments, responses of which might have been flawed by memory problems. This method did not distinguish severity of ailments that might need to be factored into computing health status. This could be the source of the insignificant difference between the health status (need) data set that breached the heterogeneity of the sample. A method that combines severity and frequency of ailments might better reveal health status and better show rural-urban disparity. It is thus recommended that a survey that employs a more pragmatic approach to the health status issue be carried out to establish a possible dichotomy. Despite the shortcomings of the research, given the large volume of credible data, the results are credible enough to establish confidence in the survey.

There was the problem of getting the required number of the aged and those with tertiary education in some settlements, therefore sample targets had to be changed. In the Kumasi Metropolis, the number of university graduates was increased for the Kwame Nkrumah University of Science and Technology in Kumasi where university graduates are concentrated. Second, some respondents had the problem of determining their incomes. Such persons were guided to determine the responses. Third, there was the problem of determining ages, especially for the illiterate. Some were guided to determine their ages using historical landmarks. Without doubt, some ages were mere guesses. Fourth, there were a few missing values, especially with questions that called for memory.

\section{Conclusion}

Predisposing, enabling and restrictive factors have emerged as strong factors influencing utilisation and explaining differences in the health care use between the rural and urban district. This trend of utilisation confirms Andersen-Newman model. Discrepancies however emerge in need-utilisation behaviour between the two districts. Even though the urban district uses health services more than the rural, this difference is not reflected in the relative impacts of health status (need) of the two 
districts on utilisation. It is evident that differences in the predisposing, enabling and restrictive variables explain differences in utilisation between the rural and urban districts more than need in which there is no contrasting difference between them. To ensure rural-urban equity in health care, and effective utilisation of health services in the country, the FCUBE and PHC programmes must be rigorously enforced. 


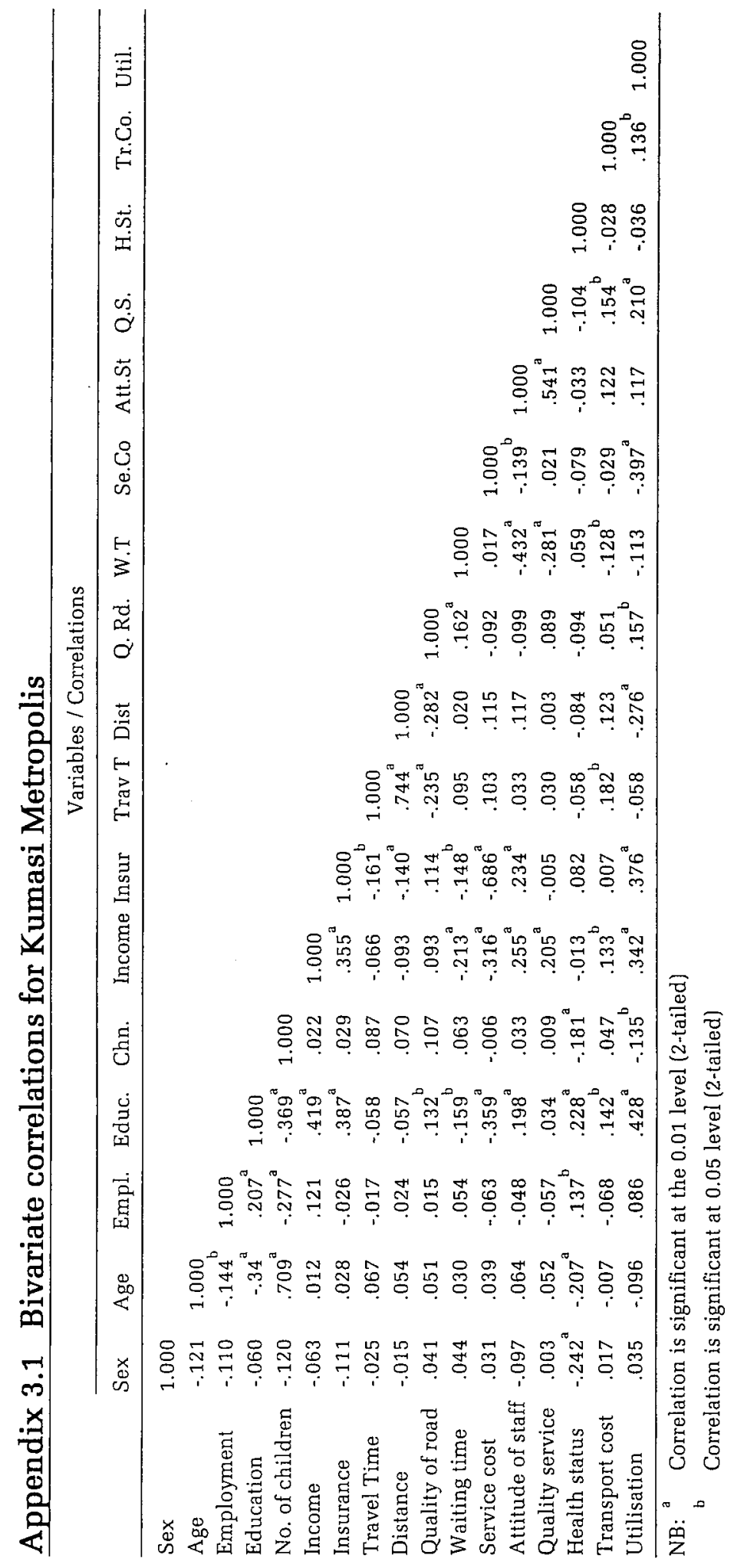




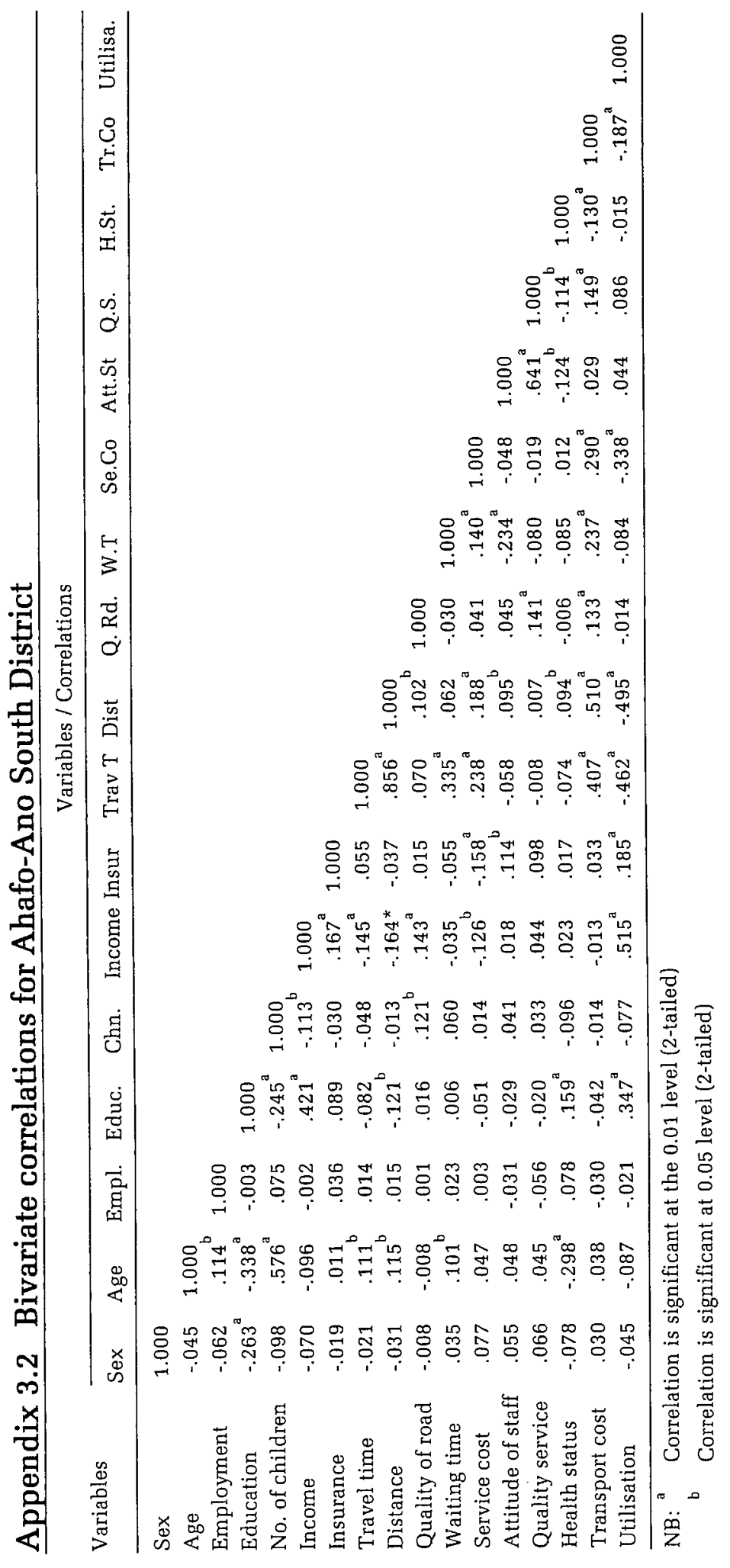




\section{Distance as a predominant factor in the utilisation of health services in the Kumasi Metropolis, Ghana}

This chapter was published as:

Buor D. Distance as a predominant factor in the utilisation of health services in the Kumasi Metropolis, Ghana. Geojournal, 2002; 56(2): 145157. 


\section{Introduction}

This paper is about the relationship between distance and the use of health services in an urban context. Most studies have revealed that distance shows an inverse relationship with the use of health services in both developed and developing countries. Yet, there are no uniform rates of decay as numerous factors have distorted the patterns (Giggs, 1983). These include the size of the facility, catchment area, range of services offered, transport availability, service cost and the nature of the health problem. Indeed, both consumer and facility attributes would interact to produce different reactions from different persons. There is yet the problem of unequal distribution of health facilities between the urban core and the periphery. This would result in patients at the periphery travelling to the core for health care, especially for specialist services. Women, who need specialist services like gynaecological services, would have to travel to the core. In the Kumasi Metropolis in Ghana, the periphery lacks maternal and child health services, so women at the periphery would have to travel to the core where such facilities are available. There is also the factor of social distance in which health care users would prefer attending the facility based on social or ethnic relationships.

In developing countries, with particular reference to Ghana, however, studies have failed to identify confounding factors in distance decay. Moreover, studies have concentrated on distance without efforts to compare with related variables of travel time and transport cost. These two variables correlate with distance, so could be used to confirm the distance factor. Transport cost would increase the overall cost of care in an area where incomes are low and a national health insurance scheme is lacking. Furthermore, in developing countries, not much has been done to compare distance with other factors influencing utilisation. The results of the survey will confirm, or disconfirm otherwise, existing surveys on the behaviour of health care users in urban settings.

It could be argued that the urban areas, due to their geographically contiguity, and their not being as vast as rural districts, do not face the problem of travel to health facilities. Yet, the poor health facilities at the urban margins, and the poor road network that links the urban margins with the urban core where health facilities are concentrated, need not be gainsaid as factors limiting utilisation by residents in such areas. Indeed, accessibility to health facilities in such urban margins could be as poor as in some rural settings. 
Research questions that emerge from the foregoing discussions are fourfold:

1 Does distance exhibit an inverse relationship with utilisation of health services in the metropolis?

2 How does distance compare with the related variables of travel time and transport cost in the utilisation of health services?

3 How does distance compare with physical factors of travel time and quality of road, and demographic and socio-economic factors that influence utilisation?

4 What are the vulnerable groups affected by the distance factor in the utilisation of health services?

The study objectives are basically two-fold. First, to examine how distance compares with other factors that influence utilisation of health services, especially the factors of travel time and transport cost that have direct bearing on distance. The second is to examine the effect of distance on vulnerable groups including women, the aged, the poor, the illiterate, and those with poor health status, i.e. the need factor. It is hoped that this study shall establish a framework and provide the baseline data for studying distance and use of health services in an urban context in Ghana, in particular, and other developing countries in general.

\section{Literature survey}

Not much work has been done on distance and health care use in developing countries since the early part of the last decade of the 20th century. Most works are concentrated in the 1980s and early part of the 1990s. The role of spatial factors in the use of health services can be studied at the aggregate or individual level. The aggregate level emphasises differential regional availability of services, whilst the individual level reflects the local accessibility of health care facilities to individuals whose personal mobility varies (Joseph and Phillips, 1984). In the developing nations, works by Muller et al. (1998); Kinman (1999); Stock (1987); Frederiksen (1964); Wilson (1997); Bailey and Phillips (1990); Stock (1983); Smith (1979); Ganatra and Hirve (1994); Oppong and Hodgson (1994), confirm the great impact of distance on utilisation of health services. In the developing nations, most people will not travel 
more than 5 kilometres to receive basic preventive and curative care (Muller et al., 1998). In a study of the effect of distance from home on attendance at a small rural health centre in Papua New Guinea, he found that attendance decreased markedly with distance. There was a $50 \%$ decrease of the number of patients at a 3.5 kilometre distance.

For women the relationship between distance and utilisation is stronger due to the complications of their reproductive functions. Several studies have shown that women have higher morbidity than men (Anderson and Andersen, 1972; Kohn and White, 1976; Cleary et al., 1982; Verbrugge, 1979). They are therefore more likely to seek more health care than men. This factor strengthens the effect of the distance problem on them. A 1994 World Bank Report indicates that in developing countries lack of transport, especially in remote areas, and poor road conditions can make it extremely difficult for women to reach even relatively nearby facilities. Walking is the primary mode of transportation, even for women in labour (World Bank, 1994). This condition also holds for periurban areas of developing countries. In Malawi, a study found that $90 \%$ of women wanted to deliver in a health care facility, but only $25 \%$ of them did. The most important reason they gave was that, by the time they realised they were in labour; they did not have enough time to get to a health facility (Lule and Ssembataya, 1996).

Campbell et al. (1991) and Carr-Hill and Sheldon (1991) confirmed the hypothesis that access to hospital services, in terms of distance, is a major factor influencing hospital use. Slack et al. (1997) observe that if services are accessible they will be utilised regardless of any notion of higher need for services. A corollary to this notion is that those with limited access to hospital services will have a lower demand for treatment and may consequently suffer a greater unmet need. This situation applies to both developed and developing countries, and to urban and rural settings. Examining the rates of hospitalisation in the East Midland region of England in an attempt to look at the role of deprivation in access to services, Slack et al. (1997) found that both deprivation and travel time are significant influences on hospitalisation rates. Small areas that are more deprived, and closer to the hospitals, are more likely to have higher rates of hospitalisation.

Using focus group discussion, Wilson et al. (1997) found that distance from the hospital was, among others, one of the reasons for poor utilisation of the maternity home at Nsawam, an urban centre in Ghana. 
The Institute of Development Studies (IDS, 1978) showed that in the Jasikan district in Ghana, a rural district, distance decay played a major role in health service utilisation. The report states that, in the Jasikan district, about $3 / 4$ of all registered patients come from within 4 miles and that most people (over $90 \%$ ) living within 4 miles do, in fact, register at a health unit. However, registration drops off quite sharply for those living farther away, and only about $1 / 10$ of the population living more than 6 miles from a health facility appear to be registered at all in Jasikan.

In evaluating health service equity at a primary care clinic in Chilimarca, Bolivia, Kinman (1999) also discovered that, within the targeted service area, usage was concentrated in a few blocks of the community and generally diminished with increasing distance from the clinic. In Nigeria, Stock (1987) found that at a distance of 5 kilometres from a dispensary, per capita utilisation fell to less than one-third of the 0-km rate. An Indian study also showed that the proportion of a community attending a dispensary decreased by $50 \%$ for every additional half-mile between the community and the facility (Frederiksen, 1964).

The geographical distance factor is strengthened by two related factors of transport cost and travel time. A long distance would involve a long travel time, depending upon the nature of road and transport. There is also the concept of transport cost. A longer distance could involve greater cost which has the potential of discouraging utilisation in a povertyendemic region. Meise et al. (1996) saw time distance as a major obstacle to hospital attendance. Acton (1976) concludes in a study of the effects of waiting time on utilisation that the length of time the patient spends in waiting at a physician's office is an important time price that determines utilisation levels. Aday and Andersen (1974) also note that this negative effect on utilisation is greater for rural farm residents because they have been found to have the highest incidence of seeing a physician.

The same could be said about travel time, which is directly related to geographical distance. A greater geographical distance might mean increased travel time, even if factors like traffic and poor roads are controlled for. Exceptions to this rule have been identified in various studies. In a study of locational and population factors in health careseeking behaviours in Savannah, Georgia, Gesler and Meade (1988) observed that though inner-city residents had shorter distances to travel, they might have taken a long time to reach health care. Shannon et al. (1973) made a similar observation in a similar study. Regarding cost of 
movement, Garner (1967) has discovered that the notion of accessibility is closely related to the concept of movement minimisation, especially when this is measured by costs involved in overcoming distance.

The distance factor is ultimately determined by poverty. Among the factors that affect utilisation of health services in the developing countries, poverty is predominant (Habib and Vaughan, 1986; Chernischovsky and Mesook, 1986; Pickett and Hanlon, 1990; Ensor and Pham-Bich-San, 1996; Delanyo et al., 1990). The monetary factor in health service use is about the most important, and the cost of movement that is determined by distance comes into a sharp focus.

Some factors interfere with distance-decay. These include socioeconomic status (Bailey and Phillips, 1990), quality of care provided, the nature of the illness and the affective behaviour of medical staff. In rural Nigeria for instance, Stock (1983) found that, people are willing to travel farther for more specialised services, or better quality care. The same could apply to urban centres. This factor of specialist services brings in disparity between men and women in their relationship with distance decay. The fact has been noted that women need health services more than men. Because of their childbearing role and the complications associated with it, women require specialist services. They would therefore be compelled to travel long distances to seek specialist services. This would apply to those living at the urban periphery where such facilities are normally lacking.

The quality of care provided can also alter the distance-decay mechanism. Smith (1979) in a similar study further confirms that, the decline in the use of health services with increasing distance to the health facility will vary in relation to the type of services offered. In the study area, in order to seek specialist services, patients may like to move to the Komfo Anokye Teaching Hospital, which is at the centre of the metropolis, from the periphery, or from the core to a peripheral hospital like the Aninwaah Medical Centre (figure 4.1) where certain specialist services are offered.

Distance decay may also be altered by the urgency of the service and by socio-cultural relationships. In a study on male bias in health care utilisation for under-fives in a rural community in Western India, Ganatra and Hirve (1994) found that parents were willing to travel greater distance to seek medical treatment for their sons, but would not for their 
daughters? The effect of distance can be enhanced or reduced by the nature of symptoms and illness suffered by patients (Girt, 1973). By implication, the stimulus to attend medical services will vary greatly between a non-urgent and an emergency visit to day accident and emergency facilities.

Figure 4.1 Distribution of health institutions and settlements in Kumasi Metropolis

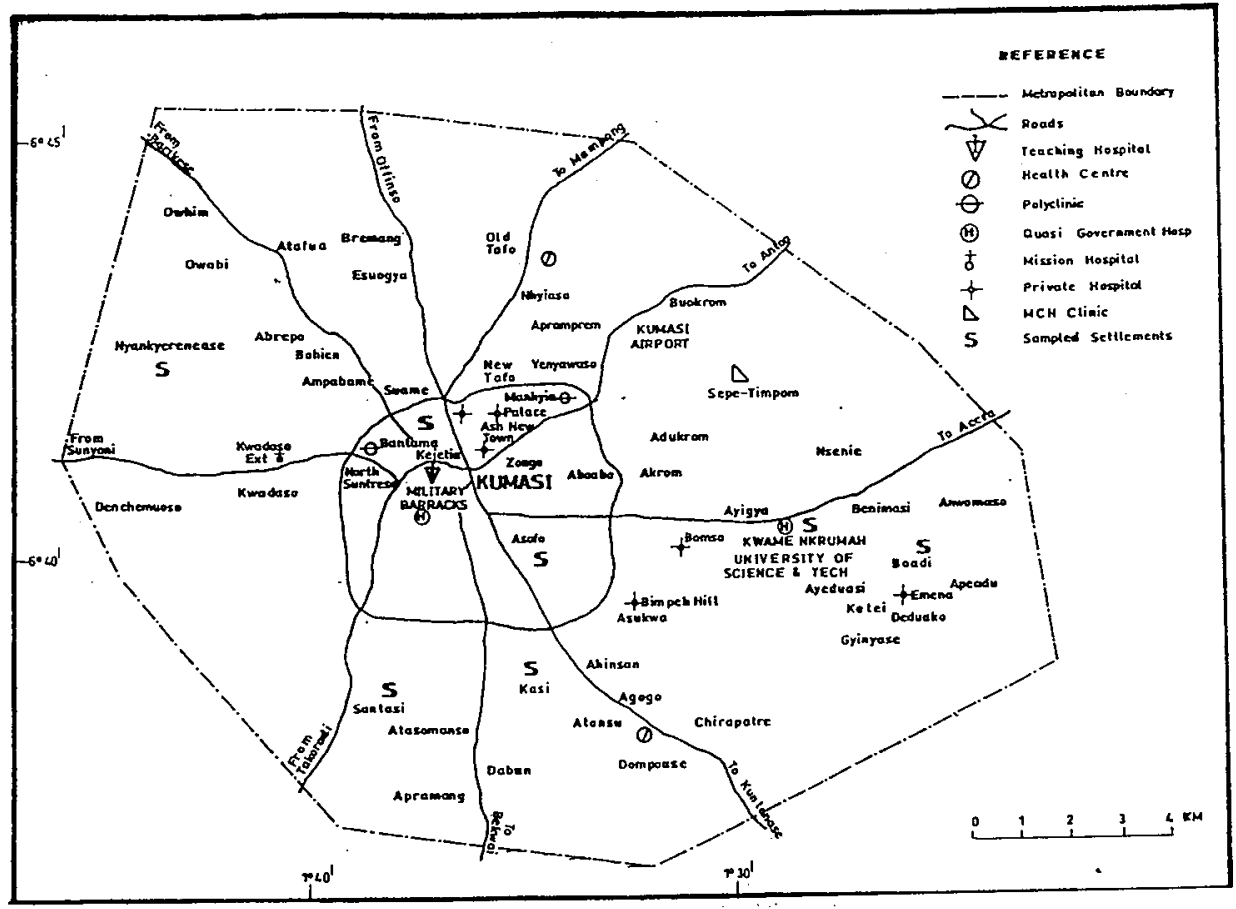

Source: Town and Country Planning Department and Ministry of Health, 1996

Social distance has also been found to have a significant effect on utilisation, barring the distance obstacle. Hays et al. (1990) observed in a survey of spatial patterns of attendance at general practitioner services in New Zealand that the Maori were less spatially bounded than other members of the sample and patients attended doctors who had been recommended by family and relations. Such recommendations were accorded greater importance than spatial considerations in attendance

In the study area, parents put a premium on their male children, so give them better attention in terms of education and health care. 
patterns. Roghmann and Zastowny (1979) and Morrill (1970) at separate studies confirmed the influence of social distance on utilisation. Gesler and Meade (1988) also observed that people who had lived in an area for a short time might have preferred to visit a doctor or clinic closer to their previous residence. Phillips (1979) shares a similar view.

Distance decay could also be influenced by demography and socioeconomic status. Joseph and Poyner (1982) indicate that both consumer and facility attributes would interact to produce different reactions from different persons. Distance may as a result have very different implications for individuals. Within this context lie educational and wealth status, as well as social distance. A study of Mangere in New Zealand concluded that, whilst distance decay generally influenced the use of health services, higher socio-economic groups were able to consult doctors further away (Burn, 1974). In Ghana the high illiteracy rate is more likely to affect utilisation. Unfortunately the government policy of Free Compulsory Universal Basic Education (FCUBE) is not receiving the desired response. The affective behaviour of medical staff could also affect the distance factor. In Tanzania, a study found that $21 \%$ of women delivered at home because of the rudeness of the health staff even though they thought delivering in a health facility was safer (Biego et al., 1995).

To some medical geographers, distance decay is more an intervening obstacle to health care use other than the major factor influencing its use. Kaliszer and Kidd (1981) for instance found that employment status, parity, and age were more important influences than accessibility, although they felt that greater distances than they examined might play a bigger role.

The literature concentrates on the primary role of distance in utilisation and the factors that affect distance decay. There is a dearth of data on the interrelationships between distance, travel time and transport cost, factors that are functionally related. There is also a dearth of data, especially in developing countries, on the position of distance among the various independent factors influencing utilisation. Finally, the effect of distance on utilisation of health services by vulnerable groups like women, the aged, and the poor has not received attention. These areas need emphasis in a study involving spatial patterns of health care behaviour in developing countries. 


\section{Nature of health services in Ghana}

Ghana practices the pluralistic health system, which is made of three sectors. These are the popular sector, the folk sector, and the professional sector. The popular sector includes all the therapeutic options that people utilise, without consulting either folk healers or medical practitioners. In the folk sector, individuals specialise in forms of healing that are either sacred or secular, or a mixture of the two. The popular and folk sectors tend to dominate, especially in the rural areas.

The professional sector comprises the organised, legally sanctioned healing professions, such as modern Western scientific medicine. It includes not only physicians of various types and specialities, but also the recognised para-medical professions such as nurses, midwives, or physiotherapists. In Ghana, a few medical doctors have entered into the area of folk medicine. A research institution on plant medicine has been established at Mampong Akwapim in the Eastern Region by government. The relationship between folk and professional healers tend to be marked by mutual distrust and suspicion.

The use of scientific health services is influenced largely by perception and social and ethnic relations. Among a significant proportion of the rural and illiterate population, especially among the aging population, there is a perception of the low potency of scientific medicine. The tendency to use traditional herbal medicine, which is sometimes influenced by magic, is strong. Certain diseases are perceived as due to the action of the "gods". In such cases, fetishism is resorted to instead of attending the hospital. Such diseases are considered as 'not-hospitaldiseases'. Social, religious and ethnic biases also influence the use of health services. A patient may be willing to cover a longer distance to attend the hospital manned by a relative, the church he attends or a tribal member.

A problem of the health system in Ghana that influences utilisation is that there is no national health insurance scheme. There are few insurance systems run on local basis though. This problem starves the health sector financially. Government is the main financier of the health system, a factor that has affected development of the system. Saddled with financial crisis, government is unable to provide adequate funds to improve the health system. The proportion of the Gross National Product allocated the health sector in 2000 was $4.7 \%$ (World Bank, 2000). Related to the insurance system is the introduction of the cash and carry system, 
which requires a patient to pay for the services rendered him at the hospital. The introduction of this system in 1985 has caused a substantial drop in utilisation. Service cost is thus a very important factor influencing utilisation.

Finally, the concentration of health facilities in the urban areas seriously affects utilisation in the rural areas. The rural and suburban areas, though, contain more than $60 \%$ of the national population, have less than $40 \%$ of all health facilities. The three most urbanised centres of Accra, Kumasi and Sekondi-Takoradi have more than $60 \%$ of all health facilities in Ghana (Ghana Ministry of Health $[\mathrm{MOH}], 1998$ ). In the Ashanti Region, which is the most populous region, the capital, Kumasi, has more than $34 \%$ of all the health facilities in the region (Ghana $\mathrm{MOH}, 2000$ ). The problem confronting the country in the utilisation of health services are thus poor economy, misguided perception, which is a function of illiteracy, poor allocation of health facilities, and poverty.

\section{Theoretical framework}

General frameworks have been structured for the distance factor in the utilisation of health services. The Andersen-Newman model (1973), which forms the foundation for several frameworks, fail to emphasise the spatial dimensions in utilisation, especially, relating to the urban setting. They emphasise the predisposing-enabling-need (PEN) factors in utilisation, which relate basically to the user. Dutton (1986) introduces structural barriers, which include distance in his framework, but fails to emphasise the aggregate factors in a multidimensional framework. It is a multi-criteria model but does not emphasise the role of distance-decay. Andersen's (1995) most recent work on utilisation only introduces health outcomes. The relationship between health care use and outcomes is very controversial. Besides, the peculiarities of various spatial settings that are related to utilisation have not been critically analysed.

Poland et al. (1990) use bivariate and logit analyses in the study of the ecology of health services utilisation in Grenada. He uses a form of ecological model in his study. The variables did not cut across the entire spectrum of accessibility and socio-economic and demographic factors that influence utilisation. The role of distance therefore could not be clearly deciphered to form a basis for a meaningful framework. Hays et al. (1990) attempted an optimal model, in a holistic framework, in the study of the spatial patterns of attendance at general practitioner services. In this study, very few variables were used in the distance study. Several 
socio-economic and demographic variables were missing from the survey. The literature recognises the major role distance plays in the utilisation of health services, whilst also conceding the impact of certain factors on distance decay. The impact of distance is dictated by human behaviour, which is in turn influenced by socio-economic and demographic backgrounds. In a study like this, a holistic model involving the characteristics of the user, the provider, and restrictive factors of which distance is a part is appropriate. A hypothetical model (figure 4.2) that suits the study, adapted from a combination of the foregoing spatial and behavioural models, has been adapted for the study. It is an interaction of utilisation with provider characteristics, user characteristics and restricttive factors that are a combination of government policy that determines service cost, location and distance coverage.

Figure 4.2 A hypothetical model for the study of distance and use of health services in the Kumasi Metropolis

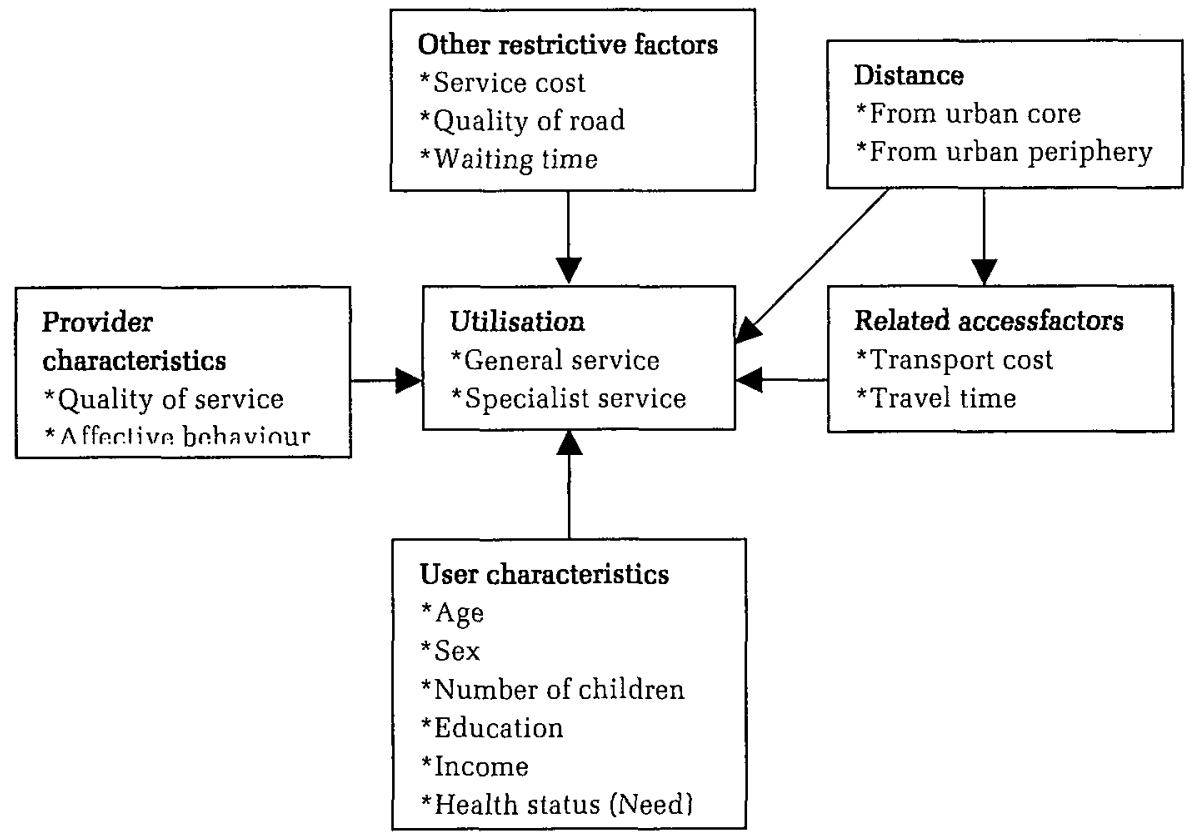

Utilisation is the dependent variable that is determined by the broad independent variables of provider characteristics, user characteristics and restrictive factors, all organised into a user environment. Patients with higher incomes are more likely to use specialist services that are more expensive. The need for a special service would defy distance decay. 
Provider characteristics of quality of service and affective behaviour of medical staff could influence utilisation, irrespective of the distance factor. A patient may be more willing to attend a health facility, which could better serve his needs, and where the staff are well behaved towards him than a nearer facility where he would not get the satisfaction he needs. Distance, either from the core or the periphery, would affect transport cost and travel time, which would influence utilisation. There is no cause-effect relationship here since human behaviour depends upon certain socio-economic backgrounds. Distance could also have a direct effect on utilisation, irrespective of the effects of the interrelated variables. Finally, there are other restrictive variables that could affect utilisation. The survey is guided by the framework. All the variables of the framework need not be reflected in the survey.

The study is based on three hypotheses. First, distance is a predominant factor influencing the use of health services in the metropolis. Second, travel time and transport cost exhibit similar quantitative relationships with distance in the utilisation of health services. Greater distances would mean greater travel times and transport costs. Third, women, the aged, the poor, the illiterate and the sickly are the vulnerable groups that would be more influenced by the distance factor in utilisation.

\section{Data and methods}

The survey is an empirical cross-sectional covering a growing metropolis in Ghana, the Kumasi Metropolis. A sample of 250, representing .02\% of the metropolitan population is used for the study. The sample was drawn from 7 settlements, both core and periphery. The core settlements are Asafo and Bantama, and the peripheral settlements being Boadi, Kaase, Kwame Nkrumah University of Science and Technology, Nyankyerenease and Santase (figure 4.1). The selection was to ensure spatial balance. It also ensured a balance in the distribution of health facilities that are concentrated at the core. The sample sizes are 100 for the urban core settlements, and 150 for the periphery. Stratified and systematic sampling procedures were used for the data collection. The stratification factors are age, sex, education and income. In the selection of the settlements, the level of accessibility to health institutions was considered. Formal interview and questionnaire instruments were respectively applied on the illiterate and literate. Some of the literate preferred the formal interview to avoid the problem of callbacks. 
The selection of houses for locating the respondents was by systematic random sampling, and the selection of the respondents by both simple random and purposive sampling. A balance of the stratification factors was needed; so, where one factor was under-represented, the purposeful procedure was used to ensure a balance. This was a possible source of bias. The other sources of bias were the non-cooperativeness of 10 persons, and the non-response to some of the questions, such as those relating to marital status. These biases would not have a significant impact on the results, since those involved were few.

The independent variables used for the study were distance, travel time, transport cost, quality of road, income, waiting time, quality of service, age, sex, educational status, number of children, insurance status, and health status. Travel time, waiting time, quality of road, and distance constitute the physical factors of accessibility, whilst the other factors could be organised under predisposing, enabling, and need factors, and provider characteristics. Utilisation is the dependent (outcome) variable.

Distance is defined as the distance covered to the health service utilised more regularly whilst travel time in the questionnaire was defined as the time taken to cover the distance by a vehicle from ones' home to the location of the facility. Transport cost as defined in the questionnaire is the cost of movement by a vehicle to and from a hospital, whilst income is the monthly income of a household. For those not earning regular monthly incomes, expenditure was used as proxy. Waiting time is defined as the time spent between the time a respondent arrived at a hospital and the time he is invited to a consulting room to see a doctor.

For quality of service, respondents were asked to indicate their opinion based on indicators like, waiting time, time taken for consultation, laboratory services, affective behaviour of medical staff and availability of drugs. Age is defined as age at the last birthday, whilst educational status is defined as completed educational level. The number of children is explained as the dependents of a respondent. For insurance status, fully insured and partly insured are defined as insured. The partly insured are those who enjoy free medical care from their workplaces. Services for this category do not cover as broad category of services as the fully insured who pay premiums. They nevertheless enjoy free basic services including surgery that is very expensive. Health status is defined in the questionnaire as the number of times a person fell sick. The periodicity of sickness was used as an indicator for assessing health status. Utilisation 
is defined as the number of times a person attended hospital/health centre, the last three times he/she fell sick.

Both nominal and ranked data were used for the variables. Income, distance and age were entered as continuous variables, whilst sex and insurance status were entered as nominal data. Male was given a code 0 and female 1 , and uninsured 0 and insured 1 . Health status, quality of road, quality of service, educational status and utilisation were entered as ranked (ordinal) data. For utilisation, the number of attendances at a hospital or health centre the last three times a respondent fell sick was used as a measure. The ranks were 0-3; 0 being rarely, 1, irregularly, 2 moderately, and 3, regularly. Health status is assessed as the number of times a respondent fell sick. The ranks were 1-5, ranging from 1 for once a week, and 5 being rarely. Quality of service was as determined by respondents, who were guided by factors that determine quality. The ranks were 1-4, ranging from 1 for poor, and 4 for very good. Educational status was assessed as the highest level of education attained. Neverbeen-to-school was given a value of 1 , basic education, 2, secondary education 3 , and tertiary education 4 .

Multiple regression is used for the analysis. This is preceded by crosstabulation of distance and the other independent variables. This was to find out whether there were linear relationships between these variables and utilisation. Multiple regression is appropriate for the analysis since the variables are mostly continuous and ranked (ordinal). Bivariate correlations have also been used to show the strength of association between utilisation and distance and other study variables. The stepwise method has been used to eliminate the variables that have no significant effect on utilisation, whilst Kendall's tau-c test has been used to show whether there are significant differences among the sub-variables of age, sex, education, health status and income (at (0.05 probability) and utilisation by distance. Bar graphs were used to show the differences in utilisation among the related variables of distance, travel time and transport cost.

\section{Distribution of the study variables}

The distribution of the study variables is indicated in table 4.1. 
Variables

Values

Age:

Mean

42.10

$\mathrm{SD}$

Sex (\%):

male 40.0

female

60.0

Educational status (\%):

never-been-to-school

29.6

primary

28.0

secondary

28.8

tertiary

13.6

Income per month (द'000s)l\%f:

below 100

100-199

18.2

200-299

12.1

$300-499$

26.7

$500+$

38.5

mean

563947.4

$\mathrm{SD}$

638185.2

SE

40606.8

missing [3]

Health insurance status (\%):

uninsured

72.4

insured

Frequency of sickness (\%):

once a week

once in 2 weeks

once a month

once in 3 months

30.4

rarely

Distance (in km.) l\% f:

less than 3

Status of road (\%):

minor road 
- table 4.1 continued -

Variables

Values

Service cost (in G):

Mean

39622

SD

29337

Transport cost (in e):

Mean

1848

$\mathrm{SD}$

Travel time (in minutes):

Mean

15.9

SD

Waiting time (in minutes):

Mean

124.1

SD

Number of children (mean)

Quality of service (\%):

poor

satisfactory

good

53.0

very good

missing [3]

Utilisation (dependent variable)[\%]:

not at all (rarely)

once (irregularly)

twice (moderately)

always (regularly)

b

The exchange rate was $\$ 1=\not 7000$

Missing numbers are absolute values, not percentages

"Distance was entered as a continuous variable

Source: Based on Field Data, 2001

Greater proportion of the respondents cover less than 3 kilometres to attend hospital ${ }^{2}$, whilst over $5 \%$ cover more than 10 kilometres for health care. Over $73 \%$ cover up to 5 kilometres to seek health care. Major road is the main road network used to access health services. Mean travel time, though low, shows a high SD, meaning a considerable disparity among respondents. Mean waiting time of over 2 hours is quite considerable, whilst the SD of service cost is close to the mean service cost of $\not 39622$

2 Hospital in this context is used to denote health institution patients attend for health care. Hospitals and health centres are the predominant health institutions in the metropolis. 
(\$5.66), indicating a great disparity among respondents in the price paid for health care.

The respondents are predominantly economically active. The sex ratio is a faint reflection of the national sex ratio. Mean income of $\$ 563,947.4$ $(\$ 80.56)$ is below the $S D$, implying marked variation in income. The mean number of children of 3.86 is below the national Total Fertility Rate (TFR) of 4.6 (GSS, 1999). Quality of service is generally good, whilst health insurance status is poor. Only $4 \%$ are fully insured. Utilisation of health services in the metropolis is not generally encouraging. Almost $63 \%$ do not utilise health services regularly. Finally, the health status of the respondents is generally good, with $66 \%$ either rarely falling sick, or falling sick in every 3 months.

\section{Results}

Distance shows a strong inverse relationship with utilisation as indicated by the compound bar graph (figure 4.3). There is relatively a steep distance-utilisation gradient. Utilisation declines as distance increases. The gradient is less steep for travel time whilst transport cost exhibits a positive relationship with utilisation, so has no impact on it (figures 4.4 and 4.5). The bivariate correlations depict similar relationships. Whereas the correlation is -.276 (.01 Sig.) for distance, it is -.058 for travel time and .123 for transport cost. A multiple regression model of utilisation shows a similar relationship (table 4.3).

A multiple regression model was used to show the position of distance among the various factors that influence utilisation. This was found necessary in the formulation of a policy framework. Multiple regression analysis is preceded by correlation analysis (table 4.2). The associations between various variables and utilisation are stronger for educational status, insurance status, service cost and income than for distance. The correlations are significant at 0.01 probability. Education exhibits the highest association of .428 . 


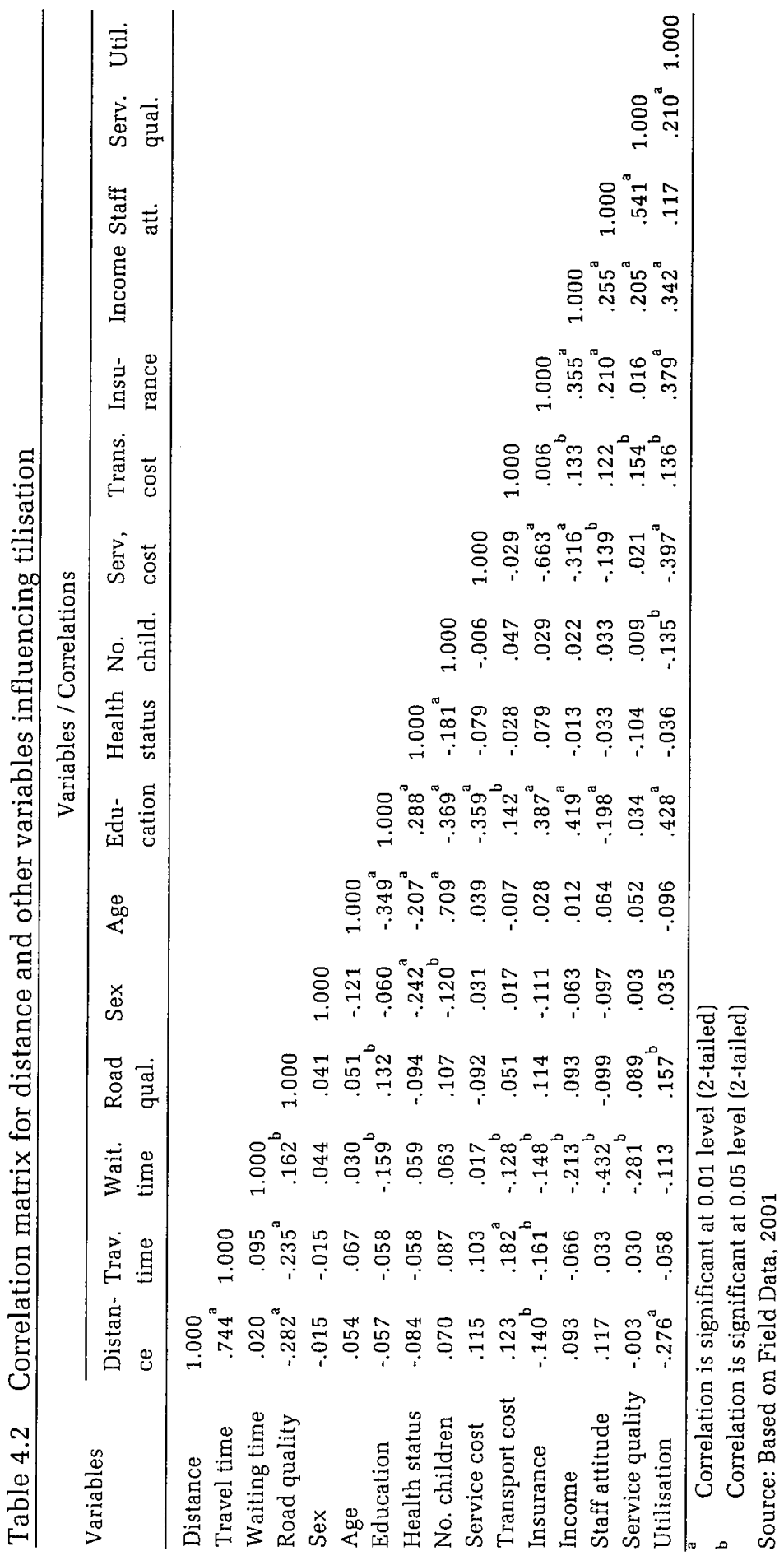


Table 4.3 Multiple regression (stepwise) factors for independent variables

\begin{tabular}{lrrrrr}
\hline Model & Beta coefficients & Significance & $\mathrm{R}$ & $\mathrm{R}^{2}$ & Adjusted $\mathrm{R}^{2}$ \\
\hline 1 Education & .401 & .000 & .401 & .161 & .157 \\
2 Education & .385 & .000 & .531 & .282 & .275 \\
Distance & -.347 & .000 & & & \\
3 Education & .305 & .000 & .572 & .327 & .318 \\
Distance & -.309 & .000 & & & \\
Service cost & -.231 & .001 & & & .343 \\
4 Education & .303 & .000 & .595 & & \\
Distance & -.296 & .000 & & & \\
Service cost & -.239 & .000 & & & \\
Service quality & .168 & .002 & & & \\
& .327 & .000 & .605 & & \\
5 Education & -.291 & .000 & & & \\
Distance & -.241 & .002 & & & \\
Service cost & .156 & .004 & & & \\
Service quality & .109 & .049 & & & \\
Health status & & & &
\end{tabular}

Source: Based on Field Data, 2001

Figure 4.3 Distance and utilisation of health services in Kumasi

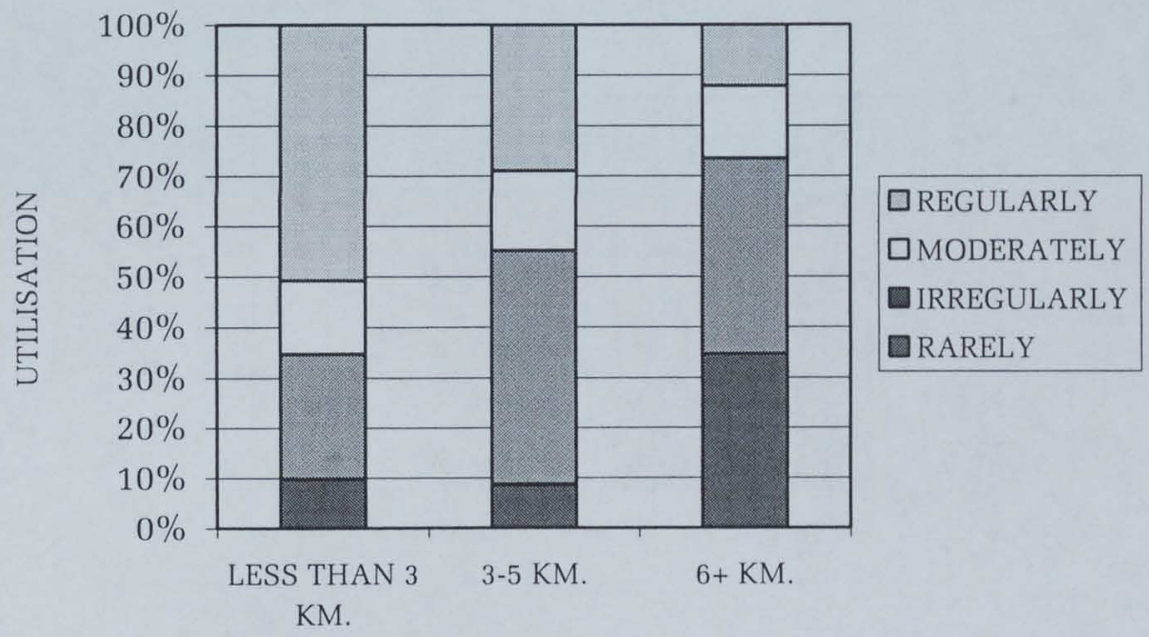

DISTANCE

Source: Based on Field Data, 2001 
Figure 4.4 Travel time and utilisation of health services in Kumasi Metropolis

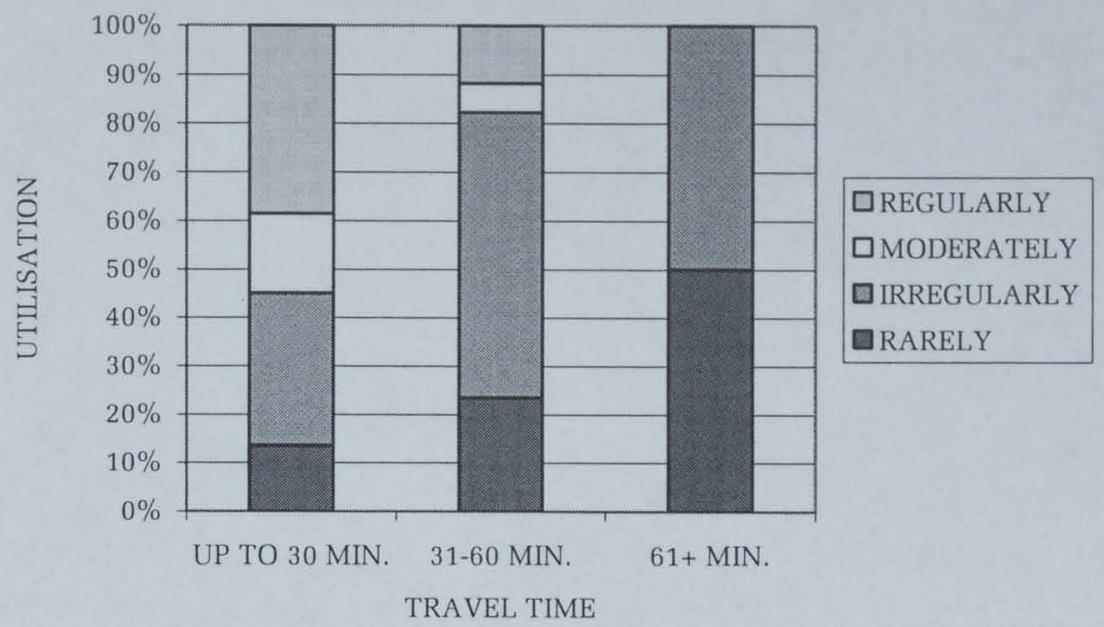

Source: Based on Field Data, 2001

Figure 4.5 Transport cost and utilisation of health services in Kumasi Metropolis

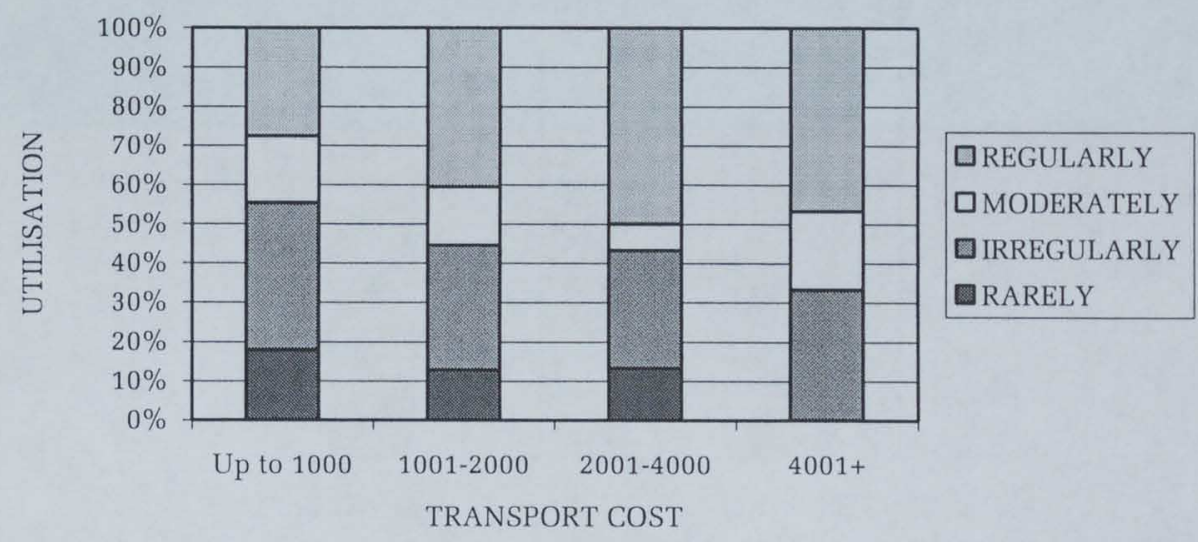

Source: Based on Field Data, 2001 
The Regression coefficients are indicated in table 4.3. Travel time and number of children were eliminated because of their strong association with other variables to avoid the problem of multicollinearity. Whereas the correlation between travel time and distance is .744, that between number of children and age is .709. Distance was retained because it is the theme of study and assumes a great importance in the analysis of utilisation of health services in developing countries, whilst number of children was eliminated in favour of age because age is a strong predisposing factor in utilisation.

The stepwise method was used as a means of confirming the position of distance and the other factors in explaining utilisation behaviour. The results are indicated in table 4.3. Five variables are identified as being significant predictors. These are education, distance, service cost, quality of service and health status, following an order of importance. Distance shows an inverse relationship with utilisation of health services at a high probability of .000 at a coefficient of -.291 . The coefficient is however lower than education, which has a coefficient of .327. The implication is that, education is the only variable that exceeds distance in explaining the greater proportion of utilisation. Distance thus occupies a significant position in the utilisation model. The model has a modest adjusted coefficient of determination of .352, a common measure of the goodness of fit of a regression model. Other variables that have a probability of .05 or less, so are significant in explaining the utilisation model alongside distance and education are service cost, service quality and health status. Although the correlation coefficient between income and utilisation of health services is .342, it does not emerge as a significant variable, using stepwise procedure. One reason for this situation is the effect of service cost. If service cost is removed from the variables, income emerges as a significant variable. The other reason may be that, in the metropolis, a good number of the respondents either enjoy full health insurance or receive some subsidy on health costs from their employers. This area requires further research.

For the feasibility of policy initiatives, the relationship between distance and utilisation has been separately analysed by gender, age, literacy, income and health status. Specifically, the study targets vulnerable groups for policy initiatives on the distance problem. The vulnerable groups are women, the aged, the illiterate, the poor, and the sickly. The impact of the distance factor on the vulnerable groups is indicated in tables $4.4-4.8$. 
Table 4.4 Sex and utilisation of health services by distance (\%)

\begin{tabular}{|c|c|c|c|c|c|c|c|c|c|c|c|c|}
\hline \multirow{3}{*}{$\begin{array}{l}\text { Distance in } \\
\mathrm{km} \text {. }\end{array}$} & \multicolumn{12}{|c|}{ Sex / Utilisation (\%) } \\
\hline & \multicolumn{4}{|c|}{ Male } & \multicolumn{4}{|c|}{ Female } & \multicolumn{4}{|c|}{ Total } \\
\hline & 0 & 1 & 2 & 3 & 0 & 1 & 2 & 3 & 0 & 1 & 2 & 3 \\
\hline Less than 3 & 11.5 & 25.0 & 5.8 & 57.7 & 8.8 & 25.0 & 20.0 & 46.3 & 9.8 & 25.0 & 14.4 & 50.8 \\
\hline $3-5$ & 11.1 & 48.1 & 11.1 & 29.6 & 7.1 & 45.2 & 19.0 & 28.6 & 8.7 & 46.4 & 15.9 & 29.0 \\
\hline $6+$ & 42.9 & 38.1 & 9.5 & 9.5 & 28.6 & 39.3 & 17.9 & 14.3 & 34.7 & 38.8 & 14.3 & 12.2 \\
\hline
\end{tabular}

Source: Based on Field Data, 2001

NB: Codes for utilisation: $0=$ rarely; $1=$ irregularly; $2=$ moderately; $3=$ regularly

Table 4.5 Age and utilisation of health services by distance

\begin{tabular}{|c|c|c|c|c|c|c|c|c|c|c|c|c|}
\hline \multirow{3}{*}{$\begin{array}{l}\text { Distance in } \\
\mathrm{km} \text {. }\end{array}$} & \multicolumn{12}{|c|}{ Age / Utilisation (\%) } \\
\hline & \multicolumn{4}{|c|}{$18-59$} & \multicolumn{4}{|c|}{$60+$} & \multicolumn{4}{|c|}{ Total } \\
\hline & 0 & 1 & 2 & 3 & 0 & 1 & 2 & 3 & 0 & 1 & 2 & 3 \\
\hline Less than 3 & 6.4 & 24.8 & 14.7 & 54.1 & 26.1 & 26.1 & 13.0 & 34.8 & 9.8 & 25.0 & 14.4 & 50.8 \\
\hline $3-5$ & 5.6 & 48.1 & 16.7 & 29.6 & 20.0 & 40.0 & 13.3 & 26.7 & 8.7 & 46.4 & 15.9 & 29.0 \\
\hline $6+$ & 11.0 & 42.1 & 13.2 & 15.8 & 54.5 & 27.3 & 18.2 & 0.0 & 34.7 & 38.8 & 14.3 & 12.2 \\
\hline
\end{tabular}

Table 4.7 Literacy and utilisation of health services by distance

\begin{tabular}{|c|c|c|c|c|c|c|c|c|c|c|c|c|}
\hline \multirow{3}{*}{$\begin{array}{l}\text { Distance in } \\
\mathrm{km} \text {. }\end{array}$} & \multicolumn{12}{|c|}{ Literacy / Utilisation (\%) } \\
\hline & \multicolumn{4}{|c|}{ Illiterate } & \multicolumn{4}{|c|}{ Literate } & \multicolumn{4}{|c|}{ Total sub-sample } \\
\hline & 0 & 1 & 2 & 3 & 0 & 1 & 2 & 3 & 0 & 1 & 2 & 3 \\
\hline Less than 3 & 25.0 & 32.5 & 17.5 & 25.0 & 3.3 & 21.7 & 13.0 & 62.0 & 9.8 & 25.0 & 14.4 & 50.8 \\
\hline $3-5$ & 23.5 & 35.3 & 17.6 & 23.5 & 3.8 & 50.0 & 15.4 & 30.0 & 8.7 & 46.4 & 15.9 & 29.0 \\
\hline $6+$ & 41.2 & 52.9 & 5.9 & 0.0 & 31.3 & 31.3 & 18.8 & 18.8 & 34.7 & 38.8 & 14.3 & 12.2 \\
\hline
\end{tabular}



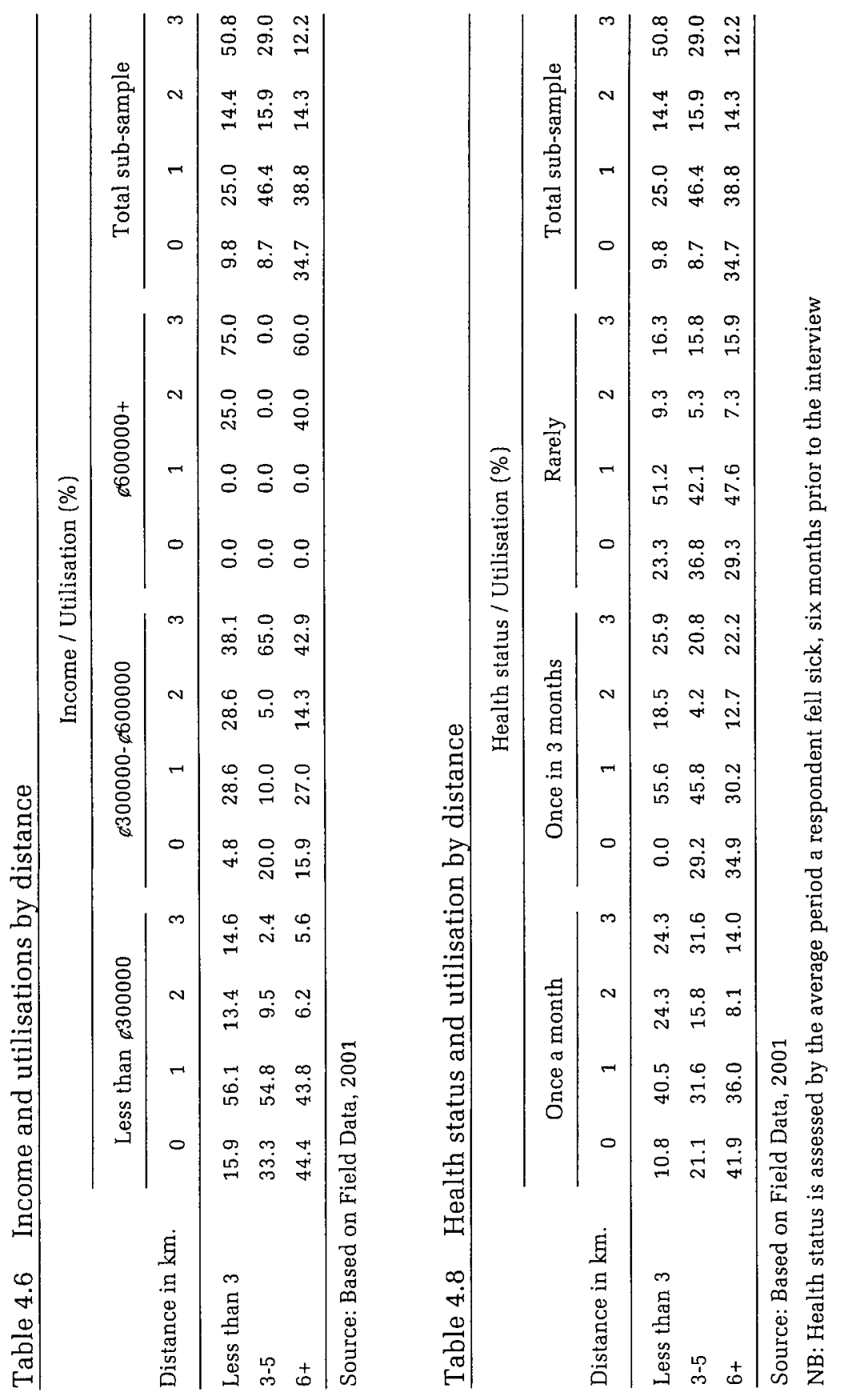
Males are more affected by distance in the utilisation of health services than females, as indicated by the Kendall's tau-c results (table 4.9). The economically active age group, 18-59, is more affected by distance than the aged. Whereas the Kendall's tau-c value for the economically active is -.308 , that for the aged is -.241 . The literate, as indicated by the results, take greater advantage of nearer health facilities than the illiterate. Consequently, the literate are more influenced by distance decay. Whereas the Kendall's tau-c value for the literate is -.347, it is -.205 for the illiterate. An important factor to note in the survey with regard to the vulnerable groups is that, they all, apart from the sickly, utilise health facilities less (table 4.10).

Table 4.9 Kendall's tau-c test results

\begin{tabular}{|c|c|c|}
\hline Variable/sub-variables & Value & Approx. Sig. \\
\hline \multicolumn{3}{|l|}{ Sex: } \\
\hline male & -.354 & .000 \\
\hline female & -.261 & .000 \\
\hline \multicolumn{3}{|l|}{ Health status: } \\
\hline falls sick once a month & -.267 & .005 \\
\hline falls sick once in three months & -.202 & .034 \\
\hline rarely falls sick & -.375 & .000 \\
\hline \multicolumn{3}{|l|}{ Age: } \\
\hline $18-59$ & -.308 & .000 \\
\hline $60+$ & -.241 & .049 \\
\hline \multicolumn{3}{|l|}{ Income: } \\
\hline less than 4300000 & -.192 & .049 \\
\hline $4300000-600000$ & -.356 & .000 \\
\hline $6600000+$ & -.251 & .007 \\
\hline \multicolumn{3}{|l|}{ Literacy: } \\
\hline literate & -.347 & .000 \\
\hline illiterate & -.205 & .024 \\
\hline
\end{tabular}

Source: Based on Field Data, 2001 
Table 4.10 Patterns of utilisation of health services* by socio-economic and demographic variables

\begin{tabular}{llr}
\hline Variables & Sub-groups & Utilisation (\%) \\
\hline Sex & Male & 40.0 \\
& Female & 35.3 \\
Health status & Sick once a month & 37.6 \\
& Sick once in three months & 38.2 \\
& Scarcely gets sick & 36.0 \\
Age & $0-59$ & \\
& $60+$ & 20.4 \\
Income & Less than $\notin 300000$ & 13.6 \\
& $\not 300000-600000$ & 7.7 \\
& $\not 601000+$ & 46.2 \\
Literacy & Illiterate & 66.7 \\
& Literate & 18.9 \\
\end{tabular}

* Utilisation here refers to the proportion of the sub-variable that utilises the services regularly

Source: Based on Field Data, 2001

\section{Discussion}

The survey has clearly revealed that there is an inverse relationship between distance and utilisation of health services in the Kumasi Metropolis. Though with a modest adjusted coefficient of determination of .352, a common measure of the goodness of fit of a regression model, it could be concluded that the model nevertheless has succeeded in giving a clear picture of the predominant position of distance in the utilisation of health services in the metropolis. The respondents tend to use health facilities nearer them, hence, supporting the hypothesis that distance has a negative effect on utilisation. In relative terms, distance is a predominant factor in the use of health services in the metropolis. Most of them use facilities within a 3-kilometre radius. This has been the trend in developing countries. Education however has a stronger relationship with utilisation than distance, whilst the influence of service cost, quality of service, income and health status (need) is significant. In a multiple regression framework (stepwise), transport cost is eliminated as insignificant. It has no influence on utilisation by distance, whilst travel time exhibits a weak negative association with utilisation.

What emerges from the survey is that, distance is the sole physical accessibility variable that influences utilisation, and a very important 
factor among the independent variables that influence utilisation of health services. Since distance is related to transport cost and travel time, it would have been expected that these variables would exhibit inverse relationships with utilisation, as distance does. However, they do not. Travel time shows a weak negative relationship with utilisation. The reason for a weak negative association between travel time and utilisation is that, the metropolis is not very extensive, so it does not take long, as in the rural areas, to reach a health facility.

As regards transport cost, it could be explained that, they are generally low in the metropolis. There has been fuel price stability, a factor that determines transport cost, for almost two years. Transport cost covers a very insignificant proportion of minimum wage, and would not prevent attendance at the hospital. Moreover, in the metropolis, earning power is much greater, so the low cost of transport could be borne by the lowincome earner. The key factor is thus distance.

When comparing distance with other factors, it is clear that it plays a major role. Education is the only factor that assumes a greater significance than distance. Other factors that exhibit significant relationships with utilisation are also factors that affect distance decay. These are education, service cost, service quality, and health status, and these are inter-related. The educated are more likely to have access to high income and insurance that are enabling factors in utilisation. They are also able to take prompt and positive decisions about utilisation, being aware of the implications of ill health. In a hospital where service cost is low, patients may be more prepared to overlook the distance factor and attend. As evident in the survey results, service cost is an important factor in utilisation in the developing countries. Quality of service and health status could also defy distance decay.

The vulnerable groups of women, the aged, the sickly, the illiterate and the poor are not more greatly influenced by the distance factor as was hypothesised. They are influenced less by distance decay than the other groups. Incidentally however, these vulnerable groups, apart from the sickly, utilise health services less. Certain conclusions could be drawn from these results. First, these vulnerable groups generally lack the enabling capacity to utilise health services. This is indicated by the wide disparity between the poor and the rich in the utilisation of health services. It may not be due to distance. The other consideration is that the vulnerable groups may be in need of specialist services that could not be 
within easy reach. In this case the distance decay factor would be of no effect. These areas need further investigation.

The framework could not be fully justified. Transport cost has not been validated by this research as influencing utilisation, though a related variable. Distance, has been found as a very significant factor that influences utilisation. Second, the user characteristics of age and sex do not have an influence on utilisation. Third, affective behaviour of medical staff does not influence utilisation. The survey did not justify certain hypotheses. The first is that transport cost, a factor related to distance, does not show an inverse relationship with utilisation, and the association between travel time and utilisation is weak. The second is that the vulnerable groups of women, the aged, the sickly, the illiterate and the poor are not influenced by the distance decay factor. It has however strongly established the predominant role of distance in the utilisation of health services.

Certain policy implications emerge from the survey. First, since most respondents patronise health services at distances of less than 3 kilometres, the peripheral areas of the metropolis that are starved of health facilities must receive priority attention in the provision of health centres and other health facilities. A 3-kilometre utilisation model is recommended. In this, primary health care centres within 3-kilometre radius that are to be manned by medical assistants is recommended, especially at the periphery that lacks health facilities. Second, since utilisation is generally low in the metropolis in general, and for most vulnerable groups in particular; and since there is such a wide disparity in regular utilisation between low and high-income earners, the introduction of a National Health Insurance Scheme is recommended. Third, access roads from the periphery to the core of the metropolis must be improved, to facilitate movement to the core for specialist services. Finally, since education has come out clearly as the most important factor affecting utilisation, it is recommended that the government policy of Free Compulsory Universal Basic Education (FCUBE) be fully implemented.

\section{Conclusion}

Distance, a predominant factor in health care utilisation, has been found to show a strong inverse relationship with the utilisation of health services in the Kumasi Metropolis. With the metropolitan margins starved of health facilities, and the distance factor being predominant, the danger 
of self-medication is never in doubt. Such a trend negates the principle of equity in health care. The problem of distance is at tandem with the major factors that influence utilisation: education, service cost, quality of health care and health status. Any policies used to address the distance factor should therefore be holistic, involving all such factors. Since the whole problem hinges on finance, a National Health Insurance Scheme and a comprehensive poverty alleviation programme are urgent.

The research has not delved into the health implications of the restrictive factor of distance. What are the implications of the distance factor for health status? What health problems defy the distance factor in the utilisation of health services? It has not justified the influence of distance decay and utilisation by vulnerable groups. Is the principal factor affecting these vulnerable groups lack of financial capacity to utilise health services, a lack of need or the use of non-conventional intervening facilities? These are areas for further research in the entire syndrome of utilisation of health services in urban environments. This paper has provided a broad framework for the study of the relationships between distance and other factors influencing utilisation. Not all the variables have been tested by this survey, though, it is hoped it will serve as a baseline framework allowing other works on distance and utilisation of health services to emerge. 


\section{Analysing the primacy of distance in the utilisation of health services in the Ahafo-Ano South District, Ghana}

This chapter was published as:

Buor D. Analysing the primacy of distance in the utilisation of health services in the Afaho-Ano South District, Ghana. International Journal of Health Planning and Management, 2003; 18: 293-311.

Copyright John Wiley \& Sons Limited. Reproduced with permission. 


\section{Introduction}

The study analyses the role of distance in the utilisation of health services in a predominantly rural district in Ghana. Patients, especially in the rural areas in developing countries, are farther away from health facilities, and this affects their utilisation of health services. In the analysis of distance and utilisation, the composite effects of distance and interrelated factors of travel time and transport cost, have least been analysed. Second, little attention has been given to research to identify the impact of distance on vulnerable groups like the illiterate, poor, aged, females and sickly in the utilisation of health services. Besides, the relative importance of distance among the key factors of utilisation of health services needs to be analysed.

The distance problem cannot be identified in isolation. It interrelates with other utilisation variables of need, predisposing and enabling factors. For instance, how strong would distance decay be if a patient suffers from serious metabolic infections that require specialist service that is located several kilometres away, farther from the immediate health centre that does not have the required facilities? And would a highly educated public officer refuse to attend a health facility because of distance? Will education as a predisposing factor not be relevant here? What about the enabling factors of income and insurance? If a patient sees the need to access health care, which is farther away, and the transport cost is too high due to long distance, will it result in utilisation? And for the one with high income, will a high transport cost discourage him from accessing health care?

A patient with a high income who does not see the need for health care would not access it even if he has to cover one kilometre; whilst the one who appreciates the need for it due to a good level of education would risk raising a loan to access health care if the distance and service cost are such that he has to pay so much for them. It is for such reasons that Joseph and Poyner (1982) might be supported that both consumer and facility attributes interact to produce different reactions from different persons. It thus becomes difficult to settle on the distance factor alone as the most important determinant of utilisation. This calls for a multiple regression approach in examining the role of distance in utilisation of health services.

There is also the issue of relating distance to variables that have some bearings on distance. Most studies have always isolated the distance 
variable without any relationships with other variables or using the multiple regression approach. A study of the role of distance would be more meaningful if it were related to travel time and transport cost. Such relationships would establish the basis for more meaningful conclusions.

\section{Research questions and objectives}

Research questions emerging from the analysis are as follows:

1 Do patients really use health facilities nearer them?

2 What factors are directly related to distance?

3 How does distance compare with other access, demographic and socio-economic factors in determining utilisation?

The objectives that directed the research were to:

1 to compare the accessibility variables of travel time and transport cost with distance in the utilisation of health services;

2 to assess how socio-economic and demographic factors compare with distance in the utilisation of health services;

3 to compare the relative effects of combination of distance and key physical and socio-economic variables on utilisation.

\section{Literature review and background}

In developing countries studies amply show the important role of distance in reducing the use of health facilities, especially in rural areas. Ganatra and Hirve (1994), in a study of male bias in health care utilisation for under-fives in a rural community in western India found that distance was a very important factor affecting utilisation. Ensor and Pham-BichSan (1996) found in a study of access and payment for health care among the poor in northern Vietnam that utilisation reduces with increase in distance. Okafor (1984) in a study of accessibility to General hospitals in Rural Bendel State in Nigeria found that distance was a discouraging factor in utilisation. In a similar study, Okafor (1990), in a survey of the spatial dimensions of accessibility to general hospitals in rural Nigeria concluded that residents from longer distances from a health institution utilised health services less. Muller et al. (1998) carried out a survey on the effects of distance from home to a health centre on attendance at a small rural health centre in Papua New Guinea. Results confirmed other findings that distance decay is an important factor affecting utilisation in rural areas in developing countries. 
The distance problem seriously affects women in the uptake of health services. By virtue of their reproductive functions, women have higher morbidity than men (Verbrugge, 1979; Cleary et al., 1982). They are more likely to seek more frequent health care than their male counterparts. In the deprived rural areas where health facilities are inadequate and access roads are few and in a deplorable state, they face acute distance problems. A 1994 World Bank Report confirms that, in developing countries lack of transport in remote areas, coupled with poor road conditions, make it difficult for women to reach relatively nearby health facilities, and that even women in labour are sometimes compelled to walk to nearby health centres for health care (World Bank, 1994). The same problem holds for ageing men.

The concept of "activity space", which is related to the allocation of health facilities, puts the distance factor into a clearer perspective. In developing countries, health facilities are concentrated in the urban centres to the detriment of the rural areas. In Kenya for instance, it is estimated that only $10 \%$ of doctors serve rural areas. Doctor-topopulation ratios range from $1: 990$ in the cities to $1: 70,000$ in the rural areas (Good, 1987); whilst in the Republic of Korea, there are 91 doctors for every 1,000 inhabitants in the capital city, with only 12 in the rural areas (ILO, 2000). In India, $35 \%$ of rural population receive health care within 2 kilometres, whilst $84 \%$ of those living in urban areas have similar access (Akhtar and Izhar, 1994). Consequently, in rural areas, patients have to travel long distances to receive health care.

Distance decay, which some medical geographers see more an intervening obstacle to health care use other than the major factor influencing it (Kaliszer and Kidd, 1981), is subject to certain limitations. These include the nature of illness, quality of care and social and wealth status, and the relationship of the patient to the physician of health facility (social distance). A very serious health problem would obviate the distance factor if it calls for covering a longer distance to receive health care. In rural Nigeria, patients are prepared to cover long distances to receive specialist services and better quality care (Stock, 1983). In emergency cases, distance may sink into insignificance. A study of male bias in health care for under-fives in a rural community in western India showed that parents were willing to cover greater distances to seek health care for their sons, but would not for their daughters (Ganatra and Hirve, 1994). The decline in the use of health services with increasing distance to the 
health facility will vary in relation to the type of services offered (Smith, 1979).

There is also the concept of social distance whereby patients are comfortable in attending certain health facilities, irrespective of the geographical distance. The preference of traditional medicine over scientific medicine in developing nations has been found to be partly due to its lower social distance, as much as it often is physically more proximate (Gesler and Meade, 1988). The cultural parameters within which people were socialised directly influence their perceptions of the aetiology of particular ailments, and of the most appropriate treatments (Buschkers and Slikkerveer, 1982). Hays et al. (1990) discovered in a survey of spatial patterns of attendance at general practitioner services in New Zealand that the Maori were less spatially bound than other members of the sample and patients attended doctors who had been recommended.

Poverty has been observed as a key factor affecting utilisation of health services (Pham-Bich-San, 1996). Delanyo et al. (1990) in a survey on user satisfaction with health services in government health facilities found that one of the key causes of dissatisfaction is their inability to bear the high cost of service. Related to income is cost of service. The introduction of hospital user charges in the Congo led to a sharp drop in the numbers of even antenatal visits and visits in childcare clinics (Turshen, 1999). Education has also been found to show a positive relationship with the use of health services (Grossman, 1975) and especially education of women. Swenson et al. (1993), examining the factors related to the utilisation of pre-natal care in Vietnam conclude that educated women utilise such services more than the illiterate. A similar study by Raghupathy (1996) on education and the use of maternal health care in Thailand showed clearly the positive impact of education of women on the use of maternal health care. An ILO study carried out in Bolivia, Egypt and Kenya revealed that access of women to maternal and child health services was strongly influenced by their level of education and rural-urban status (ILO, 2000). The important roles of income and education emphasise the role of class in utilisation. Such gender and socio-economic factors, which influence utilisation, could offset the distance factor

Geographical distance closely interrelates two factors: travel time and transport cost. A longer distance would involve higher travel time and 
transport cost. Aday and Andersen (1974), in structuring a framework for access to medical care, found that the negative effect of distance on utilisation of health services is greater for rural residents, who have been found to have the highest need to see a physician. Travel time, for instance, could impede utilisation, especially during the farming season and festive days. With poor roads, which lengthen the time for covering distances to health facilities, rural patients may prefer using intervening health facilities.

Andersen and Newman (1973) structured a three-tier framework of need, predisposing and enabling factors in the analysis of utilisation of health services. In their framework however, they did not introduce restrictive factors such as distance, waiting time, travel time, transport cost, and also the characteristics of the providers, which could reduce utilisation. Aday and Andersen (1974), Dutton (1986), and Andersen (1995), however moved a step further to introduce access and restrictive factors. For a thorough analysis, there is the need to use both models. This study has attempted to use a combination of these models.

The picture in the Ahafo-Ano South (rural) District of Ghana is a reflection of the general scenario of the developing countries. Though the district covers an area of 1,420 square kilometres (Ghana, $\mathrm{MOH}$, Ashanti, 2000, p.4) with a population of 133,632 (GSS, 2002, p.47), it has only 1 public hospital situated at the district capital, Mankranso, 6 health centres, and 3 clinics/maternity homes (figure 5.1). It has no Mission hospital. With only 2 doctors (Ghana, MOH, Ahafo-Ano South, 2000, p.1), the doctor-population ratio in the district is 1:66816.

In Ghana, about $35 \%$ of rural households cover a distance of between 1 and 9 miles to travel to the nearest hospital, whilst over $20 \%$ cover over 30 miles to travel to the nearest hospital (GSS, 1993). In the Ahafo-Ano South District, the road quality is poor. Over $90 \%$ of the roads are untarred. They are characterised by potholes and gullies. Most of the roads are not motorable during the rainy season. The poor nature of the roads brings in its wake high transport cost and long travel times. During emergencies, such as delivery cases, accident cases and comas after protracted diseases, one of the very few vehicles has to be hired to the nearest health centre at charges that are sometimes higher than the hospital fees to be charged. 
The stress of long distance travel, sometimes on foot or over rough roads in vehicles, and the cost involved in long distance movements, could scare away rural illiterate people who are very much used to traditional medicine. The problem of accessibility could induce the use of selfmedication and traditional medicine, with their attendant fatal health risks.

The research is guided by four hypotheses. First, there is a strong inverse relationship between distance and the use of health facilities. Second, distance is interrelated with transport cost and travel time in influencing utilisation. Third, income, and service cost are the other major significant factors influencing utilisation of health services. Fourth, distance has stronger negative effects on the vulnerable groups of illiterate, poor, aged, females and the sickly in influencing the utilisation of health services.

\section{Methods}

\section{The sample and data collection}

The survey was a retrospective, cross-sectional survey covering a deprived rural district in Ghana, the Ahafo-Ano South District. A total sample of 400 drawn from households was used. The stratification factors are age, sex, education, employment and income. The selection of settlements was guided by the status of physical accessibility to health facilities. Selected settlements are Mankranso, Sabronum, Wioso, Mpasaaso, Adukrom, Faamang, Betinko, Aburaso, Nyamebekyere and Kunsu. The selected settlements are fewer where there are health facilities (figure 5.1).

Systematic random sampling was used to select the houses from which respondents were randomly selected from households. The sample interval for selecting the houses was 3 for minor settlements, and 5 for major settlements. The survey covered 1,732 houses. In all, 16 persons, earmarked as respondents, failed to respond to the interview on grounds that they did not see any changes in the quality of their lives by spending time on such interviews. These were the main sources of bias in the data collection. Precision would not be affected since substitutes with similar characteristics were found. The main research instrument was formal face-to-face interview, because most of the respondents were not literate enough to fill the questionnaire. Even among the literate, some opted to be interviewed to avoid the problem of call-backs that would have delayed the survey. 
Figure 5.1 Distribution of health institutions and settlements in AhafoAno South District

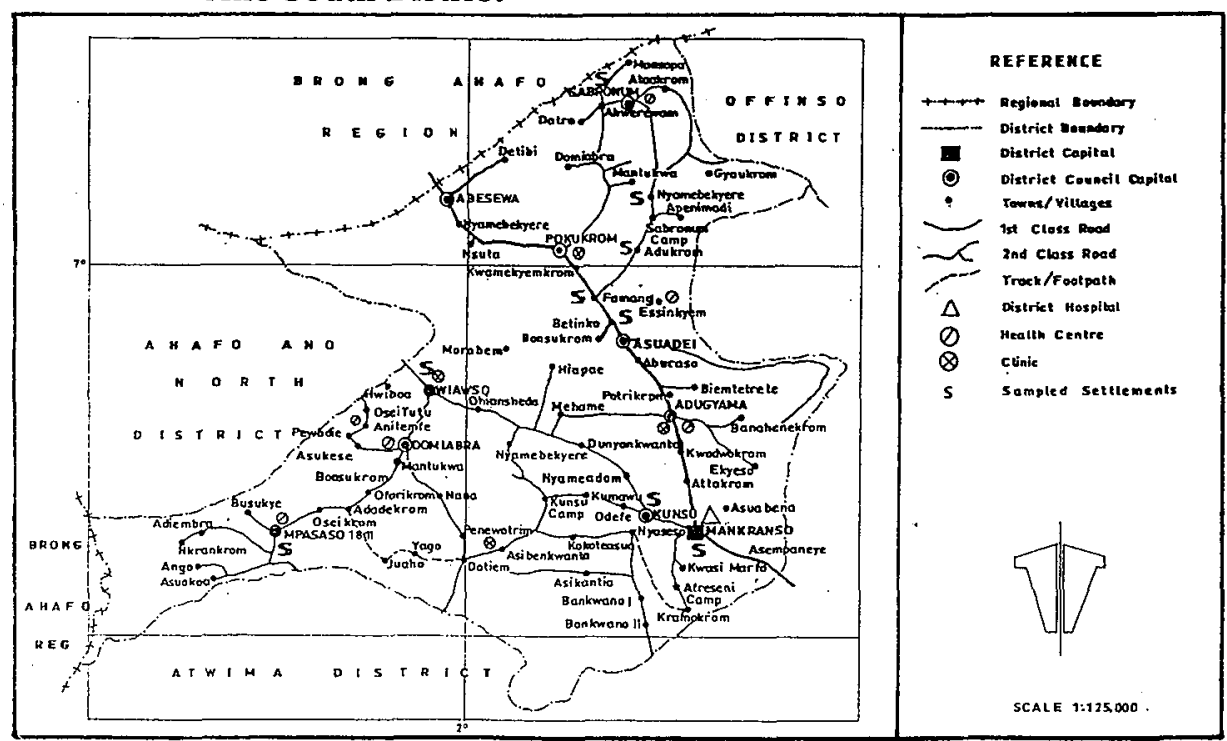

Source: District Assembly and Ministry of Health, Mankranso, 19yb

\section{The variables}

The independent variables used for the survey are distance, travel time, quality of road, service cost, transport cost, income, waiting time, age, sex, educational status, number of children, health status and attitude of medical staff. Quality of service, insurance status, employment and marital status were not included in the variables. In the rural district, it was found through reconnaissance survey that rural residents do not bother much about quality. All they need is to attend hospital or health centre for health care. They generally do not discriminate, perhaps, due to low level of education and low incomes. It was found that quality is more a function of education, which is lower in the rural district. With regard to insurance it was found that the proportion that was insured was rather insignificant. Unemployment is rare in the district. Most of the residents are farmers, and ample land is available for farming. It is thus not a major variable factor. Nor is marital status. Men and women of marriageable age are either legally married or cohabiting.

The independent variables were organised into predisposing, enabling, need and restrictive factors. Health status falls under need; education, number of children, age and sex fall under predisposing factors; income is the enabling factor. The restrictive factors are distance, travel time, waiting time, service cost, transport cost and quality of road. 
The frequency of illness of the respondents is high; hence, the need for health care would be high, depending on perceived need. Education is quite low in the district. Family size in the district is high. A large family size would mean a lower average income in a predominantly poor community. There are however pockets within the community where family sizes are lower, hence the need to include it to measure the differential effects on utilisation. Incomes are generally low. There are, however, some differences in levels of income in the district. Distances to health facilities, involving long travel times, are quite long. Poor access roads would increase travel times, hence impede utilisation. So is waiting time, which is a problem in the only district hospital. Service cost is high, considering the low incomes of respondents.

Utilisation is the dependent (outcome) variable. Utilisation is operationalised as the number of times respondents attended hospital the last three times they experienced illness spells. Quantitative values are assigned for the purpose of data analysis. Non-attendance at a hospital/health centre for the last three illnesses is quantified " 0 " and identified as "rarely", whilst one attendance is quantified " 1 " and defined as "irregularly". Two attendances are quantified " 2 " and defined as "moderately regularly", whilst all three attendances are quantified " 3 " and defined as "regularly". Education was categorised into four levels and quantified 1 to 4 . "Neverbeen-to school" was quantified as 1, "primary education", 2; "secondary education," 3"; and "tertiary education" as 4 . Quality of road was coded as 1 for "minor road", 2 for "secondary road", and 3 for "major road". Health status is defined as the number of times a respondent fell sick within given periods. "Once a week" is quantified as 1 , "once a fortnight", 2; "once a month", 3; "once in three months", 4, and "rarely", 5. All the other independent variables were entered as continuous variables.

\section{Data analysis}

Data were analysed quantitatively using bivariate correlation and multiple regression. Independent variables of distance, travel time, waiting time for a doctor and quality of road were regressed separately on utiliszation to find out the relative relationships. Multiple regression (stepwise) was used to determine the relative strengths of the independent variables on utilisation. Significance was determined by a probability value of less than or equal to 0.05 ( $p \leq .05)$. 


\section{Distribution of health facilities}

The Ahafo-Ano District has only one public hospital, the Mankranso District Hospital, which is not centrally placed (figure 5.1) with regard to road network and distance from the scattered settlements. The status of this hospital is lower than that of the polyclinics in a metropolis. No specialist services are performed, and there are very scanty facilities for laboratory tests. It does not merit the referral point for the rural district, which it was intended to be. There is only one resident doctor who performs general health services. In the district, there are three public and two mission health centres that have limited facilities for laboratory tests. These health centres are taken care of by senior nurses and medical assistants'. In most cases, health problems that are minor (and should have been treated) are referred to Mankranso district hospital, or KATH in Kumasi.

Added to the problem of scanty health facilities are the poor roads linking them to the settlements. Apart from the few settlements on the main trunk road linking Kumasi Metropolis with Sunyani, another regional capital, none of the roads in the district is tarred. They are all minor roads that are not easily accessible during the rainy season. There are few vehicles operating in the district, which makes transport cost relatively expensive. In the event of an emergency, the few transport owners charge exorbitant fares to take patients to the nearby hospital, which is the district hospital. Apart from the Roman Catholic Health Centre at Domeabra (figure 5.1) none of the public and private health centres has a means of transport to transfer patients to the district hospital in case of emergencies. They are provided with motorbikes, which are inconvenient for such a purpose. Worst of all, they can hardly be used during the rainy season. In view of the poor roads and transport facilities, a good proportion of patients in the outlying scattered settlements make their journey to the hospital on foot.

\section{Results}

\section{Characteristics of the sample}

Table 5.1 presents the characteristics of the sample used in the survey. Distance, both geographical and time distance, falls under restrictive factors in the utilisation framework. Mean distance to the nearest health facility is quite high, being 19.7 kilometres, with a high standard

A medical assistant is not a trained doctor. He/she is a senior nurse who has had some additional training in medical care. 
deviation of 19.4 kilometres. Over $47 \%$ of the respondents cover up to 10 kilometres to attend a health facility, and over $47 \%$ cover 16 kilometres and above in a rural area where roads are poor and transport cost high to reach a health facility ${ }^{2}$. With regard to travel time, which is directly linked with distance, although the mean travel time is above 32 minutes, $17 \%$ spend an hour or more travelling to health centres to receive health care.

Table 5.1 Characteristics of respondents

\begin{tabular}{|c|c|}
\hline Variable & Value (valid \%) $\mathrm{N}=400$ \\
\hline \multicolumn{2}{|l|}{ Sex: } \\
\hline male & 40.0 \\
\hline female & 60.0 \\
\hline \multicolumn{2}{|l|}{ Age: } \\
\hline $0-59$ & 79.8 \\
\hline $60+$ & 20.2 \\
\hline \multicolumn{2}{|l|}{ No. of children: } \\
\hline 0 & 12.8 \\
\hline $1-3$ & 32.2 \\
\hline $4-6$ & 33.8 \\
\hline $6+$ & 21.2 \\
\hline missing & 12.5 \\
\hline mean & 4.85 \\
\hline \multicolumn{2}{|l|}{ Educational status: } \\
\hline never-been-to-school & 42.5 \\
\hline basic education & 32.5 \\
\hline secondary education & 24.0 \\
\hline tertiary education & 1.0 \\
\hline missing & 0.3 \\
\hline \multicolumn{2}{|c|}{ Health status (how frequent you fall sick): } \\
\hline once a week & 1.8 \\
\hline once a fortnight & 7.5 \\
\hline once a month & 26.3 \\
\hline once in three months & 28.5 \\
\hline rarely & 36.0 \\
\hline
\end{tabular}

The mean distance respondents are prepared to cover to attend health facilities is $\mathbf{5 . 2}$ kilometres. 
- table 5.1 continued -

Variable

Value (valid \%) $\mathrm{N}=400$

Income per month (in Ghana cedis):

less than $₫ 150,000$

27.1

\&150,000-300,000

56.4

$4300,000-500,000$

11.8

$₫ 500,000-1,000,000$

4.8

missing

.03

mean

[226364.66]

SD

[157003.77]

Distance (in km.):

less than 3

26.6

$3-5$

13.4

6-10

7.3

11-15

5.6

$16+$

47.1

missing

1.3

mean

[19.7]

$\mathrm{SD}$

[19.4]

Waiting time (in minutes):

less than 60

43.7

60-120

39.2

121-180

15.1

181-240

1.0

$241+$

1.0

missing

0.5

mean

[76.0]

SD

[61.5]

Travel time (in minutes):

less than 10

20.6

10-15

19.5

16-30

25.2

$31-60$

17.7

$61+$

17.0

missing

0.5

mean

[32.2]

SD

[29.4]

Service cost (in Ghana cedis):

less than $₫ 30,000$

46.6

\&30,000-50,000

31.3

$450,000-100,000$

21.3 
- table 5.1 continued -

\begin{tabular}{|c|c|}
\hline Variable & Value (valid \%) $N=400$ \\
\hline above 4100,000 & 0.8 \\
\hline missing & 0.3 \\
\hline mean & {$[36634]$} \\
\hline SD & [26022] \\
\hline \multicolumn{2}{|c|}{ Transport cost (in Ghana cedis): } \\
\hline less thanc 500 & 39.5 \\
\hline $4500-1,000$ & 4.0 \\
\hline$\not 1,000-2,000$ & 13.3 \\
\hline $42,000-4,000$ & 12.3 \\
\hline$\notin 4,000-8,000$ & 19.8 \\
\hline$\not 8,000+$ & 11.3 \\
\hline mean & {$[3287]$} \\
\hline $\mathrm{SD}$ & [4321] \\
\hline \multicolumn{2}{|l|}{ Quality of road: } \\
\hline footpath & 3.7 \\
\hline minor Road & 45.0 \\
\hline secondary road & 18.9 \\
\hline major Road & 32.4 \\
\hline \multicolumn{2}{|l|}{ Attitude of staff: } \\
\hline poor & 0.0 \\
\hline satisfactory & 18.8 \\
\hline good & 59.1 \\
\hline very Good & 21.3 \\
\hline missing & 0.3 \\
\hline \multicolumn{2}{|c|}{ Utilisation: } \\
\hline \multicolumn{2}{|c|}{ (Times attended hospital the last three illnesses) } \\
\hline not at all (rarely) & 28.5 \\
\hline once (irregularly) & 41.5 \\
\hline twice (moderately) & 11.0 \\
\hline thrice (regularly) & 19.0 \\
\hline
\end{tabular}

Source: Based on Field Data, 2001

Transport cost, though moderate, could be high for the very poor. The average transport cost of three thousand two hundred and eighty-seven cedis $(43,287)^{3} / \$ 0.40$ is about one-half the daily minimum wage. The high transport cost in some areas is due to the poor nature of roads and

Pesewas, the lowest units of the currency, are without value, so are not used in the medium of exchange. 
inadequate transport facilities. The poor nature of roads, which has a direct effect on distance, could have a significant effect on utilisation. Almost $50 \%$ of respondents traverse minor roads to access health facilities. Service cost is rather high, given the poverty level. The average service cost of over thirty six thousand cedis is worth five days' minimum wage. The attitude of staff is quite good, so is not likely to pose a problem to the use of health care. Income is rather low in the district, evidence of the high level of rural poverty in Ghana. Mean monthly income is two hundred and twenty-six thousand three hundred and sixty-four cedis $(226,364)$, less than about thirty dollars, falling within the poverty level. Health status is not encouraging. Over $35 \%$ of the respondents fall sick once a month, whilst $36 \%$ rarely fall sick. Health services are used irregularly. Only $11 \%$ of respondents utilise health services regularly.

\section{Distance and related variables and utilisation of health services}

Distance, and related variables to it, travel time and transport cost, were related to utilisation to compare the differences (figures 5.2-5.4).

Figure 5.2 Distance and utilisation of health services

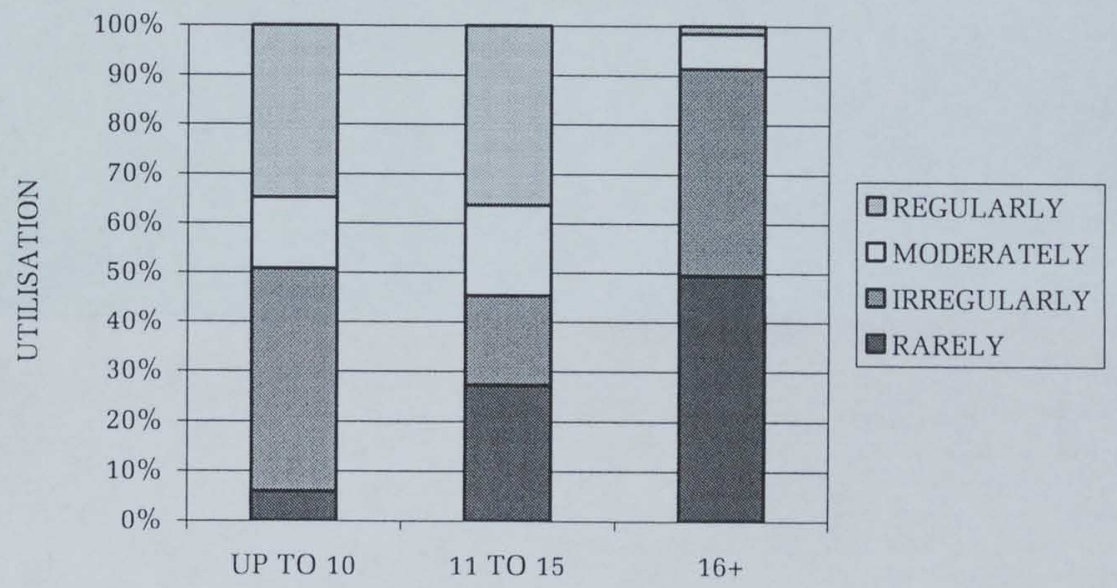

DISTANCE IN KILOMETRES 
Figure 5.3 Travel time and utilisation of health services

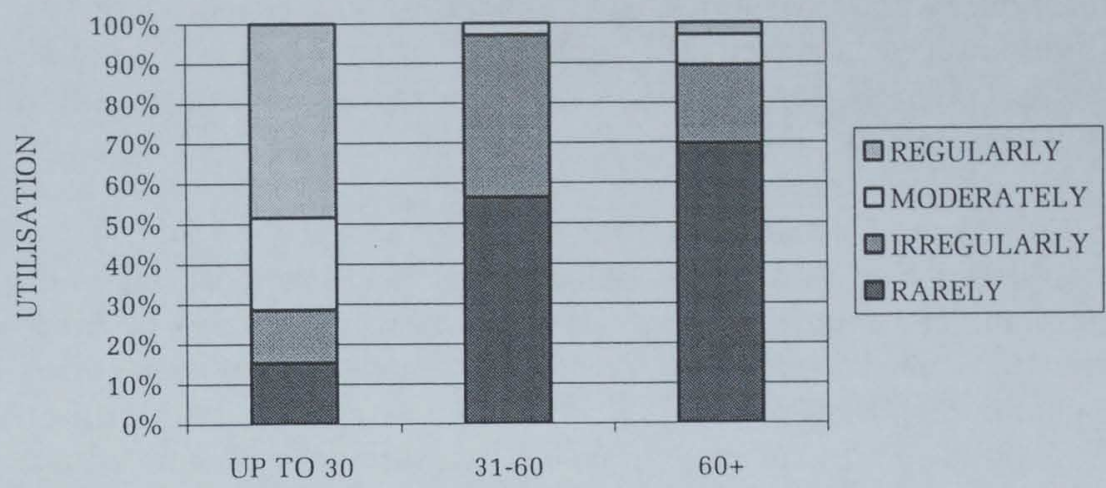

TRAVEL TIME IN MINUTES

Figure 5.4 Transport cost and utilisation of health services

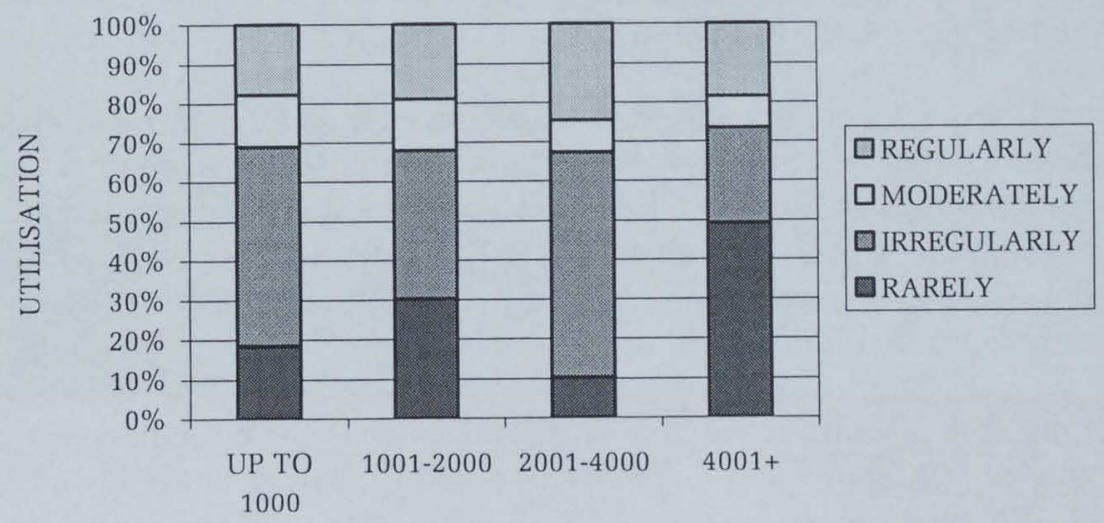

TRANSPORT COST IN CEDIS

There was a strong negative association between distance and travel time on the one hand, and utilisation of health services on the other hand. Longer distances and travel times resulted in lower utilisation. The same could not be said about transport cost and utilisation. The pattern was not consistent. The correlation between distance and travel time, which was as high as .856 , reflected their similar relationship with utilisation. The correlation matrix (Appendix 5.1) showed the association between these related variables and utilisation. Whereas the correlation coefficient 
between distance and utilisation was -.553 , it was -.462 for travel time and -.187 for transport cost. All three showed a negative association with utilisation, with transport cost showing a weaker correlation with utilisation. The distance-utilisation gradient was so steep that the hypothesis that the longer the distance, the shorter the rate of utilisation was clearly demonstrated.

\section{Multiple regression analysis}

Distance was weighted against other factors of utilisation using multiple regression. The multiple regression analysis was preceded by bivariate correlation analysis to see the association between them and utilisation (Appendix 5.1). Distance made the strongest association with utilisation. It was followed by income, travel time, service cost and education following a descending order of importance, at a high probability of 0.01 .

The multiple regression (stepwise) factors for the various variables are indicated in table 5.2. Travel time was removed from the model due to a multi-collinearity problem. The correlation between travel time and distance was .856. Travel time was removed in favour of distance because of the stronger relationship of distance to utilisation.

Apart from distance, the variables that showed a significant relationship with utilisation in order of importance were income, service cost, education, waiting time and transport cost. The adjusted coefficient of determination $\left(\mathrm{R}^{2}\right)$ was as high as 0.541 . The indication is that it is a good model. Income emerged as the second most important variable, apart from distance, that influenced utilisation.

The research also investigated how distance affects the vulnerable groups namely the illiterate, poor, aged, women and the ailing in the utilisation of health services (tables 5.3-5.7). Kendall's tau-c values and their approximate significance are indicated below the sub-variables. The results showed that vulnerable groups of the aged, females and the ailing were more strongly influenced by distance decay, whilst the utilisation of the illiterate and the poor were not differentially influenced by distance decay. 
Table 5.2 Regression coefficients of independent factors on utilisation

\begin{tabular}{lrrr}
\hline Model/variables & Beta coeff. & Sig.( $p$-value) & Adjusted $R^{2}$ \\
\hline 1 Distance & -.572 & .000 & .325 \\
2 Distance & -.496 & .000 & .499 \\
Income & .426 & .000 & \\
3 Distance & & & .515 \\
Income & -.461 & .000 & \\
Service cost & .417 & .000 & \\
& -.136 & .002 & \\
4 Distance & & & .527 \\
Income & -.454 & .000 & \\
Service cost & .354 & .000 & \\
Education & -.137 & .001 & \\
& .133 & .004 & .535 \\
5 Distance & & & \\
Income & -.487 & .000 & \\
Service cost & .334 & .000 & \\
Education & -.140 & .001 & \\
Waiting time & .138 & .003 & \\
& .104 & .014 & \\
Distance & & .541 \\
Income & .536 & .000 & \\
Service cost & .335 & .000 & \\
Education & .156 & .000 & \\
Waiting time & .139 & & \\
Transport cost & .101 & & \\
\hline
\end{tabular}

Source: Based on Field Data, 2001

Table 5.3 Literacy and utilisation of health services by distance

\begin{tabular}{|c|c|c|c|c|c|c|c|c|c|}
\hline \multirow[b]{3}{*}{ Utilisation } & \multicolumn{9}{|c|}{ Literacy / Distance (\%) } \\
\hline & \multicolumn{3}{|c|}{ Literate } & \multicolumn{3}{|c|}{ Illiterate } & \multicolumn{3}{|c|}{ Total } \\
\hline & $\begin{array}{l}\text { Up to } \\
10 \mathrm{~km} .\end{array}$ & $\begin{array}{r}11 \text { to } \\
15 \mathrm{~km} .\end{array}$ & $\begin{array}{l}16+ \\
\mathrm{km}\end{array}$ & $\begin{array}{l}\text { Up to } \\
10 \mathrm{~km} .\end{array}$ & $\begin{array}{r}11 \text { to } \\
15 \mathrm{~km} .\end{array}$ & $\begin{array}{l}16+ \\
\mathrm{km} .\end{array}$ & $\begin{array}{l}\text { Up to } \\
10 \mathrm{~km} .\end{array}$ & $\begin{array}{r}11 \text { to } \\
15 \mathrm{~km} .\end{array}$ & $\begin{array}{l}16+ \\
\mathrm{km} .\end{array}$ \\
\hline 0 & 2.7 & 0.0 & 46.2 & 10.8 & 50.0 & 53.8 & 5.9 & 27.3 & 49.5 \\
\hline 1 & 38.9 & 0.0 & 39.6 & 54.1 & 33.3 & 45.0 & 44.9 & 18.2 & 41.9 \\
\hline 2 & 15.0 & 20.0 & 11.3 & 13.5 & 16.7 & 1.3 & 14.4 & 18.2 & 7.0 \\
\hline 3 & 43.4 & 80.0 & 2.8 & 21.6 & 0.0 & 0.0 & 34.8 & 36.4 & 1.6 \\
\hline $\begin{array}{l}\text { Kendall's tau-c } \\
\text { Approx. Sig. }\end{array}$ & & $-.478 / .000$ & & & $431 / .000$ & & & & \\
\hline
\end{tabular}


Table 5.4 Income and utilisation of health services by distance

\begin{tabular}{|c|c|c|c|c|c|c|c|c|c|c|c|c|}
\hline \multirow[b]{3}{*}{ Utilisation } & \multicolumn{12}{|c|}{ Income / Distance (\%) } \\
\hline & \multicolumn{3}{|c|}{ Less than $\varnothing 300,000$} & \multicolumn{3}{|c|}{$\varnothing 300,000-600,000$} & \multicolumn{3}{|c|}{$6600,000+$} & \multicolumn{3}{|c|}{ Total } \\
\hline & $\begin{array}{l}\text { Up to } \\
10 \mathrm{~km} .\end{array}$ & $\begin{array}{r}11-15 \\
\mathrm{~km} .\end{array}$ & $\begin{array}{l}16+ \\
\mathrm{km} .\end{array}$ & $\begin{array}{l}\text { Up to } \\
10 \mathrm{~km} .\end{array}$ & $\begin{array}{c}11-15 \\
\mathrm{~km} .\end{array}$ & $\begin{array}{l}16+ \\
\mathrm{km} .\end{array}$ & $\begin{array}{l}\text { Up to } \\
10 \mathrm{~km} .\end{array}$ & $\begin{array}{r}11-15 \\
\mathrm{~km} .\end{array}$ & $\begin{array}{l}16+ \\
\mathrm{km} .\end{array}$ & $\begin{array}{l}\text { Up to } \\
10 \mathrm{~km} .\end{array}$ & $\begin{array}{r}11-15 \\
\mathrm{~km} .\end{array}$ & $\begin{array}{l}16+ \\
\mathrm{km}\end{array}$ \\
\hline 0 & 8.3 & 50.0 & 52.7 & 1.6 & 0.0 & 40.0 & 0.0 & 0.0 & 0.0 & 5.9 & 27.3 & 49.5 \\
\hline 1 & 60.3 & 25.0 & 43.2 & 18.0 & 12.5 & 37.1 & 20.0 & 0.0 & 100.0 & 44.9 & 18.2 & 41.9 \\
\hline 2 & 14.9 & 16.7 & 3.4 & 13.1 & 25.0 & 17.1 & 0.0 & 0.0 & 0.0 & 14.4 & 18.2 & 7.0 \\
\hline 3 & 16.5 & 8.3 & 0.7 & 67.2 & 62.5 & 5.7 & 80.0 & 100.0 & 0.0 & 34.8 & 36.4 & 1.6 \\
\hline $\begin{array}{l}\text { Kendall's } \\
\text { tau-c/ } \\
\text { Appr. Sig. }\end{array}$ & \multicolumn{3}{|c|}{$-.410 / .000$} & \multicolumn{3}{|c|}{$-.506 / .000$} & \multicolumn{3}{|c|}{$-.494 / .155$} & & & \\
\hline
\end{tabular}

Table 5.5 Age and utilisation of health services by distance

\begin{tabular}{|c|c|c|c|c|c|c|c|c|c|}
\hline \multirow[b]{3}{*}{ Utilisation } & \multicolumn{9}{|c|}{ Age / Distance (\%) } \\
\hline & \multicolumn{3}{|c|}{$0-59$} & \multicolumn{3}{|c|}{$60+$} & \multicolumn{3}{|c|}{ Total } \\
\hline & $\begin{array}{l}\text { Up to } \\
10 \mathrm{~km} .\end{array}$ & $\begin{array}{l}11 \text { to } \\
15 \mathrm{~km} \text {. }\end{array}$ & $\begin{array}{l}16+ \\
\mathrm{km} .\end{array}$ & $\begin{array}{l}\text { Up to } \\
10 \mathrm{~km} .\end{array}$ & $\begin{array}{l}11 \text { to } \\
15 \mathrm{~km} .\end{array}$ & $\begin{array}{l}16+ \\
\mathrm{km} .\end{array}$ & $\begin{array}{l}\text { Up to } \\
10 \mathrm{~km} .\end{array}$ & $\begin{array}{l}11 \text { to } \\
15 \mathrm{~km} \text {. }\end{array}$ & $\begin{array}{l}16+ \\
\mathrm{km} .\end{array}$ \\
\hline 0 & 5.9 & 23.5 & 44.9 & 5.9 & 40.0 & 38.5 & 5.9 & 27.3 & 49.5 \\
\hline 1 & 44.4 & 17.6 & 44.9 & 47.1 & 20.0 & 37.2 & 44.9 & 18.2 & 41.9 \\
\hline 2 & 14.4 & 11.8 & 8.2 & 14.7 & 40.0 & 10.3 & 14.4 & 18.2 & 7.0 \\
\hline 3 & 35.3 & 47.1 & 2.0 & 32.4 & 0.0 & 14.1 & 34.8 & 36.4 & 1.6 \\
\hline $\begin{array}{l}\text { Kendall's tau-c } \\
\text { Approx. Sig. }\end{array}$ & & $-.434 / .000$ & & & $558 / .000$ & & & & \\
\hline
\end{tabular}

Table 5.6 Sex and utilisation of health services by distance

\begin{tabular}{|c|c|c|c|c|c|c|c|c|c|}
\hline \multirow[b]{3}{*}{ Utilisation } & \multicolumn{9}{|c|}{ Sex / Distance (\%) } \\
\hline & \multicolumn{3}{|c|}{ Male } & \multicolumn{3}{|c|}{ Female } & \multicolumn{3}{|c|}{ Total } \\
\hline & $\begin{array}{l}\text { Up to } \\
10 \mathrm{~km} .\end{array}$ & $\begin{array}{r}11 \text { to } \\
15 \mathrm{~km}\end{array}$ & $\begin{array}{l}16+ \\
\mathrm{km}\end{array}$ & $\begin{array}{l}\text { Up to } \\
10 \mathrm{~km} .\end{array}$ & $\begin{array}{r}11 \text { to } \\
15 \mathrm{~km}\end{array}$ & $\begin{array}{l}16+ \\
\mathrm{km} .\end{array}$ & $\begin{array}{l}\text { Up to } \\
10 \mathrm{~km} .\end{array}$ & $\begin{array}{r}11 \text { to } \\
15 \mathrm{~km}\end{array}$ & $\begin{array}{l}16+ \\
\mathrm{km} .\end{array}$ \\
\hline 0 & 5.4 & 0.0 & 45.9 & 6.2 & 54.5 & 45.9 & 5.9 & 27.3 & 49.5 \\
\hline 1 & 50.0 & 9.1 & 50.0 & 41.6 & 27.3 & 50.0 & 44.9 & 18.2 & 41.9 \\
\hline 2 & 6.8 & 27.3 & 4.1 & 19.5 & 9.1 & 4.1 & 14.4 & 18.2 & 7.0 \\
\hline 3 & 37.8 & 63.6 & 0.0 & 32.7 & 9.1 & 0.0 & 34.8 & 36.4 & 1.6 \\
\hline $\begin{array}{l}\text { Kendall's tau-c/ } \\
\text { Approx. Sig. }\end{array}$ & \multicolumn{3}{|c|}{$-.456 / .000$} & \multicolumn{3}{|c|}{$-.463 / .000$} & & & \\
\hline
\end{tabular}


Table 5.7 Health status and utilisation of health services by distance

\begin{tabular}{|c|c|c|c|c|c|c|c|c|c|c|c|c|}
\hline \multirow[b]{3}{*}{ Utilisation } & \multicolumn{12}{|c|}{ Health status / Distance (\%) } \\
\hline & \multicolumn{3}{|c|}{ Sick every month } & \multicolumn{3}{|c|}{ Sick every 3 months } & \multicolumn{3}{|c|}{ Rarely falls sick } & \multicolumn{3}{|c|}{ Total } \\
\hline & $\begin{array}{l}\text { Up to } \\
10 \mathrm{~km} .\end{array}$ & $\begin{array}{r}11-15 \\
\mathrm{~km} .\end{array}$ & $\begin{array}{l}16+ \\
\mathrm{km} .\end{array}$ & $\begin{array}{l}\text { Up to } \\
10 \mathrm{~km} .\end{array}$ & $\begin{array}{r}11-15 \\
\mathrm{~km} .\end{array}$ & $\begin{array}{l}16+ \\
\mathrm{km} .\end{array}$ & $\begin{array}{l}\text { Up to } \\
10 \mathrm{~km} .\end{array}$ & $\begin{array}{r}11-15 \\
\mathrm{~km} .\end{array}$ & $\begin{array}{l}16+ \\
\mathrm{km} .\end{array}$ & $\begin{array}{l}\text { Up to } \\
10 \mathrm{~km} .\end{array}$ & $\begin{array}{r}11-15 \\
\mathrm{~km} .\end{array}$ & $\begin{array}{l}16+ \\
\mathrm{km}\end{array}$ \\
\hline 0 & 4.7 & 33.3 & 54.4 & 0.0 & 16.7 & 24.1 & 11.9 & 28.6 & 42.6 & 5.9 & 27.3 & 49.5 \\
\hline 1 & 37.5 & 11.1 & 39.7 & 48.2 & 0.0 & 40.2 & 49.3 & 42.9 & 48.5 & 44.9 & 18.2 & 41.9 \\
\hline 2 & 20.3 & 22.2 & 5.9 & 12.5 & 33.3 & 12.5 & 10.4 & 0.0 & 5.9 & 14.4 & 18.2 & 7.0 \\
\hline 3 & 37.5 & 33.3 & 0.0 & 39.3 & 50.0 & 23.2 & 28.4 & 28.6 & 2.9 & 34.8 & 36.4 & 1.6 \\
\hline $\begin{array}{l}\text { Kendall's } \\
\text { tau-c/. } \\
\text { Appr. Sig. }\end{array}$ & \multicolumn{3}{|c|}{$-.532 / .000$} & \multicolumn{3}{|c|}{$-.496 / .000$} & \multicolumn{3}{|c|}{$-.345 / .000$} & & & \\
\hline
\end{tabular}

NB tables $5.3-5.7$ :

Utilisation codes: $0=$ rarely; $1=$ irregularly; $2=$ moderately; $3=$ regularly

Source: Based on Field Data, 2001

\section{Discussion}

The survey has shown the strong negative effect of distance on the utilisation of health services. Of the related variables of transport cost and travel time, it is travel time that showed a very strong correlation with distance and utilisation. The correlation between transport cost and utilisation was weak, implying a low effect of transport cost on utilisation. The low effect of transport cost on utilisation was due to the stabilization of transport fares by the government. Transport fares were not high enough to discourage travels to health centres. The low impact of transport cost on utilisation notwithstanding, the long-term effect need not be discounted, in a fragile economy. With travel time and transport cost strongly interrelated with distance, a policy to address the distance problem would therefore simultaneously address the effects of the other two factors.

Income also showed a strong relationship with utilisation. Service cost had a weaker effect than distance and income on utilisation. Although high income might not necessarily result in utilisation (for spending depends on a person's priorities), a person cannot pay for service cost if he does not have the means. This is truer in a system where there is no national health insurance scheme (sick fund) to ensure easy access to health services. Ability to pay effectively determines the use of health services in the district. The effect of education on utilisation was also significant, although it had a lower beta value than distance and income. Higher education resulted in higher utilisation. 
Distance had no differential effect on utilisation of health services by the illiterate and the poor as indicated by the Kendall's tau-c results. The reason explaining this, with respect to the illiterate, was the frequency and nature of illness. The illiterate fell sick more frequently than the literate. Whereas $5.6 \%$ of the literate fell sick once a fortnight, $14.1 \%$ of the illiterate did, and whereas 41.35 of the literate rarely fell sick, $28.8 \%$ of the illiterate did. The same reason could be assigned to the poor. Since income had a strong impact on utilisation, the explanation of the poor not being influenced more strongly by distance decay than the wealthy is still a puzzle.

The aged, female and sickly were more influenced by distance in the utilisation of health services. The aged may be affected by the stress of long distance travel. The ailing utilizes health facilities nearer them. The stress of long travel and the probability of influence by transport cost are not unlikely. The influence on these vulnerable groups of distance decay has a singular implication of affecting access of specialist health services if the need arises, in a predominantly rural area where such services are not equitably distributed.

The distance factor which strongly influenced utilisation showed a very strong correlation with travel time and this supports the authenticity of the distance factor. Transport cost had no influence on utilisation. This is not a permanent condition, since changes in fuel prices and cost of vehicle maintenance could increase transport fares beyond levels the poor could afford.

Three of the four hypotheses were validated by the research. The hypotheses of a strong inverse relationship between distance and utilisation, the distance factor strongly interrelating with travel time, and the aged, female and the ailing being influenced by distance decay were confirmed by the research. The hypothesis that distance decay has negative effects on the poor and illiterate in utilisation was not justified; whereas service cost and income were found to be the most important factors influencing utilisation, apart from distance. Transport cost was not found to influence utilisation. Distance was proved to be the most important factor influencing utilisation in the rural Ahafo-Ano South District. Nevertheless, the impact of income and service cost on utilisation was identified to be very strong by the multiple regression analysis. The association between travel time and utilisation was less strong than between distance and utilisation; whereas that between transport cost and utilisation was weak. 
Certain measures must be taken to address the distance and utilisation problem. Steps must be taken to address the perennial poverty problem in the rural district to empower the population to purchase health goods. Second, there must be a well-structured programme that ensures that the majority of the population, especially females, have access to formal education. Third, the distance factor must be vigorously addressed. The survey indicated that most respondents were prepared to cover an average distance of 5 kilometres to access health care. It is therefore recommended that, in the short and medium terms, primary health care clinics, with community participation in their running, be established at 5-kilometre intervals where there are no health centres, with senior nurses or medical assistants put in charge. Finally, a national health insurance scheme could help address the imbalance in health service utilisation.

\section{Conclusion}

This survey has clearly demonstrated the impact of distance on the utilisation of health services in a rural district in Ghana. The survey results are a reflection of the situation in several rural districts in developing countries. The distance factor supersedes all other factors, even though income, service cost and education also show significant relationships. Service cost and income factors bring to the fore the effect of poverty on utilisation. The transport cost factor, which is dependent on distance, adds to the financial burden problem in utilisation. Efforts must therefore be made to address the poverty and illiteracy problems of the rural district, whilst locating health facilities within 5-kilometre radius is recommended to reduce the effect of distance. The introduction of PHC clinics at 5-kilometre radii in areas where there are no health centres will not only address the distance problem but also reduce the incidence of disease. Community participation in the administration of the clinics will ensure a remarkable success because the bottom-top approach in local administration has its merits, one of which being the effective supervision of community participation. Finally, efforts must be made to introduce a national health insurance scheme to improve utilisation of health services. 


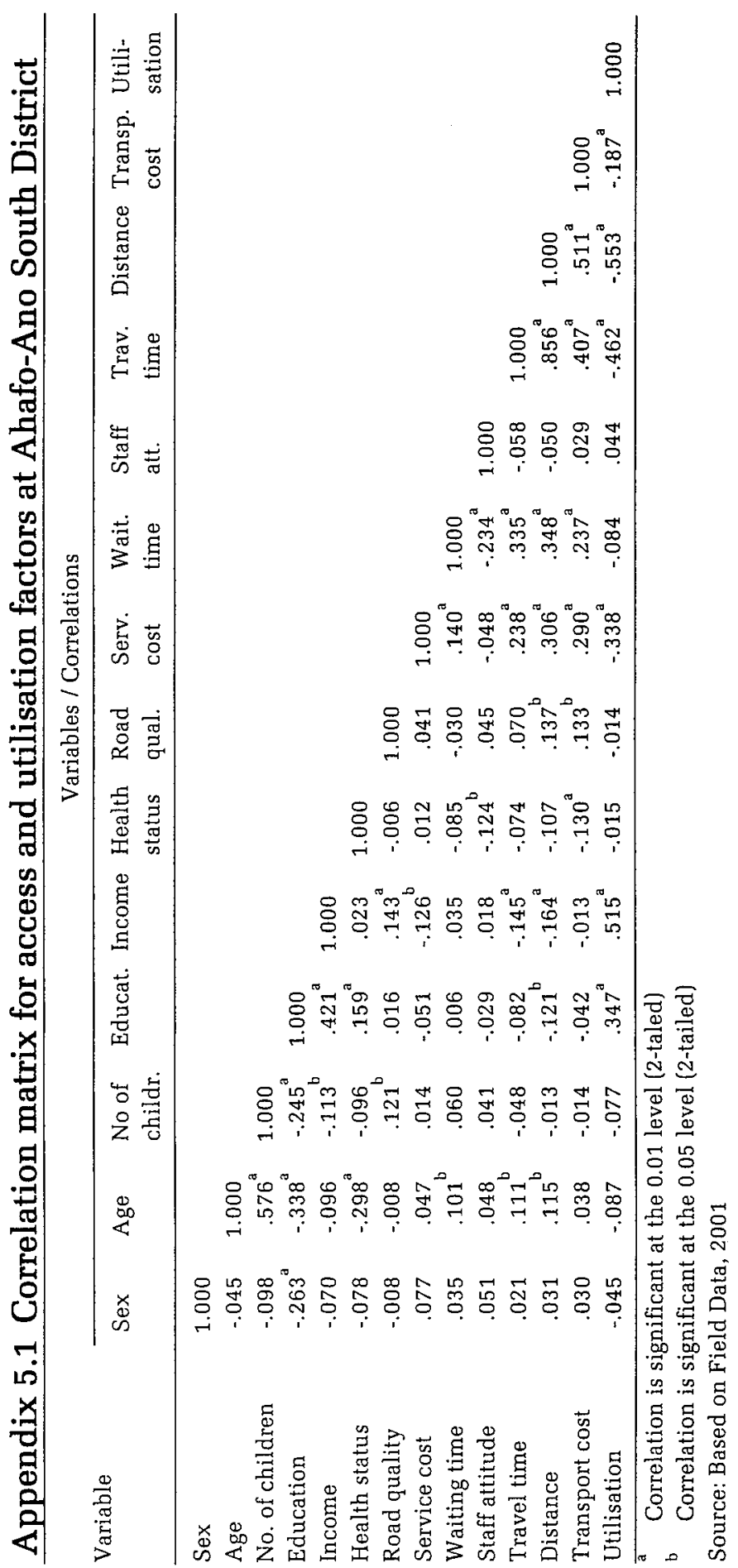




\section{Gender and the utilisation of health services the Ashanti Region, Ghana}

This chapter was published as:

Buor D. Gender and the utilisation of health services in the Ashanti Region, Ghana. Health Policy (in press).

Reprinted with the permission from Elsevier. 


\section{Introduction and background}

This paper addresses the role of gender in the utilisation of health services in the Ashanti Region of Ghana. Generally, utilisation of health services in developing countries is low. The low rate of utilisation is due to, among other factors, long distance to health facilities (Phillips, 1996; Stock, 1987), the unequal distribution of health facilities between the rural and urban areas (Good, 1987), and poverty (Habib et al., 1986; Chernichovsky and Meesook, 1986; Ensor and San, 1996; Pckett and Hanlon, 1990).

Demographic factors also play a meaningful role in the use of health services in developing countries. The demographic factor of sex shows some correlation with the use of health services. In the developing countries, where custom and tradition is predominant, especially in the rural areas such as the area under study, the discrimination by gender is likely to influence utilisation by women. In the study area, women are supposed to be subservient to men who dominate decision-making. Among some of those in which the agrarian occupation is predominant, the man takes custody of the income from farm proceeds. Even among women traders and those engaged in other income-generating activities, the man has access to the women's financial resources. The ability to purchase health resources is thus mostly dependent upon the man. Coupled with the generally low incomes in Ghana, (the percentage of the population below the national poverty line being 31.4 per cent for the rural population) (World Bank, 2000, p.62), utilisation of health services by women especially, will be in serious jeopardy.

Another issue with women's inability to access health facilities is that they are saddled with domestic services such that, the time to attend a health facility to receive health care is limited, unless emergencies arise. They have to take care of the children and ensure that food, water, fuel wood and other needs of the household are available. The time to spare to receive health care is thus a lot of precious time lost, except under cases of emergency.

There is also the issue of formal education, a strong determinant of utilisation of health services, in which the woman is discriminated against. In the study area, as in most other rural communities, the role of the woman, by culture, is basically domestic. Until in recent times when modernisation seems to be gradually penetrating the rural sector, to send a girl to school was considered a waste of time, energy and money. The 
woman is supposed to procreate and take care of the home. Most girls have therefore been denied schooling. The illiteracy factor has effects on utilisation. Education has been identified as a key predisposing factor in the Dutton's (1986) model of utilisation. Other behavioural models identify it as such. To Robinson and Wharrad (2000) female literacy is recognised as a further important variable influencing the use of health services and health outcomes. In Ghana, about $40 \%$ of females above age 15 can neither read nor write. For males, the illiteracy rate is 22 per cent (World Bank, 2000, p.82). With illiteracy come the problems of unemployment, poverty, low assessment of health need, taboos, selfmedication, little or no insurance and increasing use of traditional medicine.

It is thus clear that the men has several advantages over the women in the accessing of health facilities even though women's health needs are more than men, given their reproductive functions that serve as a drain on health. Good found that in India, women consulted Traditional Medical Practitioners (TMPs) the most, and therefore, did not use scientific health services as much. They accounted for 55 to 60 percent of consultations of TMPs (Good, 1987). In a study on women and health care in metropolitan Mumbai in Maharashtra, Nadraj et al. (1998) discovered that women had a higher morbidity rate than men across all the age groups. It was also revealed that there was underutilisation of health services by women both for deliveries and other illnesses (Nadraj et al., 1998).

A few works have however shown that women, especially in the reproductive age group, utilise health services more than men. In a study of the gender gap in primary health care resource in utilisation in Central Asia, Cashin et al. (2002) found that both in absolute and per capita terms, the principal users of primary health care are women of reproductive age and children under five. Women of reproductive age were found to consume approximately 1.5 times the average per capita primary health care resources, while men in the same age group consume approximately one-half of the average (Cashin et al., 2002). The study was however not related to the proportion of women in the reproductive age group needing the services, as compared to men. It could therefore not be said to be scientific. This not withstanding, this trend cannot serve as a basis for concluding gender utilisation patterns since the use of secondary and tertiary services are urgent; especially for women who bear the burden of reproduction, with its attendant fatal health risks. 
Gender disparities have a negative impact on the use of health services. Ojanuga and Gilbert, in a work on women's access to health care in developing countries, established the premise that a myriad of sociocultural factors negatively impinge upon the physical well-being and accessibility of appropriate health care facilities of women (Ojanuga and Gilbert, 1992). Santow holds the position that in developing nations, women's roles affect their use of health services, since health, as a good is allocated, and the men who monopolise family decisions have a strong influence on who should utilise health care (Santow, 1995). Given the physiology of women and the numerous problems that they encounter, especially with gynaecological complications, they must have abundant access to health services. Studies on morbidity and how it relates to utilisation show that adult women report more symptoms than men, who are more likely to use medical care (Briscoe, 1987; Gijsbers Van Wijk et al., 1992). In spite of such health problems faced by women in developing countries, their health needs have largely been neglected (Lane and Meleis, 1991).

Other factors that influence the use of health services by women include education, income, insurance status and place of residence. In developing countries, the education of women influences their use of all types of modern health services (Bhanu, 1994). In a study of the use of health services in the hill villages in central Nepal, Bhanu discovered that educated women used all forms of modern health services. In a study of accessibility, quality of care and prenatal care use in the Philippines, Wong et al. (1987) established that the education of women is associated with increased use of modern prenatal care. In a study of factors related to the utilisation of prenatal care in Vietnam, Swenson, et al. found that the woman's educational level and total number of living children were the most significant predictors of prenatal care utilisation (Swenson et al., 1993). To Robinson and Wharrad (2000) female literacy is recognised as a further important variable influencing the use of health services and health outcomes. In Ghana, however, about $40 \%$ of females above the age of 15 can neither read nor write. For males, the illiteracy rate is 22 per cent (World Bank, 2000, p.82). When these percentages are converted into numbers, it would be realised that the differences are very large.

Poverty is a factor generally considered as a cause of poor utilisation of health services in developing countries. Habib and Vaughan, in a household survey in rural Iraq, found that the use of higher-level government health services and private clinics did increase substantially 
with increasing income (Habib et al., 1986). In a survey of the influence of income, education, and work status on women's well-being, Mead et al. (2001) observed that women living in poverty are less likely than their higher-income counterparts to have health insurance and use preventive services, and more likely to have access problems, suffer from chronic illnesses, and report low overall health scores. In Ghana, most women are homemakers, hence, earn little or no income. Their services are not quantified in monetary terms.

Health insurance is a strong determinant of hospital use in both developed and developing countries (Tilford et al., 1999; Khandker and McCormack, 1999; Fong, 1999; Criel et al., 1999). In a study of the Bwamanda hospital insurance scheme in Zaire (now Democratic Republic of the Congo), Criel et al. found that utilisation increased among insured patients (Criel et al., 1999). Access to health insurance, without doubt, is a function of education, is very low for women, as compared to men.

The other factor of utilisation is the place of residence. Health facilities in developing countries tend to be concentrated in the urban centres; so revealed access by both men and women in the urban centres would tend to be higher. The Metro-Manila region in the Philippines, though contains $25 \%$ of the country's population, has 43 per cent of total hospital beds (Phillips, 1986). In Kenya it is estimated that only 10 per cent of the country's doctors serve rural areas, and that some 70 per cent of all doctors are in urban private practice. Doctor-to-population ratios range from 1:990 in the cities to $1: 70,000$ in the rural areas (Stock, 1987). Since education of women influences their utilisation of health services and the urban areas are centres of educational institutions, utilisation would tend to be higher in the urban centres.

In Ghana, full access to health services is as low as 25 per cent of the total population. The World Bank (1997, p.78) is silent on differences by gender. With discrimination by culture and the relatively low level of education of women, a factor that determines health care use, effective access to health care by women is bound to be lower than their male counterparts. In Ghanaian societies, the authority structure weighs more in favour of the husband who monopolises decision-making (Nukunya, 1992), and such decisions include accessing health care. Within the elite (educated) nuclear family, the pattern of relationship between husband and wife tends to be one of shared roles, greater intimacy and equality (Lloyd, 1966). 
Incomes are generally low in Ghana. The percentage of the population below the national poverty line is 31.4 per cent, and it is 34.3 per cent for rural and 26.7 per cent for urban (World Bank, 2000, p.62). Currently, the daily minimum wage is just above one dollar $\$ 1$. Women are more affected by the income problem, since most of them are homemakers so do not earn real incomes.

Figure 6.1 Kumasi Metropolis and Ahafo-Ano South District in Ashanti Region

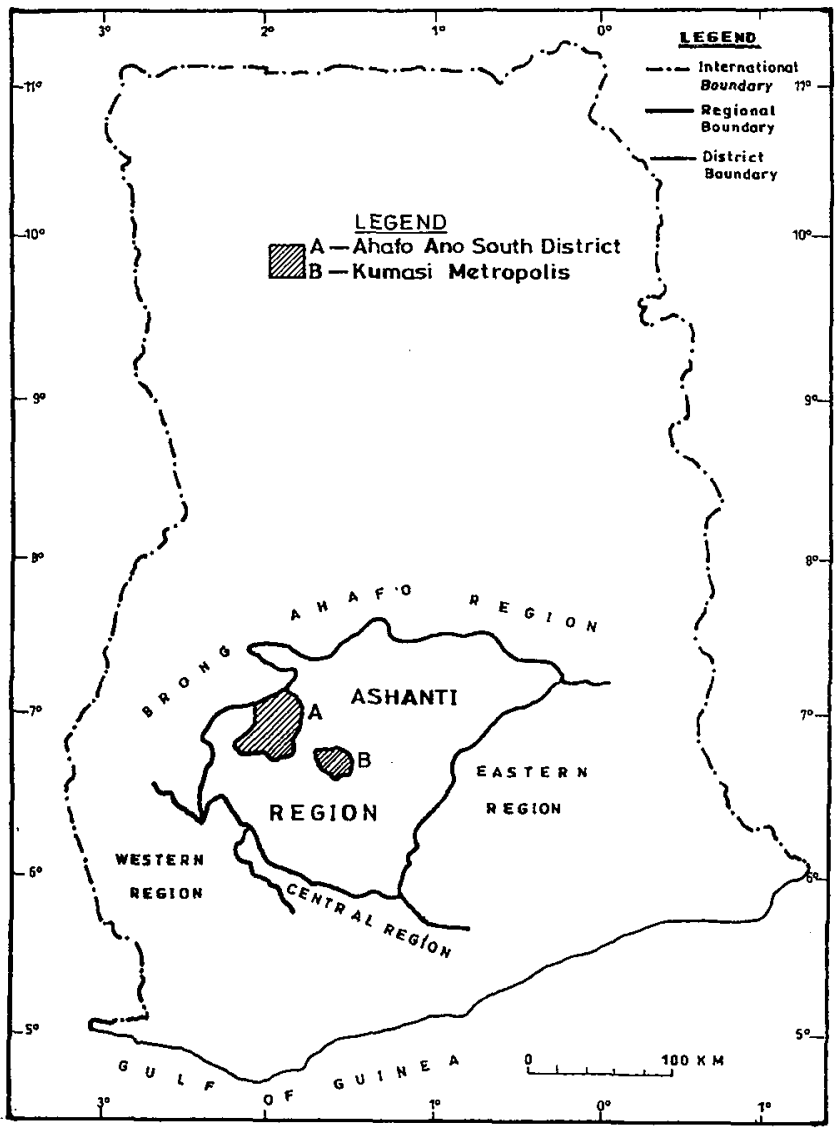

Source: Town and Country Planning Department Kumasi, 1996

The concentration of health facilities is in the urban areas of Ghana that have high-income opportunities and educational facilities that are an advantage in access and use of health services. In Ghana, the two Teaching Hospitals are located in the two main metropolises of Ghana: Accra and Kumasi whilst all the remaining eight Regional hospitals are in 
the regional capitals. The rural areas boast, at best, of rural health centres and a few private hospitals. In the Ashanti Region of Ghana (figure 6.1) that is selected for this study, about $50.6 \%$ of all hospitals are concentrated in the Kumasi Metropolis (Ghana, MOH, 2000), which constitutes less than $33 \%$ of the regional population (GSS, 2002, p.47) and about $1 \%$ of the regional land area (Ghana, $\mathrm{MOH}, 2000$ ).

Given that females are a vulnerable group, by virtue of their reproductive role and complex health conditions, and given that they are responsible for the health care of their children in the Ghanaian culture and lifestyle, there is the need for a thorough investigation into their utilisation patterns of health services, as compared with their male counterparts to establish facts on equity in health care. The bottlenecks to their utilisation must be identified as a basis for structuring a policy framework for utilisation of health services by gender. This paper is basically to structure a model of utilisation of health services by gender using primary data from two districts in Ghana, urban and rural, and by this study, recommend effective intervention measures.

\section{Objectives and hypotheses}

The main objectives of this paper are to evolve a model of utilisation by gender and to recommend effective intervention measures. The specific objectives of this paper are to:

1 examine the male-female differences in the utilisation of health services in the Ashanti Region;

2 examine, in a multivariate framework, the significant factors that influence the utilisation of health services by gender;

3 structure a schematic model of utilisation of health services by gender;

4 recommend proactive intervention measures to remove the bottlenecks in the utilisation of health services by the female population.

The study was guided by three hypotheses. First, women are more likely to be influenced by income, distance, education and service cost in the utilisation of health services. Second, quality of service has a greater effect on males than females. Third, health status has a greater effect on males than females in the utilisation of health services.

\section{Theoretical background}

Whereas a general framework for utilisation of health services has been structured, very little has been done about the utilisation of health services by gender. Most works have centred on Andersen and Newman's 
behavioural, predisposing-enabling-need (PEN) model (Andersen and Newman, 1973) which discussed gender and utilisation under the broad framework of predisposing factors. There have also been quantitative models like Morrill and Earickson (Morril and Earickson, 1968; KonKyun, 1972). Aday and Andersen's input-output model (Aday and Andersen, 1974), and Dutton's model (1986) which addressed physicianuser-provider characteristics as well as structural barriers were all a modification of Andersen-Newman model. Some of the most recent works are by Oppong and Hodgson (1994) and Andersen (1995) and Albizu-Garcia et al. (2001).

Examining the spatial accessibility to health care in a rural district in Ghana, Oppong and Hodgson concentrated on physical accessibility factors primarily, whilst Andersen's new framework only introduces the controversial health outcomes as a factor in utilisation. There is thus a vacuum in the studies in utilisation of health services by gender, that of isolating certain variables for thorough investigation using a multivariate technique, and structuring an explanatory model for the genderutilisation syndrome. Albizu-Garcia et al. examine gender and health services for a mental health problem in Puerto Rico using Andersen's socio-behavioural model. He isolated mental health so did not give a broad coverage of utilisation of health services by gender. For a broader coverage of the problem, Andersen's behavioural model shall combine with physical factors like distance, travel time and waiting time, which constitute restrictive factors of utilisation. This study therefore examines four broad dimensions of utilisation namely, predisposing factors, need factors, enabling factors and restrictive factors.

\section{Methods}

\section{Study design}

This study is a cross-sectional survey covering two districts, Ahafo-Ano South (rural) and Kumasi Metropolis (urban) (figure 6.1), of the eighteen administrative districts in the Ashanti Region of Ghana. The Ahafo-Ano South District and Kumasi Metropolis are respectively representative of rural and urban districts in the Region and the country as a whole. The Ashanti Region from which the two districts were selected is the most cosmopolitan in the country, assembling all classes of people with diverse socio-cultural and economic characteristics. Data for the analyses were collected between August 2000 and February 2001. The predictor and independent variables were obtained during the same period when the raw data were collected. 


\section{Sampling and data collection}

The target population included socio-economic and cultural diversity, made up of individuals of 18 and above. The minimum age of maturity is pegged at 18. At this age, a person is considered as an adult and could exercise his/her franchise. This assumes that an adult shall have completed secondary school and may be entering a tertiary institution; so that this study regards such a person to be independent enough to take decisions on his health needs. A sample of 650 made up of 400 from the rural district, (which, supposedly, has more accessibility and utilisation problems,) and 250 from the urban district was used for the study. With regard to gender, the proportions were 60 per cent for females, who have greater barriers to access to health care but who need health services most. The proportion is a reflection of the lower sex ratio. The samples were thus 390 and 260 for females and males respectively. The respondents were selected from sub-strata including age, income, marital status and educational status from both rural-urban strata. In all, seventeen settlements, 7 from the metropolis and 10 from the rural district were selected for the survey, and 3,108 houses $(1,732$ for the rural district and 1,376 for the urban district) were involved in the sample survey in which the systematic procedure was used for selecting the sample. The selection took into consideration the distribution of health facilities and road network.

Data were collected from households using the questionnaire and formal interview instruments. The formal interview procedure was chosen because of the large illiterate and semi-literate population since there is the advantage of avoiding frequent call-backs. Both open-ended and close-ended questions constituted the questionnaire some of which were ranked for ease of coding and quantitative analysis. There were also a few non-responses, 10 in the metropolis and 16 in the rural district. These could constitute potential sources of bias. Such bias was limited because substitutes of similar characteristics were found. There were a few missing values in the administered questionnaire.

\section{The study variables}

The dependent variable for the study is utilisation of health services, which is operationalised as the number of times a person attended a hospital or health centre to receive health care the last three times he or 
she experienced illness spells ${ }^{1}$. The independent variables are grouped into four categories namely predisposing, enabling, need and restrictive factors. The variables are age, education and employment as predisposing variables; income and health insurance as enabling variables; health status as need variable; and distance, travel time, waiting time, service cost, quality of service, transport cost, and attitude of medical staff as restrictive factors.

Age affects utilisation in the sense that different age groups have peculiar health conditions, and the health conditions for women in the reproductive age group differ from those who have attained menopause. Education has a great impact on utilisation, as revealed by several survey results, especially for women. Income and health insurance, the enabling factors, are very crucial in determining health care use in an economy where poverty is predominant. Distance is an important factor impeding utilisation in developing countries, and this could have an influence on a typical vulnerable group like women. Service cost is about the main factor influencing utilisation in developing countries, and is more likely to influence females who have a lower financial capability than males. A higher transport cost is more likely to affect females who have lower incomes than males. Travel and waiting times are likely to show differences in utilisation by gender due to the stress they generate, whilst the affective behaviour of medical staff could scare utilisation in an area where the need factor is not strong enough to influence utilisation. Women are more unlikely to bear the insults of medical staff than men. Health status, which identifies the need factor, is a key factor in utilisation. This is however subject primarily to the enabling factors.

\section{Statistical analysis}

Data were analysed quantitatively using both continuous and ranked data. Multiple regression was used in the analysis due to the nature of the data. Multiple regression is appropriate for the analysis since the variables are mostly continuous and ranked (ordinal). Variables of sex, employment and insurance which could not be ranked were entered as dichotomous variables. Values (ranked) were assigned to the noncontinuous variables that influence utilisation. Utilisation was ranked from " 0 " for non-attendance of hospital for the last three times a

In the study area, sickness is defined in terms of perceived illness. A person considers himself as sick if his condition is such that he cannot carry out his normal daily duties. Sickness is thus considered as such when severe. A patient thus seeks health care only when his condition is severe. 
respondent experienced sick spells, to " 3 " for attending for all three being respectively identified as rarely, irregularly, moderately and regularly. Health status was assessed by the number of sicknesses experienced within certain intervals. This ranged from "1" for falling sick once a week, to " 5 " for falling sick rarely ${ }^{2}$. Another ranked variable that entered into the regression model was quality of health care, as assessed by respondents. The quantitative codes ranged from " 1 " for poor to "4" for very good. Respondents were guided by the following criteria: regular availability of a doctor; regularity of laboratory services; use of diagnostic facilities; time spent in consultation; availability and quality of drugs, and affective behaviour of medical and paramedical staff.

A multiple regression analysis was preceded by a bivariate correlation matrix to examine the strength of associations between the dependent and independent variables. This was also necessary to find out possible multicollinearity to exclude some variables that exhibit very strong correlation (Anderson et al., 1994). In the regression model, the variables that proved significant at a probability $(p)$ value equal to or less than .05 were selected. Values that were significant, using the stepwise method, were all put in a single regression model to get a common basis for comparison.

\section{Results}

\section{Distribution of the study variables}

The distribution of the study variables is indicated in table 6.1. Males utilise health services more than females who have a weaker health status. The difference is significant. Whereas females utilise health services more rarely, males utilise them more regularly. In the predisposing variables, the level of illiteracy is higher for females than for males, whilst there are far more males than females attaining higher education. The difference of the sexes by age is not significant. Regarding income, males have higher average incomes than females, and also a higher standard deviation for income than females, indicating wide disparities of income among males. Going by the grouped income data however, differences are not significant, whilst a greater percentage of males than females are insured.

Differences by distance, travel time, waiting time, quality of service, transport cost and staff attitude towards patients are not significant. For

2 The assumption is that every health problem reported was severe. 
service cost, even though the difference is not significant, the average is higher for females than males. Females thus pay more for service cost than males. The standard deviation for females is higher than males.

Table 6.1 Distribution of study variables by gender $(\mathrm{N}=650 ; \mathrm{sd}=$ standard deviation)

\begin{tabular}{|c|c|c|c|}
\hline Variable/sub-variable (\%) & Male $(n=260)$ & Female $(n=390)$ & $\chi^{2}$ sig. ( $p$-value) \\
\hline \multicolumn{4}{|l|}{ Predisposing } \\
\hline \multicolumn{4}{|l|}{ Education: } \\
\hline Never-been-to school & 30.8 & 42.1 & \multirow{4}{*}{.000} \\
\hline Basic education & 28.8 & 32.1 & \\
\hline Secondary education & 30.8 & 22.6 & \\
\hline Tertiary education & 9.6 & 3.3 & \\
\hline \multicolumn{4}{|l|}{ Age: } \\
\hline $0-59$ & 78.1 & 81.3 & \multirow[t]{2}{*}{.184} \\
\hline $60+$ & 21.9 & 18.7 & \\
\hline \multicolumn{4}{|l|}{ Employment: } \\
\hline Employed & 93.7 & 89.0 & \multirow{3}{*}{.028} \\
\hline Unemployed & 6.3 & 11.0 & \\
\hline Missing & {$[5]$} & {$[8]$} & \\
\hline \multicolumn{4}{|l|}{ Enabling } \\
\hline \multicolumn{4}{|l|}{ Income per month $(\phi)$ : } \\
\hline Less than 100000 & 21.2 & 21.4 & \multirow{8}{*}{.254} \\
\hline $100000-200000$ & 47.1 & 49.4 & \\
\hline $200000-300000$ & 17.4 & 13.4 & \\
\hline $300000-500000$ & 8.5 & 12.1 & \\
\hline $500000+$ & 5.8 & 3.6 & \\
\hline Missing & [1] & [3] & \\
\hline Mean & [382600] & [337263] & \\
\hline SD & {$[548720]$} & {$[357692]$} & \\
\hline \multicolumn{4}{|l|}{ Insurance: } \\
\hline Insured & 15.0 & 10.5 & \multirow[t]{2}{*}{.057} \\
\hline Uninsured & 85.0 & 89.5 & \\
\hline \multirow{2}{*}{\multicolumn{4}{|c|}{$\begin{array}{l}\text { Need } \\
\text { Health status (how many times do } \\
\text { you fall sick?): }\end{array}$}} \\
\hline & & & \\
\hline Once a week & 0.8 & 2.1 & \multirow{5}{*}{.000} \\
\hline Once a fortnight & 7.3 & 5.9 & \\
\hline Once a month & 22.7 & 29.7 & \\
\hline Once in 3 months & 21.2 & 34.6 & \\
\hline Rarely & 48.1 & 27.7 & \\
\hline
\end{tabular}


- table 6.1 continued -

\begin{tabular}{|c|c|c|c|}
\hline Variable/sub-variable (\%) & Male $(n=260)$ & Female $(n=390)$ & $\chi^{2}$ sig. ( $p$-value) \\
\hline \multicolumn{4}{|l|}{ Restrictive } \\
\hline \multicolumn{4}{|l|}{ Distance in kilometres: } \\
\hline Less than 3 & 35.7 & 34.5 & \\
\hline $3-5$ & 17.4 & 18.4 & \\
\hline $6-10$ & 11.2 & 13.2 & \\
\hline $11-15$ & 7.0 & 4.2 & .556 \\
\hline $16+$ & 28.7 & 29.6 & \\
\hline Missing & [2] & [5] & \\
\hline Mean & [13.3] & {$[14.0]$} & \\
\hline $\mathrm{SD}$ & {$[16.7]$} & {$[17.6]$} & \\
\hline \multicolumn{4}{|l|}{ Travel time in minutes: } \\
\hline Up to 30 & 78.7 & 73.9 & \\
\hline $31-60$ & 13.0 & 14.2 & \\
\hline $61+$ & 10.3 & 11.8 & .728 \\
\hline Missing & {$[7]$} & {$[18]$} & \\
\hline Mean & 25.8 & 26.3 & \\
\hline$S D$ & 26.6 & 26.1 & \\
\hline \multicolumn{4}{|l|}{ Waiting time in minutes: } \\
\hline Less than 60 & 35.8 & 34.6 & \\
\hline $61-120$ & 43.8 & 39.3 & \\
\hline $121-180$ & 13.8 & 17.6 & \\
\hline $181-240$ & 4.6 & 5.7 & .548 \\
\hline $241+$ & 1.9 & 2.8 & \\
\hline Waiting time & {$[-]$} & {$[3]$} & \\
\hline Mean & 91.1 & 96.8 & \\
\hline $\mathrm{SD}$ & 71.4 & 78.3 & \\
\hline \multicolumn{4}{|l|}{ Service cost in cedis (屯): } \\
\hline Less than 30000 & 45.0 & 39.5 & \\
\hline $30000-50000$ & 27.9 & 32.3 & \\
\hline $50000-100000$ & 27.1 & 27.4 & \\
\hline Above 100000 & 0.0 & 0.8 & .252 \\
\hline Missing & {$[2]$} & {$[-]$} & \\
\hline Mean & 35839 & 39067 & \\
\hline SD & 25272 & 28617 & \\
\hline \multicolumn{4}{|l|}{ Quality of service: } \\
\hline Poor & 1.9 & 1.6 & \\
\hline Satisfactory & 39.6 & 34.8 & \\
\hline Good & 45.4 & 49.9 & .614 \\
\hline Very Good & 13.1 & 13.8 & \\
\hline Missing & {$[-]$} & {$[5]$} & \\
\hline \multicolumn{4}{|l|}{ Transport cost in cedis $(\ell)$ : } \\
\hline Less than 500 & 31.5 & 31.5 & \\
\hline $500-1000$ & 11.9 & 10.0 & \\
\hline $1000-2000$ & 23.5 & 23.8 & \\
\hline
\end{tabular}


- table 6.1 continued -

\begin{tabular}{lrrr}
\hline Variable/sub-variable (\%) & Male $(\mathrm{n}=260)$ & Female $(\mathrm{n}=390)$ & $\chi^{2}$ sig. $(p$-value $)$ \\
\hline $2000-4000$ & 13.5 & 11.3 & .818 \\
$4000-8000$ & 12.7 & 15.6 & \\
$8000+$ & 6.9 & 7.7 & \\
Mean & 2609.6 & 2816.9 & \\
SD & 3767.2 & 4188.3 & \\
& & & .511 \\
Attitude of hospital staff: & & & \\
Poor & 3.1 & 5.4 & \\
Satisfactory & 24.6 & 22.2 & \\
Good & 55.0 & 54.9 & .007 \\
Very Good & 17.3 & 17.5 & \\
Missing & {$[-]$} & {$[2]$} & \\
& & & \\
Utilisation & & & \\
Rarely & 21.9 & 23.8 & \\
Irregularly & 41.9 & 36.2 & \\
Moderately & 7.3 & 15.9 & \\
Regularly & 28.8 & 24.1 & \\
\hline
\end{tabular}

Source: Based on Field Data, 2001

\section{Multiple regression analysis}

Multiple regression analysis is used to examine the relative impacts of the independent variables on utilisation. Multiple regression analysis is preceded by a correlation matrix (table 6.2) to examine the association among the variables. Correlation coefficients are very strong between travel time and distance for both males and females. To avoid the problem of multicollinearity, travel time was eliminated from the multiple regression analysis. Theoretically, distance is a more significant factor in explaining utilisation behaviour than travel time. The variables that exhibit a relatively higher correlation with utilisation for males, following a descending order of significance, are distance, education, insurance, service cost and income; and for females, they are distance, travel time, education, income and service cost. Whereas the association between distance, income and travel time are stronger for females than males, that between insurance and service cost is stronger for males than females, whilst education is almost at par.

The multiple regression (stepwise) results are indicated in table 6.3. The stepwise method was used to select the key variables influencing utilisation; which were distance, education, service cost, income, quality of service and health status for males; and distance, income, education, service cost and transport cost for females, following a sequence of significance. 


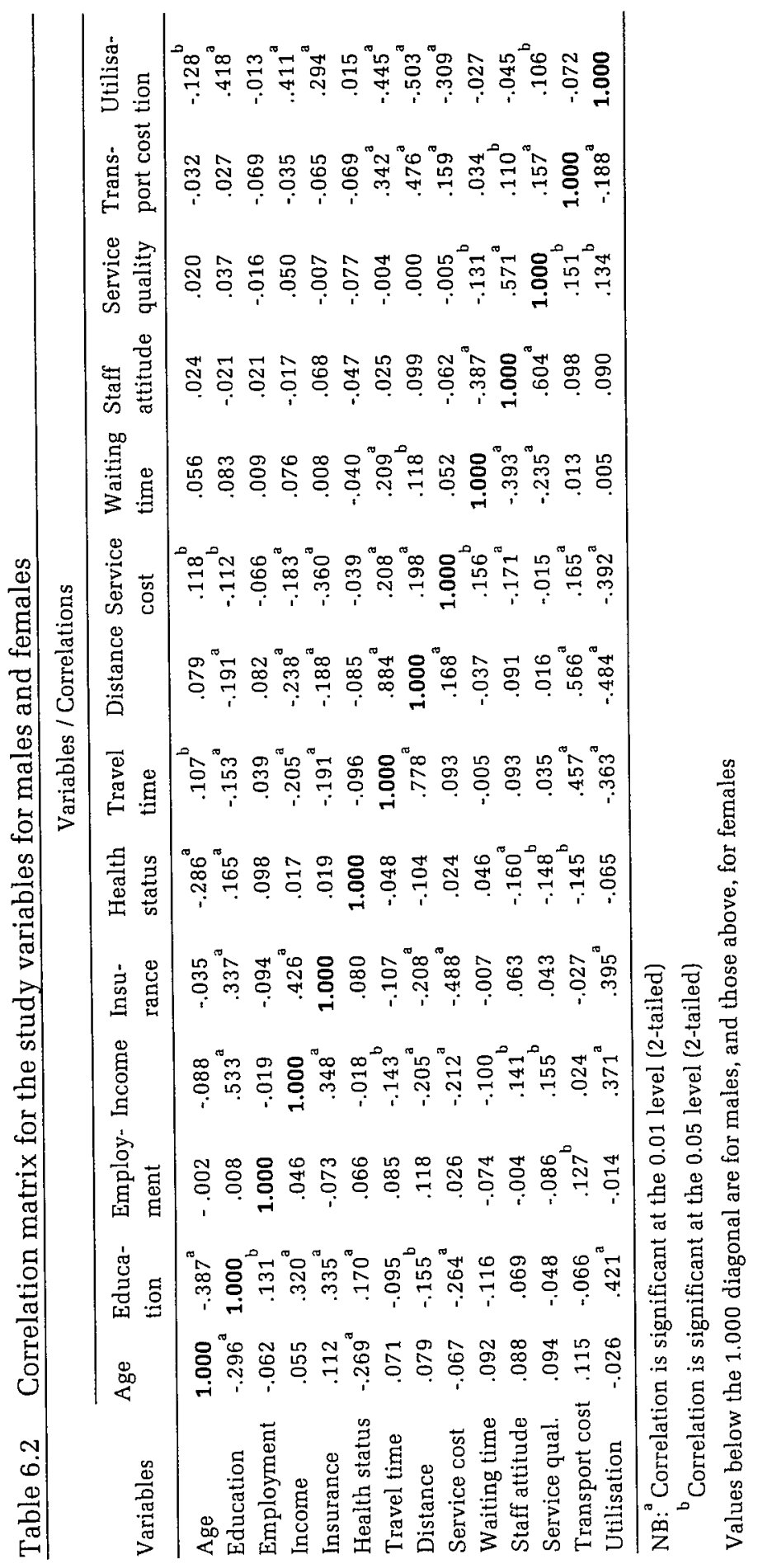


Table 6.3 Multiple regression factors

\begin{tabular}{|c|c|c|c|c|}
\hline \multirow{2}{*}{ Variable } & \multicolumn{2}{|c|}{ Males } & \multicolumn{2}{|c|}{ Females } \\
\hline & Beta Coeffi. & $p$-value & Beta Coeffi. & $p$-value \\
\hline Distance & -0.424 & 0.000 & -0.452 & 0.000 \\
\hline Education & 0.295 & 0.000 & 0.213 & 0.000 \\
\hline Service Cost & -0.235 & 0.000 & -0.187 & 0.000 \\
\hline Income & 0.126 & 0.015 & 0.186 & 0.000 \\
\hline Health Status & -0.124 & 0.010 & -0.062 & 0.124 \\
\hline Quality of Service & 0.129 & 0.010 & 0.064 & 0.113 \\
\hline Transport Cost & 0.071 & 0.223 & 0.129 & 0.005 \\
\hline Waiting Time & 0.108 & 0.028 & 0.002 & 0.959 \\
\hline Adjusted R Square & \multicolumn{2}{|c|}{.459} & \multicolumn{2}{|c|}{.434} \\
\hline
\end{tabular}

Source: Based on Field Data 2001

For the single regression model, based on common significant variables for both males and females, the variables that make significant impact on utilisation for males (in order of importance) are distance, education, service cost, quality of service, income and health status. For females, the variables are, distance, education, service cost and income. Whereas distance and income have greater effects on utilisation by females than males, education, service cost, health status, and quality of service, have greater effects on utilisation behaviour of males than females. Whereas the adjusted regression square (Adjusted $R^{2}$ ) for males is .459 , it is .434 for females, implying that the results for males more adequately explain the utilisation situation more than females. Both are however averagely high, being based on a composite regression of above .6 .

\section{Discussion}

Males utilise health services more regularly than females, even though females have the greater need of health services, considering their comparatively weak health status. This has serious implications for gender equity in health care, especially taking cognisance of the fact that females are a vulnerable group in the Ghanaian society. They are also more influenced by income in the utilisation of health services than their male counterparts, and also pay higher for service cost than males. The average income for males is higher than for females. This puts women at a disadvantage in the utilisation of health services. This weak position of females in the utilisation of health services is reflected in the effect of distance decay on their utilisation behaviour. The selection of the sample was spatially balanced. Health facilities are scattered, apart from the core 
of the Kumasi Metropolis, capital of the Ashanti Region. The effect of distance decay implies that females may not access specialist health services that are not equitably distributed in the region.

Males are more influenced by service cost but less by income. The difference in beta co-efficient is not too high. The predominant factor here is the ability to pay that is determined by income; and with females paying more for health care, the effect of the cost factor on them is considerable. Education affects males more than females. The education of females is generally low in the region, and for females, it is the most important predisposing factor, apart from distance, influencing utilisation. It is a more variable factor for males than for females, and this explains the difference in its effects on utilisation. Health status has a greater effect on males than females. Its effect on female utilisation behaviour is insignificant. The implication here is that more males than females who fall sick would decide to receive health care, even though females have a relatively weaker health status. This factor could be dependent on the predisposing factor of education and the enabling factor of income, and for the fact that females averagely pay more for service cost. Quality of service being an influential factor in the utilisation of health services for males than females could be explained by the income and education factors. Quality of service is compatible with high incomes. It is also a determinant of the level of education. It calls for a minimum level of education to appreciate what quality of care means and where to access it.

In general terms however, distance, education, service cost and income are the principal factors influencing utilisation in the region. The factors influencing utilisation tend to marginally favour males than females. Given the relatively weaker health status of females, and their vulnerability, it was expected that they would enjoy a higher utilisation rate. On the contrary, their male counterparts enjoy higher utilisation than they do. It calls for pragmatic policies to address the imbalance and ensure equity.

Some hypotheses have not been justified by the study. First, whereas females are more affected by distance and income than males in the use of health services, males are rather more influenced by education and service cost in their health care behaviour. The influence of education and service cost on women's health care use behaviour is however statistically significant. The hypotheses that quality of service and health 
status influence male more than females have however been justified.

A model of utilisation by gender (figure 6.2) emerges as a basis for hypotheses formulation and further surveys. The following facts underpin the emerging model:

1 Males utilise health services more than females.

2 Females have a relatively poorer health status, hence, their greater need for health services.

3 Income has a greater impact on female utilisation of health services.

4 Quality of service has a greater impact on male utilisation behaviour.

5 Education, distance and service cost have high effects on both males and females in the utilisation of health services.

Figure 6.2 A schematic diagram showing utilisation by gender in the Ashanti Region of Ghana

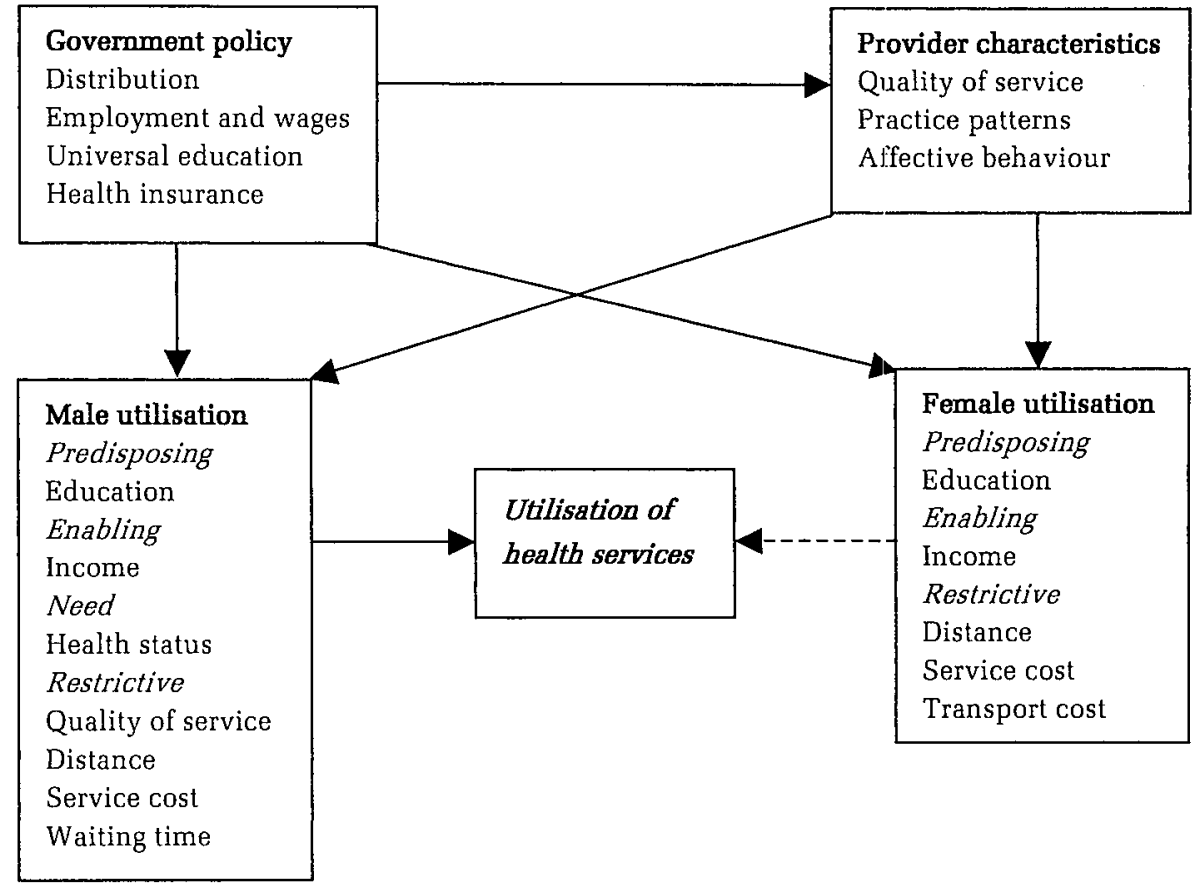

Source: Author's construct based on Survey Results, 2001

The key components of the model are government policy, provider characteristics, male utilisation and female utilisation, with utilisation of health services at the centre. The survey has established that the rate of female utilisation is weaker, whilst government policy influences 
utilisation by both males and females. The distribution of the facilities, which is determined by government policy, would show how physically accessible both sexes are to them. Income affects females the more. Poverty appears to lie at the root of poor health service utilisation for both male and female, but greater for females. Government policy on wages and employment would financially empower the population, especially vulnerable females, to access health care, whilst universal education would positively influence utilisation for both males and females. Health insurance is a very effective strategy to improve utilisation, especially, by the vulnerable females. Such policies by government would affect utilisation for both male and female.

The provider of health services, the Ministry of Health through The Ghana Health Service, would also influence utilisation by both sexes. They ensure quality care, and their practice patterns would also ensure availability of services. Affective behaviour of medical staff would motivate utilisation. Government policy would influence provider characteristics since government is the main stakeholder of medical services in Ghana. Government policy and provider characteristics have been introduced to enhance the model. These have been extracted indirectly from the results and mainly from the literature review. The provider characteristics thus influence both males and females.

The survey brings to the fore certain pertinent issues that demand appropriate policies to ensure equity in the utilisation of health services. A policy to ensure easy access to health services is also urgent. There seems to be inequity in the utilisation of health services by gender, which defeats the moral basis of social welfare. Women have greater need for health services as indicated by their relatively poor health status. It is not mere accessing health care that matters, but quality health care to which males have greater access than females.

Females are a vulnerable group in society so they need much more attention, especially in a sensitive area such as health care. To adequately access quality health care requires a regular source of income and formal education. They must have access to income through gainful employment. Those without any form of formal education that could earn them employment should be introduced to some vocational training. The National Council on Women and Development (NCWD), a government institution to ensure the development and welfare of women, must be adequately resourced to carry out vocational training programmes, whilst 
government should encourage Non-Governmental organisations in the field of female vocational training.

The survey has revealed that there is a gap between educational participation and attainment by gender. The education of the girl-child must be given priority. The government's Free Compulsory Universal Basic Education (FCUBE) policy must be carried to its logical conclusion, and females who have been at the periphery of educational attainment must be targeted in this crusade against mass illiteracy. There are several women who have passed the school-going age; however, education has been found to exhibit a positive relationship with the utilisation of health services. Efforts must be made by the Non-Formal Education Division (NFED) of the Ministry of Education to encourage them together with their male counterparts to participate in the informal education programme.

Finally, the status of insurance is rather low for both sexes. On the contrary, for quality health care and its easy access, there is the urgent need for a health insurance scheme. Currently, there is no national health insurance scheme for the country. There are some minimum health cost relief packages established by some public and private institutions for their workers. Such programmes are not sufficient enough to capitalise the health sector and to ensure adequate access. A National Health Insurance Scheme is urgent if health care would be brought to the doorsteps of the less privileged masses.

\section{Conclusion}

There is the need for equity in access to health care. This survey establishes that there is gender inequity in access to health care. Even though females show a weaker health status, and so have a greater need for health services, they relatively utilise health services less. Their poor access, related to the utilisation behaviour of their rnale counterparts, is caused mainly by abject poverty and long distances to health facilities.

Not only do females have a relatively poorer access to health services, but also they utilise poorer quality of service. Men have the advantage of utilising quality services. This could be due to their higher income status. A policy to remove gender inequity in the utilisation of health services would not only satisfy social justice, but will also ensure their safe health and positive contribution to socio-economic development. Given that they constitute greater proportion of the population, their contribution to 
national development need not be overemphasised. A pragmatic wage and income policy, and female participation in family decisions are prerequisites. To participate in decision-making and to ensure their empowerment, they must be economically stable and have an appreciable level of formal education. Although males are affected by the service cost factor, given the higher average income for males than females, and the fact that females are more affected by income than males as reflected by the multiple regression results; and also the fact that they averagely pay higher service cost than males, the argument for their disadvantage in the utilisation could be advanced.

The survey has structured a model of utilisation by gender. It has succeeded in unearthing the intrinsic differences in the utilisation of health services by gender, using the existing general utilisation models as the basis. The multiple regression technique has also been used to show the relative contribution of various independent variables to the utilisation model. It must be emphasised that the survey has more than shown correlations rather than determining causes.

Further research areas have been exposed by the survey. First, to what extent does quality of service influence male utilisation? Second, the need of females for health care is statistically greater than for males, but the effect of health status on utilisation for females is not statistically significant. There is the need for a further survey on the effect of health status and utilisation on females, using a larger sample size. Third, the education factor influencing female use of health services needs to be examined in its broad dimensions. 


\section{Mother's education and childhood mortality in Ghana}

This chapter was published as:

Buor D. Mothers' education and childhood mortality in Ghana. Health Policy; 2003; 64(3): 297-309.

Reprinted with the permission from Elsevier. 


\section{Introduction and the problem}

The argument that the education of women has greater impact on the survival of their children has been advanced in several health care literature. In Ghana however, very little has been done to organise scattered information into a comprehensive treatise. Although there have been reports on surveys on child mortality, and of their mothers' education in survey reports, notably, the Ghana Demographic and Health Surveys (GDHS), such reports have not been organised and comprehensively analysed for the purpose of discovering policy implications. Nor have there been efforts to exarnine the childhood mortality and fertility patterns from geographical perspectives, which is urgent in structuring a comprehensive policy framework. Third, very little has been done in developing a graphic (linear regression/curve estimation) model to depict the relationship. Studies have tended to be either purely qualitative, or using simple descriptive statistics to analyse the relationship, which are not adequate in establishing reality.

In sum, though there have been surveys on childhood mortality and maternal education, with the latter constituting the independent variable, not much, especially in Ghana, has been done in offering explanations using the geographical approach and a regression analysis. There is also the need for a model of establishing a strong foundation for a sound child health and maternal education. It is to bridge such a research gap, and to discover a strategy for a sustainable maternal education and child health that it became necessary to examine the relationship between childhood mortality and mothers' education in Ghana, using primarily 1998 GDHS and World Bank data.

The rate of infant and child mortality is very alarming in Africa and developing countries. The World Bank (2000) indicates that infant mortality rate for sub-Saharan Africa is 92 per 1,000; and for under-five mortality rate, it is as high as 151 per 1,000. This is rather high compared with 26 per 1,000 and 31 per 1,000 for infant mortality and under-five mortality rate respectively for upper middle-income countries. So important is child survivorship to general health attainment of countries that The World Health Organisation (WHO) has identified it between the two measures of health attainment at the country level in terms of the average level of population health and the distribution of population health or health equality. These are disability-adjusted life expectancy (DALE) and the index of equality of child survival (WHO, 2000). 
The role of the mothers' education in child survivorship has been made evident by several literature on health in developing countries. In subSaharan Africa, whereas the proportion of childhood deaths of mothers with 1 to 3 years of formal education is 0.92 , it is 0.77 for those with 4 to 6 years of schooling; and for those with $7+$ years of schooling, it is 0.56 (Hobcraft, 1993).

The role of maternal education in childhood survival could be seen in their use of prenatal and child health care services. In Thailand, Raghupathy found that secondary education was the most consistent predictor of prenatal care use (Raghupathy, 1996); and in Vietnam, Swenson et al. (1993) discovered that the woman's educational level and total number of living children were the most significant predictors of prenatal care utilisation. With regard to childcare, which is a significant factor in child survival, the educated woman is keener. In Ghana, whereas 42.2 per cent of mothers without formal education immunised their children against TB, DPT, polio, and measles between 1989 and 1993, 86.7 per cent of mothers with secondary education and above did (GSS and MI, 1999, p.101). The educated and those of high socioeconomic status utilise health services more than the uneducated and those of low social class (Wyss et al., 1996).

Another advantage the educated woman has is accessing income sources. Income is about the greatest impediment to the use of health facilities in developing countries (Pickett and Hanlon, 1990; Chernichovsky and Meesook, 1986; Habib et al., 1986). The educated woman has a high probability of getting a job that carries good pay. The population of women is more than men, and the few educated women have access to jobs, especially in the formal sector. In Ghana, the sex ratio (ratio of male to female population) is 96.1 , with females constituting $51 \%$ of total population (GSS, 2000).

Education would thus give the woman the economic empowerment to be able to freely decide to take her child to hospital for health care. It is a tool to demolish the barrier to participation in family decisions. In African countries, as in Ghana, authority in the family rests largely on the man who has control over family resources, a factor that determines the use of health care. Whereas in the traditional families the man monopolises decision making, in the elite (educated) families the woman plays a meaningful role, enjoying some autonomy (Ojanuja and Gilbert, 1992). Yet, in Ghana, the illiteracy rate is rather high for women. Whereas 
the adult male illiteracy rate is 22 per cent of those aged 15 and above, it is as high as 40 per cent for females (World Bank, WDI, 2000, p.82). This inequity has serious implications for the development of women. The Government's Free Universal Basic Education (FCUBE) programme, in which education is to be free at the basic level, has not witnessed a remarkable success. In the rural areas especially, access to basic education is low.

In Ghana, as in several African countries, women bear the greater burden of childcare. Men relegate such responsibilities to the women, thus making their domestic burden rather enormous. On the issue of supporting children among the Akans, the largest ethnic group in Ghana, Bleek writes (1987): "Having children, both in the sense of bearing them and in the plain sense of supporting them, is mainly a woman's affair. As we have seen, Akan men often do not support their children".

In Ghana, the incidence of child survivorship and education of women have their spatial perspectives. There would be variation by rural-urban, rural-peri-urban, rural-semi-urban and within urban nodes. Within urban nodes, urban core and urban periphery would tend to vary, given that residential arrangements in urban areas correlate with wealth and social status. Women of high rank in the civil and public services would tend to occupy the core sector in the metropolis. There is a great disparity in the distribution of health care facilities in Ghana. The urban areas have greater proportion of all types of health care facilities (including child care services) in Ghana. The poor physical accessibility, coupled with low level education and poverty, put rural women at a disadvantage in their care for their health and that of their children.

There is yet another problem that has implications for childhood survival; and that is the lack of a national health insurance scheme that has the potential of affecting equity in access to health facilities. Health insurance has been found to exhibit a high positive association with the utilisation of health services in developing countries. In a study of the Bwamanda hospital insurance scheme in Zaire (Democratic Republic of the Congo), Criel et al. (1999) found that utilisation increased among insured patients. The burden of health care on government, in the absence of a national health insurance scheme, is quite great. Resources committed to the health sector are inadequate; yet there is more concentration on tertiary health services to the detriment of primary health care. 
This paper examines, using secondary sources, the impact of mothers' education on child survivorship in Ghana. The operating arguments are four. First, infant mortality, which is endemic in the Ghanaian society thus constitutes a serious health problem, cannot be addressed without a development of maternal education. The development of the two should therefore be simultaneous. The education of the girl-child, as a policy, should be seen in the broad perspective of creating a broader platform for dealing with child health. The second argument is that a clear policy to establish a pilot project of integration of child health and maternal education services would be urgent if a strong association between child health and maternal education were established. There is currently no such project, a factor that makes it difficult to structure a hypothesis on the two events. Such a project would form the basis for a hypothesis and an empirical survey on the emerging results. The third basis for the research is that a regression approach is needed to break the hold of simple descriptive statistics that have been the analytical tool for such surveys. The fourth argument is that studies on child survivorship and maternal education have usually missed the spatial focus. It is hoped the results would better bring to focus the impact of mothers' education on child survivorship and strategies of ensuring sustainable child health and maternal education.

\section{Methods}

The independent variable is mothers' education, and how it relates to the promotive factors of infant and child mortality. These factors include, antenatal care, maternal nutrition, child nutrition, and postnatal care as indicated mainly by child vaccination. In antenatal care, the care provider and place of delivery have been selected for analysis. The level of education of mothers and how it relates to these variables have been examined. The dependent (outcome) variables are childhood mortality and the prevalence of childhood diseases namely, respiratory tract infection, fever and diarrhoea. The morbidity conditions are analysed to find out how they reinforce mortality conditions. The relationship between these variables is time-based. The 1998 GDHS data is largely used. The study examines the spatial dimension, rural-urban variations. Thus the study assumes a spatio-temporal dimension.

The 1998 GDHS was a nationally representative survey of 4,843 women aged 15-49 and 1,546 men aged 15-59 ${ }^{1}$. The survey covered the 5-year

1 For the purpose of this paper, women data is used. 
period of 1993 to 1998. The GDHS data is based on a two-staged stratified, nationally representative sample of households (GSS and MI, 1999). At the first stage of sampling, 400 Enumeration Areas (EAs) were selected using systematic sampling with probability proportion to size (PPD) method. The EAs were selected from a subsample of 1,000 EAs, made up of 138 urban EAs and 262 rural EAs. A complete household listing operation was then carried out in the EAs having less than 500 households. EAs with 500 or more households were segmented into two or three equal parts with a minimum of 200 households, and one segment was selected randomly. The list of households provided a sampling frame for the second stage selection. At the second stage of sampling, a systematic sample of 15 households per EA was selected in all regions, except in the Northern, Upper West and Upper East Regions, where the number per EA was increased to $20^{2}$. The Household response rate (HRR), Eligible woman response rate (EWRR) and Overall response rate (ORR) for women were as high as 99.1 per cent, 97.4 per cent, and 96.6 per cent respectively (GSS and MI, 1998).

With specific reference to infant and child mortality on which the study is based, the quality of data could be said to be credible. The reliability of mortality estimates depends on the extent to which date of birth and age at death are accurately reported and recorded and the completeness with which child deaths are reported. Omission of births and deaths has a direct effect on mortality estimates whilst displacement of dates could affect mortality trends. Age misreporting at death may distort the pattern of mortality. There was fairly complete information on the date at death for all children. There was however some evidence of omission of deaths in the most recent five-year period. There is also some evidence of misreporting of birth dates. Early infant deaths however were not found to have been under reported (GSS and MI, 1998, p.81-82). The quality of data could therefore be ascertained. The quality of mortality data could further be ascertained by the low level sampling errors as indicated in table 7.1. Given the number of cases (N) the Sample Error (SE) and Relative Error (RE) are rather insignificant, so are an indication of the quality of the sample, which justifies the credibility of the results.

2 There are ten regions in the country. These three regions are the less densely populated and the most economically and socially deprived. 
Table 7.1 Sampling errors for mortality statistics for women

\begin{tabular}{lrrrr}
\hline Variable & Value (R) & $\begin{array}{r}\text { Standard error } \\
\text { (SE) }\end{array}$ & $\begin{array}{r}\text { Number of } \\
\text { cases (N) } \\
\text { [Unweighted] }\end{array}$ & $\begin{array}{r}\text { Relative error } \\
\text { (RE) }\end{array}$ \\
\hline Neonatal mortality rate & 32.335 & 2.700 & 6635 & 0.084 \\
Infant mortality rate & 61.197 & 3.639 & 6644 & 0.059 \\
Child mortality rate & 52.382 & 3.213 & 6700 & 0.061 \\
Under-five mortality rate & 110.373 & 4.876 & 6709 & 0.044 \\
Post neonatal mortality rate & 28.862 & 2.360 & 6644 & 0.082 \\
\hline
\end{tabular}

Source: GSS and MI, 1998

A simple linear regression model (curve estimation) has been structured to show the relationship between mothers' education and infant mortality. The codes used for the levels of education are as follows:

0 - no formal education;

1 - primary education;

2 - middle/junior secondary school;

3 - secondary education and above.

Beta coefficient and adjusted coefficient of determination $\left(\mathrm{R}^{2}\right)$ derived are -.898 and .710 , respectively, which are quite high to 468 .

\section{Education of women and child health in developing coun- tries}

The positive relationship between women's education and child health in developing countries rests upon a sound theoretical foundation. A great barrier to the use of scientific health services in developing countries is superstition, which is a function of illiteracy. There is a strong tendency to utilise traditional medicine and self-medication that are major sources of child mortality. The attainment of more formal education is very urgent for women in developing countries in overcoming the cultural constraints and prohibitive social norms (Jejeebhoy, 1995). The uneducated use more of traditional medicine (Heggenhougen, 1989), with concomitant risks to health. In sub-Saharan Africa, the trend is that, the more the number of years spent in school by women, the higher the survival rate of their children (Hobcraft, 1993).

In a study of the differential effect of mothers' education on mortality of boys and girls in India, Katherine and George found that improved mothers' education reduced mortality at all ages below five years for both sexes (Bourne and Walker, 1991). In another study on mothers' education and survival of female children in a rural area in Bangladesh it was found 
that for boys, a change in mothers' education from no schooling to 1-5 years resulted in reducing the predicted risk of death by $45 \%$, while for girls the reduction came to only 7 per cent. Similarly, a change in mother's education from no schooling to six or more years of schooling resulted in a reduction of risk of 70 per cent for boys, whilst for girls it was only 32 per cent (Bhuiya and Stretfield, 1991). The educated woman would not use health services recklessly, but effectively through compliance with the directions of the physician. The educated mothers are more committed to following the instructions of the physician to ensure recovery from illnesses. They are more likely to spend a longer time with the physician, explaining the problem and listening to his instructions. They could record their problems at home before coming to see the doctor, and could also record instructions given by the doctor. They have a high probability of reporting back to the doctor if they or their children are not recovering (Caldwell et al., 1983).

An important factor in the healing process is going by physicians' instructions concerning dosage levels, in which the educated mother has an advantage. She can read and know the times to take a dosage, and the quantity to take at a time. She can also detect where a particular drug has expired, so should be disposed of. In most developing countries where foreign language is used as the national medium of communication, she could overcome the language barrier when she goes to the hospital for treatment. Such languages in which health literature is written are better able to explain health conditions than the local languages that lack the appropriate definition of terminologies.

The referral system is least respected in developing countries where illiteracy and poverty predominate. In a study of risk approach in antenatal care: evaluation of the referral compliance in the Kasongo District in Eastern Zaire, Dujardin et al. (1995) gathered that the referral success rate was $33 \%$; and the main explanation was the low socioeconomic status of the residents in the area. The educated woman is thus more likely to go by referral instructions in getting her child treated.

By complying with physicians' instructions, the educated woman has a higher probability of recovering from ailments, and ensuring the survivorship of her children. Bor, et al in a study of the socio-economic disadvantage and child morbidity in Australia concluded that, there was a consistent pattern with children of the most socio-economically disadvantaged mothers manifesting the worst health (Bor et al., 1993). 
Yach and Von Schirnding share the view that the education of women is strongly related to child survival (Yach and Von Schirnding, 1994).

The chief stimulus to health transition programmes has been found to be the demonstration of significant differentials in the survival of children by the education of their mothers (Caldwell, 1986), and the education of women has almost as powerful an effect on whole societies in improving child survival at every level of mothers' education. A United Nations study of 15 developing countries on mothers' education and child survival concluded that an additional year of mothers' schooling reduces child mortality by 6.8 per cent (Mensch et al., 1985).

Education of women therefore is very crucial to the survival of their children. It is therefore urgent that health issues in developing countries take into consideration the education of the girl-child who will grow to be a mother and rearers of children. It is imperative that a policy is initiated to ensure the literacy of the girl-child.

\section{Status of childhood mortality}

The rate of infant mortality in Ghana has been declining steadily, though high when compared with the middle-income economies that Ghana is aspiring to attain. In 1975 , it was 99.6 per 1,000 live births (GSS and MI, 1999, p.83). This declined ten years later in 1985 to 77.2 per 1,000 live births. In 1996 eleven years later, it further decreased to 56.7 per 1,000 live births. The status of infant health in Ghana is better compared with countries in West African sub-region, and among low-income countries in which Ghana falls. In 1998, whereas the rate for Ghana was 65 per 1,000 live births, it was 88 for Cote d'Ivoire and 104 for Burkina Fasso (World Bank, WDR, 2000, p.286-287). It was 68 per 1,000 for low-income countries, and 92 for Sub-Saharan Africa. Results from the 1998 GDHS, in combination with data from the 1993 GDHS show a marked decline in infant and under-five mortality. Infant mortality declined from 100 per 1,000 live births to 57 per 1,000 live births in the last 20 years (GSS and MI, 1999, p.83).

The possible factors responsible for the steady decline are, among others, the rate of vaccination against the six childhood killer diseases, declining female illiteracy, use of antenatal and postnatal facilities, and improvement in childhood nutrition. The proportion of children fully vaccinated before age one increased from 43 per cent in 1993 to 51 per cent in 1998 (GSS and MI, 1999, p.102). Moreover, the gap in female-male difference in educational participation is narrowing, with more females 
attaining secondary and tertiary education (GSS and MI, 1999, p.xxi). The government policy of Free Compulsory Universal Basic Education (FCUBE) has had some minimum impact on society by ensuring that as many females as possible of school-going age get enrolled, the bottlenecks in the policy notwithstanding. Perhaps, the significant improvement in the use of antenatal and postnatal facilities, and improvement in childhood nutrition are the most significant factors in childhood survival in Ghana. The percentage of births to women receiving antenatal care from a doctor, nurse or midwife is 89 percent, up from 86 percent in 1993 (GSS and MI, 1999, p.91); and the proportion of children breastfed within 1 hour and 1 day has markedly increased (GSS and MI, 1999, p.114).

\section{Childhood mortality and mothers' education}

Education of mothers shows an inverse relationship with childhood mortality. Children of mothers with higher education show a lower mortality rate, as indicated in table 7.2.

Table 7.2 Neonatal, post-neonatal, infant, child, and under-five mortality by mother's education

\begin{tabular}{|c|c|c|c|c|c|}
\hline \multirow{2}{*}{ Mother's education } & \multicolumn{5}{|c|}{ Type of mortality } \\
\hline & NN & PNN & $q_{0}$ & ${ }_{4} q_{1}$ & ${ }_{5} q_{0}$ \\
\hline No education & 33.8 & 32.3 & 66.1 & 69.3 & 130.8 \\
\hline Primary ${ }^{1}$ & 41.1 & 29.2 & 70.3 & 45.4 & 112.5 \\
\hline Middle/jss ${ }^{2}$ & 28.6 & 24.9 & 53.5 & 39.9 & 91.3 \\
\hline Secondary+ & 10.5 & 26.3 & 36.8 & 23.9 & 59.8 \\
\hline Total & 32.3 & 28.9 & 61.2 & 52.4 & 110.4 \\
\hline
\end{tabular}

1 Primary education constitutes the first 6 years of formal schooling. The nursery or kindergarten school precedes it.

2 Middle school was a bridge between primary school and secondary (high) school. It is now replaced by the Junior Secondary School (JSS).

$N B$ : NN=neonatal mortality; PNN=post neonatal mortality; $q_{11}=$ infant mortality; ${ }_{4} q_{1}=$ child mortality; ${ }_{5} \mathrm{q}_{11}=$ under-five mortality.

Source: GSS/MI, 1999, p.85

It is clear from the data that there is an education-lower mortality gradient. Children of mothers of higher education experience lower mortalities at all levels of childhood mortality. The exceptions are neonatal mortality and infant mortality in which children of mothers of primary education exceeded those of no education. This follows a trend in developing countries. Women with mere primary education, and staying in the rural areas, who are distant from urban life with its elitism 
and modernism, will tend to slip into the condition of illiteracy. There will however be differences based on marital partners. Educated husbands of women with no education are more likely to influence the attitudes of their wives in childcare.

Beta coefficient and adjusted coefficient of determination $\left(\mathrm{R}^{2}\right)$ derived are -.898 and .710 respectively, which are quite high. A graphic model (linear regression/curve estimation) emerges from the relationship between infant mortality and mothers' education (table 7.2) as depicted in figure 7.1.

The model clearly depicts a strong inverse relationship between mothers' education and infant mortality. As mothers' education increases, child mortality rate declines, and vice versa. This relationship has been the trend in developing countries.

Figure 7.1 Infant mortality and mothers' education

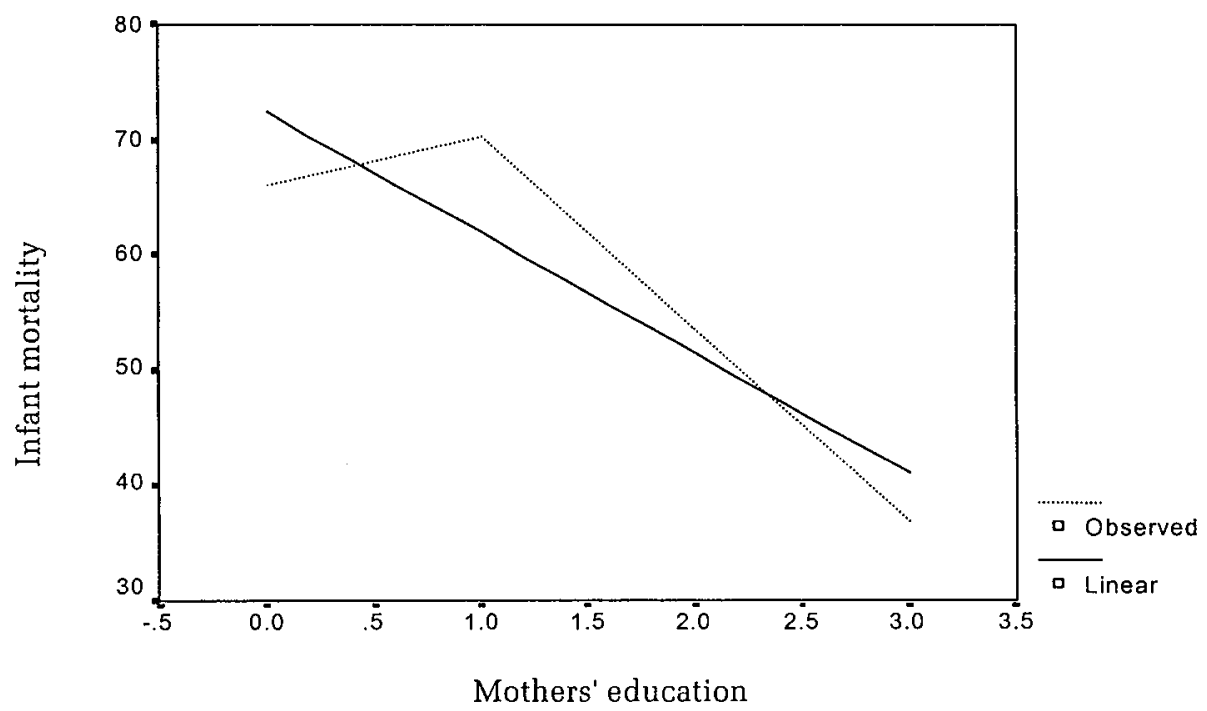

Source: Based on 1998 GDHS Data

There are differences in mortality by place of residence. Childhood mortality at every level is lower in the urban than the rural areas. Infant and child mortalities for rural and urban areas in Ghana are indicated in figures 7.2 and 7.3 respectively. 


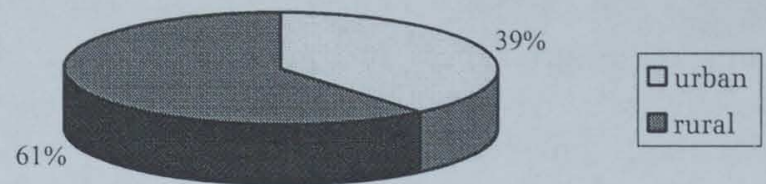

Source: Based on GSS and MI, 1999, p.85

Figure 7.3 Under-5 mortality by place of residence

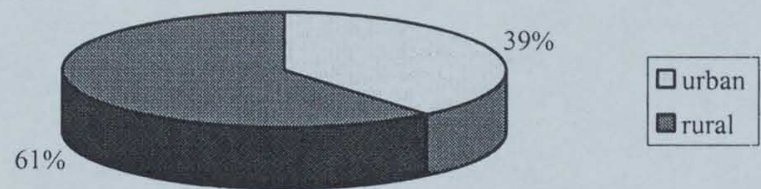

Source: Based on GSS and MI, 1999, p.85

For infant mortality, the rate is 42.6 per 1,000 live births for urban areas, and 57.5 per 1,000 live births for rural areas. For under-5 mortality, the rates are 78.6 and 122.0 per 1,000 live births for urban and rural areas respectively. Thus, the differences in childhood mortality between the urban and rural areas are significant. The mortality by place of residence could be linked with the education of mothers. There is a dichotomy in the level of educational attainment by rural-urban in Ghana and other developing countries. Illiteracy rate is higher in the rural areas than urban areas. Illiteracy is thus a function of place of residence, with the rural areas experiencing a greater rate. Illiteracy rate of mothers in the rural areas is higher than the urban areas. This is due to lack of adequate educational facilities in the rural areas, rural poverty and low standards of living, and the cultural notion that the place of the woman is the home, 
so there is no need for a woman to aspire towards higher educational attainments.

The other reasons for the high childhood mortality in the rural areas, apart from the illiteracy of mothers which forms the main hypothesis for this paper is that, there are fewer health facilities in the rural areas, especially for maternal and child health. Other factors that could influence childhood mortality in the rural areas are poverty, reliance on traditional medicine and poor physical access to health facilities. Moreover, access to non-clinical services like immunisation is poor.

\section{Use of health promotive factors and services and mothers' education}

Mother's education also shows a positive relationship with the use of facilities that promote the health of the child. Factors that have been identified for the purpose of this paper are, antenatal care, nutrition of both child and mother, and childhood vaccination. For antenatal care, the factors considered are maternal vaccination, place of delivery, and the provider.

\section{Antenatal care}

The health of the mother during and after pregnancy has a significant impact on the health of the child. Therefore, in the analysis of childhood mortality, the health of the mother needs to be considered. One of the health problems that affect mother and child, which is a factor of maternal and child mortality, is tetanus. The percentage of births to mothers who received two doses or more tetanus toxoid injections during pregnancy was higher for those with secondary education and above than for other levels of education as indicated in table 7.3.

Table 7.3 Percent distribution of births by number of tetanus toxoid injections mother received during pregnancy by mother's education

\begin{tabular}{lrrrrr}
\hline & \multicolumn{5}{c}{ Number of tetanus toxoid injections } \\
\cline { 2 - 6 } & No inj. & One dose & $\begin{array}{r}\text { Two doscs } \\
\text { or more }\end{array}$ & $\begin{array}{r}\text { Don't know/ } \\
\text { missing }\end{array}$ & Total \\
\hline No education & 26.6 & 26.2 & 46.3 & 0.9 & 100.0 \\
Primary & 17.2 & 31.2 & 49.3 & 2.3 & 100.0 \\
Middle/jss & 10.8 & 31.9 & 56.1 & 1.2 & 100.0 \\
Secondary+ & 7.0 & 24.4 & 67.4 & 1.3 & 100.0 \\
Total & 17.9 & 29.1 & 51.6 & 1.3 & 100.0 \\
\hline
\end{tabular}

Source: GSS and MI, 1999 
There is a direct relationship between the level of education and tetanus toxoid vaccinations. The numbers of vaccinations increase with increase in the level of mothers' education for two or more doses, which is the requirement by the health authorities. There is, on the other hand, an inverse relationship between the level of mothers' education and nonparticipation in the vaccination; the higher the level of mothers' education, the lower the non-participation rate.

The proportion of mothers delivering at health facilities shows a direct relationship with their level of education. More mothers with secondary education and above deliver at health facilities than those of the other levels of education (figure 7.4). On the contrary, there were more mothers of no education delivering at home (figure 7.5 ).

Deliveries at a health facility depend upon the ability to pay, which is a predicament for the rural poor. In the rural areas in Ghana, Traditional Birth Attendants (TBAs) operate on a larger scale. Poor rural women find the TBAs a welcome solace because of the high cost of delivering at health facilities. This factor is confirmed by the rural-urban disparity in delivery at home, which is $22.7 \%$ for urban women and $66.2 \%$ for rural women. This problem calls for a policy to ensure that rural women have easier access to antenatal services.

Figure 7.4 Proportion of deliveries at a health facility by mothers' education

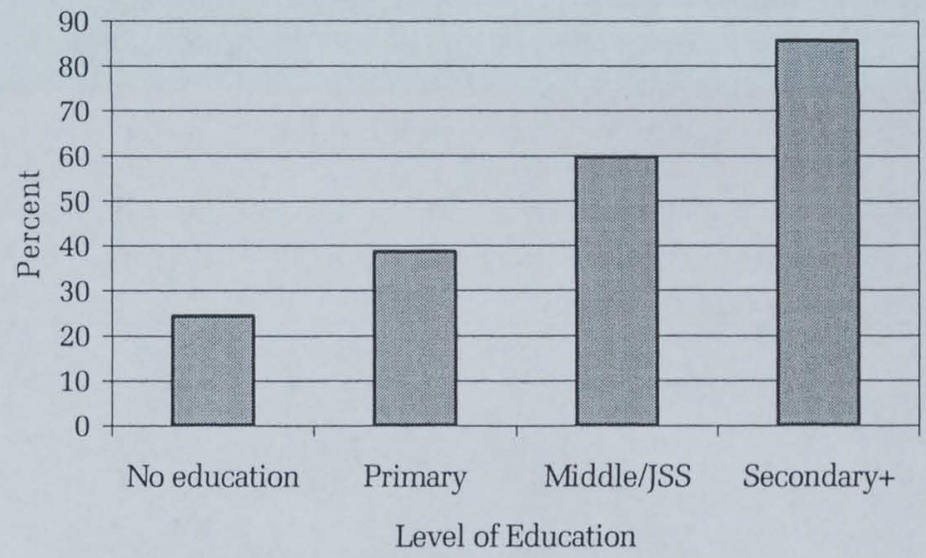

Source: Based on, GSS and MI, 1999, p.96 
Figure 7.5 Proportion of deliveries at home by mothers' education

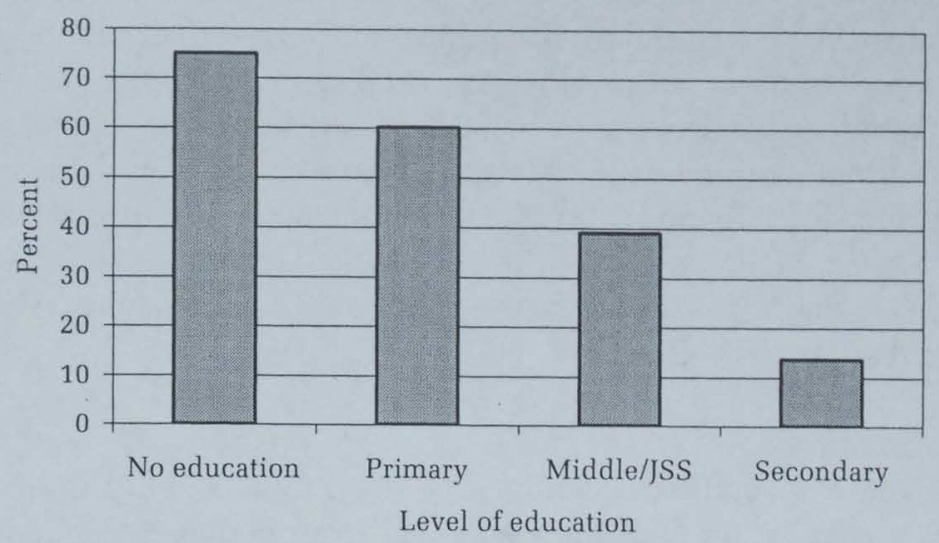

Source: Based on GSS and MI, 1999

\section{Maternal and child nutrition}

Maternal nutrition is very urgent in ensuring the nutrition of the child, especially, regarding breastfeeding. The percentage of women whose body mass index (BMI) was less than $18.5 \mathrm{~kg} . / \mathrm{m} 2$, the standard used in the survey, was greater for women with no education than for those with secondary education and above. Whereas it was $12.7 \%$ for those with no education, $11.2 \%$ for those with Primary education, and 10.8 for those with Middle School/JSS education, it was $5.8 \%$ for women with Secondary education and above (GSS and MI, 1999, p.123). Whereas the difference between those with secondary education and above was significant, it was not significant between the other levels. Nutrition calls for financial resources, and for that matter, adequate income, which could be guaranteed for those with higher education ${ }^{3}$. There is a significant difference between rural and urban. Whereas it is $5.4 \%$ for urban areas, it is $13.4 \%$ for the rural (GSS and MI, 1999, p.123). The poverty factor explains this dichotomy.

Breastfeeding is however not encouraging, and does not show a significant difference by education. Among children under three years of age, median breastfeeding duration in months showed no significant difference by mothers' education. Whereas for exclusive breastfeeding, it

3 In Ghana, educational level is the main determinant for employment and rank in the civil and public services. Women with no or low education find themselves in the informal sector where regular income is not guaranteed. 
was 0.6 for those with no education and primary education, it was 0.7 for those with Middle/JSS education and Secondary education and above. There was however a significant difference by rural-urban, with the median for the urban being 2.1, and for the rural being 0.6 (GSS and MI, 1999, p.117). Whereas for those with secondary education and above, the pressures of formal employment may make it difficult for exclusive breastfeeding, lack of education for the illiterate makes it difficult for them to embrace exclusive breastfeeding. It is popularly held, especially in the rural areas, that exclusive breastfeeding could lead to dehydration of children, and affect their growth.

\section{Childhood vaccination}

Vaccinations show a significant difference by mothers' education. It shows a steep no education-education gradient, irrespective of the immunisation campaigns mounted by governments for the last two decades. The percentage of children who are fully vaccinated, having received BCG, measles and three doses of DPT and polio (excluding polio 0) according to the level of their mothers' education, is indicated in figure 7.6.

Figure 7.6 Percentage of children fully vaccinated by mothers' education

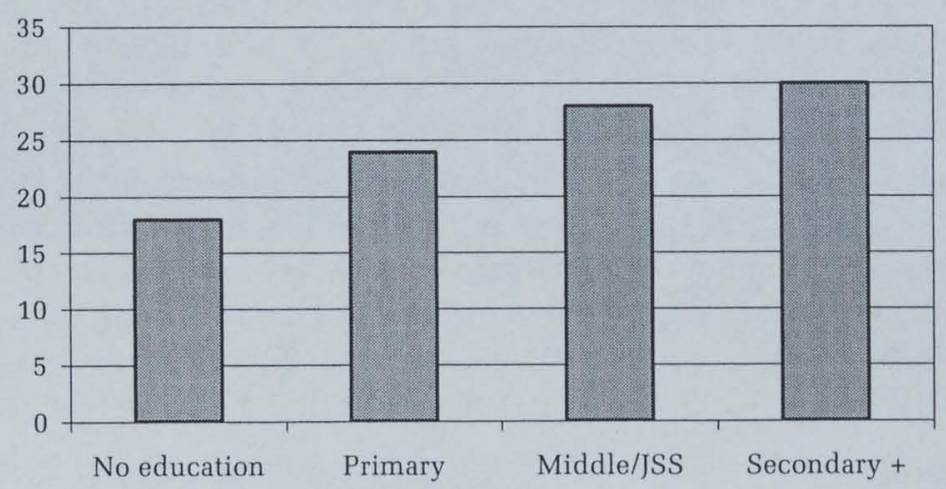

Source: Based on GSS and MI, 1999, p.104

\section{Disease prevalence and malnutrition among children by mothers' education}

The hallmark of the promotive facilities is to ensure the health of children, as evident by certain indicators. The measurement of these indicators would reinforce the mortality factor in the overall assessment 
of child health, and how it relates to the education of their mothers. For the purpose of this paper, the diseases that have been selected for exhibiting a relationship with mothers' education are diarrhoea, acute respiratory infection (ARI), and fever. The malnutrition of children is also related to mothers' education. These are risk factors of childhood mortality. These risk factors and their relationship with mothers' education are respectively indicated in tables 7.4 and 7.5.

Table 7.4 Percentage of children under five years suffering from diarrhoea, respiratory tract infection and fever by mother's education

\begin{tabular}{lrrr}
\hline & & \multicolumn{2}{c}{ Disease } \\
\cline { 2 - 4 } Mother's education & Diarrhoea & Ari & Fever \\
\hline No education & 21.3 & 15.3 & 28.1 \\
Primary & 20.7 & 13.6 & 25.8 \\
Middle/jss & 14.5 & 12.9 & 25.4 \\
Secondary+ & 8.2 & 10.0 & 30.9 \\
\hline
\end{tabular}

Source: GSS and MI, 1999

Table 7.5 Percentage of children under five years suffering from malnutrition by mother's education

\begin{tabular}{lrrr}
\hline Mother's education & \multicolumn{3}{c}{ Type of malnutrition } \\
\cline { 2 - 4 } & Height-for age & Weight-for-height & Weight-for-age \\
\hline No education & 13.1 & 1.9 & 8.1 \\
Primary & 8.7 & 1.3 & 5.2 \\
Middle/JSS & 6.7 & 1.2 & 2.9 \\
Secondary+ & 4.0 & 0.0 & 1.7 \\
\hline
\end{tabular}

Source: GSS and MI, 1999

Whereas differences between levels of education are significant for diarrhoea and insignificant for ARI, education has no impact on the prevalence of fever. Fever is an endemic tropical disease that does not necessarily need knowledge of it or financial resources to protect oneself from it. The same applies to ARI, which could be contracted through pollution, an endemic problem in developing countries. There is a clear distinction between the illiterate mothers and those with secondary education and above in the prevalence of childhood malnutrition, with respect to Height-for-age and Weight-for-age. 


\section{Development and childhood mortality}

The hypothesis that could be formulated, based on research data, on the relationship between development and infant and child mortality is that childhood mortality is a function of development. Developed economies tend to have low infant and child mortality rates, whilst developing economies tend to have very high infant and child mortality rates. The infant mortality rate per 1,000 live births for Ghana is 65 ; for low-income economies, 82, and for high-income economies, 6 (World Bank, WDR, 2000, p.286-287). The developed economies tend to have a better health care delivery system. Secondly, high incomes ensure better maternal and child nutrition and general health care. Access to better health facilities is also regular. Health insurance is a national policy for most developed economies, which ensures that the obstacle to non-attendance is removed.

Maternal welfare is closely linked with childcare. The health and social status of the mother is a strong determinant of child health and welfare, and the maternal welfare is linked with her level of enlightenment, her education. Given that literacy rate declines with economic growth, one could infer that child health is ensured in a developed economy through the education or enlightenment of the mother. This proposition buttresses the hypothesis that is being vindicated through theoretical analysis.

\section{Policy implications}

The survey has clearly identified that mothers' education has a significant impact on childhood morbidity and mortality. It could emphatically be hypothesised, going by the survey, that mothers' education exhibits an inverse relationship with childhood mortality. The model that emerges is that, mothers who have an appreciable level of education are able to cater better for the health needs of their children. They have access to higher incomes through employment with good pay. With relatively better access to financial resources, they have better access to antenatal and postnatal services, and are in a better health condition to ensure better health of their children.

The other issue with the women-education-child health syndrome is a policy to ensure easy access to antenatal and postnatal health services. The gap in the distribution of such services between the rural and urban areas must be bridged. Access roads to rural health centres must be improved to increase accessibility, whilst measures must be taken to 
increase the quantity and quality of rural health services. Primary health care services must be emphasised.

The government's Free Compulsory Universal Basic Education (FCUBE) that intends, among other objectives, to get a significant proportion of female children in school, has not achieved a significant success. Whereas the adult illiteracy rate for males is $22 \%$, it is $40 \%$ for females (World Bank, 2000, p.82). Currently, basic education, that is supposed to be free, is not free after all. Parents are responsible for providing certain basic infrastructure for schools and buying basic textbooks for their wards. The examination fees for the Basic Education Certificate Examination ${ }^{4}$ and other fees charged have discouraged several parents from taking their children to school. In the event of educational sponsorship, parents, especially those in the rural areas, are more inclined to sacrifice for their male children. This follows after the cultural notion that the place for the woman is the home. Government should ensure that basic education is free indeed, as defined in the FCUBE programme, and that secondary education is made accessible to the girlchild.

The rural secondary schools must be well resourced, in terms of personnel and equipment to attract the right calibre of academic staff. Since a greater proportion of girls is in the rural areas, the improvement in the facilities in the rural secondary schools would ensure that as many as those who pass the entrance examination enter.

The girl-child should be exposed to child health even from the basic level of education. The Ministries of Education, Health, Women and Children's Affairs should structure curricula for a special education of the girl-child on health issues related to women and children. They must be exposed to reproductive and child health issues. A special class should be devoted to that, apart from the general science classes.

The Non-Formal Education programme that targets adult illiterates should be intensified. There should be an integrated programme prepared by the Ministries of Education, Health, Women and Children's Affairs and Agriculture to reach out to adult learners, whilst the Ministry of Agriculture could carry out the education on maternal and child health

4 It is the final examination taken by Junior Secondary School students for entry into Senior Secondary School. 
through its extension services programme. The extension officers are at the grassroots, interacting with the rural women, so could carry out this information better.

The provision of basic health facilities and antenatal and child health services calls for prioritisation in the disbursement of the health budget. For a developing country like Ghana, a reduction in public spending for tertiary care facilities, specialist training, and initiating clinical care with lower cost-effectiveness will help increase the effectiveness of health spending (World Bank, 1993, p.13). There tends to be too much emphasis on clinical services other than primary health services. The reduction in tertiary health spending would save money for the provision of basic health services in the rural areas. These preliminary measures should precede the programming for health insurance, which would be the solution to the endemic financial predicament of the health sector and poor access to health services by the poor.

Besides, the strong correlation between maternal education and child health services calls for the establishment of a pilot project of integrating the two services. A strategy must be found to get the two integrated. Thereafter, a hypothesis could be formulated on the two events, based on the results, and an empirical survey conducted to assess the viability. Some strategies have been recommended. These include a basic and secondary school curricula that would expose the girl-child to the basic rudiments of child health, and the integrated programme among the four ministries to equip women with basic health care techniques of children through informal education and agricultural extension services programmes.

Finally, since poverty is the most serious factor affecting health conditions in general in the developing countries, efforts must be made to get women in gainful employment to improve upon their income base. Unemployed women, due to low or no formal education, must be equipped with vocational skills, and made accessible to minimum credit facilities that could give them economic empowerment.

\section{Conclusion}

Childhood mortality is quite high in Ghana, and measures are urgent to address it. In addressing the problem, the maternal factor comes into sharp focus, since maternal health is intricately linked with child health and vice-versa. In examining the relationship, the survey and other 
sources have shown succinctly the impact of mothers' education. A pilot project to integrate the education of women and maternal and child health is necessary, in order to serve as a basis for establishing its efficacy. To ensure the realisation of the objective of sustainable child health calls for a permanent source of health funding through a comprehensive health insurance, and the reduction in tertiary health expenditure to free funds for the provision of basic health services, especially for the rural areas. The empowerment of women through formal education and easy access to income sources are urgent prerequisites of sustainable child health. 

in the Ahafo-Ano South District of Ghana

This chapter has been submitted as:

Buor D. Income and the utilisation of health services in the Ahafo-Ano South District of Ghana. 


\section{Introduction and background}

The relationship between income and health service utilisation has been comprehensively analysed in medical geographic and other health care literature. Analysis however tends to focus on the effects of income on utilisation, not linking it with other major factors like distance, service cost, and insurance, transport cost, travel time and waiting time, to find out its relative importance. The other research gap has been that there is the sweeping assumption that income has such a strong relationship with service cost, leading to the conclusion that low-income earners would be affected by service cost whilst high-income earners would patronise health care. Such assumption may not be supported in certain situations, especially in the developing countries where misplaced priorities might influence the decision to spend money on areas other than health. In rural areas for instance, a man may spend extra income marrying another woman, or on alcohol other than health care. He would prefer using traditional medicine other than see the physician.

Research on the effects of income on utilisation has also concentrated on the bivariate approach, other than the multivariate, bringing in other related factors in a multivariate framework. Works by McKinlay (1972), Grossman (1975), Caldwell (1983) and Raghupathy (1996) used the bivariate approach in analysing utilisation. Yet, the multivariate approach offers a firmer basis for comparing independent variables that influence utilisation. In a research of such nature where variables follow a linear pattern, the multiple regression approach normally produces precise results. Yet this approach has not been widely used, especially in analysing the situation in African countries. The approach has been qualitative. Whilst not undermining the potency of the qualitative approach, its combination with the quantitative approach would offer a better explanation of the utilisation situation. There is yet another research gap. Which vulnerable groups are affected by the income factor in utilisation? Such area has missed the focus of health researchers. In the rural areas of developing countries, the vulnerable groups are women, the aged, children, the poor, and the illiterate. In a study of this nature, the ailing needs to be added. Such a study will unearth objective policy implications.

The income factor needs a more pragmatic analysis to provide the basis for a more comprehensive approach in addressing the problem. Research must go beyond the general impression that the income factor is predominant in the utilisation of health services, especially in the rural 
areas of developing countries, and identify related pathways of studying such a phenomenon to establish a broader framework for addressing the problem.

The situation in Ghana could offer a firm basis for making conclusions about the status in Sub-Saharan Africa. The selected rural district, AhafoAno South, is a typical rural area surviving predominantly on agricultural economy, with a few cottage industries. A few proportion of the population is engaged in the service and commercial sectors. There are a few public and civil servants some of whom operate from the Kumasi Metropolis that is over 30 kilometres away. This is because lack of basic infrastructure like potable water, access roads, well-equipped markets and schools and health facilities in the area. The population cannot rely on agriculture for survival due to the unstable prices for agricultural commodities. In some areas, overuse of the land is turning the forested agricultural land into savannah ecology. Incomes are thus generally low. Apart from those employed in the civil and public services, and the few well-established traders, sustainable incomes are denied a majority of the population. In fact, some of them rely on remittances from relatives in the urban areas.

Health facilities are also poor. There is only one government hospital and five health centres with poor laboratory facilities. Since there is only one hospital that does not boast of adequate basic laboratory facilities, there is often congestion, which brings in the problem of waiting time. Those who could afford travel to adjoining hospitals that are over 30 kilometres away, whilst those who cannot afford face the problem of long waiting time. Access roads are rather poor and this causes the problem of long travel time to health facilities. Some are inaccessible during the rainy season. Transport cost in a few areas is high. In such areas drivers charge illegal fares due to the inadequacy of transport facilities and the poor nature of access roads. This beefs up the overall cost of health care, which is higher considering the low average income of the area. Such a situation would seriously affect health care use, in an area where health is affected by poor nutrition and exposure to environmental hazards like vector affliction. More than $60 \%$ of the population is prone to malaria. Health insurance, which could relieve the population from the problem of a low uptake of health care, is at a low level in the district due to poverty and ignorance. 
The situation in the study area is thus complex. The poverty factor interlocks with several other factors like travel cost, which is related to distance, service cost and health insurance. Income is a variable factor even though majority of the population are in the low-income group. Women, the ailing, illiterate and the aged are more likely to be affected by the income factor. Because of low participation in formal education, a factor that is dictated by culture, women have low access to jobs in the formal sector that guarantee regular income. With no well-organised social security system, most of the aged rely on relatives and children for their health needs. The poverty factor thus has the potential of affecting utilisation in the district.

\section{Research questions and objectives}

Given the problem in the study area, the following research questions emerge. First, to what extent does income influence utilisation in the rural district? Second, how does income relate to factors like transport cost, service cost and insurance that are interrelated? Three, what is the position of income among the key access, need, predisposing and enabling factors of utilisation? Finally, how does utilisation by income affect vulnerable groups of women, the aged, the illiterate and the ailing? The objectives that result from the research questions are fourfold. First, to examine the magnitude of income on utilisation of health services. Second, to show the relationship between income and transport cost, service cost and insurance. Third, to examine, using multiple regression, the position of income among other key factors influencing the utilisation of health services. Finally, to structure a model on income and utilisation of health services in the rural district.

\section{Literature survey and conceptual framework}

Incomes have been found to show a direct relationship with the utilisation of health services, especially in developing countries where sources of health financing and levels of health insurance are low. In most studies, income and service cost have been related. Low-income earners have been found to be affected by the service cost factor, so a distinction is not clearly made between the two factors. Several studies have indicated that poverty has a negative effect on the utilisation of health services (Habib et al., 1986; Pickett and Hanlon, 1990; Delanyo, 1992; Ensor and Pham-Bich-San, 1996). Habib et al. (1986), in a household survey in rural Iraq, found that the use of higher-level government health services and private clinics did increase substantially with increasing income. Mead et al. (2001) in study of the influence of 
income, education and work status on women's well being, observed that women living in poverty are less likely than their higher income counterparts to have access problems and report low overall health scores. In all such situations the rural dweller suffers more of the poverty scourge than his urban counterpart. Chernichovsky and Meesook (1986), in a study of utilisation of health services in Indonesia, confirmed earlier studies about the primacy of poverty as a barrier to the utilisation of health services.

Other studies reveal similar trends. In Central Asia, growth in out-ofpocket payments has seriously affected access to health care (McKee et al., 2002). Anglin and White (1999), in a study on poverty, health care and problems of prescription medication, concluded that poverty has had a negative association with health care and use. To Muntaner and Lynch (2000), poverty and health behaviours are key determinants of population health. They hold the position through a survey that poverty restricts the ability to effectively utilise health services especially in poor countries.

Related to income are service cost, transport cost and health insurance. The poor are more likely, in situations where there is no subsidised health insurance, to suffer more from the effects of service cost on utilisation. In developing countries, the introduction of user fees, following the recommendation of the World Bank, as a panacea for ensuring effective delivery of health care, has reduced utilisation. Ghana was one country that suffered from the negative effects of the introduction of user fees (Shaw and Griffin, 1995). In Ghana, the introduction of the Hospital Fee Regulation of 1985, under the Structural Adjustment Programme (SAP), has led to a decline in hospital use in the country as a whole (Sowa, 1993; Kwabia, 1996).

Transport cost has been related to distance in most studies, since, in most cases in developing countries, the greater the distance, the greater the transport cost; and the rural areas suffer more from the trauma of distance. Using the focus group discussion (FGD), Wilson (1997) found that the distance factor was one of the major reasons for low utilisation of the maternity home at Nsawam, an urban centre in Ghana, and the cost of transport could not be ruled out. A World Bank Report (1994) also indicates that, in the developing countries, lack of transport and poor roads can make it extremely difficult for women to reach even relatively nearby facilities. 
The distance factor, which, to a significant extent, determines transport cost, is a major problem in the rural areas where health services are poor. In Kenya, it is estimated that only $10 \%$ of the country's doctors served rural areas and the doctor-to-population ratios range from 1:990 in the cities to 1:70000 in the rural areas (Good, 1987). The situation has not improved significantly, with the current exodus of doctors from developing countries to Europe and North America to seek better conditions of service. In India, there are problems of differential access to health service in rural and urban areas, with $25 \%$ of the rural population having care within 2 kilometres, whilst $84 \%$ of those living in urban areas have similar access (Akhtar and Izhar, 1994). Thus long distance has been found to show a low rate of utilisation of health services (Stock, 1983; Bailey and Phillips, 1990; Ganatra and Hirve, 1994; Oppong and Hodgson, 1994; Muller, 1998; Kinman, 1999).

Health insurance has been found to increase the uptake of health services, but it is the high-income earners that have the capability to purchase it. In developing countries, Criel et al. (1999) found that health insurance has a significant impact on utilisation, with the insured utilising health services more than the uninsured. Supakankunti (2000), in a study of the future prospects of voluntary health insurance in Thailand, discovered that greater use of health services was the result of the introduction of the Health Card Program. Chen et al. (2001) also concluded in a study of the impact of national health insurance on the utilisation of health care by pregnant women in Taiwan that the utilisation of prenatal and intrapartum care services, especially for the more expensive services, substantially increases since the implementation of the national health insurance plan. Tilford et al. (1999), Khander and McCormack (1999) and Fong (1999), in separate studies conclude the positive effects of health insurance on the utilisation of health services.

A very important predisposing factor influencing utilisation, which could indirectly be related to income is education. Education has been found to show a positive relationship with utilisation (Grossman, 1975). The educated will tend to utilise health services more and effectively than the illiterate. Of great effect of the relationship between education and health care utilisation is the education of women (Wong et al., 1987; Caldwell, 1983; Swenson, 1993; Mensch et al., 1985; Raghupathy, 1996) who, in the Ghanaian culture are responsible for childcare. 
The study is to be carried out using a combination of Andersen-Newman (1973) and Aday and Andersen (1974) and Andersen (1995) frameworks on utilisation of health services. The latter two are based on the former, Andersen-Newman's. They observed that, need per se was not the only important factor in utilisation in developing countries. They identified predisposing and enabling factors, along with need (PEN) as the strong pull factors influencing utilisation. They failed to emphasise the spatial and access as well as provider characteristics (government policy) that have been emphasised by Aday and Andersen (1974) and Andersen (1995). In Ghana and other developing countries government is the key provider of health services and determines cost of care and location and allocation of health facilities. A combination of the PEN, spatial, and access factors of distance, time and cost, would provide a broader framework for carrying out the research.

Three hypotheses shall be tested. First, income shows a strong positive relationship with utilisation. Second, service cost, health insurance and transport cost, show a similar relationship with utilisation. Third, income is about the most important barrier to the utilisation of health services. Fourth, the vulnerable groups of the illiterate, female, ageing and sickly are adversely affected by the income factor in the utilisation of health services.

\section{Methods}

\section{The study design and variables}

The study is a retrospective-cross-sectional empirical survey that intends to examine the impact of income and related factors on utilisation of health services in a rural district. It is also correlational and not intended to assure a cause-effect relationship. Aggregated data are used in the analysis that is based on selected communities and a sample of the population, male and female above the age of 18'. The independent (predictor) variables used are age, sex, income, education, distance, service cost, transport cost, insurance, travel time, waiting time and health status; whilst the dependent (outcome) variable is utilisation. These could be categorised under predisposing-enabling-need (PEN) as well as restrictive factors.

Age 18 is the legal age of maturity. Citizens are covered by the franchise at this age. At this age, a person would have graduated from a Senior Secondary School (High School) and could take a job. 
Age is defined as age at the last birthday whilst income is average income per month of household. The collection of data on income was guided by the method used in the Ghana Living Standards Survey (GSS, 2000, p.103). The components were, wage income from employment, household agricultural income, non-farm self-employment income, rental income and net remittance and other minor sources. Since agricultural income predominates in the rural areas, average monthly agricultural produce of farmers was determined using the operating market prices. Education is conceptualised as completed level of education whilst distance is distance from home to the health facility. Service cost covers consultation cost, cost of laboratory services and drugs, whilst transport cost is the cost of transport to and from the service centre. The modes of such costs were used in the analysis. Travel time is defined as the time taken to travel, either by a vehicle or by foot or both to the service centre, whilst waiting time is defined as the time spent from arrival at the service centre to when the doctor calls the patient. Health status is defined as the number of times a respondent fell sick during specified periods, in a continuum ${ }^{2}$. Utilisation is defined as the number of times a respondent attend hospital or health centre the last three times he experienced sickness spells.

\section{Sampling and data collection}

A sample of 400 was used for the survey, the selection based on the systematic random procedure. Ten settlements (figure 8.1) scattered over the entire district to ensure spatial balance, were selected. The selection was also based on various levels of physical accessibility to the health facilities. This was guided by the status of the roads linking the settlements. The survey covered 10 settlements. In all 16 persons earmarked as respondents failed to participate in the interviews. They felt that the survey was a mere waste of time, since it would not result in the improvement of their living conditions. This however did not affect precision since persons of similar status were found to replace them. There was however a modification of the sample interval, which bias indeed, did not affect the overall quality of data.

In the study area, sickness is defined as perceived sickness. A person considers himself sick and needs medical attention only when he is not capable of going about his daily duties. It is the educated who may be very conscious about their health, caring about regular medical check-ups. This will even depend upon his wealth status. 
There were two instruments used in the data collection: the questionnaire and formal interview schedules. Whereas the questionnaire was applied to the educated, the formal interview schedule was applied to the illiterate. Some of the educated however opted for the formal interview to avoid the problem of completing the questionnaire and call-backs. The sample intervals for selecting the houses were 3 for minor settlements and 5 for relatively major settlements ${ }^{3}$. Settlements where houses had not been listed, or planned with streets separating rows houses, were listed to facilitate the use of the systematic sampling procedure.

Figure 8.1 Distribution of health institutions and settlements in AhafoAno South District

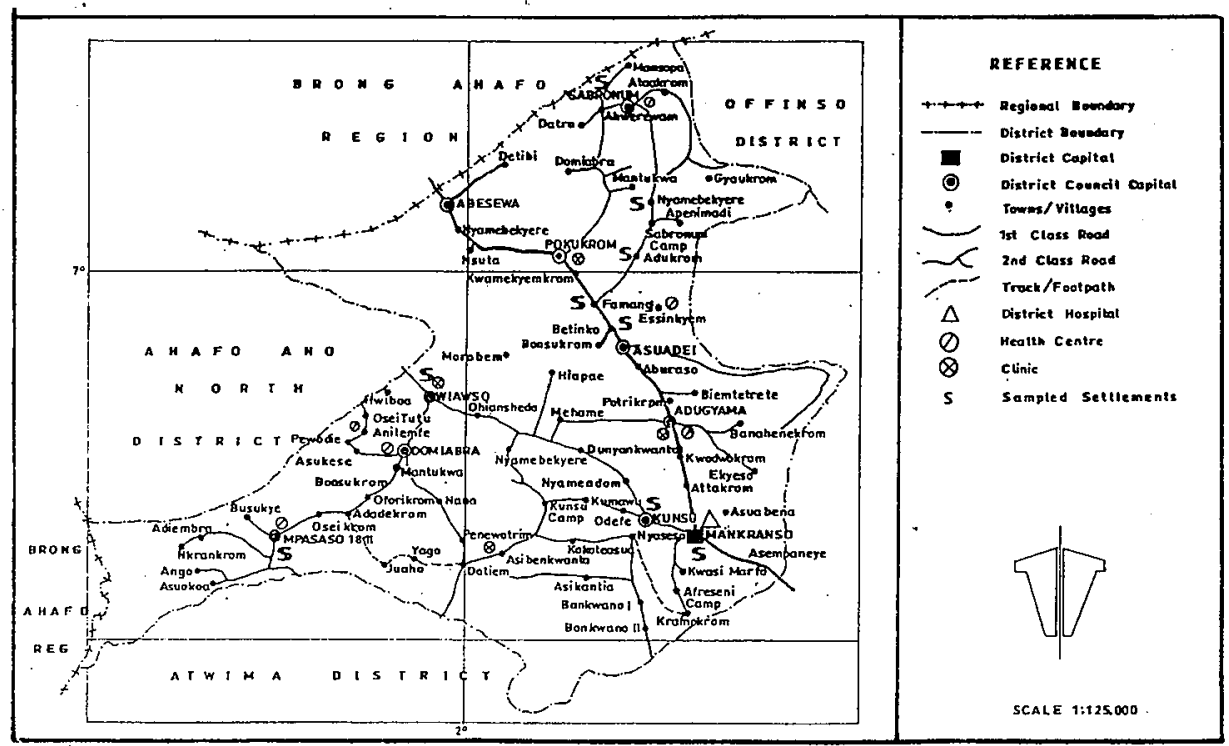

Source: District Assembly and Ministry of Health, Mankranso, 1996

\section{Data analysis}

Data were analysed using both quantitative techniques of multiple regression and Kendall's tau-c, percentages of various responses, and a chart. Linear regression was suitable since most of the data showed a linear relationship. Age, income, distance, travel time, waiting time, service cost and transport cost were entered as continuous variables,

3 Minor settlements are those with less than 1,000 population and major settlements, those with more than 2,000 population. Settlements with less than 1,000 population are Adukrom, Faamang, Betinko, Aburaso and Nyamebekyere. 
whilst health status and utilisation were entered as ranked variables. Sex and insurance were ranked as dichotomous variables. Health status was ranked from 1 to 5 . Falling sick once in a week was given a rank of 1 , once in two weeks a rank of 2 , once in a month, 3 , once in three months 4 and rarely falling sick, 5. For utilisation, non-attendance at a health facility the last three times a respondent fell sick was given a rank of 0 , for one attendance, 1, two attendances 2 , and three attendances, 3 . No attendance was defined as "rarely", one attendance, "irregularly, two attendances "moderately" and three attendances "regularly". Male and the insured were each given code 0 , whereas female and the uninsured were each given code 1.

Bivariate correlations were used to show the relationships between income, service cost, insurance and transport cost, and utilisation, whilst compound bar graph was used to show the relationship between income and utilisation based upon the responses of respondents whether high service cost would affect their utilisation behaviour.

The main thrust of the analysis was however the use of linear regression to show the relative impact of income and other major factors on utilisation. Bivariate correlations matrix was derived from the SPSS software to show the association of between the variables and utilisation and the correlations among the variables. Multiple regression was also derived from the SPSS software. Correlation matrix was also used to detect possible problems of multicollinearity. Bivariate values of $\leq .70$ were deemed to have fallen within the collinearity threshold; subsequently, one of the variables with a weaker correlation with utilisation was removed from the multiple regression model. In the multiple regression analysis, variables that showed interaction terms of $\leq .05$ were considered significant. The stepwise method was used to show the key variables that affect utilisation together with income. Kendall's tau-c was used to show the impact of the effects of income on utilisation on the vulnerable groups of women, the aged, the illiterate and the sickly.

\section{Results}

\section{Distribution of the study variables}

The distribution of the variables used for this study is indicated in table 8.1. 
Table 8.1 Distribution of the study variables $(\mathrm{N}=400)$

Variables/sub-variables

Values: standard deviation (sd), mean and \%

Age:

Mean

SD

Sex:

Male

$40 \%$

Female

$60 \%$

Income per month:

Mean

$4226,364.66$

$\mathrm{SD}$

Health insurance:

Insured

Uninsured

Educational status:

Never-been-to-school

$42.5 \%$

Basic education

$32.5 \%$

Secondary education

$24.0 \%$

Tertiary education

$1.0 \%$

Service cost:

Mean

$436,634.09$

$\mathrm{SD}$

Transport cost:

Mean

$43,287.50$

SD

Distance (in km.):

Mean

19.72

SD

Travel time (in mins.):

Mean

SD

Waiting time (in mins.):

Mean

76.02

$S D$

61.51

Health status (Periodicity of sickness):

Once a week

Once in two weeks

$7.5 \%$

Once a month

$26.3 \%$

Once in 3 months

$28.5 \%$

Rarely

$36 \%$ 
Source: Field Data, 2001. Exchange Rate: $\$ 1=\varnothing 7000$

The study variables show the background characteristics, and utilisation problems of respondents. Incomes are generally low. The average income is barely above a dollar a day; and, with a relatively high standard deviation, the variation is wide. There are several of the respondents who earn less than one dollar a day. The insurance status is rather too low. Education on health insurance is rather negligible; and, if given, poverty would impede access to it. The level of education is also very low. More than $42 \%$ can neither read nor write. With mean service cost above 50 cents, and most respondents receiving less than a dollar a day, a low level of utilisation of health services would not be in doubt. Mean transport cost, though low, cannot be afforded by some of the respondents in areas where access roads are too bad. Mean distance is great, and show wide disparities. This reflects in travel time. Waiting time is also high, with wide disparities. Health status is barely average, and not very appreciable. Over $35 \%$ fall sick at least once a month. Utilisation, as would be expected, is poor. Less than $20 \%$ utilise health services regularly.

\section{Income, related variables and utilisation}

Income shows a high association with utilisation. The bivariate correlation between income and utilisation is .515 , being significant at 0.01 level (2-tailed) (table 8.2). The relationship between income and utilisation of health services could be shown using a compound bar graph (figure 8.2). 


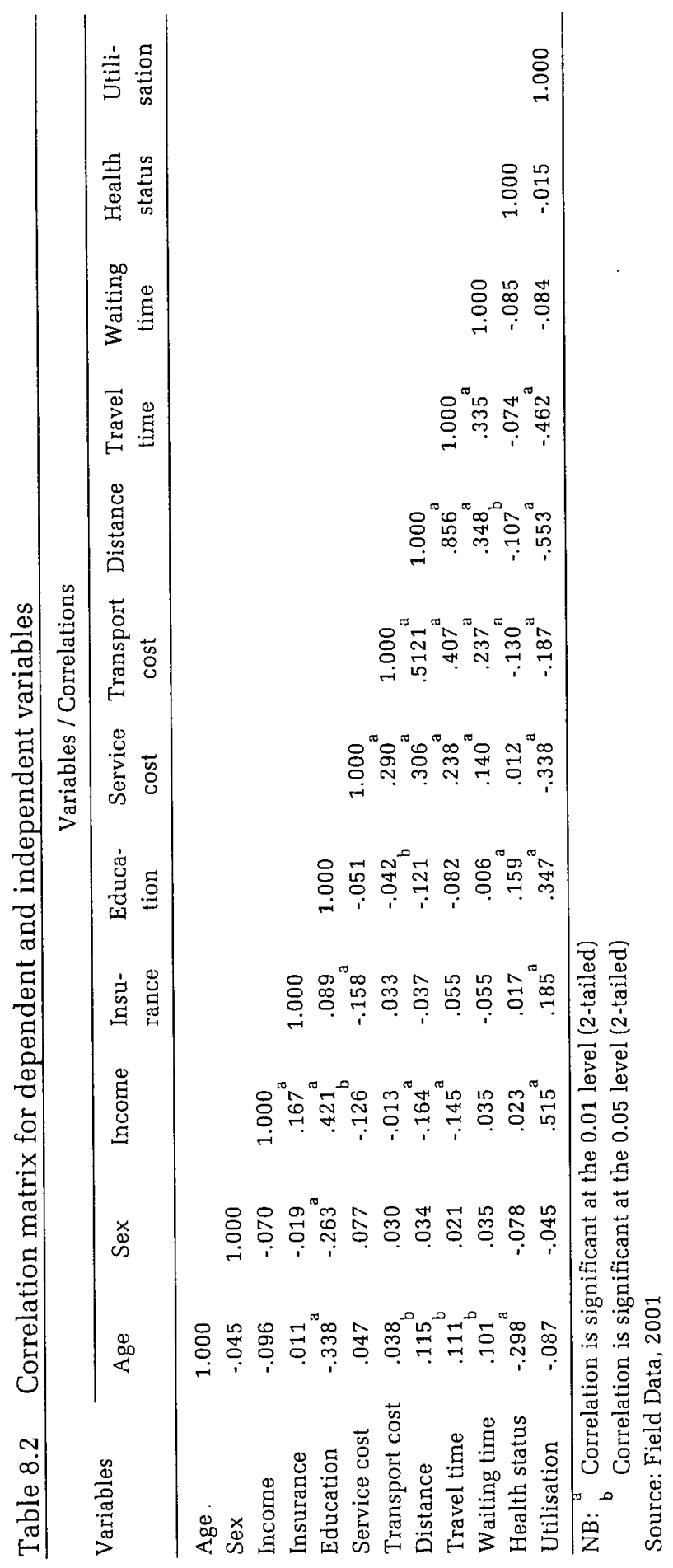


Figure 8.2 Income and utilisation of health services

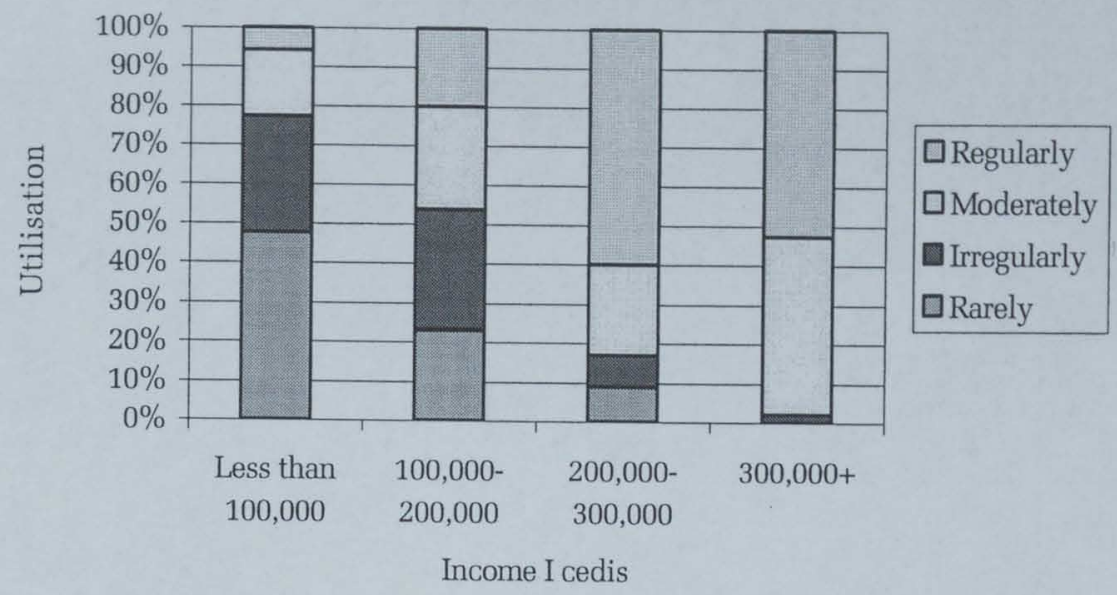

Source: Based on Field Data, 2001

The graph shows clearly that there is a positive association between income and utilisation of health services. High-income earners tend to use health services more regularly. Over $95 \%$ of the highest income earners utilise health services either moderately or regularly. On the contrary, about $48 \%$ of the very poor rarely utilise health services. Of the related variables, apart from service cost, the others, insurance and transport cost do not give a similar pattern. The correlation between service cost and utilisation is -.338, which is below that of income. That of insurance is .185 and transport cost -.187 (all three being significant at 0.01 (2-tailed). Nevertheless, the fact is established that, going by bivariate correlations, these three variables have significant association with utilisation thus, emphasising the predominance of the income factor.

Responses of respondents to whether service cost discourages them from accessing health care by income shows clearly the positive impact of income on the utilisation of health services (table 8.3). Respondents were asked whether service cost discourages them from utilising health care. The responses were, "regularly", "moderately", and "irregularly". ChiSquare $\left(\chi^{2}\right)$ results indicate a significant difference by income at .000 significance, indicating a strong impact of income on cost of service. If all the other independent variables are considered, it is only distance that exceeds income in the strength of association with utilisation. Travel time shows an association which is a little lower than income. 
Table 8.3 Effects of service cost on utilisation by income as reported by respondents

\begin{tabular}{lrrrr}
\hline & \multicolumn{4}{c}{ Income (ष) [\%] } \\
\cline { 2 - 5 } Response & $\begin{array}{r}\text { Less than } \\
100,000\end{array}$ & $\begin{array}{r}100,000- \\
200,000\end{array}$ & $200,000-$ & $300,000+$ \\
\hline Regularly & 22.3 & 68.8 & 8.9 & 0.0 \\
Moderately & 35.0 & 56.7 & 7.6 & 0.6 \\
Irregularly & 21.1 & 45.5 & 19.5 & 13.8 \\
Total & 27.0 & 56.6 & 1.7 & 4.6 \\
\hline
\end{tabular}

Source: Field Data, 2001

\section{Regression analysis}

Regression analysis was necessary due to the linear nature of the data. The correlation matrix showed the association among variables, whilst regression shows the relative impact of the independent variables on the dependent variable, utilisation. The correlation matrix shows a strong correlation between travel time and distance, as high as .856 (table 8.2). Travel time was thus removed from the regression analysis to avoid multicollinearity problem. Distance was retained because it makes a stronger association with utilisation than travel time.

The stepwise method was used to show variables that are significant. The regression results are indicated in table 8.4. The impact of income on utilisation is very significant, and the beta coefficient relatively higher. The impact is greater than service cost, which shows a negative impact on utilisation, even though the levels of significance are the same. Income is exceeded only by distance in the utilisation of health services. Transport cost has no impact on utilisation whilst the impact of education is relatively weaker. The impact of health status is negligible. Those with poorer health status utilise health services less. The adjusted co-efficient of determination of .529 , which shows the level of fit of the model is quite high. It is based on a regression coefficient of .732. The model is thus a good one hence, confidence in the results is not in doubt. 
Table 8.4 Regression factors

\begin{tabular}{|c|c|c|}
\hline Variables & Beta coefficients & Significance \\
\hline Distance & -.501 & .000 \\
\hline Income & .355 & .000 \\
\hline Service Cost & -.160 & .000 \\
\hline Transport Cost & .126 & .002 \\
\hline Education & .140 & .000 \\
\hline Health Status & -.080 & .025 \\
\hline Adjusted Regression Square $\left(R^{2}\right)$ & \multicolumn{2}{|c|}{.529} \\
\hline
\end{tabular}

Source: Based on Field Data, 2001

Table 8.5 Relative effects of income on utilisation on vulnerable groups

\begin{tabular}{lcr}
\hline Variables / Sub-variables & Kendall's tau-c & Significance \\
\hline Literacy: & & .000 \\
Literate & .504 & .002 \\
Illiterate & .209 & \\
& & .000 \\
Sex: & & .000 \\
Male & .484 & \\
Female & .377 & .000 \\
& & .003 \\
Age: & & \\
18-59 & .440 & \\
$60+$ & .305 & .471 \\
& & .240 \\
Health status: & & .000 \\
Once a week & .163 & .000 \\
Once a fortnight & .262 & .000 \\
Once a month & .337 & .604 \\
Once in 3 months & .366 & \\
Rarely & & \\
\hline
\end{tabular}

Source: Field Data, 2003

The effects of income on utilisation have greater impact on vulnerable groups of the illiterate, females, ageing and sickly. The relative effects as depicted by Kendall's tau-b results are indicated in table 8.5. The results indicate that the illiterate, female, aged and sickly are limited by income in the utilisation of health services. The literate, male, economically active and healthy are at an advantage. They are less affected by the effect of income on utilisation. 


\section{Discussion}

Income has clearly exhibited itself as a factor that strongly correlates with the utilisation of health services in the rural district. The poor are less likely to utilise health services. This factor is further illustrated by the negative effect of service cost on utilisation. Incidentally, the effect of service cost on utilisation is lower than for income. Transport cost does not influence utilisation. Whereas transport cost is not relatively very high, one explanation for such a situation is that respondents tend to utilise health facilities that are nearer them, implying a lower transport cost. The effect of education is far lower than income. This could be explained by the fact that there are no clear cleavages in the levels of education in the district. A very significant proportion of the respondents is either illiterate or has received just basic education ${ }^{4}$. Health status has a very negligible effect on utilisation. This need factor was what Andersen and Newman (1973) postulated that would not have a significant effect, without combining with other factors, in developing countries. Their argument has been vindicated by this research. In the developing countries, the predisposing and enabling factors, and restrictive factor of distance, tend to have greater effects on utilisation than need. The distance factor has emerged as the most important factor influencing utilisation. It is indeed, a motivating factor. In the rural area, one may have the financial means to access health care, but if the distance to the health institution is far, he shall be discouraged and may prefer using intervening opportunities like pharmacy shops, herbal medicine and "charlatans". The level of education might limit this attitude.

Vulnerable groups of the illiterate, females, ageing and the ailing are negatively affected by the income factor in accessing health care. The illiterate are less likely to earn high incomes. They are either farmers who do not earn regular incomes, and whose production is dictated by natural forces, or small-scale entrepreneurs who lack planning abilities for increased production and also lack the power to access bank credits to expand their operations. The lack of a consistent social security system for workers leaves the aged pensioner in a poor status. In the rural area, most of the aged do not have access to social security scheme since most of them will not have operated in the formal sector. The ailing are affected by the income factor. In the rural area, as already intimated, most of the residents do not have access to formal wage employment. They are

4 The standard of basic education products are quite low, such that, with time, their status gets no better than the illiterate. 
farmers, and the farming system is labour-intensive. The ailing will therefore suffer from acute poverty unless assisted by his relatives. With the NHIS yet to be fully implemented, the ability of the ailing non-worker to access health care is in serious jeopardy.

The hypothesis that income shows a strong correlation with utilisation has been vindicated. So has the hypothesis that the vulnerable groups of the illiterate, female, aged and sickly are adversely affected by income in the utilisation of health services. Insurance and transport cost have not been found to show an impact similar to income on utilisation ${ }^{5}$. Nor has the hypothesis that income is the most important factor influencing utilisation. Distance has rather been found to have the greatest effect on utilisation.

The research results have concomitant policy implications. First, health facilities must be within easy reach of the population. With an ailing economy, it shall be difficult for government to put up more hospitals and health centres. As an immediate measure, primary care centres manned by professional nurses or medical assistants could be established at reasonable distances, say at 5-kilometre interval. These centres could be developed into health centres, as funds are made available by the Ministry of Health. The communities could be made to be involved in the financing and management of the services. Second, there must be an aggressive programme to economically empower the citizens to reduce poverty. This can be done by ensuring free and compulsory education at least at the basic level whilst facilities are made available to facilitate access to secondary education". Third, the rural population, especially women, should be exposed to vocational skills to enable them engage in small-scale industries to improve their income opportunities. Finally, the access problem would keep hanging if government does not take a bold

"The Government of Ghana in 2001 passed the National Health Insurance Bill. The scheme was inaugurated in March 2004. It is yet to be fully implemented. An experimental scheme in which some districts have been selected to operate a Mutual Health (Support) Organisation (MHO) has been instituted. Reports indicate that some district communities are achieving success in this pilot project.

(6 The government has introduced a Free Compulsory Universal Basic Education (FCUBE) programme. This has not achieved tremendous success. Some parents find difficulty in providing basic equipment like writing materials, and to pay certain basic fees. 
step to fully implement a national health insurance scheme ${ }^{7}$. A means must be found for the rural communities to make a minimum contribution to the scheme to make them easily access health care.

Figure 8.3 A conceptual model on income and utilisation in the rural district

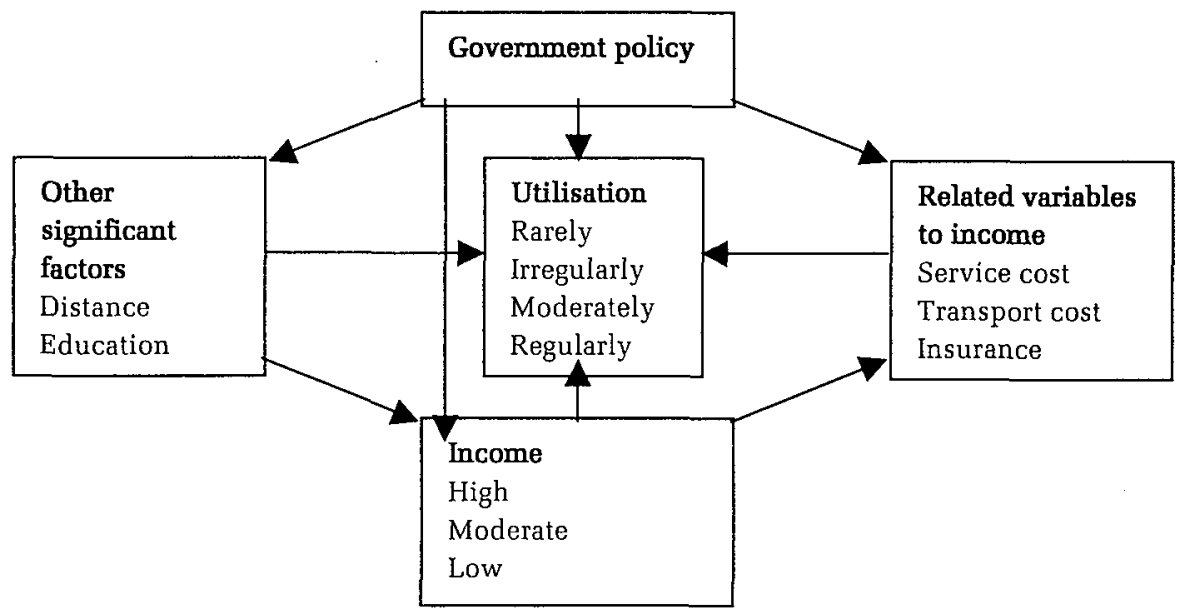

Source: Author's Construct Based on Survey Results, 2003

A conceptual model of income and utilisation in the rural district emerges from the survey (figure 8.3). Income is related to service cost, transport cost and insurance at one level. These are the direct relationships. At another level, it is indirectly related to distance and education. The distance factor would involve transport cost, which affects income, so is educational cost. All these variables influence utilisation. Government policy affects all the variables. It affects the related variables to income, other significant factors affecting utilisation, and income, hence, utilisation.

\section{Conclusion}

The survey has made it evidently clear that income is a very important factor influencing utilisation in the rural district, confirming other surveys. Distance is the only single factor that more significantly explains

7 Even though insurance showed a positive bivariate association with utilisation, it does not show as a significant factor by the linear regression analysis. This is due to the very insignificant proportion of the respondents enjoying health insurance. Transport cost, though does not show as a significant factor in the bivariate correlation, is a potential factor that could influence utilisation, especially with the escalating oil prices. 
utilisation behaviour than income. The income factor is more reinforced by the negative impact of service cost, which is related to income, on utilisation. It is also evident that vulnerable groups of the illiterate, women, the aged and the ailing are more affected by the income factor in the utilisation of health services. This defies equity in health care. Although the results are compatible with several other surveys, this survey has the added advantage of using a multivariate analysis in determining the position of income among the other important variables in the utilisation of health services in the rural area. Second, a quantitative model has been used to identify the sufferers in the incomeutilisation syndrome that is urgent for policy implications. Third, a conceptual model of income and utilisation has emerged to serve as a basis for examining the utilisation behaviour in rural areas of developing countries. 
The potential of a national health insurance scheme for improving the utilisation of health services in Ghana

A case study of Kumasi Metropolis 


\section{Introduction and background}

The problem of financing health services has engaged the serious attention of governments of developing countries. Saddled with economic predicaments, developing countries allocate very scanty resources to the health sector. Whereas health care is a right, a social responsibility of the state, inadequacy of resources makes it pretty difficult for governments to ensure adequate access of their citizens to health care. In developing countries, public expenditure in the health sector rarely exceeds an average of 5 per cent of Gross Domestic Product (GDP), or $\$ 10.00$ per capita per year (United Nations, 1996). In Ghana as a whole, health takes only 4.7 per cent of GDP (World Bank, 2000). There is also the problem of allocation of resources to the various health sectors, which defies equity. In Ghana for instance, in the 1980 s, spending on specialist tertiary care amounted to $40 \%$ of the health budget, yet this benefited only $1 \%$ of the total population; whilst primary health care spending was only about $15 \%$ of the health budget (Gatrell et al., 2000).

There is also the problem of a large income inequality, poverty, uneven geographical spread of both health services, ability to pay and a very large informal sector. The problem of a large income inequality will make the fixing of a national premium in an equitable insurance system difficult, whilst mass poverty will affect the ability to pay. Besides, mass unemployment and a very large unorganised informal sector, amidst mass illiteracy, will create a problem of the collection of premium. In Ghana, government poverty alleviation strategy has suffered the problem of loan recovery from beneficiaries.

There is the frightening issue of user charges that significantly affect the utilisation of health services. In the Congo, the introduction of user charges led to a steep drop in numbers of antenatal visits and visits to childcare clinics (Turshen, 1999). In Ghana, the introduction of the user fees has resulted in a significant drop in the utilisation of health services. The Cash and Carry Scheme, which enjoins on the user of health services to pay fully for the cost of service, was introduced in the mid-80's as a product of the Structural Adjustment Programme (SAP). Immediately after the introduction of the user fee, attendance at health care centres fell (Washington and Enyimayew, 1989). Nationally, outpatient utilisation fell from 4,468,482 in 1984 to $1,607,386$ in 1985 and 2,051,501 in 1986 (Dakpallah, 1988). In a study of user fees, health staff incentives, and service utilisation in Kabarole district, Uganda, Kipp et al. (2001) gathered that, after the introduction of cost sharing, overall utilisation of 
general outpatient services, assessed by combining the data from all the participating units, dropped by $21.3 \%$. These confirm the effect of poverty on utilisation. Various studies establish that poverty is a predominant factor in utilisation. Cost of service scares people away from seeking health care, and the worst affected are low-income earners (Habib et al., 1986; Chernichovsky and Meesook, 1986; Pickett and Hanlon, 1990; Ensor and Pham-Bich-San, 1996; Delanyo et al., 1992).

Access to insurance, on the other hand, has been found to improve health care use. Health insurance, which is very important in utilisation, is least developed in most developing countries. In Ghana the NHIS was inaugurated in March 2004. A Mutual Health Organisation (MHO) supervised by the government has been introduced in selected districts as a pilot project to prepare for the full implementation of a NHIS. Utilisation is higher for insured patients in developing countries where health insurance exists. In a study of the Bwamanda hospital insurance scheme in Zaire (Democratic Republic of the Congo), it was realised that utilisation increased among insured patients (Criel et al., 1999). Supakankunti (2000), in a study of the future prospects of voluntary health insurance in Thailand, discovered that greater use of health services was the result of the introduction of the Health Card program. There was an improvement in accessibility to health care and a high level of satisfaction among Card holders. Chen et al. (2000) conclude in a study of the impact of national health insurance on the utilisation of health care services by pregnant women in Taiwan that the utilisation of prenatal and intrapartum care services, especially for the more expensive services, substantially increased in Taiwan since the implementation of the national health insurance plan.

Developing countries are faced with hard choices in financing health care and ensuring that their people enjoy adequate access to health care. External funding had hitherto been the solace of most countries. In 1990 for instance, most sub-Saharan African countries obtained at least $25 \%$ of their health care financing from external sources. In Ghana, 199 donors were active in the health sector in 1992 (International Labour Organisation, 2000). Such a trend however is not sustainable, so developing countries will have to adopt a more pragmatic and sustainable approach in addressing the problem of health financing. In recent years, the nature of external funding has changed, with overall levels of support reduced and a shift towards imposing specific conditions on receiving governments. 
Certain factors characterise the insured patients in developing countries. These include income, education, employment and marital status. In a comparative analysis of private health insurance purchasing decisions with national health insurance in Taiwan, Liu and Chen (2002) realised that higher income and education levels are associated with increased probabilities and larger quantities of private insurance purchases. The study also revealed that married females, the employed and household heads working in state-run enterprises are more likely to purchase private insurance than their counterparts (Liu and Chen, 2002). Supakakunti (2000), in a study of future prospects of voluntary health insurance in Thailand observed that employment, education levels and the presence of illness are significant factors influencing health (insurance) card purchase in Thailand. In Ghana government policy of Free Universal Basic Education (FCUBE) faces serious financial and logistic constraints, making access difficult for low-income earners.

Given the potential of health insurance in ensuring a higher utilisation of health services and the mobilisation of funds to capitalise the health sector in Ghana, it becomes imperative that such a scheme be examined in its broad dimensions. It is the primary aim of this paper to utilise empirical evidence drawn from a sample of 250 from the communities in the Kumasi Metropolis, supported by opinions of policy makers as well as health, and economic planning professionals, to examine the potential of health insurance in addressing the utilisation problem.

This paper evaluates the potential of the insurance system as a vehicle for ensuring adequate access and use of health services in Ghana. A framework for a workable NHIS is also recommended. The specific objectives of the paper are three-fold: Firstly, to establish the desire of communities for a NHIS. Secondly, to examine the operations of existing health insurance schemes in Ghana and other developing countries with the view of establishing an acceptable and effective strategy. Thirdly, to assess the health service utilisation behaviour of the insured vis-à-vis the uninsured of the sampled population.

The study is guided by the following hypotheses: First, a national health insurance scheme will have a positive impact on utilisation of health services. Second, education and income have a greater positive effect on insurance purchase than other socio-economic and demographic variables. 


\section{Health insurance strategies in developing countries}

Several works have been produced on health insurance models, strategies and experiences in developing countries. Micro insurance, which involves communities that pool risks, i.e. community-based health insurance (CBHI), dominates the insurance portfolios in developing countries. McCord, in case studies of health care micro insurance from Uganda, Tanzania, India and Cambodia identified four models of health insurance namely, partner-agent model, community-based model, fullservice model and provider model (McCord and Michael, 2001). In the partner-agent model the study found that clients sought care earlier with reports of improved health, and it includes preventative care. In the community-based model it was found that no prevention and permission from group leader was required. Doctors could not tell between insured and uninsured patients and there were incentives to oversubscribe. In the full-service model, there was no incentive to be treated early and cover provided only 24 hours after hospitalisation while reimbursement only partially covers costs. In the provider model, door-to-door primary care competed with the state and it is becoming a clinic service but incentives work at this level. It involved preventative care with enrolment examinations. The provider model seems to compare with the comprehensive insurance package provided by the sick fund in most industrialised nations. In developing countries, poverty and employment make if pretty difficult for premiums to be paid, hence the need for state support in insurance regimes. With developing problems struggling with the perennial problems of poverty as reflected in low per capita incomes, strict discipline in state spending is urgent in order to attend to critical issues like health care.

Coverage must also be moderately wide to ensure higher enrolment, whilst an education on the entire insurance package, especially on risk pooling, was necessary, especially for the illiterate poor. Besides, clients must be guided on the best way to safe for the premiums, and that there must be periodic assessment of the products to determine viability and effectiveness.

In a study of the synthesis of case studies of micro insurance and other forms of extending social protection in health in Latin America and Caribbean, financial sustainability is found to be precarious due to the fact that almost all these systems target low-income populations. Second, there is scant capacity to collect premiums that would sustain them over the long run and these populations have higher a health risk profile. Third, the size of the beneficiary portfolio of micro-insurances and their 
efforts at increasing penetration are major issues (International Labour Organisation, 1999). The situation thus calls for a blend of both high and low income earners to beef up the financial capacity of the insurance, with government providing subsidies to reduce risk created by the imbalances in the premium payable.

Writing on the emerging movement of community based health insurance in sub-Saharan Africa Jutting and Wisemann (2001) note that, given the unique ethnic, lingual and cultural diversity within African nations, the $\mathrm{CBHI}$ approach may be particularly valuable because it allows adaptation to local conditions. It was also found that the implementation of CBHI schemes in Sub-Saharan Africa has had mixed results with viability and acceptance largely depending on design and management of the scheme, community participation, regulations at the level of the health care provider, quality of services and on the socio-economic and cultural context. The study concluded that a public-private partnership may provide scope for improvement of $\mathrm{CBHI}$.

For developing countries like Ghana, the adoption of private insurance with its high premium, and not giving room for the poor who are not capable of paying could not be recommended. As a start, public-owned insurance with flexible arrangements for insurance purchase making provision for the very poor and people in the informal sector is strongly recommended. As their economies improve, other sophisticated forms could emerge. Nevertheless, persons with high incomes could be encouraged to be associated with the various sophisticated forms as a precursor for broad-based insurance systems as their economies increase.

\section{Status of health insurance in Ghana}

The structure of the insurance system in Ghana is depicted in table 9.1. There are about three main types namely, the public/Mutual Health Organisations (MHOs), private, and the community micro insurance. Benefits enjoyed by some semi-autonomous state institutions like the universities could be categorised as some quasi-insurance since that undercuts their total remuneration. The NHIS is yet to be fully operative; and government, through the Ministry of Health, is experimenting with the MHOs in selected districts as a precursor to the national insurance scheme.

The country, until the National Health Insurance Act, 2001 (Parliament of the Republic of Ghana, 2001), had not been able to structure out a health 
insurance policy, as a means of ameliorating the cost burden for health care on the population, and for ensuring the financial capacity of the health system. There is however in place a health-user exemption policy in which certain category of patients and the very poor, which genuinely cannot pay for the services, are exempted. This policy is however more a theory than practice.

Contributors to the Social Security and National Insurance Trust (SSNIT), which include all workers both in public and private sector, have $1 \%$ of their contributions allocated for health care when they go on pension, but this proportion is not utilised by contributors for that purpose (Daily Graphic, 2000). There is a free medical care policy for civil and public servants, which is part of their conditions of service. The health care package has some limitations. Payment for drugs for instance is only limited to drugs that are meant to cure ailments. Costs of blood tonics meant to alleviate anaemia for instance are not reimbursed, and there are no compensations for disabilities caused by accidents. In view of large numbers of beneficiaries and teething financial constraints, coverage of services is very limited. In some institutions, specific amounts are fixed per person per period, and administrative red tape makes access very difficult. The system is bedevilled with a lot of bottlenecks, including lack of funds for prompt payment of care costs. This system is supposed to be part of the workers' incentives. 


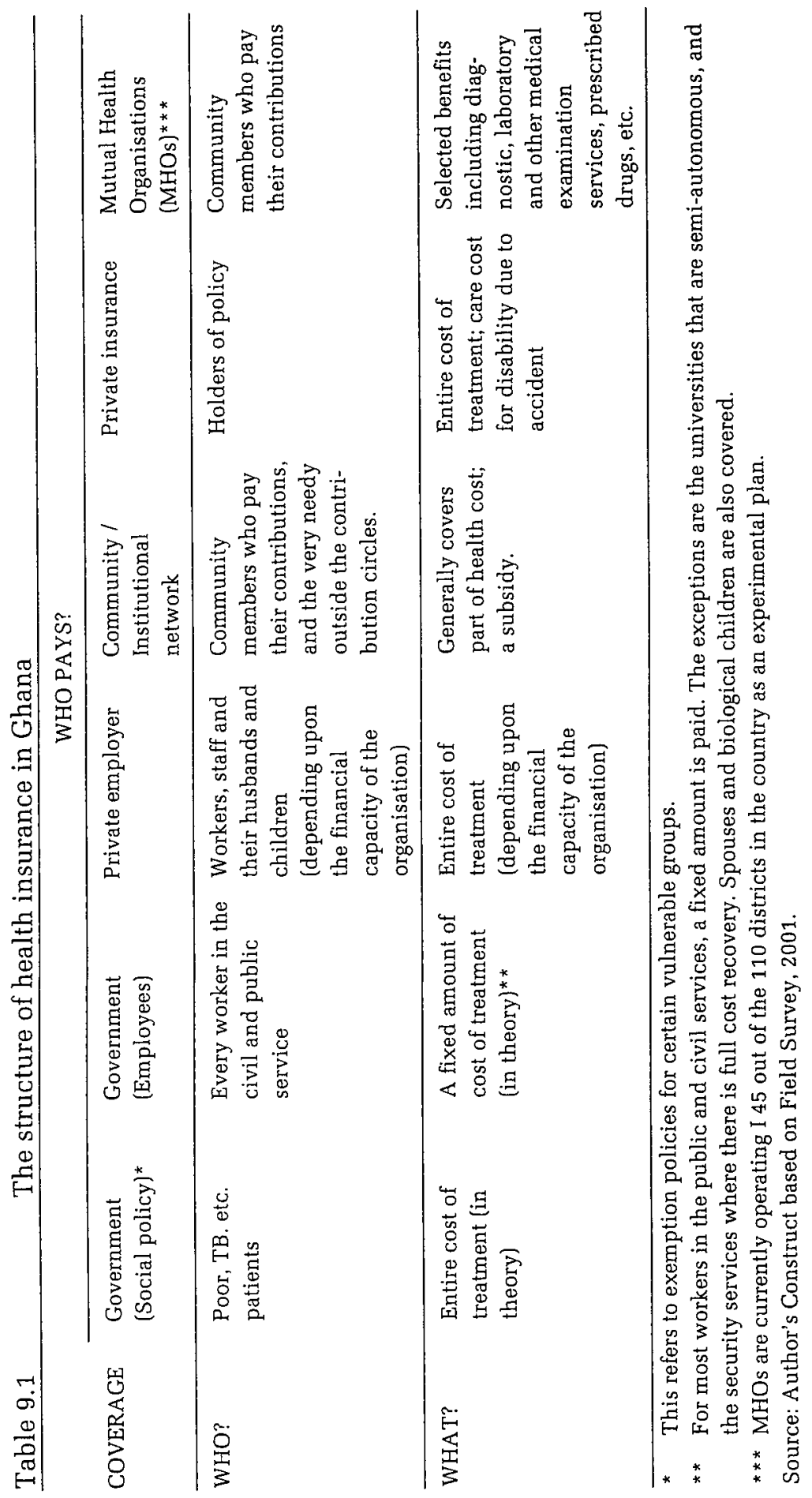


Staff and workers in semi-autonomous state institutions like the universities and armed forces, as well as health workers, enjoy a wider range of health benefits than those in the civil and other public services. The health care covers their wives/husbands, children and a specified number of dependants. This is a form of insurance since it undercuts full financial rewards of workers and staff. At the universities for instance, a number of dependants, apart from biological children, also enjoys a proportion of the health benefits. Annual payments are paid as premium on behalf of the dependants to access health services. Beneficiaries enjoy $50 \%$ of the cost of drugs and other services, whilst consultation is free.

There are community and institution-based social support systems. In some communities, contributions are made to assist community members in areas like health, education and family care in the event of bereavement of the husband or parents. Some of these operate like the cooperative system. In some communities and institutions, welfare clubs have been formed to assist members in the event of need. A few health and life insurance organisations are operating, in which policyholders pay premium on monthly basis. The package varies from company to company, and the quantum of the premium determines the coverage of benefits. There are micro insurance organisations in some health institutions. At the Aninwaah Medical Centre in the Kumasi Metropolis for instance, there is a package where pregnant women pay monthly premium for access to antenatal care. A more popular micro insurance scheme (MHO), is that of Nkoranza in the Brong-Ahafo Region that is primarily rural. It is known as the Nkoranza Community Health Insurance Scheme. It has been active for a decade and now enrols 40 percent of the catchment area population, covering nearly 48,000 beneficiaries (Mossialos and Dixon, 2002). The plan currently provides inpatient services, including Caesarean sections, but not routine deliveries. The Commercial Market Strategies (CMS), a non-governmental organisation (NGO), is assisting Nkoranza to explore their options for adding normal deliveries including pre-and post-natal care as a plan benefit to improve maternal-child care.

The Ashanti Region's Civil Servants Association in the Ministry of Health has taken a bold initiative by introducing the Ashanti Region Civil Servants Medical Care Scheme. Although they are supposed to enjoy free medical care, the benefits are seriously affected by financial and logistic constraints, so they decided to organise an insurance scheme to enjoy better health care. A reviewable monthly premium of five thousand cedis 
$(45,000.00)$ is charged. The spouse and three biological children of the insured below the age of 18 are beneficiaries.

The government has however made efforts at introducing a NHIS that is yet to receive full implementation. In 1996/97, the Ministry of Health commissioned a team to carry out a pilot survey in the Eastern Region of Ghana on the potentials for introducing a NHIS. The team was to find out the minimum premium to be paid by each insured each month. The team came out with a recommendation of a monthly insurance premium of six thousand cedis $(66,000.00)(\$ 1.33)$, which was found to be too high by the Ministry, in view of mass unemployment and poverty. The Ministry rather suggested community-based insurance schemes. Currently a private health insurance scheme has been initiated by the Ghana Health Insurance Company, with the support of the Ministry of Health and the SSNIT. The Ministry proposes the $1 \%$ of contributors' contribution meant for health become the retiree's contribution to the Ghana Health Care Company Scheme (Daily Graphic, 2000).

As part of its manifesto, the ruling National Patriotic Party (NPP) government, proposed a NHIS to replace the Cash and Carry Scheme, which enjoined on health care users to pay fully for services rendered. Upon winning the 2000 General Elections, the government was obliged to carry out its manifesto, which won it mass support. Accordingly, a National Health Insurance Bill was prepared in 2001, passing into Parliamentary Act, National Health Insurance Act 2001. The Act establishes National Health Insurance Council which shall, among other functions, oversee the development of appropriate criteria, and formulae for disbursement of a National Health Insurance Fund and also oversee the operations of the Health Insurance Plans and the Mutual Health Organisations (MHOs) and support them appropriately to achieve the policy goals of the government.

Before the scheme is fully implemented, the government, through the Ministry of Health, has started the operation of Mutual Health (Support) Organisations (MHOs) in selected districts in the country on experimental basis. In the Ejisu-Juaben district of the Ashanti Region, over 30,000 persons had registered with the MHO by August 2002, out of which 27,000 had fully paid their premium, and 3,000 having settled part payments for the year 2002. An amount of 250 million cedis $(\$ 250,000,000.00 / \$ 30,487.80)$ has been realised (Daily Graphic, 2002). 


\section{Data and methods}

\section{Study design}

The study is cross-sectional involving the second largest metropolis in Ghana. The study is both qualitative and quantitative. Qualitative results were used to reinforce the quantitative results. Two sets of data were used. The first is data extracted from a general survey on the utilisation of health services in Ghana using the metropolis as a case study. The other data are based on the responses of opinion leaders, policy makers, and professionals: economic planner, health care and legal practitioners. The study involved male and female respondents above the age of 18 who are capable of deciding on their health services utilisation and access to health insurance behaviours.

\section{The study variables}

The variables used in the study are demographic and socio-economic. They are age, sex, income, employment, education, marital status, health status, insurance status and utilisation. Utilisation is used as the dependent variable. Age could have an impact on utilisation even among the insured. The youth and economically active population may be more disposed to utilise more health services than the aged. The notion is that the aged have outlived their usefulness so, in case of those who may be too weak to travel to receive health care, they may not get dedicated and committed family members to assist them. There is also the problem of ability to pay for a more comprehensive health care that carries a more expensive premium. In the same vein are women who, by virtue of their biological status, suffer more ailments than men. It is likely they may feel bored with periodic runs to hospitals so may not be as regular as men. They may also lack the financial capacity to pay the premium. Income status could also affect utilisation due to inability of the clients to pay the premium. The employed are also more predisposed to access insurance than the unemployed. Some employees enjoy some form of insurance at their workplaces.

Education is a strong predisposing factor in utilisation. The educated will tend to have a stronger taste for scientific medicine. Education shows a direct positive relationship with the use of health care (Grossman, 1975). The education of women, especially, shows a positive relationship with the use of health services (Caldwell, 1983; Wong et al., 1987; Swenson et al., 1993; Raghupathy 1996). In Ghana the adult illiteracy rate is quite high, with $30 \%$ of adults unable to read and write (World Bank, 2002). There could be disparity in the use of health services by marital status, 
especially of women, even among the insured. The married seem to be responsible and cautious. The couple could encourage each other in effectively utilising health services, especially when one of them has attained higher education.

Utilisation is defined as the number of times a respondent attended health institution for treatment the last three times he experienced sickness spells, whilst health status is defined as the number of times a respondent fell sick within some specified periods: once a week; once a fortnight; once a month; once in three months, and rarely. In the study area in general, ill health is perceived as a health condition in which one could not carry out his normal daily duties. What this implies is that ill health is defined in terms of a severe condition that attracts medical attention.

Marital status was categorised into two: married and unmarried. Cohabitation was categorised under married since a married man performs almost the same functions under co-habitation as under legal marriage, and the woman in cohabitation obliged to perform the same services and show commitment as under legal marriage. Education is categorised into four: never-been-to school; basic education; secondary education and tertiary education. Insurance is categorised into insured and uninsured, whilst residence is categorised into metropolis and rural.

\section{Sampling and data collection}

The selected study area, Kumasi Metropolis, is one of the most cosmopolitan in Ghana, embracing people of various ethnic groups. It is also at the converging centre of transport routes to all parts of the country. It is a booming commercial centre. Its main market is the largest in Ghana; and for a long time, the largest in West Africa. It is a city of cultural and socio-economic diversity. It is therefore an appropriate study area. Sampled opinions are more likely to reflect the national opinion.

Two sets of sample were used: the general population and opinion leaders and professionals. The sample of the general population was 250 made up of 100 males and 150 females above the age of 18, the legal age of maturity. There were 16 opinion leaders made up of local (traditional) chiefs, assemblymen, unit committee members who are legislators at the local and community levels, and 3 professionals, i.e. a medical practitioner, legal practitioner and an economic planner. The opinions of the professionals were very relevant since they were respectively well- 
informed about the health, legal and financial implications of health care. The sample for the general population was selected using systematic random technique, whilst chiefs, opinion leaders and professionals were selected by purposive sampling from various communities and institutions. The main components of the questions were their opinion on health insurance, the insured and utilisation patterns of their communities, forms of social support in their communities, a health insurance system they would given the living conditions of their communities, and their attitude to a national health insurance package. Local chiefs responded to the questions with the support of their elders who were seated with them. There was flexibility in their responses.

Formal interview and questionnaire instruments were applied on the illiterate and educated respectively. For the general population, 16 selected respondents refused to participate in the interview. Nevertheless, respondents of similar characteristics substituted these persons. The questionnaire covered background information, spatial relationships with health facilities, utilisation of health services patterns and insurance status. Both factual and opinion questions, and open-ended and closeended questions constituted the questionnaire.

\section{Data analysis}

Data for the general population were quantitatively and qualitatively analysed, whilst that of opinion leaders and professionals were analysed qualitatively. The differences in the relationships of the various variables with insurance were determined using the non-parametric technique of Chi Square. This was to find out whether differences were significant in order to determine the variables that were likely to have an effect on access to insurance. A correlation matrix was also built up to show the association between the variables and insurance, and between insurance and utilisation. Bivariate correlations were used to determine the nature of association between the variables. This was to confirm the association between the two variables. Pie charts are also used to illustrate some respondents' responses.

Quantitative codes (ranked/ordinal data) were assigned the noncontinuous variables of health status, education and utilisation; whereas sex, marital status, employment and insurance status were entered as dichotomous variables. Age and income were entered as continuous variables. For health status the quantitative codes ranged from 1 for "once a week" to 5 for "rarely". Education ranged from 1 for "never-been-to 
school" to 4 for "tertiary education". Utilisation ranged from 0 for "no use" (rarely) to "always" (regularly); whereas for sex, male was given a code of 0 and female, 1 . Married is given code 1 and unmarried 0 , whereas employed is given code 1 and unemployed 0 . Insured is given code 1 and uninsured 0 .

\section{Characteristics of respondents and insurance}

The characteristics of the respondents vis-à-vis insurance status are indicated in table 9.2. Variables with significant differences by insurance status are income, education, marital status and utilisation. There are vast variations in income in the metropolis. There are the key public servants and well-endowed entrepreneurs who earn huge incomes, compared with a mass of casual workers in the informal sector, as well as manipulative workers in the formal sector who receive mean incomes that put them below the poverty line. Besides, there are the huge numbers of unemployed, most of whom stay at the slums and squatter settlements. Education is another variable factor. There is a vast difference between those with tertiary education and other levels of education. Education is a very important variable that influences access to insurance. Those with high education have access to permanent jobs with good pay.

The married are more insured than the unmarried. The unmarried seem to have unplanned life and are less cautious about life whilst the married, who may have children to cater for, are more likely to be cautious about life. In the metropolis, marriage is becoming a bit rare because of the increasing cost of living. Young men are scared of it.

The effect of insurance on utilisation is very significant. There is a steep utilisation-insurance gradient, with more insured utilising health services. This trend has been predominant in the developing countries. 
Table 9.2 Characteristics of respondents and insurance status ( $\mathrm{N}=250)$

\begin{tabular}{lrrr}
\hline Variables & Insured \% & Uninsured \% & Significance \\
\hline Sex: & & & \\
Male & 34.0 & 66.0 & .065 \\
Female & 23.3 & 76.3 & \\
Age: & & & .567 \\
$0-59$ & & & \\
$60+$ & 28.4 & 71.6 & \\
Income (in द '000s): & 24.5 & 75.5 & \\
Less than 300,000 & & & \\
300,000-600,000 & & & \\
601,000+ & 14.1 & 85.9 & \\
& 23.1 & 76.9 & \\
Employment: & 55.2 & 44.8 & \\
Unemployed & & & \\
Employed & & 69.2 & \\
& 30.8 & 72.4 &
\end{tabular}

How frequent you fall sick (Health

status):

Once a week

33.3

66.7

Once a fortnight

8.3

91.7

25.7

74.3

.547

Once in 3 month

27.6

72.4

Rarely

31.5

68.5

Education:

Never-been-to school

Basic education

30.6

82.9

.000

Secondary education

76.5

69.4

Tertiary education

23.5

Marital status:

Unmarried

16.0

84.0

.003

Married

33.9

66.1

Utilisation:

Rarely

11.1

88.9

Irregularly

9.5

90.5

.000

Moderately

32.4

67.6

Regularly

48.4

51.6

Source: Based on Field Data, 2001 


\section{Prospects for the introduction of a national health insurance scheme}

The general population indicate their strong desire for the introduction of a NHIS. A good number of them had very little knowledge of health insurance, so had to be educated before they could make a response on their desire for its adoption. The responses of the general population to their desire for the introduction of a NHIS are indicated in figure 9.1.

The desire for the introduction of a NHIS is quite strong among the communities. There was however a problem with the willingness to pay. A significant proportion of the respondents are unwilling to pay (figure 9.2). About $36 \%$ of respondents are not willing to pay. Out of this number, a greater proportion is in the low-income group (figure 9.3).

Figure 9.1 Respondents' desire for a NHIS
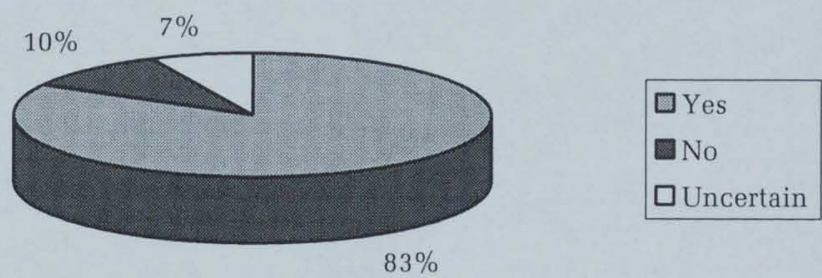

Source: Based on Field Data, 2001

Figure 9.2 Willingness to pay premium
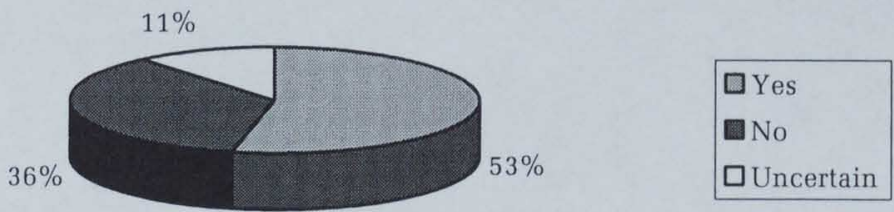

Source: Based on Field Data, 2001 


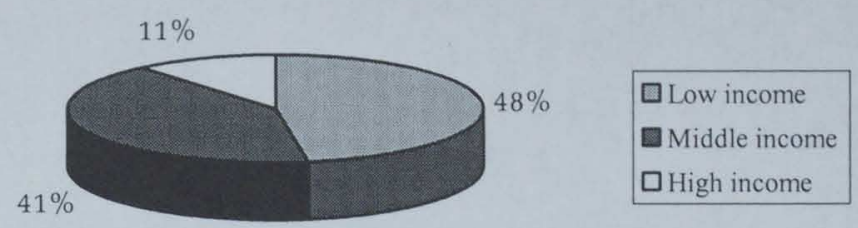

Source: Based on Field Data, 2001

Although the proportion that is not willing to pay is quite significant, prospects for the introduction is not jeopardized. More than $50 \%$ are prepared to pay, which is quite encouraging. Greater proportion of those unwilling to pay is in the lower income group, receiving less than three hundred thousand cedis $(\$ 300,000.00 / \$ 35)$ a month. In developing countries, this is not a strange development. Mass poverty is a barrier, necessitating exemption policies.

Recommendations for premiums to be paid, exemptions, mode of collection and insurance coverage, have been made based upon these findings. Also, possible bottlenecks to the operation of such a scheme have been identified. The questions and the respective responses by the opinion leaders/policy makers and the professionals are indicated in table 9.3 . 


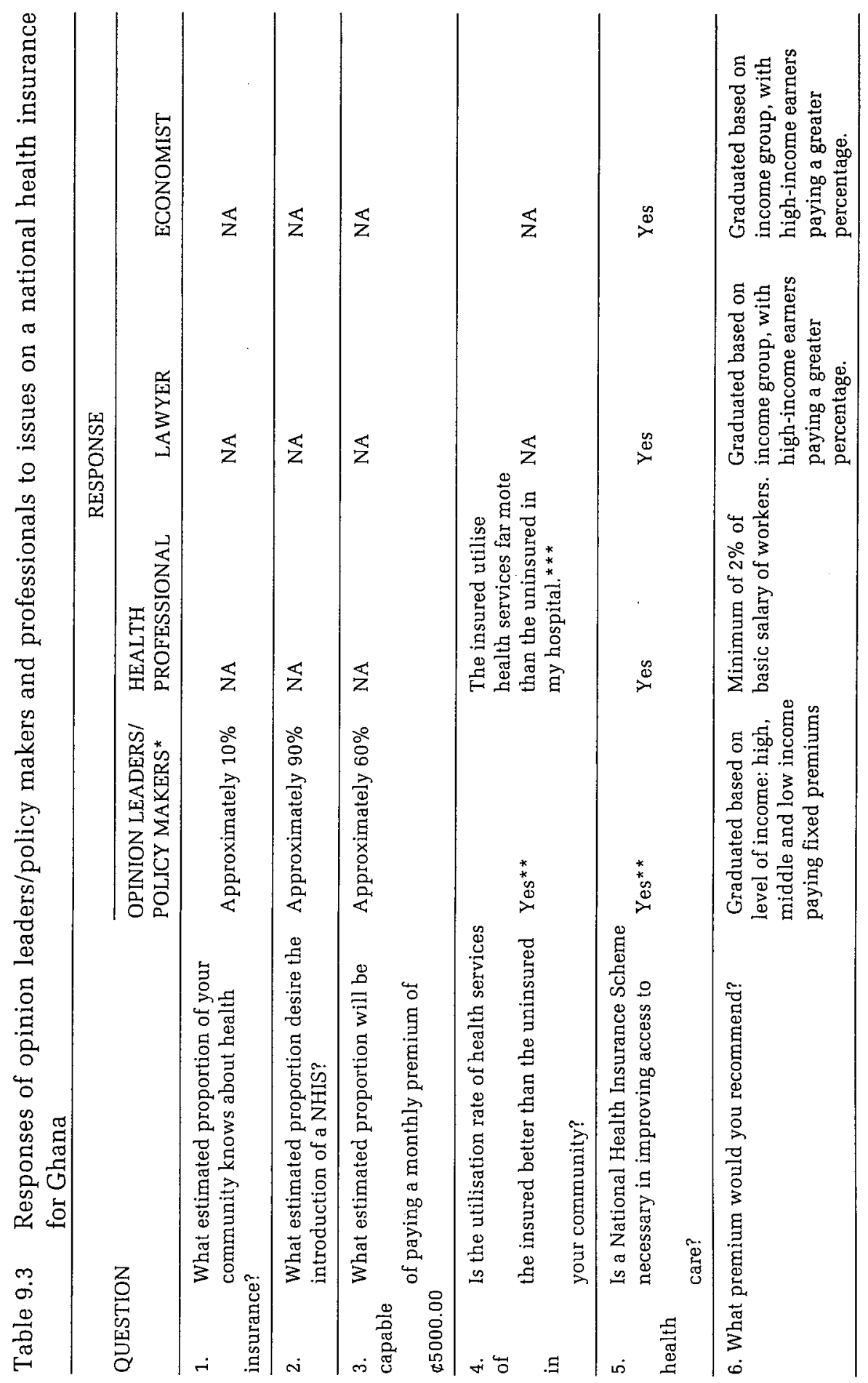




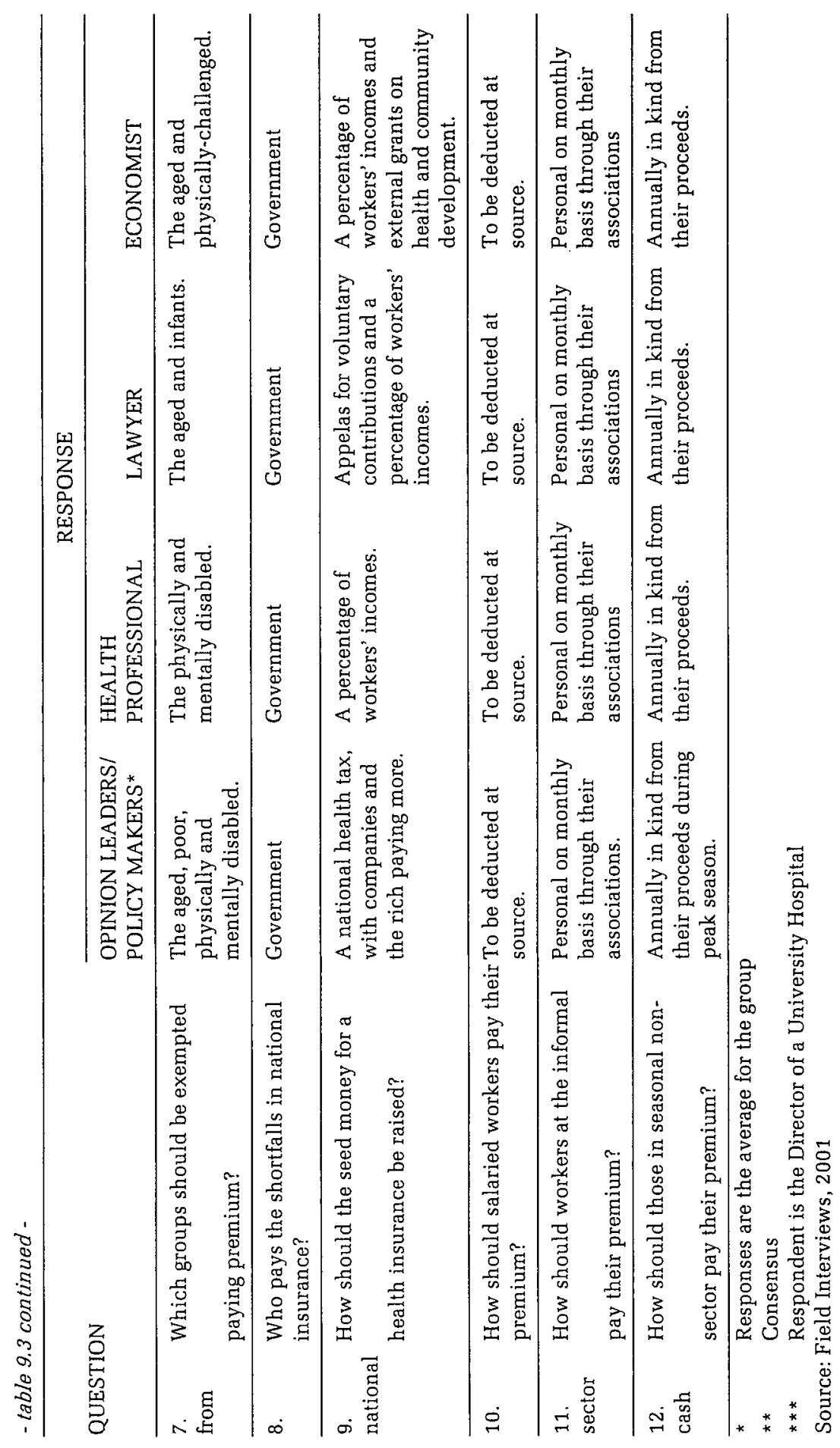


Responses indicate that a very significant proportion of respondents have very little knowledge of health insurance in the various communities. This shows the very low level the insurance system has reached in the country. Interviews revealed the strong desire of the communities for the introduction of a NHIS, even though a significant proportion will not be capable of paying monthly premium ${ }^{1}$. Community leaders also gave indication of the regular use of health services by the insured in their communities. All policy makers and community leaders were of the opinion that the insured utilise health services more than the uninsured in their communities, and that the desire for the introduction of a system that would ease the cost burden if health care was very strong among the communities. Community leaders pinpointed some insured persons in the community they knew who regularly visited the hospital for treatment when sick. The Director of the Kwame Nkrumah University of Science and Technology University Hospital confirmed that records showed that the rate of utilisation of patients on insurance was very high. All respondents were of the strong opinion that the introduction of a NHIS would significantly improve access to health care and also financially empower the health sector to perform more creditably.

Apart from the health professional who recommended a progressive health insurance, $2 \%$ of workers' income, greater majority of the other respondents recommended a form of insurance premium where the rich pay a greater proportion of their income or a greater fixed premium. They recommended a graduated premium based on income: high, middle and low income levels.

All respondents recommended that some groups should be exempted from paying premium. Whereas opinion leaders/policy makers and the economist recommended that the aged and physically and mentally disabled be exempted, the lawyer recommended the exemption of the aged and infants; and, to the health professional, it is only the physically and mentally disabled who should be exempted. He was of the view that employment avenues must be opened for the healthy to work to support the economy and the health budget. Given the large proportion of the unemployed (regular income-earners), to exempt the unemployed would put the sick fund under a serious strain that could eventually collapse it.

This survey was carried out before the inauguration of a NHIS in March 2004. 
All respondents responded that government pay the shortfall in the health insurance budget.

On the issue of initial (seed) money for the health insurance, opinion leaders/policy makers recommended a national health tax, with companies and industrial and commercial establishments and the highincome earners paying more. The health professional recommended a certain percentage of workers' income to be deducted at source, whilst the lawyer recommended appeals for voluntary contributions and a percentage of workers' incomes. The economist, on the other hand, recommended a percentage of workers' incomes and external grants on health and community development. In the NHIS Law 2003, $2.5 \%$ of workers' monthly social security contributions is to be deducted on monthly basis to be used as seed money. The implication is that the $2.5 \%$ of workers' contribution is their premium.

All respondents recommended deduction of workers' premiums at source, whilst for workers at the informal sector, they recommended personal payments made through their association leaders on monthly basis. They further recommended a means must be found to identify those who do not belong to any association and get them to pay. It was the opinion of respondents that it should be obligatory to belong to an association in order to get the licence to operate. For those at the seasonal non-cash sector like farmers, the consensus was that they pay annual premiums in bulk (cash or kind) during the peak harvest season. A strategy should be put in place to let them pay annual premiums in kind where marketing problems are encountered.

\section{Insurance status and utilisation patterns}

Table 9.4 indicates the correlation (association) between the various independent variables in the utilisation of health services. The variables that show significant correlations with utilisation, following an order of importance, are education, insurance, income and marital status; whilst education and income relatively show a strong association with insurance. The relationship between education and income is relatively strong, making education and income the key factors in access to insurance. There is a positive association between insurance and utilisation. 
Table 9.4 Bivariate correlations of independent variables

\begin{tabular}{lccccccccc}
\hline & \multicolumn{8}{c}{ Variables / Correlations } \\
\cline { 2 - 11 } Variables & Sex & Age & Marit. & Income & Empl. & Health & Educa. Insur. & Util. \\
\hline Sex & 1.000 & & & & & & & & \\
Age & -.121 & 1.000 & & & & & & & \\
Marital & .007 & .087 & 1.000 & & & & & & \\
Income & -.063 & $.012^{\mathrm{b}}$ & $.168^{\mathrm{a}}$ & 1.000 & & & & & \\
Employm. & -.110 & $-.144^{\mathrm{b}}$ & $.278^{\mathrm{a}}$ & .121 & 1.000 & & & & \\
Health st. & $-.242^{\mathrm{a}}$ & $-.207^{\mathrm{a}}$ & $-.056^{\mathrm{a}}$ & -.013 & $.137^{\mathrm{b}}$ & $1.000^{\mathrm{a}}$ & & & \\
Education & -.060 & $-.349^{\mathrm{a}}$ & $.110^{\mathrm{a}}$ & $.419^{\mathrm{a}}$ & $.207^{\mathrm{a}}$ & $.228^{\mathrm{a}}$ & $1.000^{\mathrm{a}}$ & & \\
Insurance & -.111 & .028 & $.187^{\mathrm{a}}$ & $.355^{\mathrm{a}}$ & -.026 & .082 & $.387^{\mathrm{a}}$ & $1.000^{\mathrm{a}}$ & \\
Utilisation & .035 & -.096 & $.231^{\mathrm{a}}$ & $.342^{\mathrm{a}}$ & .086 & -.036 & $.428^{\mathrm{a}}$ & $.379^{\mathrm{a}}$ & 1.000 \\
\hline
\end{tabular}

NB: Correlation is significant at 0.01 level (2-tailed)

Correlation is significant at 0.05 level (2-tailed)

Source: Based on Field Data, 2001

The impact of insurance on utilisation of health services could be established by multiple regression (stepwise method). The variables that are significant are indicated in table 9.5.

Table 9.5 Multiple regression factors

\begin{tabular}{lrr}
\hline Variables & Beta coefficients & Significance $(p$-values $)$ \\
\hline Education & .284 & .000 \\
Insurance & .201 & .001 \\
Marital Status & .143 & .014 \\
Income & .139 & .029 \\
Health Status & -.128 & .032 \\
Adjusted $\mathrm{R}^{2}$ & & .261 \\
\hline
\end{tabular}

Dependent variable: Utilisation

Source: Based on Field Data, 2001

Insurance has a very strong impact on utilisation as indicated in table 9.3. It is education that is stronger than insurance among the factors. The coefficient of determination (adjusted $\mathrm{R}^{2}$ ) though low does not negate confidence in the results. Indeed, health insurance is poorly developed in Ghana; and, as indicated in the sample, a very small proportion of the respondents are insured, with some, especially those in government institutions, being partially insured. The size of the sample is more likely to influence the results. The adjusted $\mathrm{R}^{2}$ is reasonable enough to establish some confidence in the results. The F-test confirms the multiple regression results. The test shows that there is a significant difference between the insured and uninsured in the utilisation of health services. 
Qualitative results on the impact of insurance on utilisation confirm the quantitative results. Opinion leaders and the health professional confirm a positive association between insurance and utilisation of health services. Thus, a state insurance policy, if rigorously pursued, would open avenues for regular and effective use of health services to enhance health, which is a sine qua non of development.

\section{Discussion}

The need for the population to get insured in order to improve access to health care need not be overemphasised. The survey has established beyond reasonable doubt that insurance relates positively to the utilisation of health services. There are significant differences among the respondents in education, income, marital status and utilisation by insurance. The factors that have stronger association with insurance are education, health status and income. The impact of insurance of utilisation is relatively strong, as shown by the regression results.

Income has been a very important factor determining access to insurance in the study area. There is thus the need for a pragmatic poverty alleviation programme to ensure a significant reduction in poverty to ensure adequate access to insurance, hence to health care use. The government's poverty alleviation strategy must be strengthened. There is currently the problem of recovering short and medium term loans granted residents to expand their economic activities. This is crippling the poverty alleviation fund. A comprehensive programme for loan recovery must be embarked upon.

Education is another important factor determining access to insurance, hence to utilisation. The educated are enlightened enough to recognise the need for the use of health care, which is facilitated through access to insurance. The educated are also more likely to get employment with good pay, so have easier access to regular income that could empower them to access insurance. The educated are more familiar with insurance procedures than the illiterate. Government Free Compulsory Universal Basic Education (FCUBE) programme must be enhanced to ensure that as many children of school-going age as possible are in school. Emphasis must be given to the education of the girl-child. Illiterate adults could be helped to, at least, be able to read and write through informal schooling; something the government is already experimenting. 
Qualitative results through interviews also confirm quantitative results. Policy makers and opinion leaders confirm that the insured in their communities utilise health services more than the uninsured. Qualitative research sampled opinions of community leaders and professionals on the prospects and pattern of a NHIS for Ghana. Knowledge of health insurance is quite low for the study area, therefore calls for a thorough education programme on health insurance and its prospects for health and access to health care. All respondents see the need for the introduction of a NHIS for Ghana. Opinions are divided, even among the sampled professional on the type of premium to be paid. Although the consensus is that it should be graduated by level of income, with the high-income earners paying a greater percentage of their income as premium, such a position would not ensure equity, and could draw such a scheme into a national social crisis. The recommendation of the health professional, which operates in most advanced countries, is more acceptable. There must be the establishment of a national sick fund into which monthly premiums of a fixed percentage for all workers should be paid.

The survey results also indicate that communities expect a national health tax to be drawn from a certain percentage of workers' incomes and from voluntary donations to serve as seed money for the national health insurance to take off. The economist also recommends that external grants earmarked for health and community development be channelled into the seed money. The opinion leaders and professionals support these ideas. These funds shall give the insurance a strong financial foundation to ensure a resounding take-off, and also to limit risk-pooling.

There shall be the problem of payment of premiums by workers at the informal sector of the economy that constitutes a greater part of the national economy. This has been a problem in developing countries where a social health insurance policy is being implemented. The problem gets more serious with those who do not belong to a recognised association. A Parliamentary Act enjoining all workers in the informal sector to belong to a recognised association shall help address such a problem. Another alternative is the daily payment of premium. A more serious problem will be the assessment of their daily incomes, especially for the floating workers like the petty traders. For those in the non-cash sector, the recommendation that they pay in bulk during the harvesting season is upheld. 
The consensus of the respondents is that there be exemptions from payment of premiums. What ran through the responses during the interview was that the aged and physically and mentally disabled should be exempted. Respondents were not convinced that the very poor should be exempted. They rather hold the position that government should create employment avenues for the poor who are strong enough to work to enable them contribute to a health insurance fund. Whilst upholding the need for arrangements by government to create jobs for the poor to empower them to pay premiums, the fact that an eradication of unemployment is a near-impossibility cannot be denied. The same is the case with poverty alleviation, even in the industrialised countries. The NHIS should thus be seen as a form of social support system to relieve the burden of the very poor.

The MHOs currently mounted by the government in selected districts as a precursor for the establishment of a NHIS is a laudable idea. It must be spread to the other districts in the country. When a NHIS is fully established, such MHOs that are subscribed primarily by non-wage earners must be made to run concurrently with the NHIS, and be supported from a National Health Insurance Fund.

The hypotheses set up by this study have been vindicated. Firstly, a NHIS will have a positive impact on utilisation of health services. Second, education and income have a greater positive effect on insurance purchase than other socio-economic and demographic variables.

\section{Conclusion}

It is evident from the research that health insurance addresses the problem of utilisation of health services and health care. Unfortunately, inequity exists in access to health insurance. The poor and illiterate are more affected by the pandemic of poor access of health insurance. There is the need for a NHIS to address such inequity to ensure that there is adequate access to insurance and concomitant health care by the vulnerable in the society. A progressive taxation model must be used for payment of the premium by regular salary/wage earners, whilst workers at the informal sector pay their premiums through their organised associations. This plan would ensure adequate financial resources to guarantee the effective implementation of a NHIS. Other insurance portfolios like private insurance schemes, voluntary insurance schemes and MHOs could be introduced as the economy improves and more and more people get employed and receive regular income. This will ensure a 
healthy competition that would make for the efficiency of the national health insurance portfolio, and also offer a broader coverage for those who can afford. The poor and needy would have been satisfied their basic health needs through the NHIS. To address the problem of utilisation of health services, there would also be the need for a public education on the need to access health services as regularly as possible. Finally, since poverty and illiteracy lie at the roots of poor access and utilisation of health services, an aggressive poverty alleviation strategy must be adopted, not forgetting the government's Free Compulsory Universal Basic Education (FCUBE), which must be seriously implemented. 


\section{Literature}

Aase A. Towards a methodology for regional welfare planning. Norsk Geographic Tidskrift (Norwegian Journal of Geography), 1991; 45: 213-227.

Abugri BA. Health care delivery strategies in Ghana: a study of accessibility and utilisation in the West Mamprusi district of the Northern Region, Ghana. Trondheim: Department of Geography, University of Trondheim, 1995. (thesis)

Acton JP. Non-monetary factors in the demand for medical services: some empirical evidence. Journal of Political Economy, 1975; 85: 595-614.

Acton JP. Demand for health care among the urban, with specific emphasis on the role of time. In: Rosett R (ed.). The Role of Health Insurance in the Health services sector. New York: National Bureau of Economic Research, 1979.

Aday LA, Andersen MR. A framework for the study of access to medical care. Health Services Research, 1974; 9: 208-220.

Aday LA, Andersen RM. Development of indices of access to medical care. Ann Arbor: Health Administration Press, 1974.

Aday LA, Lee ES, Spears B, Chung CW, Youssef A, Bloom B. Health insurance and utilisation of medical care for children with special care needs. Medical Care, 1993; 31(11): 1013-1026.

Akhtar R, Izhar N. 1994. Spatial inequalities and historical evolution in health provision. In: Phillips DR, Verhasselt Y (eds.). Health and development. London: Routledge, 1994.

Albizu-Garcia CE, Alegria M, Freeman D, Mildred V. Gender and health services use for a mental health problem. Social Science and Medicine, 2001; 53(7): 865-878.

Andersen MR. Revisiting the behavioral model and access to medical care. Journal of Health and Social Behavior, 1995; 36: 1-10.

Andersen R, Newman JF. Societal and individual determinants of medical care utilisation in the United States. Milbank Memorial Fund Quarterly, 1973; 81(winter): 95-123.

Anderson DW, Andersen RM. Patterns of use of health services. In: Freeman H, Levine S, Reeder L (eds.). Handbook of medical sociology, 2nd edn. Engelwood Cliffs: PrenticeHall, 1972.

Anderson DR, Sweeney DJ, Williams TA. Introduction to statistics: concepts and applications, 3rd edition. New York: West, 1994.

Anglin MK, White JC. Poverty, health care, and problems of prescription medication. Substance Use and Misuse, 1999; 34(14): 2073-2093. 
Awusabo-Asare K. Estimating fertility and childhood mortality for the Western Region of Ghana from pregnancy history data. Master of Arts Degree in Demography. Canberra: Australian National University, 1980.

Bailey W. Phillips DR. Spatial patterns of use of health services in the Kingston Metropolitan Area, Jamaica. Social Science and Medicine, 1990; 30(1): 1-12.

Barnes ND, Bern-Klug M. Income characteristics of rural older women and implications for health status. Journal of Women Aging, 1999; 11(1): 27-37.

Bentham G, Haynes R. Health, personal mobility and the use of health services in rural Norfolk. Journal of Rural Studies, 1985; 1: 231-239.

Berhane Y, Hoegberg U, Byass P, Wall S. Gender, literacy, and survival among Ethiopian adults, 1987-96. Bulletin of the World Health Organization, 2002; 80: 714-720.

Bhanu BN. Use of health services in hill villages in Central Nepal. Health Transition Review, 1994; 4: 1151-1166.

Bhuiya A, Stretfield K. Mothers' education and survival of female children in a rural area of Bangladesh. Population Studies, 1991; 45(2): 235-252.

Biego $\mathrm{G}$ et al. Survey on adult and childhood mortality, Tanzania. Calverton, MD: Macro International, 1995.

Bleek W. Family and family planning in Southern Ghana. In: Oppong C (ed.). Sex roles, population and development in West Africa. London: Heinemann, 1987.

Bohland J, French P. Spatial aspects of primary health care for the elderly. In: Warnes AM (ed.). Geographical perspectives on the elderly. Chichester: Wiley, 1982.

Bor W, Najman JM, Andersen M, Morrison J, Williams G. Socio-economic disadvantage and child mortality: an Australian longitudinal study. Social Science and Medicine, 1993; 36(8): 1053-1061.

Bourne LK, Walker MG. The differential effect of mothers' education on mortality of boys and girls in India. Population Studies, 1991; 45(2): 203-219.

Bowling A, Farquhar M, Browne P. Use of services in old age: data from three surveys of elderly people. Social Science and Medicine, 1991; 33(6): 1181-1192.

Briscoe M. Why do people go to the doctor?: sex differences in the correlates of GP consultation. Social Science and Medicine, 1987; 25: 507-513.

Bronstein JM, Morrisey MA. Determinants of rural distance for obstetrics care. Medical Care, 1990; 28(9): 863-864. 
Buor D. Mothers' education and childhood mortality in Ghana. Health Policy, 2003; 64: 297309.

Buor D. The predominance of distance in the utilisation of health services in the Kumasi Metropolis, Ghana: an International Journal on Human Geography and Environmental Sciences. Geojournal, 2002; 56(2): 145-157.

Burn CO. Utilisation of medical care services in Mangere, Auckland. Mangere: University of Auckland, 1974. (unpublished MA thesis)

Buschkers WFL, Slikkerveer LJ. Health care in East Africa: Illness behaviour of the Easter Oromo in Haraghe (Ethiopia). Assen: Van Gorcum, 1982.

Caldwell JC, Reddy PH, Caldwell P. The social component of mortality decline: an investigation in South India employing alternative methodologies. Population Studies, 1983; 37: 185-205.

Caldwell IC. Routes to low mortality in poor countries. Population and Development Review, 1986; 12: 171-220.

Caldwell JC. Mass education as a determinant of mortality decline. In: Caldwell JC, Santow $\mathrm{G}$ (eds.). Selected readings in the cultural, social and behavioural determinants of health. Canberra: Australian National University, 1989.

Campbell DA, Redford JMC, Burton P. Unemployment rates: an alternative to the Jarman Index? British Medical Journal, 1991; 303: 755-760.

Carr-Hill RA, Sheldon T. Designing a deprivation payment for general practitioners: the UPA(8) Wonderland. British Medical Journal, 1991; 302: 393-396.

Cashin EC, Borowitz M, Zuess O. The gender gap in primary health care resource utilization in Central Asia. Health Policy and Planning, 2002: 17(3): 264-272.

Chen LM, Wen SW, Li CY. The impact of national health insurance on the utilisation of health care services by pregnant women: the case in Taiwan. Maternal and Child Health Journal, 2001; 5(1): 35-42.

Chernichovsky D, Meesook OA. Utilisation of Health Services in Indonesia. Social Science and Medicine, 1986; 23(6): 611-620.

Cleary PD, Mechanic D, Greenley JR. Sex differences in medical care utilisation: an empirical investigation. Journal of Health and Social Behavior, 1982; 23: 106-119.

Cockerham WC. Medical sociology. Englewood Cliffs: Prentice Hall, 1978.

Criel B, Van der Stuyft P, Van Lerberghe W. The Bwamanda hospital insurance scheme: effective for whom? A study of its impact on hospital utilisation patterns. Social Science and Medicine, 1999; 48(7): 897-911. 
Daily Graphic. Monday May 1, 2000, Graphic Corporation, Accra-Ghana.

Dakpallah FG. (1988). Financing of health services: effects of cost recovery mechanisms on health services in developing countries: a case study of Ghana. University of Wales, 1988. (Ph.D. thesis)

Deaton A. Health, inequality, and economic development. Princeton: World Health Organization, 2001.

Delanyo D, Boohene A, Ntow S, Matemara B, Attipoe D, Ankrah AV. What does the public want from us? Research report on a study of user satisfaction with services in government health facilities in the Eastern Region of Ghana. Koforidua: MOH, Eastern Region, Ghana, 1992.

Delvin JF, Yap MT. Structural adjustment programmes and the UNCED agenda: explaining the contradictions. Rio de Janeiro, 1993.

De Vise P. Misused and misplaced hospitals and doctors, Commission on College Geography Resource 22. Washington: Washington Association of American Geographers, 1973.

Dhungel B, Dias HD. Planning for rural health services in Nepal. Third World Planning Review, 1988; 3: 239-254.

Donabedian A. Definition of quality and approaches to its assessment, vol.1. Ann Arbor: MI, Health Administration Press, 1980.

Donabedian A. Evaluating the quality of medical care. Milbank Memorial Fund Quarterly, 1996; 44: 166-206.

Dujardin B, Clarysse G, Criel B, De Brouwere V, Wangata N. The strategy of risk approach in antenatal care: evaluation of the referral compliance. Social Science and Medicine, 1995; 40(4): 529-535.

Dutton D. Financial, organisational and professional factors affecting health care utilisation. Social Science and Medicine, 1986; 23(7): 721-735.

Ensor T, San PB. Access and payment for health care: the poor of Northern Vietnam. International Journal of Health Planning and Management, 1996; 11(1): 69-83.

Evans DB, Tandon A, Murray CJL, Laurer JA. Comparative efficiency of national health systems: cross national econometric analyses. British Medical Journal, 2001; 323: 307310.

Evans RG, Stoddard GL. Producing health, consuming health care. Social Science and Medicine, 1990; 31: 1347-1363.

Folland ST. Predicting hospital market shares. Inquiry, 1983; 20: 34-44. 
Fong $\mathrm{C}$. The influence of health insurance status on nonurgent pediatric visits to the emergency department. Academical Emergency Medicine, 1999: 6(7): 744-748. Division of Emergency Medicine, Children's Hospital, Harvard Medical School, Boston, MA, USA.

Fredericksen H. Maintenance of malarial eradication. Duplicated Report. Geneva: WHO/ Mal. 429, 1964.

Ganatra B, Hirve S. Male bias in healthcare utilisation for under-fives in a rural community in western India. Bulletin of World Health Organisation, 1994; 72(1): 101-104.

Garner BJ. Models of urban geography and settlement location. In: Chorley JR, Haggett P (eds.). Models in geography. London: Methuen and Co. Ltd, 1967.

Gatrell AC. Geographies of health: an introduction. Oxford: Blackwell, 2002.

Gatrell AC, Thomas C, Bennett S, Bostock L, Thomas C, Popay J, Williams G, Shahtahmasebi $S$. Understanding health inequalities: locating people in geographical and social spaces. In: Graham H (ed.). Understanding Health Inequalities. Buckingham: Open University Press, 2000.

Gesler WM, Meade MS. Locational and population factors in health care-seeking behaviour in Savannah, Georgia. Health Services Research, 1988; 23(3): 443-460.

Ghana Ministry of Health. Annual report 1997. Accra: Ghana MOH, 1998.

Ghana Ministry of Health. 1999 Annual report, Ahafo-Ano South District. Mankranso: Ghana MOH, 2000.

Ghana Ministry of Health. 1999 Annual report, Ashanti Region. Kumasi: Ghana MOH, 2000.

Ghana Statistical Service. Rural communities in Ghana: report of a national rural community survey carried out as part of the third round of the Ghana living standard, survey 1991/92, Accra: GSS, 1993.

Ghana Statistical Service. Ghana demographic and health survey, 1993. Accra: GSS, 1994.

Ghana Statistical Service. Ghana demographic and health surveys, 1998. Demographic and Health Surveys. Accra: GSS, Macro International Inc, 1999.

Ghana Statistical Service. Ghana living standards survey: report of the fourth round. Accra; GSS, 2000 .

Ghana Statistical Service. Population and housing census, preliminary results. Accra: GSS, 2000.

Ghana Statistical Service. Population and housing census, Summary report of final results. Accra: GSS, 2002. 
Ghana Statistical Service and Micro International. Ghana demographic and health survey 1998. Calverton: GSS and MI, 1999.

Giggs JA. Health. In: Pacione M (ed.). Progress in urban geography. London: Croom, 1983.

Gijsbers Van Wijk CMT, Kolk AMM, Van den Bosch WJHM, Van den Hoogen HJM. Male and female morbidity in general practice: the nature of sex differences. Social Science and Medicine, 1992; 35: 665-678.

Girt JL. Distance to general medical practice and its effects on revealed ill health in a rural environment. Canadian Geographer, 1973; 17: 154-166.

Glaser AW. Health insurance in practice. San Francisco/London: Jossey-Bass Publishers, 1991.

Glewwe P. Why does mother's schooling raise child health in developing countries? Journal of Human Resources, 1999; 34: 124-159.

Good CM. Ethnomedical systems in Africa: patterns of traditional medicine in rural and urban Kenya. New York: Guilford Press, 1987.

Grossman M. The demand for health: a theoretical and empirical investigation. New York: NBER, 1972.

Grossman M. The correlation between health and schooling. In: Terleckyi NE (ed.). Household production and consumption. New York: Colombia University Press, 1975.

Grytten J. The effect of supplier inducement on Norwegian dental services: some empirical findings based on a theoretical model. Community and Dental Health, 1991; 8(3): 221231.

Habib OS, Vaughan JP. The determinants of health service utilisation in Southern Iraq: a household survey. International Journal of Epidemiology, 1986; 15(3): 395-403.

Habib OS, Guilkey DK, Griffin CC, Popkin BMK. The demand for primary health services utilisation in Southern Iraq: a household interview survey. International Journal of Epidemiology, 1985: 15(3): 395-403.

Harpham T, Lusty T, Vaughan P. In the shadow of the city: community health and the urban poor. Oxford: Oxford University Press, 1988.

Hays MS, Kearns AR, Moran W. Spatial patterns of attendance at general practitioner services. Social Science and Medicine, 1990; 31(7): 773-781.

Heggenhougen HK. Perceptions of health care options and therapy-seeking behaviour. In: Cleland J, Hill AG (eds.). The health transition: methods and measures. Cambridge: Cambridge University Press, 1989. 
Helman C. Culture, health and illness. Bristol: John Wright and Sons Ltd, The Stonebridge Press, 1984.

Hennekens CH, Buring JE. Descriptive studies. In: Mayrent SL (ed.). Epidemiology in Medicine. Boston/Toronto: Little, Brown and Co, 1987.

Hobcraft JN. 1993. Women's education. Child welfare and survival: a review of the evidence. Health Transition Review, 1993; 3: 150-175.

Hopkins EG, Pye AM, Solomon M, Solomon S. The relation of patients' age, sex and distance from surgery to the demand on the family doctor. Journal of the Royal College of General Practitioners, 1968; 16: 368-378.

International Labour Organization STEP. Synthesis of case studies of micro insurance and other forms of extending protection in health in Latin America and Caribbean. Geneva: ILO, 1999.

International Labour Organization, Department of Communication. Health care: the key to decent work. Geneva: ILO, 2000.

Institute of Development Studies. Research Reports. Health needs and health services in rural Ghana. Brighton: University of Sussex, 1978.

Jejeebhoy SJ. Women's education, autonomy, and reproductive behaviour: experience from developing countries. New York: Oxford University Press, 1995.

Jolly R, King M. The organisation of health services. In: King $\mathrm{M}$ (ed.). Medical care in developing countries. Nairobi: Oxford University Press, 1966.

Joseph AE, Phillips DR. Accessibility and utilisation: geographical perspectives on health care delivery. London: Harper and Row, 1984.

Joseph AE, Poyner A. Interpreting patterns of public service utilization in rural areas. Economic Geography, 1982; 58: 262-273.

Jutting J, Wisemann D. The emerging movement of community based health insurance in Sub-Saharan Africa. Africa Spectrum, 2001; 35(2): 193-210.

Kaliszer M, Kidd M. Some factors affecting attendance at ante-natal clinics. Social Science and Medicine, 1981; 15D: 421-424.

Kambarin K. The impact of structural adjustment on access to health care: the care of Christian Health Association of Ghana (CHAG) and the rural people. Bergen: Institute of Administration and Organisational Science, University of Bergen, 1996. (MPhil thesis)

Khandker RK, McCormack LA. Medicare spending by beneficiaries with various types of supplemental insurance. Medical Care Research and Review, 1999; 56(2): 137-155. 
Kinman EL. Evaluating health service equity at a primary care clinic in Chilimarca, Bolivia. Social Science and Medicine, 1999; 49(5): 663-678.

Kipp W, Kamugisha J, Jacobs P, Burnham G, Rubaale T. User fees, health staff incentives, and service utilisation in Kabarole district, Uganda. Bulletin of the World Health Organisation, 2001; 79(11): 1032-1037.

Kohn R, White KL. Health care: an international study. Oxford: Oxford University Press, 1976.

Kon-Kyun R. Patient characteristics, hospital characteristics, and hospital use. In: Fuchs VR (ed.). Essays in the economics of health and medical care. New York: National Bureau of Economic Research, 1972.

Kroeger A. Anthropological and socio-medical health care research in developing countries. Social Science and Medicine, 1983; 17(3); 147-161.

Kroneman MW, Van der Zee J. Health policy as a fuzzy concept: methodological problems encountered when evaluating health policy reforms in an international perspective. Health Policy, 1997; 40: 139-155.

Kwabia B. Implications of ERP/PAMSCAD for economic well-being of children in Ghana. In: Ardayfio-Schandorf $\mathrm{E}$ (ed.). The changing family in Ghana. Accra: Ghana Universities Press, 1996.

Lane SD, Meleis AI. Roles, work, health perceptions and health resources of women: a study in an Egyptian delta hamlet. Social Science and Medicine, 1991; 33(10): 1197-1208.

Larson JS. The measurement of health-concepts and indicators. New York: Greenwood Press; 1991.

Lillard LA, Rogowski J, Kingston R. Insurance coverage for prescription drugs: effects on use and expenditures in the medical population. Medical Care, 1999; 37(9): 926-936.

Liu T-C, Chen C-S. An analysis of private insurance purchasing decisions with national health insurance in Taiwan. Social Science and Medicine, 2002; 55(5): 755-774.

Lloyd BB. Education and family life in the development of class identification among the Yoruba. In: Lloyd PC (ed.). New Elites in Tropical Africa. London: London University Press, 1966.

Lule GS, Ssembataya M. Intention to deliver and pregnancy outcomes. International Development Resource Center, 1996.

Marrée J, Groenewegen P. Back to Bismarck: Eastern European health care systems in transition. Aldershot: Avebury, 1997. 
McCord MJ. Health care microinsurance- case studies from Uganda, India and Cambodia. Small Enterprise Development, 2001; 12(1): 25-38.

McKee M, Heady J, Falkingham J. Health care in central Asia. Buckingham: Open University Press, 2002.

McKinlay JB. Some approaches and problems in the study of the use of services-an overview. Journal of Health and Social Behavior, 1972; 13: 115-152.

Mead H, Witkowski K, Gault B, Hartmann H. The influence of income, education, and work status on women's well-being. Women's Health Issues, 2001; 11(3): 160-172.

Meise U, Kemmler G, Kurz M, Rossler W. Quality of location as a principle in psychiatric health care planning. Gesundheistswesen, 1996; 58(1 suppl.): 29-37.

Mellington N, Cameron L. Female education and child mortality in Indonesia. Bulletin Indonesian Economic Studies, 1999; 35: 115-144.

Mensch B, Lentzner H, Preston S. Socio-economic differentials in child mortality in developing countries. New York: United Nations, Department of International Economic and Social Affairs, 1985.

Morrill RL, Earickson RJ. Hospital Variation and Patient Travel Distances. Inquiry, 1968; 5 : $1-9$.

Morrill DC, Gage HG, Robinson NA. Patterns of demand in general practice. Yournal of the Royal College of General Practitioners, 1970; 19: 331-342.

Morrow RH. Macroeconomics and health. British Medical Journal, 2002; 325: 53-54.

Mossialos E, Dixon A. Funding health care: an introduction. In: Mossalios E, Dixon A, Figueras J, Kutzin J. Funding health care: options for Europe. Buckingham: Open University Press, 2002.

Muller I, Smith T, Mellor S, Rare L, Genton B. The effects of distance from home on attendance at a small rural health centre in Papua New Guinea. International Journal of Epidemiology, 1998; 27(5): 878-884.

Muntaner C, Lynch J. Income inequality, social cohesion, and clas relations: a critique of Wilkinson's neo-Durkheimian research programme. International Journal of Health Services, 1999; 29(1): 59-81.

Mustard CA, Kaufert P, Kozyrskyj A, Mayer T. 1998. Sex differences in the use of health care services. New England Journal of Medicine, 1998; 338(23): 1678-1683.

Nadraj S, Madhiwalla N, Sinha R, et al. Women and health care in Mumbai (India): A study of morbidity, utilization and expenditure on health care in the households of the metropolis. SNDT Churchgate: Centre for Enquiry into Health and Allied Themes, 1998. 
Nemet GF, Bailey AJ. Distance and health care utilisation among the rural elderly. Social and Medicine, 2000; 50: 1197-1208.

Nukunya GK. Tradition and change in Ghana. Accra: Ghana Universities Press, 1992.

O'Brien B. The effect of patient charges on the utilisation of prescription medicines. Journal of Health Economics, 1989; 8: 109-112.

Ojanuga DN, Gilbert C. Women's access to health care in developing countries. Social Science and Medicine, 1992; 35(4): 613-617.

Okafor FC. Accessibility to general hospitals in rural Bendel State, Nigeria. Social Science and Medicine, 1984; 18(8): 661-666.

Okafor FC. The spatial dimensions of accessibility to general hospitals in rural Nigeria. Socio-Economic Planning Sciences, 1990: 24(4): 295-306.

Oppong JR, Hodgson MJ. Spatial accessibility to health care in Suhum District, Ghana. The Professional Geographer, 1994; 46(2): 199-209.

Parliament of the Republic of Ghana. National Health Insurance Act. Accra: Parliament of the Republic of Ghana, 2001.

Phillips DR. Spatial variations in attendance at general practitioner services. Social Science and Medicine, 1979; 13(3): 169-181.

Phillips DR. Primary health care in the Philippines: banking on the Barangays? Social Science and Medicine, 1986; 23(10): 1105-1117.

Phillips DR. Health and health care in the Third World. New York: Longman, 1990.

Phillips DR. The demand for the utilization of health services. In: Pacione M. (ed). Medical geography: progress and prospects. London: Groom Helm, 1996.

Pickett G, Hanlon JJ. Public health administration and practice. St. Louis: Times Mirror/Mosby College Publishing, 1990.

Poland BD, Taylor SM, Hayes MV. The ecology of health services utilisation in Grenada, West Indies. Social Science and Medicine, 1990; 30(1): 13-24.

Porter J, Coyte PC, Barnsley J, Croxford R. The effects of fee bundling on dental utilization. Health Services Research, 1999; 34(4): 901-921.

Pyle GF. The geography of health care. In: Hunter JM (ed). The geography of health and disease. Chapel Hill: University of North Carolina, 1974.

Raghupathy S. Education and the use of maternal health care in Thailand. Social Science and Medicine, 1996; 43(4): 459-471. 
Ramesh A, Hyma B. Traditional Indian Medicine In Practice in an Indian Metropolitan City. Social Science and Medicine, 1981; 15D: 69-81.

Rathwell T, Phillips DR. Health, race and ethnicity. London: Croom Helm, 1986.

Republic of Ghana. Annual Estimates, 1995. Accra: Ministry of Health, 1996.

Robinson J, Wharrad H. Invisible Nursing: exploring health outcomes at a global level. Relationships between infant and under-5 mortality rates and the distribution of health professionals, GNP per capita, and female literacy. Journal of Advanced Nursing, 2000; 32(1): $28-40$.

Roghmann KJ, Zastowny TR. Proximity as a factor in the selection of health care providers. Social Science and Medicine, 1979; 13D: 61-69.

Santow G. Social roles and physical health: the case of female disadvantaged in poor countries. Social Science and Medicine, 1995: 40 (2): 147-161.

Shannon GW, Bashshur RL, Metzner CA. The concept of distance as a factor in accessibility and utilisation of health care. Medical Care Review, 1969; 26: 143-161.

Shannon GW, Dever GEA. Health care delivery; spatial perspectives. New York: McGrawHill, 1974.

Shannon GW, Skinner JL, Bashshur RL. Time and distance: the journey for medical care. International Journal of Health Services, 1973; 3(2): 237-244.

Shaw PR, Griffin CC. Financing health care in Sub-Saharan Africa. Directions in development series. Washington DC: World Bank, 1995.

Sindelar JL. Differential use of medical care by sex. Journal of Political Economy, 1982: 90(5): 1017-1018.

Sintonen H, Maljanen T. Explaining the utilisation of dental care: experiences from the Finnish dental market. Health Economics, 1995; 4(6): 453-466.

Slack R, Ferguson B, Ryder S. Analysis of hospitalisation rates by electoral ward: relationship to accessibility and deprivation data. Health Services Management Research, 1997; 10: 24-31.

Smith DM. Where the grass is greener: living in an unequal world. Harmondsworth: Penguin, 1979.

Sowa NK. The impact of structural adjustment on the population of Africa: the implications for education, health and employment, Ghana, Aderanti Adepoju. London: UNFPA, 1993. 
Sox CM, Burstin HR, Edwards RA, O'Neil AC, Brennan TA. Hospital admissions through the emergency department: does insurance status matter? American Journal of Medicine, 1998; 105(6): 506-512.

Stock R. Distance and the utilisation of health facilities in rural Nigeria. Social Science and Medicine, 1983; 17: 563-570.

Stock R. Understanding health care behaviour: a model together with evidence from Nigeria. In: Akhtar R (ed.). Health and disease in tropical Africa. London: Harwood, 1987.

Supakankunti S. Future prospects of voluntary health insurance in Thailand. Health Policy and Planning, 2000; 15(1): 85-94.

Swenson IE, Thang N-M, Nhan V-Q, Tieu P-X. Factors related to the utilisation of pre-natal care in Vietnam. Journal of Tropical Medicine and Hygiene, 1993; 96(2): 76-85.

Taylor CE, Sarma RSS, Parket RL, Reinke WA, Farugnee R. Child and maternal health services in rural India: the Narangual experiment, vol.2. Baltimore Md: World Bank and Johns Hopkins University Press, 1983.

Thomas CJ. Sociospatial variation and use of services. In: Herbert DT, Johnston RJ (eds.). Social Areas in Cities, vol.2. Chichester: Wiley, 1976.

Tilford JM, Robbins JM, Shema SJ, Farmer FL. Response to health insurance by previously uninsured rural children. Health Services Research, 1999; 34(3): 765-775.

Turshen M. Privatizing health services in Africa. New Brunswick: Rutgers University Press, 1999.

United Nations. Africa recovery, special issue on mid-term review of UN agenda for Africa. $\mathrm{UN}, 1996,10(2): 96$.

Veitch MD. Population growth and the health services. In: Ominde JH, Ejiougu CN (eds.). Population growth and economic development in Africa. Bungay: The Chaucer Press, 1992.

Verbrugge LM. Female illness rates and illness behaviour: testing hypotheses about sex differences in health. Women and Health, 1979; 4: 61-79.

Verbrugge LM, Steiner RP. Physician treatment of men and women patients. Sex bias or appropriate care. Medical Care, 1981; 19: 609-632.

Waddington C, Enyimayew KA. A price to pay: The impact of user charges in Ashanti-Akim District, Ghana. International Journal of Health Planning and Management, 1989; 4: 1747.

Waitzkin H. Report of the WHO Commission on Macroeconomics and Health: a summary and critique. Lancet, 2003; 361: 523-526. 
Walters NM, Zietsman HL, Bhagwandin N. The geographical distribution of diagnostic medical and dental X-ray services in South Africa. South African Medical Journal, 1998; 88: 383-389.

Whitelegg J. Inequalities in health care: problems of access and provision. Retford: Straw Barnes Press, 1982.

Wilson JB, Collison AH, Richardson D, Kwofie G, Senah KA, Tinkorang EK. The maternity home waiting concept: the Nsawam, Ghana experience. International Journal of Gynaecology and Obstetrics, 1997; 59(suppl.2): 165-172.

Wong EL, Popkin BM, Guilkey DK, Akin JS. Accessibility, quality of care and pre-natal care use in the Philippines. Social Science and Medicine, 1987; 24(11): 927-944.

World Bank. World development report 1991: the challenge of development. Oxford: Oxford University Press, 1991.

World Bank. World development report 1993: investing in health: world development indicators. Oxford: Oxford University Press, 1993.

World Bank. World development report 1994. Washington DC: World Bank, 1994.

World Bank. World development indicators, Washington DC: World Bank, 1997.

World Bank. World development indicators. Washington DC: World Bank, 1999.

World Bank. World development indicators. Washington DC: World Bank, 2000.

World Bank. World development indicators. Washington DC: World Bank, 2002.

World Bank. World development indicators 2003. Oxford: Oxford University Press, 2002.

World Health Organization. The promotion and development of traditional medicine. Geneva: WHO Technical Report Series 622, 1979.

World Health Organization. World health report, 2000. Geneva: WHO, 2000.

World Health Organization. World health report 2002: reducing risks, promoting healthy life. Geneva: WHO, 2002.

World Health Organization, Commission on Macroeconomics and Health. Macroeconomics and health: investing in health for economic development. Geneva: WHO; 2001.

Wyss K, Whiting D, Kilma P, Mclarty DG, Mtasina O, Tanner M, Lorenz N. Utilisation of government and private health services in Dar es Salaam. East African Medical Journal, 1996; 73(6); 357-363. 
Yach D, Von Schirnding YE. Towards a higher priority for health on the development agenda. Public Health Review, 1994; 22(3-4): 339-374.

Yeomans KA. Statistics for the social scientist. New York: Penguin, 1979. 


\section{Summary}

The thesis examines the factors that impact on access and utilisation of health services in Ghana. The utilisation behaviour of residents of a typical urban and a typical rural district are used as representing the entire Ghanaian experience. Literature has demonstrated the dichotomy in utilisation between rural and urban areas, with urban residents having advantage over rural. It also shows that in developing countries, such as Ghana, need (health status) is not as significant as predisposing, enabling and restrictive factors in determining utilisation. Women are at a disadvantage, implying gender inequity, whilst health insurance has a strong positive effect on utilisation. Empirical data from the study area confirm the theoretical foundations. Quantitative analyses are made, supported by a few qualitative methods, whilst empirical papers dominate the thesis.

Chapter 1, The Overview, looks at Ghana's economy and its socioeconomic conditions and health status. The nation, though having rich natural resources, is poor. Resources have not been won to improve the socio-economic conditions of the people. Poverty is a predominant feature, especially in the rural areas and urban fringes. Gross National Income (GNI) per capita is below $\$ 400$, which is far below the average for low-income countries including China and India, though better than some countries in the deprived West African sub-Region. Yet, population growth rate and the total fertility rate are quite high, implying that, if measures are not taken to improve micro economic indicators, economic status would continue to decline, and standards of living deteriorate. Health promoting factors of access to safe water and sanitation are not favourable. Percentage of the population with access to safe water falls below that for low-income countries, though access to sanitation is comparatively slightly better. Coupled with these poor socio-economic indicators are inadequate health facilities. The health personnel problem is rather alarming: a physician takes care of over 10,000 people, which falls far below the average of a physician per 2,000 people for low-income countries including China and India. Health facilities are concentrated in the main urban centres to the detriment of the rural population.

Literature for the status of access and use of health care in developing countries identifies cost, distance and education as the principal factors influencing utilisation. The cost problem deprives the poor of access to health facilities whilst distance impedes utilisation by those who don't 
have access to good transport. The need factor in utilisation is subsumed by the predisposing, enabling and restrictive factors like distance, travel and waiting times. Insurance has been found to improve utilisation by the few that have access to it. Unfortunately, the insurance system is poorly developed in developing countries. In Ghana, a National Health Insurance Scheme (NHIS) is yet to take off, after Parliament has passed the Bill. Access and use of health services is thus strongly influenced by the political ecology.

The empirical part of this thesis is based on a cross-sectional survey about access and utilisation of health services in Ghana, using a rural and an urban district as case studies. The Andersen-Newman model has been fundamental to the models used for the thesis. A probability sample was drawn using systematic randomisation. Data were analysed using crosstabulations, bivariate correlation, linear regression, and maps and charts. Explanatory models have been structured for some outcomes. Biases arising out of difficulty of some respondents to supply data and consistency in applying the systematic random technique were effectively addressed.

Chapter 2 is made up of an analysis of existing data, concerning the economy, health spending and health status in Sub-Saharan Africa, isolating the position of Ghana in the Sub-Region. It specifies the relationship between health outcomes and strength of the economy for Sub-Saharan African countries and shows whether Ghana's health status could be predicted from her economic strength. Data at country level were collected from WHO and World Bank databases. Multiple regression was used for the analysis. It was found that the association between wealth and health is very strong. HIV infection showed as a factor influencing health status. Ghana is doing better in terms of healthy life expectancy than can be predicted based on its economic position.

Chapter 3 discusses the comparative analysis of utilisation of health services in rural and urban settings in Ghana. Two districts, Kumasi Metropolis and Ahafo-Ano South District were used as case study. Formal interview and questionnaire schedules were the research instruments used for data collection. A multiple regression model was used for the study that is based on the Andersen-Newman model. Results showed that there was a need-utilisation discrepancy in the study area. Although health status (need), which has no significant influence on utilisation, does not significantly differ between the rural and urban districts, the urban district used health services more than the rural. The 
study also showed that health status (need) is insignificant in explaining differences in utilisation between the two areas, and is relatively a weaker factor, compared with predisposing-enabling-restrictive factors, in determining utilisation in both areas. Finally, predisposing, enabling and restrictive factors were found to explain differences in utilisation between the two districts. Whereas education, distance and service cost were the most important factors influencing health care use in the metropolis, distance and income emerged as the most important factors in the rural Ahafo-Ano South District. The research was subject to some biases that had the potential to influence the results even though efforts were made to limit negative repercussions on it. There were problems of memory that could affect data on income and regularity of attendance. Secondly, sample targets for the aged and tertiary education had to be changed for lack of such respondents in some areas. Finally, health status was assessed by the number of ailments, avoiding severity of ailments that could affect the need factor. Such weaknesses run through the other access and utilisation papers. It has been recommended that health facilities in the rural areas be increased, formal education given a broader coverage and income opportunities improved. Finally, it is recommended that a national health insurance scheme be introduced to improve access.

Chapters 4 and 5 examine the role of distance in the utilisation of health services. Two published papers emerged, one on the Kumasi Metropolis and one on the Ahafo-Ano South District, which is rural. Both used the formal (face-to-face) interviews and questionnaires as instruments of data collection whilst the systematic random sampling technique was used in the sampling framework. Distance had a greater effect on utilisation in the rural district than in the metropolis; though, in the Kumasi Metropolis distance emerged as the most important factor after education and followed immediately by service cost. In the Kumasi Metropolis, the vulnerable groups of women, the aged, the sickly, the illiterate and the poor were not found to be more strongly affected by distance decay. In the Ahafo-Ano South District where the nature of roads is very poor however, distance emerged as the most important factor influencing utilisation.

Chapters 6 and 7 discuss gender issues in utilisation. It is made up of two published papers: one, a review paper, on the impact of education of mothers on childhood mortality in Ghana, and the other, an empirical paper, on gender and utilisation of health services in the Ashanti Region of Ghana. In the previous, secondary data mainly drawn from the Ghana 
Demographic and Health Surveys (1998) and World Bank (2000) data were used. A regression model and charts were used to illustrate the relationship. The factors that were measured against mothers' education were infant mortality, maternal and child nutrition, childhood vaccination, antenatal care and incidence of childhood diarrhoea. The survey established that there was an inverse relationship between mothers' education and child survivorship. It was also found that the use of basic health facilities that relate to childhood survival showed a direct relationship with mothers' education. Emphasis on the education of the girl-child, providing adequate maternal and child health services to improve access, and the initiation of a project to integrate maternal education and child health services have been recommended.

The gender and the utilisation paper sought to structure a model for gender-based health services utilisation for the Ashanti Region of Ghana and to recommend intervention measures to ensure gender equity in the utilisation of health services. A multiple regression model was used for the analysis. The survey has revealed that although females have a greater need for health services than males, they do not utilise health services as much. Quality of service, health status, service cost and education had greater effect on male utilisation than females whilst distance and income had greater influence on females than males. To ensure equity in health care it is recommended that females be empowered through increased access to formal education and sustainable income opportunities. A model on utilisation of health services by gender emerged. The key components were government policy, provider characteristics, male utilisation and female utilisation, with utilisation of health services at the centre. Government policy directly affects provider characteristics, male and female utilisation through distribution, employment and wages, universal education and health insurance policies. Health providers influence male and female utilisation through quality of service, practice patterns and affective behaviour. The need factor was found to affect males whilst the predisposing factor of education and need factor of income affected both sexes. Quality of service affected males whilst distance and service cost were common to both sexes.

Chapter 8 attempts to establish the primacy of income in the utilisation of health services in a rural district in Ghana. It is also driven by the passion of determining the position of income among the key variables influencing utilisation. A sample of 400 , selected using systematic random, the questionnaire and formal interviews instruments, is used for 
the survey. Using multiple regression as tools of analysis, the survey has established that income is exceeded only by distance as the most important factor influencing the utilisation of health services in the rural district. It has also been established that the illiterate, female, ageing and the sickly are vulnerable to the income-utilisation syndrome. Recommendations to improve utilisation, and a conceptual model of utilisation, have emerged.

The final chapter addresses the role of health insurance in utilisation, using the Kumasi Metropolis as case study. The rural district was not drawn into the analysis due to the poor development of insurance there. A sample of 250 persons drawn using systematic random procedure was used. Data were collected using formal interviews and the questionnaire. The interviews covered the communities, health and legal personnel and economists. Data were analysed using linear regression and the qualitative approach. Results showed that there is a strong positive association between access to insurance and utilisation of health services. Popular opinion wants a certain percentage of workers' (in formal sector) income to be deducted as premium whilst a systematic mechanism be introduced to collect premiums from workers in the informal sector. It is strongly recommended that a national health insurance scheme be introduced as a mechanism for addressing the underutilisation problem. 


\section{Samenvatting'}

In dit proefschrift wordt verslag gedaan van onderzoek naar de factoren die van invloed zijn op de toegankelijkheid en het gebruik van gezondheidszorg in Ghana. Om een beeld te geven van de ervaringen in heel Ghana, wordt het gebruik door zowel bewoners van een typische stedelijk gebied, als van een typisch ruraal gebied in het onderzoek betrokken. In literatuur is aangetoond dat het gebruik van zorg in de steden en buiten de steden aanzienlijk verschilt met een gunstigere positie voor de mensen in stedelijke gebieden. Ook blijkt uit de literatuur dat in ontwikkelingslanden zoals Ghana het gebruik van gezondheidszorg niet zozeer wordt bepaald door de behoefte (gezondheidsstatus), als wel door achtergrondkenmerken en opvattingen, mogelijkheden om zorg te gebruiken en beperkende factoren (de bekende 'predisposing' en 'enabling' factoren uit het model van Andersen en Newman). Vrouwen zijn in het nadeel, hetgeen ongelijkheid der seksen impliceert, en een ziektekostenverzekering heeft juist weer een positief effect op het gebruik. De theoretische uitgangspunten worden bevestigd door de empirische gegevens uit het onderzoeksgebied. Er zijn kwantitatieve analyses gedaan, ondersteund door enkele kwalitatieve methoden. De meeste hoofdstukken betreffen empirische analyses.

In hoofdstuk 1, Overzicht, wordt de economie, de sociaal-economische omstandigheden en de stand van de gezondheidszorg in Ghana bekeken. Hoewel het land rijk is aan grondstoffen, is het toch een arm land. De grondstoffenrijkdom is niet gebruikt om de sociaal-economische omstandigheden van de mensen te verbeteren. Armoede overheerst, vooral buiten de steden en aan de rand van de steden. Het Bruto Nationaal Inkomen per hoofd van de bevolking ligt onder de 400 Amerikaanse dollar, hetgeen ver onder het gemiddelde van landen met lage inkomens is, waaronder China en India; aan de andere kant is het wel hoger dan het gemiddelde in de West-Afrikaanse subregio. De bevolkingsgroei en de totale vruchtbaarheid liggen echter behoorlijk hoog, hetgeen betekent dat de economische positie nog verder zal verslechteren en de levensstandaard nog verder zal dalen, als er geen maatregelen worden getroffen om de micro-economische indicatoren te verbeteren. Gezondheids-

1 Vertaling: Mw. M. van Leeuwe 
bevorderende factoren zoals toegang tot veilig water en sanitair zijn schaars. Het percentage mensen voor wie veilig water toegankelijk is, ligt onder dat van landen met lage inkomens, hoewel, aan de andere kant, dat voor het gebruik van sanitair weer juist wat beter uitvalt. Naast deze slechte sociaal-economische indicatoren zijn ook de gezondheidsfaciliteiten inadequaat. Het personeelsprobleem in de gezondheidszorg is alarmerend: één dokter op 10.000 mensen, tegenover het gemiddelde van één op de 2.000 in landen met lage inkomens, zoals China en India. De gezondheidszorgfaciliteiten bevinden zich voornamelijk in de belangrijkste stedelijke gebieden, zodat de mensen in de gebieden buiten de steden slecht bedeeld zijn.

In de literatuur over de stand van de gezondheidszorg en de toegankelijkheid en het gebruik ervan in ontwikkelingslanden worden kosten, afstand en opleidingsniveau genoemd als de belangrijkste factoren die het gebruik bepalen. Voor de armen zijn de kosten het grootste probleem, terwijl de afstand een hindernis is voor hen die niet over goed transport kunnen beschikken. De factor 'behoefte aan gezondheidszorg' is ondergeschikt aan de 'predisposing', 'enabling' en beperkende factoren, zoals afstand, reistijd en wachttijden. Ziektekostenverzekering blijkt het gebruik te bevorderen, maar is slechts voor enkelen een optie. Het ziektekostenverzekeringssysteem is helaas slecht ontwikkeld in ontwikkelingslanden. In Ghana moet een landelijk ziektekostenverzekeringssysteem (National Health Insurance Scheme, NHIS) nog worden opgezet, omdat de wet die dat regelt nog maar net is angenomen. De toegankelijkheid en het gebruik van de gezondheidszorg wordt derhalve sterk beïnvloed door politieke factoren.

Het empirische deel van dit proefschrift is gebaseerd op een crosssectioneel onderzoek naar toegankelijkheid en gebruik van de gezondheidszorg in Ghana, waarbij zowel een ruraal als een stedelijk gebied worden gebruikt. Het Andersen-Newman model heeft als basis gediend voor de modellen in dit proefschrift. Met behulp van systematische, maar willekeurige selectie werd een waarschijnlijkheidssteekproef getrokken. De gegevens zijn geanalyseerd met behulp van kruistabellering, bivariate correlatie, lineaire regressie en kaarten en grafische voorstellingen. Selectie doordat sommige respondenten problemen hadden om bepaalde vragen te beantwoorden zijn adequaat opgelost. 
Hoofdstuk 2 bestaat uit een analyse van bestaande gegevens, betreffende de economie, de uitgaven aan gezondheidszorg en de gezondheidstoestand van de bevolking in de Afrikaanse landen ten zuiden van de Sahara, waarbij de positie van Ghana afzonderlijk kon worden beschouwd. De relatie tussen de volksgezondheid en de staat van de economie van de landen ten zuiden van de Sahara kon zo worden gespecificeerd; bovendien kon op die manier worden bezien of de gezondheidsstatus van de bevolking in Ghana voorspeld kan worden uit haar economische positie. De landelijke gegevens werden gehaald uit de databanken van de WHO en de Wereldbank. Voor de analyse werd gebruik gemaakt van multiple regressie. Het verband tussen welvaart en gezondheid bleek zeer sterk te zijn. Het aantal mensen met een HIVinfectie is, zo bleek uit de analyse, een factor die de gezondheidsstatus van een land sterk beïnvloedt. Ghana scoort hoger in termen van levensverwachting en gezondheid dan haar economische positie zou doen verwachten.

In hoofdstuk 3 komt de vergelijkende analyse van het gebruik van gezondheidszorg in stedelijke en rurale gebieden aan de orde. Twee gebieden, namelijk Kumasi Metropolis en Ahafo-Ano Zuid, dienden als case study. Om gegevens te verzamelen vonden er gestructureerde vraaggesprekken plaats en werden er vragenlijsten verstuurd. Er werd gebruik gemaakt van een multiple-regressiemodel, gebaseerd op het Andersen-Newman model. Uit de resultaten bleek dat binnen het onderzochte gebied er een discrepantie was tussen de behoefte aan en het gebruik van zorg. Hoewel de gezondheidsstatus (behoefte) die het gebruik niet aantoonbaar beïnvloedt, geen significant verschil vertoont tussen de gebieden in de steden en buiten de steden, blijkt het wel zo te zijn dat men in de steden meer gebruik maakt van de gezondheidszorg dan buiten de steden. Het onderzoek toonde ook aan dat de gezondheidsstatus (behoefte) niet doorslaggevend is voor de verklaring van gebruiksverschillen tussen de twee gebieden; het heeft een geringe samenhang met gebruik vergeleken met de predisposing, enabling en beperkende factoren. Tot slot bleken ook de predisposing, enabling en beperkende factoren doorslaggevend voor de verklaring van het verschil in gebruik tussen de twee gebieden. In de metropolis waren opleiding, afstand en kosten van de zorg de belangrijkste factoren die het gebruik van de gezondheidszorg beïnvloedden; daartegenover waren in het rurale gebied van Ahafo-Ano 
Zuid de afstand en het inkomen doorslaggevend. Er waren wat afwijkingen binnen de procedures van selectie en dataverzameling in het onderzoek die de resultaten zouden kunnen beïnvloeden, ondanks alle moeite die werd getroost om deze negatieve invloed zo klein mogelijk te houden. Er waren geheugenproblemen die wellicht de gegevens betreffende inkomen en frequentie van gebruik van zorg zouden beïnvloeden; bovendien moesten de steekproefquota onder de ouderen en mensen met een hogere opleiding worden aangepast, simpelweg omdat er een gebrek was aan dergelijke respondenten. En, ten slotte, de gezondheidsstatus werd bepaald aan de hand van het aantal ziekten of klachten, waarbij de ernst daarvan buiten beschouwing werd gelaten, terwijl die de behoefte aan zorg wel kan beïnvloeden. Bij de overige empirische hoofdstukken over toegankelijkheid en gebruik van de gezondheidszorg kunnen dezelfde kanttekeningen worden geplaatst.

Aanbevolen wordt de beschikbaarheid van gezondheidszorg in de rurale gebieden te vergroten, de toegang tot scholing te vergroten en de inkomensmogelijkheden te verbeteren. Ook wordt aanbevolen een landelijk ziektekostenverzekeringssysteem in te voeren om de toegankelijkheid te verbeteren.

In de hoofdstukken 4 en $\mathbf{5}$ wordt de rol die afstand speelt in het gebruik van de gezondheidszorg nader onderzocht. Twee verhandelingen waren het resultaat: één over de Kumasi Metropolis en één over het ruraal district Ahafo-Ano Zuid. Bij beide werd gebruik gemaakt van gestructureerde interviews en vragenlijsten om de gegevens te verzamelen; bij de steekproeftrekking werd gebruik gemaakt van systematische, willekeurige selectie. De afstand speelde in het ruraal gebied een grotere rol voor het gebruik dan in de stad; echter, in de Kumasi Metropolis bleek de afstand de belangrijkste factor na opleiding, onmiddellijk gevolgd door de kosten van de zorg. Het bleek dat de kwetsbare groepen - vrouwen, ouderen, zieken, analfabeten en armen - in Kumasi Metropolis niet sterker werden benadeeld naarmate zij verder verwijderd waren van de zorg. In het ruraal Ahafo-Ano Zuid, daarentegen, zijn de wegen in zeer slechte staat en daardoor is de afstand van doorslaggevend betekenis in het gebruik van de zorg.

In de hoofdstukken 6 en 7 wordt de invloed van sekse op het gebruik van zorg geanalyseerd. De hoofdstukken bestaan uit twee gepubliceerde 
verhandelingen. De eerste, die is gebaseerd op bestaande gegevens, gaat over de invloed van het opleidingsniveau van de moeders op kindersterfte in Ghana; de tweede, gebaseerd op zelf verzamelde gegevens, over het verband tussen sekse en het gebruik van gezondheidszorg in Kumasi Metropolis en Ahafo-Ano Zuid. In de eerste verhandeling werden hoofdzakelijk gegevens gebruikt uit de demografische en gezondheidsstatistieken van Ghana (Ghana Demographic and Health Surveys, 1998) en de Wereldbank (2000). Om de relatie in beeld te brengen werd gebruik gemaakt van een regressiemodel en grafische voorstellingen. Het opleidingsniveau van de moeder werd afgezet tegen kindersterfte, voedingspatroon van moeder en kind, kindervaccinatie, prenatale zorg en diarree bij kinderen. Het onderzoek toonde een positieve relatie aan tussen het opleidingsniveau van de moeder en de overlevingkansen van het kind. Ook werd aangetoond dat er een rechtstreeks verband bestond tussen het gebruik van fundamentele faciliteiten van de gezondheidszorg om de overlevingskansen van kinderen te vergroten, en het opleidingsniveau van de moeder. Aanbevolen werd meer nadruk te leggen op de opleidingsmogelijkheden van meisjes, adequate gezondheidszorg voor moeders en kinderen te leveren om deze toegankelijker te maken, en een project te starten om de opleiding van de moeders en de gezondheidszorg voor kinderen te integreren.

In verhandeling over sekse en gebruik van de zorg werd getracht een model op te zetten voor gebruik van gezondheidszorg op basis van sekse voor het Ashanti-gebied van Ghana, waarin Kumasi Metropolis en AhafoAno Zuid liggen. Er werd gezocht naar mogelijke interventiemaatregelen om seksegelijkheid in het gebruik van zorg te bewerkstelligen. Voor de analyse werd gebruik gemaakt van een multiple-regressiemodel. Onderzoek wees uit dat hoewel vrouwen meer gezondheidszorg nodig hebben dan mannen, zij niet zoveel gebruik maken van die zorg als mannen. Kwaliteit van de zorg, gezondheidsstatus, kosten van de zorg en opleiding hadden een sterkere uitwerking op het gebruik van de zorg door mannen dan door vrouwen, terwijl, aan de andere kant, afstand en inkomen meer effect hadden op vrouwen dan mannen. Om gelijkheid in de zorg te realiseren wordt aanbevolen vrouwen meer ruimte te geven door hun officiële opleidingsmogelijkheden uit te breiden en hun meer mogelijkheden te bieden op een vast inkomen. Deze uitkomsten passen in een model voor gebruik van gezondheidszorg op basis van sekse, waarvan de 
belangrijkste ingrediënten zijn regeringsbeleid, kenmerken van de verstrekker van de zorg en gebruik door mannen en door vrouwen, en als centrale afhankelijke variabele het gebruik van gezondheidszorg. Het regeringsbeleid beïnvloedt de kenmerken van het zorgaanbod en het gebruik van zorg door mannen en vrouwen via de spreiding van voorzieningen, werkgelegenheid en lonen, universele opleidingsmogelijkheden en ziektekostenverzekeringen. De zorgverstrekkers beïnvloeden het gebruik door mannen en vrouwen via de kwaliteit van de diensten, praktijkpatronen en affectief gedrag. Behoefte aan zorg bleek bij mannen samen te hangen met gebruik, terwijl opleiding en inkomen bij zowel mannen als vrouwen met zorggebruik samenhing. Kwaliteit van de zorg laat een samenhang met gebruik zien bij mannen, terwijl afstand en de kosten van de zorg op beide seksen hetzelfde effect hadden.

In hoofdstuk 8 wordt een poging gedaan het grote belang van inkomen vast te stellen voor het gebruik van zorg in een ruraal gebied in Ghana. Ook is het de bedoeling de relatieve positie vast te stellen van inkomen ten opzichte van andere sleutelvariabelen die het gebruik beïnvloeden. Voor het onderzoek werd een systematische, willekeurige steekproef van 400 personen getrokken; er werd gebruik gemaakt van vragenlijsten en gestructureerde interviews. Met behulp van multiple regressie werd aangetoond dat inkomen enkel wordt overtroffen door afstand als belangrijkste factor die het gebruik van gezondheidszorg in het ruraal gebied beïnvloedt. Ook werd vastgesteld dat analfabeten, vrouwen, ouderen en zieken kwetsbaar zijn door de combinatie van laag inkomen en weinig zorggebruik. Het onderzoek besloot met aanbevelingen om het gebruik te bevorderen.

Het laatste hoofdstuk behandelt de rol van ziektekostenverzekering in het gebruik van zorg. Hierbij werd gekeken naar de stad Kumasi Metropolis. Het ruraal gebied is niet voor de analyse gebruikt, omdat ziektekostenverzekeringen daar nog nauwelijks tot ontwikkeling zijn gekomen. Er werd een systematische, willekeurige steekproef van 250 personen getrokken. De gegevens werden verzameld door middel van gestructureerde interviews en vragenlijsten. Daarnaast werden interviews gehouden met sleutelpersonen uit de gezondheidszorg, de juridische sector en ook economen. Met behulp van lineaire regressie en de kwalitatieve benadering in de interviews met sleutelpersonen werden de 
gegevens geanalyseerd. De resultaten wezen uit dat er een sterk positief verband is tussen toegang tot verzekeringen en het gebruik van zorg. Men zou het liefst zien dat in de formele sector een bepaald percentage van het inkomen van de werknemers wordt ingehouden voor de ziektekostenverzekering en in de informele sector een algemeen systeem van premieinhouding wordt georganiseerd om de verzekeringsbijdragen van werknemers in deze sector te innen. Het zou ten zeerste aan te bevelen zijn een landelijk ziektekostenverzekeringssysteem te introduceren om het gebruik van de zorg te stimuleren. 


\section{Acknowledgement}

It could be deciphered after a quick view of this document that this thesis has been produced with the financial support of some organisations, and the academic guidance of academic supervisors. I am full of gratitude to The Netherlands Foundation for the Advancement of Tropical Research (WOTRO), the main financiers of the project. The officers directly involved in the administration of the WOTRO fund such as the executive secretary, treasurer and officer responsible for the $\mathrm{PhD}$ Fellowship have indeed been supportive. They carried out their related functions with concern, alacrity, professional efficiency and perspicuity. The Netherlands Institute for Health Services Research (NIVEL) deserves no mean gratitude for its financial and logistic support. The Institute supplemented the financial support provided by WOTRO. The entire staff at NIVEL provided the moral support. Some were helpful in giving technical guidance. The Council for the Advancement of Social Science Research in Africa (CODESRIA) that provided some financial support for the initial stage of the thesis, and that was instrumental in engaging the support of WOTRO, deserves an enhanced acknowledgement.

Admittedly, the success of an academic project of such status depends upon the effective and efficient supervision, which was authoritatively provided by my supervisors, Professor Jouke van der Zee and Professor Peter Groenewegen, both of NIVEL. Their fruitful suggestions and critical reviews have enhanced the thesis with a good number of publications. Through interaction with them, my research horizon, in terms of methodology and analytical mechanisms, have been widened. I should remark that they have brought me from the periphery to the core of academia.

To my wife and children who have missed the affection of husband and father through absence from home, and, sometimes reduced attention when at home, I express my gratitude for their moral and prayer support.

It is therefore not an overstatement that I dedicate this thesis to WOTRO, NIVEL and my family. 


\section{Curriculum vitae}

Daniel Buor was born in Manhyia, Ghana, on 17 February 1952. In 1967 he completed Middle School, passing the Middle School Leaving Certificate Examination with distinction. In 1968 he was admitted to Agona Seventh-Day Adventist Training College in Ghana to train as a teacher, and successfully completed the programme, with distinction in practical teaching, in July 1972. Thereafter, he taught in a primary school for 6 years. From 1979 to 1981 he read Geography with Political Science at the University of Ghana, and graduated specialising in Geography in July 1981.

From 1981 to 1985 he was a tutor at the Agona Seventh-Day Adventist Secondary School, Ghana. In 1985 he was admitted to the University of Ghana, Legon, to read Geography, specialising in Population and Medical Geography. He was accordingly awarded a Master of Philosophy (MPhil.) degree in November 1988. He was appointed Lecturer in Geography at the Kwame Nkrumah University of Science and Technology, Kumasi in 1990. The courses he taught included Medical Geography, Formal Demography, Cartography and Physical Geography. In 1994, he was promoted to the rank of Senior Lecturer.

He was admitted to the University of Ghana to write a thesis in Medical Geography for the award of a Doctor of Philosophy (PhD) degree. He was among the few applicants who won the Grants offered by the Council for the Development of Social Science Research in Africa (CODESRIA) located in Senegal, to support the writing of his thesis. In September 1999, through an arrangement CODESRIA made with WOTRO, he was one of the first three candidates to be offered fellowships to write their $\mathrm{PhD}$ thesis with WOTRO financial support. The supervising institute for his programme was NIVEL (The Netherlands Institute for Health Services Research).

In October 2001, he was promoted associate professor. His areas of interest are, health services utilisation, environment and health, determinants of health status, spatial analysis of health and health care, fertility and health and gender and development. 
